\title{
Lethal and sublethal effects of insecticides on mortality, migration and host searching behaviour of tersilochine parasitoids on winter oilseed rape
}

\author{
Dissertation \\ zur Erlangung des Doktorgrades \\ der Fakultät für Agrarwissenschaften \\ der Georg-August-Universität Göttingen
}

vorgelegt von

Nadine Neumann

geboren in Freckenhorst

Göttingen, Januar 2010 
D 7

1. Referent: $\quad$ Prof. Dr. Stefan Vidal

2. Korreferent: $\quad$ Prof. Dr. Stefan Schütz

Tag der mündlichen Prüfung: $\quad$ 26.01.2010 


\section{Table of contents}

Chapter I

page

General introduction 1

Studied insect pests and their parasitoids on oilseed rape 2

Host location by parasitoids 3

Possible effects of insecticides on parasitoids $\quad 6$

Strategies for conservation of parasitoid populations in integrated

$\begin{array}{ll}\text { pest management systems } & 7\end{array}$

References $\quad 8$

\section{Chapter II}

Role of volatiles emitted from the host-plant complex in host location by the cabbage stem borer parasitoid Tersilochus obscurator on winter oilseed rape

Abstract

Introduction

Material and Methods 16

Results $\quad 22$

Discussion $\quad 32$

Acknowledgement $\quad 37$

References $\quad 37$

\section{Chapter III}

Effect of insecticide residuals on host finding cues of Tersilochus

obscurator, the key parasitoid of cabbage stem weevil

Abstract $\quad 42$

Introduction $\quad 42$

Material and Methods $\quad 44$

Results $\quad 47$

Discussion $\quad 57$

$\begin{array}{ll}\text { Acknowledgement } & 61\end{array}$

References $\quad 61$

\section{Chapter IV}

Effect of insecticides on parasitism of stem mining pests and migration of tersilochine parasitoids on winter oilseed rape (Brassica napus L.) 65

$\begin{array}{ll}\text { Abstract } & 65\end{array}$

Introduction 66

Material and Methods $\quad 67$

Results $\quad 69$

Discussion $\quad 77$

$\begin{array}{lr}\text { References } & 80\end{array}$

\section{Chapter V}

Impact of insecticide treatments on mortality, parasitism and host location of parasitoids attacking pollen beetle larvae $\quad \mathbf{8 5}$

Abstract $\quad 85$

Introduction $\quad 86$

Material and Methods $\quad 88$ 
Results

Discussion

101

References

Chapter VI

General discussion $\quad 109$

Host searching $\quad 109$

Lethal and sublethal effects of insecticides on parasitoids 112

Impact of insecticides on parasitism on oilseed rape fields $\quad 114$

Strategies for conservation of parasitoids 116

$\begin{array}{ll}\text { References } & 118\end{array}$

$\begin{array}{ll}\text { Summary } & 124\end{array}$

$\begin{array}{ll}\text { Acknowledgement } & 127\end{array}$

$\begin{array}{ll}\text { Curriculum vitae } & 128\end{array}$ 


\section{General introduction}

Oilseed rape (Brassica napus L. var. oleifera Metzg.) (Brassicaceae) is the third most commonly grown crop in Europe (FAO, 2007). In Germany, oilseed rape is cultivated on 1.46 Mill ha in 2009/2010 (UFOP, 2009). It is grown for oil, for human consumption, as well as for renewable energy resources and animal food. With the extention of the planted area in the last twenty years, damage by pests and diseases of oilseed rape became more severe (Alford et al., 2003; Lamb, 1989). One of the most important limiting factors is the large variety of pest insects attacking the oilseed rape crop (Alford et al., 2003). As a result broad-spectrum, non-selective insecticide compounds are applied in autumn, spring and summer for control these economically-important pests (Menzler-Hokkanen et al., 2006). They are often applied prophylactically without regard to pest control thresholds. Frequent applications of insecticides have caused widespread resistance of pollen beetle populations against pyrethroid compounts in many European countries, including Germany (Heimbach et al., 2006), Poland (Wegorek \& Zamojska, 2006) and Denmark (Hansen, 2003). Therefore, the integration of natural regulatory mechanisms on pest populations, such as natural enemies, becomes more important. Minimizing the harmful side-effects of insecticide application on natural enemies is one of the main objectives in IPM stategies. Therefore, optimization of insecticide use, e.g. product selection and timing of application, while minimizing negative effects on beneficial arthropods (Flint \& Bosch, 1981). There is little information on side-effects of chemical insecticides on parasitoids of pests insects on oilseed rape.

The main objectives of this study are:

1. to investigate the role of volatile production by uninfested oilseed rape plants and by plants infested by larvae of $C$. pallidactylus in behavioural and electrophysiological bioassays and the effect of insecticide treatments

2. to study the impact of insecticide treatments on parasitism and migration of parasitoids attacking stem weevil and pollen beetle larvae in field experiments

3. to analyse lethal and sublethal effects of insecticides on parasitoids in laboratory experiments

4. to determine whether the side-effects of insecticides on hymenopteran parasitoids on winter oilseed rape can be minimized by optimization of insecticide uses, such as product selection, timing of application and reduction of field dose rates 


\section{Studied insects pests and their parasitoids on oilseed rape}

\section{Stem-boring weevils}

Two stem-mining pests of oilseed rape were investigated in this study, the cabbage stem weevil Ceutorhynchus pallidactylus (Marsham) and the rape stem weevil Ceutorhynchus napi Gyllenhal (Coleoptera: Curculionidae). Both species are univoltine. Adults of rape stem weevil migrate to crops of oilseed rape in early spring (February/March). Females lay their eggs singly into the stems and the larvae hatch after one or two weeks. The larvae mine within the stem for 3-5 weeks before they leave the plant to pupate in the soil. Adults overwinter in an earthen chamber in the soil and emerge the following spring (Schmutterer, 1956; Debouzie \& Ballanger, 1993; Paul, 2003).

Cabbage stem weevils migrate from their overwintering habitats (in leaf litter at the edges of wood or shrubs) to oilseed rape in spring (March/April) (Alford et al., 2003). Females lay their eggs in batches of 4-6 eggs (Winfield, 1992) into leaf petioles (Barari et al., 2005; Ferguson et al., 2003). First and second instar larvae feed within the pith of petioles, third instar larvae migrate to the main stems (Barari et al., 2005). Mature larvae drop to the soil for pupation (Broschewitz \& Daebler, 1987). Depending on weather conditions, pupation takes about 20-30 days (Broschewitz, 1985). New-generation adults emerge from soil at the end of June or beginning of July. After feeding on various species of Brassicaceae they migrate to their overwintering sites (Broschewitz \& Daebler, 1987).

The key larval endoparasitoids of rape stem weevil and cabbage stem weevil are Tersilochus fulvipes (Gravenhorst) and Tersilochus obscurator Aubert (Hymenoptera: Ichneumonidae), respectivelly (Ulber, 2003). They are univoltine and koinobiont. Adult parasitoids migrate to oilseed rape crops in spring (March/May) from fields where oilseed rape crop has been grown the previous year. Females lay their eggs singly into the host larva. The parasitoid larva remains in its first instar until the host larva is mature and has left the plant to pupate in the soil; then it develops rapidly and kills the host prepupa. The adult parasitoid diapauses in its pupal cocoon in soil and emerges the following spring (Lehmann, 1969; Nissen, 1997; Ulber, 2003).

\section{Pollen beetle}

The pollen beetle, Meligethes aeneus (Fabricius) (Coleoptera: Nitidulidae), is an univoltine pest on oilseed rape. The over-wintered adult beetles migrate into oilseed rape fields in spring and oviposit into buds of 2-3 mm size. The adults and the two larval instars feed on buds and flowers. The development from the egg to the adult stage takes about 40 - 50 days (Nilsson, 
1988). Mature larvae drop to the ground and pupate in soil. New-generation beetles emerge in summer and feed on flowers before hibernation starts in August (Hokkanen, 1993). Adults overwinter in field margins, woodland and hedgerows. The oilseed rape crop is most susceptible to pollen beetle damage at the early bud stage and becomes less sensitive as the crop develops (Alford et al., 2003).

The key parasitoids of pollen beetle in Central Europe are Phradis interstitialis (Thomson), Phradis morionellus (Holmgren), and Tersilochus heterocerus Thomson (Hymenoptera: Ichneumonidae) (Nilsson, 2003). These univoltine, koinobiont endoparasitoids are specialised on Meligethes spp.. The parasitised host larva continues its development until maturation. Larval development and pupation of the parasitoid takes place inside the host prepupa. Adults overwinter in cocoons in soil and emerge during the following spring (Osborn, 1960). There is a niche segregation between the parasitoid species: P. interstitialis oviposits primarily into beetle eggs within green buds, $P$. morionellus lay their eggs into larvae within buds and open flowers and T. heterocerus oviposits into second instar larvae within flowers (Osborn, 1960; Winfield, 1963; Nilsson, 2003).

Reports in the literature provide evidence that mortality due to parasitism may be a sufficient factor to avoid gradation of pest population on oilseed rape (Büchi \& Roos-Humbel, 1991; Sedivy, 1983; Alford et al., 2003). Parasitization rates of rape stem weevil larvae by $T$. fulvipes between $1 \%$ and $21 \%$ were evaluated in Germany (Ulber, 2003), while higher parasitization rates were reported in studies from France and Czechoslovakia (Jourdheuil, 1960; Sedivy, 1983). Levels of parasitism of C. pallidactylus by T. obscurator between $19.6 \%$ and 52.5\% were found at Goettingen (Klingenberg, 1991; Nitzsche, 1998; Ulber, 2003) and in France (Jourdheuil, 1960).

Parasitization rates of M. aeneus ranged from $16 \%$ to $83 \%$ in Sweden (Nilsson \& Andreasson, 1987), Germany (Nissen, 1999) and Switzerland (Büchi \& Roos-Humbel, 1991). Parasitization rates of up to $50 \%$ are likely to have an influence on pest abundance in the long run (Klingenberg \& Ulber, 1994). Hokkanenen et al. (1988) reported that in some areas of Finland where the parasitization rates of pollen beetle were as high as $60 \%$ to $80 \%$, the need for chemical control was by far less important than in areas with low parasitization rates.

\section{Host location by parasitoids}

Plants defend themselves against herbivores by using chemical and physical traits that directly affect herbivore performence or indirectly through traits that attract natural enemies 
(Takabayashi \& Dicke, 1996; Paré \& Tumlinson, 1999). Volatile organic compounds (VOCs), specifically those released following herbivory, are known to attract natural enemies.

Key hymenopteran parasitoids of major pests on oilseed rape are highly specific. Their search for hosts is described as, (i) location of the habitat of the host (the crop) (ii) location of the host within the habitat and (iii) acceptance of the host (Vinson, 1998). Parasitoids of oilseed rape use upwind anemotaxis to locate the oilseed rape crop with their hosts (Williams et al., 2007). Generally, parasitoid species are also attracted to odours of undamaged plants (Kaiser \& Cardé, 1992) and/or artificially damaged plants (Mattiacci et al, 1994; Potting et al., 1999), but these cues are relatively unreliable in indicating host presence.

Various natural enemies are known to discriminate between volatiles emitted by uninfested and herbivore-infested plants. When plants are attacked by herbivores, they may emit specific compounds that are not produced after artificial damage (Turlings et al., 1990; Dicke et al., 1990b; Paré \& Tumlinson, 1997). Chemical stimuli emenating from the host-plant complex can originate from the herbivore, the plant, or from a combination between herbivore and the plant. Although odours emitted from hosts or host products are very reliable indicators for host presence their long-range detectability is very low (Turlings et al., 1991; Vet et al., 1991). Plant volatiles produced in response to herbivore damage may contain information on the identity of the host. Therefore, herbivore-induced plant volatiles may be detectable and reliable indicators of herbivore presence and identity. Plant odours that attract natural enemies are called herbivore-induced synomones (Vet \& Dicke, 1992). Damage by herbivores can greatly increase the emission of plant volatiles (Mattiacci et al. 1994; Mumm et al., 2003; Bukovinszky et al., 2005) and these plant volatiles may be specific indicators of herbivore identity (Dicke et al., 1990b).

Herbivory can also induce de novo production of compounds in many plant species, resulting in qualitative changes in composition of the emitted blend (Turlings et al., 1990; Moraes et al., 1998; Dicke, 1999). The release of herbivore-induced plant volatiles has been shown to constitute an active response of the plant, as is apparent from de novo production of volatile compounds that are not released by intact or mechanically damaged plants (Dicke et al., 1990a; Dicke et al., 1990b; Turlings et al., 1990).

The main components of the volatile blend released from Brassica plants are terpenoids and green leaf volatiles (Mattiacci et al., 1994; Shiojiri et al., 2001). Terpenoids are a major class among volatiles that attract natural enemies (Takabayashi et al., 1994; Pichersky \& Gershenzon, 2002). They are relased in analogous amounts in herbivore-damaged and 
mechanically-damaged cabbage plants, as well as in undamaged plants (Mattiacci et al., 1994; Shiojiri et al., 2001). The volatile fraction of terpenoids predominantly consists of the hemiterpene soprene $\left(\mathrm{C}_{5}\right)$, monoterpenes $\left(\mathrm{C}_{10}\right)$ and the sesquiterpenes $\left(\mathrm{C}_{15}\right)$ and their derivates such as homoterpenes $\left(\mathrm{C}_{11}\right.$ and $\left.\mathrm{C}_{16}\right)$. Monoterpenes and sesquiterpenes are synthezised by the condensation of two or three isoprene units, respectively (Cheng et al., 2007). Because of their physiochemical properties, such as volatility, reactivity and toxicity many protective functions against abiotic and biotic factors have been documented for terpenoids (Holopainen, 2004). Terpenoids are involved in plant-pollinator interactions and have important functions in plant defense against herbivores (Paré \& Tumlinson, 1999; Pichersky \& Gershenzon, 2002; Keeling \& Bohlmann, 2006; Schie et al., 2006).

The plant-released $\mathrm{C}_{6}$ aldehydes, alcohols and esters are called "green leaf volatiles", because they embody the typical odour of undamaged and damages leaves. They are breakdown products formed by oxidation of plant lipids (Hatanaka, 1993). Plants emit green leaf volatiles during aging or when injury occurs (Visser \& Avé, 1978; Hatanaka, 1993). There is a dramatic increase of green leaf volatiles in the headspace of damaged cabbage plants compared to undamaged plants, which may impact host searching of parasitoids (Mattiacci et al., 1994; Smid et al., 2002).

Isothiocyanates are volatile breakdown products of glucosinolates which are found in Brassicaceae (Rask et al., 2000; Hopkins et al., 2009;). Glucosinolates are metabolized to the toxic isothiocyanates and other compounds by the enzym myrosinase which is stored in spezialised plant cells. When the plant tissue is damaged, e.g. by herbivores, the glucosinolates stored in the vacuole come into contact with the enzyme myrosinase. Specialist herbivores on Brassicaceae, are able to detoxify, excrete or reduce the toxicity by behavioural adaptation (Hopkins et al., 2009). More than 120 different glucosinolates have been identified so far (Fahey et al., 2001). Natural enemies use glucosinolates and their breakdown products as synomones to find their hosts within their host plant. Butenyl-isothiocyanate, which was found to attract Phradis morionellus is released in higher amounts from plants infested by pollen beetle larvae than from uninfested plants (Jönsson \& Anderson, 2008). The parasitoids T. obscurator and T. fulvipes and Platygaster subuliformis were strongly attracted to yellow water traps baited with 2-phenylethyl isothiocyanate, a component of the odour of the vegetative parts of oilseed rape (Murchie et al., 1997; Ulber \& Wedemeyer, 2006) 


\section{Possible effects of insecticides on parasitoids}

Current pest control practices are based on broad spectrum chemical insecticides which also have neurotoxic side-effects to beneficial insects. Two or three insecticide treatments were performed to control the major pests attacking oilseed rape, the rape stem weevil and cabbage stem weevil at stem elongation, the pollen beetle at bud stage and the cabbage seed weevil and the brassica pod midge at flowering (Alford et al., 2003; Menzler-Hokkanen et al., 2006; Bürger \& Gerowitt, 2009; Freier et al., 2009). Frequent applications of pyrethroid insecticides have recently caused a widespread resistance of pollen beetles in many European countries (Hansen, 2003; Heimbach et al., 2006; Wegorek \& Zamojska, 2006). Further, insecticides may harm natural enemies of pests. The main period of activity of tersilochine parasitoids (except Tersilochus microgaster) occurs in the late bud stage up to the end of flowering of oilseed rape (Johnen et al., 2006; Ulber et al., 2006). Adult parasitoids can be affected by insecticides in different ways: they can be exposed to insecticide spray droplets (Jepson, 1989 ) or to the residues on the plant foliage when foraging for hosts (Brown, 1989; Longley \& Jepson, 1996) or feeding on contaminated water droplets and nectar (Langley \& Stark, 1996). Parasitoids may be affected by increased direct mortality or by sublethal effects on their physiology and behaviour.

Sublethal effects of insecticides are defined as effects (pyhsiological or behavioural) on individuals that survive exposure to pesticides (Desneux et al., 2007). Sublethal effects of insecticides may affect fecunditiy, longevity and behaviour through neurotoxic activity. Behavioural effects of insecticides on parasitoids may be knock-down, uncoordinated movements (Desneux et al., 2004), more frequent cleaning of their abdomen and legs and a repellent or irritant effect of the pesticide (Wiles \& Jepson, 1994; Longley \& Jepson, 1996; Desneux et al., 2007). Further, the oviposition behaviour of parasitoids may be disrupted by masking of the attractive host plant odours, thereby preventing parasitoid females from recognising the host plant and the host (Thiery \& Visser, 1986; Nottingham et al., 1991), or the insecticide odour could have a direct repellent effect on the insects (Jiu \& Waage, 1990; Longley \& Jepson, 1996; Tran et al., 2004). The aphid parasitoid D. rapae spend less time foraging on Brussels sprout plants treated with the insecticides pirimicarb, permethrin and malathion compared to untreated plants (Jiu \& Waage, 1990; Umoru et al., 1996). 


\section{Strategies for conservation of parasitoid populations in integrated pest management systems}

According to threshold values of the pest populations, IPM management systems on winter oilseed rape will require chemical pesticides. The effect of insecticides on parasitoid populations may be affected by the mode of action, dosage, persistency and temporal and spatial application (Jepson, 1989; Poehling, 1989; Alford et al., 1992). One way to protect natural enemies is to optimize the timing of insecticide application. At early treatments for control of stem weevils and pollen beetles it is necessary to observe only the cabbage stem flea beetle parasitoid T. microgaster. Most parasitoid species are active on oilseed during the late bud stage or flowering. The use of phenological models to find spray windows that allow insecticide treatments consistent with good pest control and minimized effects on parasitoids could be utilized in IPM systems. Targeting of insecticide application to the crop with regard to pest incidence and parasitoid phenology on the crop has potential to minimize mortality of parasitoids (Johnen et al., 2006).

Selective insecticides might have potential to avoid harmful effects of insecticides on parasitoids in winter oilseed rape (Iwata et al., 1985; Brunner et al., 2001). Differential toxicity of various pyrethroids and a relatively low toxicity of tau-fluvalinate to parasitoids in oilseed rape (Klukowski et al., 2006; Jackowski et al., 2009) and other crops have been reported (Moreby et al., 2001). While pyrethroids are known to have a broad-spectrum activity (Casida et al., 1983), systemic insecticides, e.g. neonicotinoids, and their metabolites are claimed to be fairly safe for beneficial insects, because direct contamination only occurs when the insects feed on the plant tissue (Stapel et al., 2000). Knowledge of the relative toxicities of different insecticides to parasitoids would aid selection of appropiate products which could help to conserve natural enemies and could be used in IPM systems.

Another way for increasing the selectivity of insecticides may be using reduced application rates of insecticides. Applying insecticides at lower rates of active ingredients per unit area may protect natural enemies, whereas pest mortality remains at a high level (Ripper, 1956; Poehling, 1989; Longley et al., 1997; Booth et al., 2007). Most studies on the effect of reduced field dose rate on pests and their natural enemies have been conducted with aphids. It has been proved in various studies that reduced rates of insecticides can provide sufficient control of aphids (Ripper 1956; Poehling, 1989; Acheampong \& Stark, 2004; Booth et al., 
2007), wheras natural enemies were protected (Longley et al., 1997; Niehoff \& Poehling, 1995).

Spatial targeting of insecticides to areas of high pest density could be a scope for reducing insecticide side-effects and conserving parasitoid populations. Pests are often distributed irregularly within the crop. Major pests are edge-distributed during their immigration into the crop. This has been observed with cabbage stem weevil (Free \& Williams, 1979; Klukowski et al., 2006), pollen beetle (Free \& Williams, 1979), cabbage stem weevil (Free \& Williams, 1979; Murchie et al., 1999) and brassica pod midge (Free \& Williams, 1979; Ferguson et al., 2004). Application of insecticides only to crop edges during the immigration period of the pests could kill the pests while protecting the parasitoids in the central unsprayed area of the crop (Barari et al. 2005; Cook et al., 2006). This could be amplified by using traps crops: this so called "push-pull" strategy is focused on the manipulation of the distribution of the pests on the crop. In oilseed rape, turnip rape (Brassica rapa L.) can be used as the trap crop to "pull" the pests away from the main oilseed rape crop (Cook et al., 2006; Cook et al., 2007). Field experiments demonstrated that turnip rape crop borders reduce the abundance of cabbage stem flea beetle (Barari et al., 2005) and pollen beetle (Cook et al., 2006) in the oilseed rape main crop and reduce the need for insecticides.

\section{References}

ACHEAMPONG, S. \& STARK, J. (2004). Can reduced rates of pymetrozine and natural enemies control the cabbage aphid, Brevicoryne brassicae (Homoptera: Aphididae), on broccoli? International Journal of Pest Management 50, 275-279.

Alford, D. V., MuRCHIE, A. \& WiLliams, I. H. (1992). Observation on the impact of standard insecticide treatments on Trichomalus perfectus, a parasitoid of seed weevil on winter oilseed rape in the UK. IOBC/wprs Bulletin 18, 122-126.

Alford, D. V., NiLSSON, C. \& UlBER, B. (2003). Insect pests of oilseed rape crops. Chapter 2 In: D.V. Alford (ed) Biocontrol of Oilseed Rape Pests. Blackwell, Oxford, UK, 9-41.

BARARI, H., COOK, S. M. \& WILLIAMS, I. H. (2005). Effect of turnip rape (Brassica rapa) trap crop on stem-mining pests and their parasitoids in winter oilseed rape (Brassica napus). Biological Control 50, 69-86.

BoOTh, L. H., WrATTEN, S. D. \& P.KeHRLI. (2007). Effects of reduced rates of two insecticides on enzyme activity and mortality of an aphid and its lacewing predator. Journal of Economic Entomology 100, 11-19.

BroschewITZ, B. (1985). Untersuchungen zur Biologie und Schadwirkung des Gefleckten Kohltriebrüsslers (Ceutorhynchus quadridens Panzer) am Winterraps (Brassica napus L. var. oleifera Metzg.). PhD-thesis, Wilhelm-Pieck-Universität, Rostock. 
Broschewitz, B. \& DAEBLER, F. (1987). Beitrag zur Biologie und Schadwirkung des Gefleckten Kohltriebrüsslers (Ceutorhynchus quadridens Panz) an Winterraps. Nachrichtenblatt für den Pflanzenschutzdienst in der DDR 41, 34-37.

BROWN, K. C. (1989). The design of experiments to assess the effects of pesticides on beneficial arthropods in orchards: Replication versus plot size. In: Jepson P.C. (Ed.), Pesticide and Non-target Invertebrates. Intercept, Wimborne., 71-93.

BRUNNER, J. F., DunLEY, J. E., DOERR, M. D. \& BEERS, E. H. (2001). Effect of Pesticides on Colpoclypeus florus (Hymenoptera: Eulophidae) and Trichogramma platneri (Hymenoptera: Trichogrammatidae), Parasitoids of Leafrollers in Washington. Journal of Economic Entomology 94, 1075-1084.

BüCHI, R. \& RoOS-HuMBEL, S. (1991). Nützlinge reduzieren die Zahl der Rapsschädlinge. Landwirtschaft Schweiz 4, 69-73.

BÜRGER, J. \& GEROWITT, B. (2009). Anwendungsmuster von Pflanzenschutzmitteln in Winterweizen und Winterraps. Gesunde Pflanze 61, 11-17.

Bukovinszky, T., Gols, R., Posthumus, M. A., Vet, L. E. M. \& Lenteren, J. C. V. (2005). Variation in plant volatiles and attraction of the parasitoid Diadegma semiclausum (Hellén). Journal of Chemical Ecology 31, 461-480.

CAsida, J. E., GAMmON, D. W., GLiCKMAn, A. H. \& LAWRENCE, L. J. (1983). Mechanism of Selective Action of Pyrethroid Insecticides. Annual Review Pharmacology Toxicology 23, 413-438.

Cheng, A., Lou, Y., MaO, Y., Lu, S., WAng, L. \& Chen, X. (2007). Plant Terpenoids: Biosynthesis and Ecological Functions. Journal of Integrative Plant Biology 49, 179186.

COOK, S. M., KHAN, Z. R. \& PiCKETT, J. A. (2007). The use of "push-pull" strategies in integrated pest management. Annual Review Entomology 52, 357-400.

CoOK, S. M., Smart, L. E., Martin, J. L., Murray, D. A., WATTS, N. P. \& Williams, I. H. (2006). Exploitation of host plant preferences in pest management strategies for oilseed rape (Brassica napus). Entomologia Experimentalis et Applicata 119, 221-229.

DeBouZIE, D. \& BALlANGER, Y. (1993). Dynamics of Ceutorhynchus napi population in winter rape fields. Acta Oecologica 14, 603-618.

DesneuX, N., DeCOURTYE, A. \& DelPUECH, J.-M. (2007). The sublethal effects of pesticides on beneficial arthropods. Annual Reviews Entomology 52, 81-106.

Desneux, N., Wajnberg, E., Fauvergue, X., Privet, S. \& Kaiser, L. (2004). Oviposition behaviour and patch-time allocation in two aphid parasitoids exposed to deltamathrin residues. Entomologia Experimentalis et Applicata 112, 227-235.

DiCKE, M. (1999). Are herbivore-induced plant volatiles reliable indicators of herbivore identity to foraging carnivorous arthropods? Entomologia Experimentalis et Applicata 91, 131-142.

Dicke, M., Beek, T. A. v., Posthumus, M. A., Dom, N. B., Bokhoven, H. v. \& Groot, A. D. (1990a). Isolation and identification of volatile kairomones that affects acarine predator-prey interactions. Journal of Chemical Ecology 16, 381-396.

Dicke, M., SABelis, M. W., J.TAKabayashi, Bruin, J. \& Posthumus, M. A. (1990b). Plant strategies of manipulating predator-prey interactions through allelochemicals: prospects for application in pest control. Journal of Chemical Ecology 16, 3091-3118.

FAHEY, J. W., ZALCMANN, A. T. \& TAlalay, P. (2001). The chemical diversity and distribution of glucosinolates and isothiocyanates among plants. Phytochemistry 56, 551.

FAO. (2007). http://faostat.fao.org/site/339/default.aspx.

Ferguson, A. W., CAMPBEll, J. M., WATTS, D. J., SChMid, J. E. U. \& Williams, I. H. (2004). Phenology and spatial distribution of Dasineura brassicae and its parasitoids 
in a crop of winter oilseed rape: implications for integrated pest management. IOBC/wprs Bulletin 27, 243-252.

Ferguson, A. W., Klukowski, Z., WalczaK, B., Clark, S. J., Mugglestone, M. A., PERRY, J. N. \& WILLIAMS, I. H. (2003). Spatial distribution of pests insects in oilseed rape: implications for integrated pest management. Agricultural, Ecosystems and Environment 95, 509-521.

FREIER, B., PALUTT, B., JAHN, M., SELLMANN, J., GUTSCHE, V., ZORNBACH, W. \& MOLL, E. (2009). Netz Vergleichsbetriebe Pflanzenschutz Jahresbericht 2008. Berichte aus dem Julius Kühn-Institut 149.

FLINT, M. L. \& BosCH, R. V. D. (1981). Introduction to Integrated Pest Management. Plenum, New York, USA.

FREE, J. B. \& WILLIAMS, I. H. (1979). The distribution of insect pests on crops of oilseed rape (Brassica napus L.) and the damage they cause. Journal of Agricultural Science 93, 139-149.

HANSEN, L. M. (2003). Insecticide-resistant pollen beetles (Meligethes aeneus F) found in Danish oilseed rape (Brassica napus L) fields. Pest Management Science 59, 10571059.

Hatanaka, A. (1993). The biogeneration of green odour by green leaves. Phytochemistry 34, 1201-1218.

HeIMBACH, U., MüLleR, A. \& THIEME, T. (2006). First steps to analyse pyrethroid resistance of different oilseed rape pests in Germany: An extended abstract. IOBC/wprs Bulletin 29, 131-134.

HoKKANEN, H., HuSBERG, G.-B. \& SÖDERBLOM, M. (1988). Natural enemy conservation for the integrated control of the rape blossom beetle Meligethes aeneus F. Annales Agriculturae Fenniae 27, 281-294.

HoKKANEN, H. M. T. (1993). Overwintering survival and spring emergence in Meligethes aeneus: effects of body weight, crowding, and soil treatment with Beauveria bassiana. Entomologia Experimentalis et Applicata 67, 241-246.

Holopainen, J. K. (2004). Multiple functions of inducible plant volatiles. Trends in Plant Science 9, 529-533.

Hopkins, R. J., DAM, N. M. v. \& LOON, J. J. A. v. (2009). Role of Glucosinolates in insectplant relationships and multitrophic interactions. Annual Review Entomology 54, 57 83.

Iwata, Y., MacConnell, J. G., Flor, J. E., Putter, I. \& DinOFF, T. M. (1985). Residues of Avermectin $\mathrm{B}_{1}$ a on and in Citrus Fruits and Foliage. Journal of Agricultural Food Chemistry 33, 467-471.

JACKOWSKI, J., KLUKOWSKI, Z. \& IRZYKOWICZ, M. (2009). The effect of tau-fluvalinate and lambda-cyhalothrin on two parasitic species of Phradis spp. (Hymenoptera, Ichneumonidae, Tersilochinae). Pestycydy/Pesticides 2008 3-4, 79-92.

JEPSON, P. C. (1989). The temporal and spatial dynamics of pesticide side-effects on nontarget invertebrates. In: Jepson P.C. (Ed.), Pesticide and Non-target Invertebrates. Intercept, Wimborne., 95-127.

JIU, G. D. \& WAAGE, J. K. (1990). The effect of insecticides on the distribution of foracing parasitoids, Diaeretiella rapae (Hym.: Braconidae) on plants. Entomophaga 35, 4956.

Johnen, A., Williams, I. H., Ferguson, A. W., BüChs, W., Klukowski, Z., Luik, A., NILSSON, C. \& ULBER, B. (2006). MASTER: construction of phenological models of key parasitoids in Europe and prospects for spray windows compatible with their conservation in winter oilseed rape. CD-Rom Proceedings of the International Symposium "Integrated Pest Management in Oilseed Rape Pests", Goettingen, Germany, 3-5 April 2006. 
JÖNSSON, M. \& ANDERSON, P. (2008). Emission of oilseed rape volatiles after pollen beetle infestation; behavioural and electrophysiological responses in the parasitoid Phradis morionellus. Chemoecology 17, 201-207.

JOURDHEUIL, P. (1960). Influence de quelque facteurs écologique sue les fluctuations de population d'une biocé nose parasitaire. Ann. Epiph. 11, 445-658.

KAISER, L. \& CARDÉ, R. T. (1992). In flight orientation to volatiles from the host-plant complex in Cotesia rubecula (Hym.: Braconidae): Increased sensitivity through olfactory experience. Physiological Entomology 17, 62-67.

KEELING, C. I. \& BOHLMANN, J. (2006). Genes, enzymes and chemicals of terpenoid diversity in the constitutive and induced defence of conifers against insects and pathogens. New Phytologist 170, 657-675.

KLINGENBERG, A. (1991). Untersuchungen zur Abundanzerfassung und zu natürlichen Gegenspielern von Ceutorhynchus pallidactylus (Mrsh) und Ceutorhynchus napi (Gyll.). Diplomarbeit, Universität Göttingen.

KlingenberG, A. \& UlBer, B. (1994). Untersuchungen zum Auftreten der Tersilochinae (Hymenoptera: Ichneumonidae) als Larvalparasitoiden einiger Rapsschädlinge im Raum Göttingen 1990 und 1991 und zu deren Schlupfabundanz nach unterschiedlicher Bodenbearbeitung. Journal of Applied Entomology 117, 287-299.

KLUKOWSKI, Z., TWARDOWSKI, J. \& IRZYKOWICZ, M. (2006). Subsequent effect of taufluvalinate (Maverik) and lambda-cyhalothrin (Karate) pyrethroids on the activity of carabid beetles (Coleoptera: Carabidae) in winter oilseed rape. IOBC/wprs Bulletin 29, 125-130.

LAMB, R. J. (1989). Entomology of oilseed Brassica crops. Annual Review of Entomology 43, 211-229.

LANGLEY, M. \& STARK, J. D. (1996). Analytical Techniques for quantifying direct, residual and oral exposure of an insect parasitoid to an Organophosphate Insecticide. Bulletin of Environmental Contamination Toxicology 57, 683-690.

LEHMANN, W. (1969). Beiträge zur Parasitenfauna in Rapsbeständen. Bericht über die 10. Wanderversammlung Deutscher Entomologen, Dresden 1965, Deutsche Akademie der Landwirtschaft zu Berlin, Tagungsbericht 80, Teil III, 513-528.

LONGLEY, M. \& JEPSON, P. C. (1996). The influence of insecticide residues on primary parasitoids and hyperparasitoid foraging behaviour in the laboratory. Entomologia Experimentalis et Applicata 81, 259-269.

LONGLEy, M., JEPSON, P. C., IZQUIERDO, J. \& SOTHERTON, N. (1997). Temporal and spatial changes in aphid and parasitoid populations following applications of deltamethrin in winter wheat. Entomologia Experimentalis et Applicata 83, 41-52.

MattiacCI, L., Dicke, M. \& Posthumus, M. A. (1994). Induction of parasitoid attracting synomones in brussels sprouts plants by feeding of Pieris brassicae larvae: Role of mechanical damage and herbivore elicitor. Journal of Chemical Ecology 20, 22292247.

Moraes, C. M. D., Lewis, W. J., Paré, P. W., Alborn, H. T. \& Tumlinson, J. H. (1998). Herbivore-infested plants selectively attract parasitoids. Nature 393, 570-573.

Moreby, S. J., SOUTHWAY, S., BARKER, A. \& Holland, J. M. (2001). A comparison of the effect of new and established insecticides on nontarget invertebrates of winter wheat fields. Environmental Toxicology Chemistry 20, 2243-2254.

Mumm, R., Schrank, K., Wegener, R., Schulz, S. \& Hilker, M. (2003). Chemical analysis of volatiles emitted by Pinus sylvestris after induction by insect oviposition. Journal of Chemical Ecology 29, 1235-1251.

Murchie, A. K., SMART, L. E. \& Williams, I. H. (1997). Responses of Dasineura brassicae and its parasitoids Platygaster subuliformis and Omphale clypealis to field traps baited with organic isothiocyanates. Journal of Chemical Ecology 23, 917-926. 
Murchie, A. K., Williams, I. H. \& PERRY, J. N. (1999). Edge distribution of Ceutorhynchus assimilis and its parasitoid Trichomalus perfectus in a crop of winter oilseed rape (Brassica napus). BioControl 44, 379-390.

NieHOFF, B. \& PoEHLING, H. M. (1995). Population dynamics of aphids and syrphid larvae in winter wheat treated with different rates of pirimicarb. Agricultural, Ecosystems and Environment 52, 51-55.

NiLSSON, C. (1988). The pollen beetle (Meligethes aeneus F.) in winter and spring rape at Alnarp 1976-1978. III. Mortality factors. Växtskyddsnotiser 52, 145-150.

NILSsOn, C. (2003). Parasitoids of pollen beetles. In: D.V. Alford (ed) Biocontrol of Oilseed Rape Pests. Blackwell Publishing, Oxford, UK, 73-85.

NILSSON, C. \& ANDREASSON, B. (1987). Parasitoids and predators attacking pollen beetles (Meligethes aeneus F.) in spring and winter rape in southern Sweden. IOBC/wprs Bulletin 4, 64-73.

NisSEN, U. (1997). Ökologische Studien zum Auftreten von Schadinsekten und ihren Parasitoiden an Winterraps norddeutscher Anbaugebiete. Dissertation, Universität Kiel.

NiSSEN, U. (1999). Natürliche Gegenspieler von Rapsschädlingen. Raps 17, 76-82.

NiTZSCHE, O. (1998). Auftreten und Effizienz von Parasitoiden als natürliche Gegenspieler von Schadinsekten im Winterraps unter besonderer Berücksichtigung unterschiedlicher Bodenbearbeitungsmaßnahmen nach Winterraps. PhD thesis, Georg-August-University of Goettingen, Germany.

Nottingham, S. F., Hardie, J., Dawson, G. W., Hick, A. J., Pickett, J. A., Wadhams, L. J. \& WOODCOCK, C. M. (1991). Behavioral and electrophysiological responses of aphids to host and nonhost plant volatiles. Journal of Chemical Ecology 17, 12311242.

Osborn, P. (1960). Observation of the natural enemies of Meligethes aeneus (F.) and $M$. viridescence (F.) (Coleoptera: Nitidulidae). Parasitology 50, 91-110.

PARÉ, P. W. \& TuMLINSON, J. H. (1997). Induced synthesis of plant volatiles. Nature 385, 3031.

PARÉ, P. W. \& TuMLinson, J. H. (1999). Plant volatiles as a defense against herbivores. Plant Physiology 121, 325-331.

PAUL, V. H. (2003). Raps-Krankheiten, Schädlinge, Schadpflanzen. Th. Mann Verlag, Gelsenkirchen-Buer.

PICHERSKY, E. \& GERSHENZON, J. (2002). The formation and function of plant volatiles: perfumes for pollinator attraction and defense. Current Opinion in Plant Biology 5, 237-243.

PoEHLING, H. M. (1989). Selective application strategies for insecticides in agricultural crops. In: Jepson P.C. (Ed.), Pesticide and Non-target Invertebrates. Intercept, Wimborne., 151-175.

Potting, R. P. J., Poppy, G. M. \& SchUler, T. H. (1999). The role of volatile from cruciferous plants and pre-flight experience in the foraging bahviour of the specialist parasitoid Cotesia plutellae. Entomolgia Experimentalis et Applicata 93, 87-95.

RAsk, L., ANDrÉAsson, E., EkBOM, B., ERIKSSON, S., PontopPidAn, B. \& MEIJER, J. (2000). Myrosinase: gene family evolution and herbivore defense in Brassicaceae. Plant Molecular Biology 42, 93-113.

RIPPER, W. E. (1956). Effect of pesticides on balance of arthropod populations. Annual Reviews Entomology 1, 403-438.

SCHIE, C. C. N. V., HARING, M. A. \& SCHURINK, R. C. (2006). Regulation of terpenoids and benzenoids production in flowers. Current Opinion in Plant Biology 9, 203-208. 
SCHMUTTERER, H. (1956). Zur Lebensweise und Bekämpfung des Großen Rapsstängelrüsslers Ceutorhynchus napi (Gyll.). Zeitschrift Angewandten Entomologie 39, 302-315.

SEDIVY, J. (1983). Tersilochinae as parasitoids of insect pests of winter rape (Hymenoptera: Ichneumonidae). Cont. Am. Ent. Inst. 20, 266-276.

SHIOJIRI, K., TAKABAYASHI, J., YANO, S. \& TAKAFUJ, A. (2001). Infochemically mediated tritrophic interaction webs on cabbage plants. Population Ecology 43, 23-29.

SMID, H. M., LOON, J. J. A. V., M.A.PosthumUS \& VET, L. E. M. (2002). GC-EAG-analysis of volatiles from Brussels sprouts plants damaged by two species of Pieris caterpillars: olfactory receptive range of a specialist and a generalist parasitoid wasp species. Chemoecology 12, 169-176.

StAPel, J. O., CORTESERO, A. M. \& LEWIS, W. J. (2000). Disruptive Sublethal Effects of Insecticides on Biological Control: Altered Foraging Ability and Life Span of a Parasitoid after Feeding on Extrafloral Nectar of Cotton Treated with Systemic Insecticides. Biological Control 17, 243-249.

TAKABAYASHI, J. \& DiCKE, M. (1996). Plant-carnivore mutualism through herbivore-induced carnivore attractants. Trends in plant science 1, 109-113.

TAKABAYASHI, J., Dicke, M. \& PosthumUS, M. A. (1994). Volatile herbivore-induced terpenoids in plant-mite interactions: Variation caused by biotic and abiotic factors. Journal of Chemical Ecology 20, 1329-1354.

THIERY, D. \& VISSER, J. H. (1986). Masking of plant odour in the olfactory orientation of the Colorado potato beetle. Entomologia Experimentalis et Applicata 41, 165-172.

TRAN, D. H., TAKAGI, M. \& TAKASU, K. (2004). Effects of selective insecticides on host searching and oviposition behavior of Neochrysocharis formosa (Westwood) (Hymenoptera: Eulophidae), a larval parasitoid of the American serpentine leafminer. Applied Entomology Zoology 39, 435-441.

Turlings, T. C. J., Tumlinson, J. H., Heath, R. R., ProveauX, A. T. \& Doolittle, R. E. (1991). Isolation and identification of allelochemicals that attract the larval parasitoid, Cotesia marginiventris (Cresson), to the microhabitat of one of its hosts. Journal of Chemical Ecology 17, 2235-2251.

TuRLINGS, T. C. J., TUMLINSON, J. H. \& LEWIS, W. J. (1990). Exploitation of herbivoreinduced plant odors by host-seeking parasitic wasps. Science 250, 1251-1253.

UFOP. (2009). http://www.ufop.de/index.php.

UlBer, B. (2003). Parasitoids of Ceutorhynchid stem weevils. In: D. V. Alford (ed) Biocontrol of Oilseed Rape Pests. Blackwell Publishing, Oxford, UK, 87-95.

UlBer, B., NitzSCHE, O. \& WEDEMEYER, R. (2006). Phenology of tersilochine parasitoids in Germany and prospects for spray windows compatible with their conservation. $C D$ Rom Proceedings of the International Symposium "Integrated Pest Management in Oilseed Rape Pests", Goettingen, Germany, 3-5 April 2006.

ULBER, B. \& WEDEMEYER, R. (2006). Responses of Tersilochus microgaster and Tersilochus obscurator (Hymenoptera: Ichneumonidae) to volatile 2-phenylethyl-isothiocyanate. CD-Rom Proceedings of the International Symposium "Integrated Pest Management in Oilseed Rape Pests", Goettingen, Germany, 3-5 April 2006.

UMORU, P. A., POWELL, W. \& CLARK, S. J. (1996). Effect of pirimicarb on the foraging behaviour of Diaeretiella rapae (Hymenoptera: Braconidae) on host-free and infested oilseed rape plants. Bulletin of Entomological Research 86, 193-201.

VET, L. E. M. \& DICKE, M. (1992). Ecology of infochemical use by natural enemies in a tritrophic context. Annual Review Entomology 37, 141-172.

Vet, L. E. M., WÄCKERS, F. L. \& DiCKE, M. (1991). How to hunt for hiding hosts: The reliability-detectability problem in foraging parasitoids. Netherlands Journal of Zoology 41, 202-213. 
VINSON, S. B. (1998). The general host selection behaviour of parasitoid Hymenopteran and a comparison of initial strategies utilized by larvaphagous and oophagous species. Biological Control 11, 79-96.

VISSER, J. H. \& AVÉ, D. A. (1978). General green leaf volatiles in the olfactory orientation of the colorado beetle, Leptinotarsa decemlineata. Entomologia Experimentalis et Applicata 24, 538-549.

WEGOREK, P. \& ZAMOJSKA, J. (2006). Resistance of pollen beetle (Meligethes aeneus F.) to pyrethroids, chloronicotinyls and organophosphorous insecticides in Poland. IOBC/wprs Bulletin 29, 135-140.

WILES, J. A. \& JEPSON, P. C. (1994). Sub-lethal effects of deltamethrin residues on the within-crop behaviour and distribution of Coccinella septempunctata. Entomologia Experimentalis et Applicata 72, 33-45.

Williams, I. H., Frearson, D. J. T., BARARI, H. \& MCCARTNEY, A. (2007). First field evidence that parasitoids use upwind anemotaxis for host-habitat location. Entomologia Experimentalis et Applicata 123, 299-307.

WINFIELD, A. L. (1963). A study on the effects of insecticides on parasites of larvae of blossom beetles (Meligehtes aeneus F., Coleoptera: Nitidulidae). Entomologia Experimentalis et Applicata 6, 309-318.

WINFIELD, A. L. (1992). Management of oilseed rape pests in Europe. Agricultural Zoology Reviews 5, 51-95. 


\title{
Role of volatiles emitted from the host-plant complex in host location by the cabbage stem borer parasitoid Tersilochus obscurator on winter oilseed rape
}

\begin{abstract}
The cabbage stem weevil, Ceutorhynchus pallidactylus, is an important pest on crops of winter oilseed rape. Damage to plants is caused by larval feeding within petioles and stems. Weevil populations are under partial natural control by the key larval parasitoid Tersilochus obscurator. In this study chemical stimuli which are used by female T. obscurator for finding their endophagous host larvae were investigated. In laboratory experiments, the role of volatiles emitted from uninfested plants and from plants infested by larvae of C. pallidactylus was studied in behavioural and electrophysiological (EAG-GC/MS) bioassays, using female T. obscurator as test insects. Naive and experienced females were used in dual-choice tests and Y-olfactometer bioassays. Prior experience with host-plant cues significantly increased the probability of host finding. In olfactometer tests, parasitoids responded to volatile cues elicited by plants damaged by stem weevils. Odour of host larvae did not attract the wasps. Six of the 19 identified volatiles were released in significantly higher amounts from infested plants than from uninfested plants. Further, eight compounds were only released from infested plants and one compound only from uninfested plants. In EAG bioassays, female $T$. obscurator strongly responded to volatile compounds released from infested plants, especially Nonanal and $\alpha$-farnesene, and to 1-Hexanol, 2-ethyl, and Terpinen-4-ol released from uninfested plants.
\end{abstract}

\section{Introduction}

The cabbage stem weevil, Ceutorhynchus pallidactylus (Mrsh.) (Col., Curculionidae), is one of the most damaging stem-boring pests in winter oilseed rape (Brassica napus L. var. oleifera Metzg.) in Europe (Alford et al., 2003). Females deposit their egg batches into petioles of oilseed rape plants in April/May. Damage is caused by larval feeding within petioles and later in the main stem. In Germany yield losses of 20-30\% have been reported (Broschewitz et al., 1993). The larvae of $C$. pallidactylus are parasitized by the univoltine endoparasitoid Tersilochus obscurator Aubert (Hymenoptera: Ichneumonidae) (Ulber 2003; Ulber \& Nitzsche, 2006). Female parasitoids lay their eggs singly into the host larvae while these are mining within petioles. Parasitoid larvae hatch within hosts, but develop to second and third instar larvae not before the full-grown host larvae has migrated to soil for pupation 


\section{Chapter II}

(koinobiont). The adult wasps diapause inside their pupal coocon in the soil until emerge in the following spring (Ulber, 2003).

Foraging insect parasitoids are known to respond to a variety of stimuli, including chemical, visual, vibrational, and tactile cues (Allen et al., 1999; Meyhöfer \& Casas, 1999; Wäckers \& Lewis, 1999; Jönsson et al. 2005). Olfaction is often considered to provide the most important evidence for the presence of endophagous host larvae (Vet \& Dicke, 1992; Potting et al. 1995; Dicke 1999). Parasitoids have been found to respond to plant odours more easily than to host derived stimuli (Vet et al. 1991a). Various plant volatiles are released specifically after herbivory. These compounds can be reliable indicators for host presence and attract parasitoids (Turlings et al. 1990). As these chemicals are favourable to the plant, they are called herbivore-induced synomones (Vet \& Dicke, 1992).

Little is known about the behavioural ecology of T. obscurator and in particular about factors affecting host location. The aim of this study was to investigate, in laboratory bioassays, the olfactoric stimuli which are used by T. obscurator for encounter of host larvae. A coupled electrophysiology-gaschromatography approach was used to sub-divide the complex plant volatile blends into individual components, and to identify which individual volatile elicits olfactory activity in parasitoid females.

\section{Material and Methods}

\section{Laboratory experiments}

\section{Test insects}

To obtain a large number of female $T$. obscurator of standardized age and of similar physiological condition for the bioassays, larvae of $C$. pallidactylus were collected from main stems of unsprayed oilseed rape plants in the field. Third instar larvae were released on slices of kohlrabi in plastic boxes and reared until maturation. For pupation, the full-grown larvae were transferred to plastic boxes $(500 \mathrm{ml})$ containing a moistened soil substrate (clay-loamy soil mixed with sand). The boxes were stored under laboratory conditions (16hL : 8hD, $22^{\circ} \mathrm{C}$ ). Adult cabbage stem weevils emerging from the soil after 12 - 15 days were transferred to plastic boxes and supplied with leaves of oilseed rape. To enable an obligate prereproductive diapause, the weevils were stored under simulated winter conditions in a cooling room at a changing temperature and light regime (Table 1). By using this method, a total of 33 to $44 \%$ of larvae was successfully reared up to the adult stage. 


\section{Chapter II}

Table 1: Temperature and light regime applied to diapausing adults of $C$. pallidactylus

\begin{tabular}{ccc}
\hline $\begin{array}{c}\text { Period } \\
\text { days }\end{array}$ & $\begin{array}{c}\text { temperature } \\
\text { C }\end{array}$ & $\begin{array}{c}\text { light regime } \\
(\mathrm{h} \mathrm{L}: \mathrm{h} \mathrm{D})\end{array}$ \\
\hline 14 & 14 & $18: 6$ \\
14 & 10 & $16: 8$ \\
$70-100$ & 6 & $12: 12$ \\
21 & 10 & $16: 8$ \\
21 & 14 & $18: 6$ \\
$21-50$ & laboratory & $18: 6$ \\
\hline
\end{tabular}

For rearing adult $T$. obscurator in the laboratory, parasitoids cocoons were collected from the soil used for pupation of weevils by sieving (mesh size $2 \mathrm{~mm}$ ) and stored in petri dishes lined with moisture filter paper. As the parasitoid requires an obligate pre-productive diapause, the cocoons were also kept in a cooling room under simulated winter conditions at changing temperature and light regime (Tabel 2). In total, 28 - 40\% of field collected C. pallidactylus larvae were parasitized.

Table 2: Temperature and light conditions applied to diapausing T. obscurator

\begin{tabular}{ccc}
\hline $\begin{array}{c}\text { Period } \\
\text { days }\end{array}$ & $\begin{array}{c}\text { temperature } \\
\mathrm{C}\end{array}$ & $\begin{array}{c}\text { light regime } \\
(\mathrm{h} \mathrm{L}: \mathrm{h} \mathrm{D})\end{array}$ \\
\hline 21 & 14 & $18: 6$ \\
21 & 10 & $16: 8$ \\
$50-90$ & 6 & $12: 12$ \\
14 & 10 & $16: 8$ \\
14 & 14 & $18: 6$ \\
\hline
\end{tabular}

Emergence of adult parasitoids was initiated by transferring the cocoons to laboratory conditions. Before transferring to the experiments, females and males were stored for $5-8$ days in a cage under laboratory conditions. They were supplied with oilseed rape flowers and water. In the two-choice tests females with oviposition experience and unexperienced females were used. The effect of oviposition experience on the response of parasitoids to volatile cues emitted from the host-plant complex was investigated by using the following methodology. One group consisted of naive females which had no prior contact with infested plant material before used in the bioassay. The other group consisted of experienced females which were released for $1 \mathrm{~h}$ on leaves infested by $C$. pallidactylus larvae and allowed to oviposit $2 \mathrm{~h}$ prior to the bioassay. 


\section{Chapter II}

\section{Collection of adult parasitoids in the field}

For the GC/MS-EAG analyses, field collected parasitoids were used. They were captured in malaise traps which were exposed in insecticide-untreated fields of oilseed rape crop near Göttingen. The traps were emptied twice a day. Female parasitoids were stored for 48 hours in the laboratory and supplied with oilseed rape flowers and water before the experiment started.

\section{Artificial infestation of plants by C. pallidactylus}

Plants infested by larvae of $C$. pallidactylus were needed in the behavioural and electrophysiological bioassays with T. obscurator. Oilseed rape plants (Brassica napus, cultivar Westar) were grown under greenhouse conditions. For artificial infestation by C. pallidactylus two plants in the "6-true-leaf stage" were exposed to three females and one male of $C$. pallidactylus within an insect cage (BugDorm-2, Mega View Science and Education Services Co., Taichung, TW) measuring $60 \mathrm{~cm}$ x $60 \mathrm{~cm}$ x $60 \mathrm{~cm}$. Following an oviposition time of $24 \mathrm{~h}$, plants were removed and transferred to a climate chamber $\left(20{ }^{\circ} \mathrm{C}, 16\right.$ $\mathrm{L}: 8 \mathrm{D}, 4.000 \mathrm{lux})$. Infested plants were used in the experiments 7 - 21 days after oviposition, when larvae were in the second to third instar.

\section{Dual-choice test}

A dual-choice experiment was designed to study the behaviour of naive and experienced T. obscurator females, when given a choice between an uninfested leaf and a leaf infested by C. pallidactylus larvae. In previous experiments in a windtunnel, females of T. obscurator did not respond when exposed to different wind intensities and different light sources. Better results could be obtained by offering infested leaves in a small experimental arena to parasitoid females. In this experiment leaves of oilseed rape (Brassica napus, cultivar Westar), which had been infested with larvae of $C$. pallidactylus as describes above were used. An infested and an uninfested leaf were exposed $10 \mathrm{~cm}$ apart in a perspex cage $(30 \mathrm{~cm} \mathrm{x}$ $20 \mathrm{~cm}$ ), with two walls covered with gauze for air exchange. The base of the petioles was sealed with wet cotton wool. The experiment was performed in a room without daylight. As parasitoids are highly attracted by the light, the light source was set up below the experimental cage. Five to eight days old females of T. obscurator were released individually in the center of the experimental cage. The total residence time on the leaves was recorded within 5 min observation time. In addition, the first choice and the ovipositor probes were assessed. 


\section{Chapter II}

\section{Y-Olfactometer tests}

The response of female $T$. obscurator to olfactory stimuli involved in host microhabitat location was studied by using a Y-olfactometer. Five different sources of odour were tested: (1) infested leaf with host larvae vs. uninfested leaf; (2) infested leaf with host larvae vs. infested leaf without host larvae; (3) infested leaf without host larvae vs. uninfested leaf; (4) host larvae vs. clean air; (5) uninfested leaf vs. clean air. In the Y-olfactometer, the insects could select between two airstreams carrying odours of the different treatments. It consisted of a Y-shaped perspex tube of $27 \mathrm{~mm}$ inner diameter, with arms of $120 \mathrm{~mm}$ length connected at a $40^{\circ}$ angle to the central tube. As $T$. obscurator is strongly attracted by light, the light source was positioned at the back of the two arms of the olfactometer, thereby stimulating insect movement to this direction. The air was pumped into a gas-wash bottle filled with active charcoal and thereafter divided into two lines of Teflon tubing. The air flow was adjusted via two flow meters to $70 \mathrm{~cm}^{3} / \mathrm{sec}$. The air was piped into bottles with distilled water. The tubes were connected to two bottles containing the odour sources. Groups of five females of $T$. obscurator were released into the central tube of $15 \mathrm{~cm}$ length and allowed to choose one of the arms. Females that did not make a choice within 10 minutes were not included in the analyses. The first choice for one of the two odour sources was recorded when females moved into the respective arm of the olfactometer. To avoid any asymmetrical bias in the setup, the odour sources were changed after testing 10 parasitoids. For each combination, 30 females were tested.

\section{Collection of volatiles emitted from plants}

Potted oilseed rape plants (cultivar Westar), as described above, were used to collect the odour blend emitted from uninfested and infested plants. A total of 25 uninfested and 68 infested individual oilseed rape plants were tested. Plants infested by C. pallidactylus larvae were enclosed within an ethylen-tetraflorethylen (ETFE) bag (70 cm x $40 \mathrm{~cm} \mathrm{x} 40 \mathrm{~cm}$ ) in the greenhouse under daylight conditions, from 10 am to $1 \mathrm{pm}$. The bags were mounted on a laboratory pedesta. The opening of the bag was closed around the stem base by mounting its opposite edges between aluminium splints, and fixing with clips. Volatile trapping was started after $1 \mathrm{~h}$ to ensure air homogeneity within the bags. Volatiles were collected for 2 hours. An ETFE stopper containing two openings $(0.67 \mathrm{~mm}$ diameter $)$ was inserted into the bags. Air containing volatiles was sucked off from the interior air volume of the bag through one of the openings by using a miniature vacuum pump (DC12/16 NK Fa. Fürgut, Germany). A volatile trapping device (Prec. Charcoal filter (1.5 mg) Fa. Brechbuehler AG, Switzerland) was 


\section{Chapter II}

mounted in the tubing between the bag and the pump at the inlet part of the pump. The outlet of the pump was connected with the bag by tubing to maintain a constant air circulation. The circulation of the air was kept at a constant air flow by adjusting the pump to a power supply (PS-302 A, Fa. Conrad Electronic, Germany) at 9 volt. Plant volatiles were eluted from the absorbent characoal filter by using $75 \mu \mathrm{l}$ dichlormethan and methanol $(2: 1 ; \mathrm{v} / \mathrm{v})$.

\section{GC-MS/EAG system}

Samples were analyzed by coupled GC-MS/EAD (Weissbecker et al. 2004), using a 6890N gas chromatograph (Agilent, Palo Alto, CA, USA) and a 5973N mass spectrometer (Agilent). The GC was equipped with a split/splitless (S/SL) injector and a HP-5MS column (Agilent; $30 \mathrm{~m}, 0.25 \mathrm{~mm}$ I.D, film thickness $0.25 \mu \mathrm{m}$ ). A GRAPHPACK 3D/2 flow splitter (Gerstel, Mülheim, Germany) was used to split the effluent from the column into capillaries leading to the MS (1 m long, $0.1 \mathrm{~mm}$ ID) and to the EAD (1 m long, $0.15 \mathrm{~mm} \mathrm{ID).} \mathrm{The} \mathrm{restriction}$ capillaries resulted in an equal split of the gas flow into the two setups. A modified "olfactory detector port" (ODP-2; Gerstel) guided the capillary out of the GC oven within a flexible heating sleeve (Weissbecker et al., 2004). Volatiles were eluted from the column into a flow of helium make-up gas, and then mixed with humidified air $\left(23^{\circ} \mathrm{C}, 80 \% \mathrm{RH}\right)$. The airflow (flow rate, $400 \mathrm{ml} / \mathrm{min}$ ) was directed through the flow tube (15 cm long, $6 \mathrm{~mm}$ ID, PTFE) to the insect antenna preparation that was housed in a PTFE detector cell. Excised antennae of $T$. obscurator were placed into an antenna holder milled from a perspex disc (Färbert et al., 1997). Within the holder, the ends of the antennal contacted an electrolyte solution that provided electrical contact to a pair of $\mathrm{Ag} / \mathrm{AgCl}$ electrodes. EAD potentials were amplified by a factor of 100 with a high-impedance amplifier (input impedance $100 \mathrm{M} \Omega$; Prof. Koch, Kaiserslautern, Germany) which contained a built-in low-pass filter set to a cutoff frequency of $1 \mathrm{~Hz}$ to suppress the ubiquitous electrical supply frequency of $50 \mathrm{~Hz}$. An additional high pass filter set at a cutoff frequency of $0.01 \mathrm{~Hz}$ was used to suppress drift of the EAD signal. The amplified and filtered signal was digitized by using a 35900E A/D converter (Agilent) and recorded by the GC ChemStation software (Agilent).

\section{Analytical Conditions}

One- $\mu \mathrm{l}$ aliquots of the samples were injected into the $\mathrm{S} / \mathrm{SL}$ injector (temperature, $250^{\circ} \mathrm{C}$ ). The GC oven was programmed from $50^{\circ} \mathrm{C}$ for $1.5 \mathrm{~min}$, ascending at $6^{\circ} \mathrm{C} / \mathrm{min}$ to $200^{\circ} \mathrm{C}$; hold for 5 min. Helium was used as carrier gas $(1 \mathrm{ml} / \mathrm{min}, 24 \mathrm{~cm} / \mathrm{sec})$. The GC-MS interface was held at $280^{\circ} \mathrm{C}$. The heating sleeve of the ODP was set to $230^{\circ} \mathrm{C}$. The MS used electron impact 


\section{Chapter II}

ionization (EI) at $70 \mathrm{eV}$, in scan mode (35-300 mass units, $2.78 \mathrm{scans} / \mathrm{sec}$ ). For preliminary peak identification, the NIST mass spectral library (National Institute of Standards and Technology, Gaithersburg, MD USA) was used. Subsequently the retention time of compounds were compared with those of synthetic standards and the Retention Time Internal Database.

\section{Electroantennogram dose-response series}

Dose response series were measured by manual injection of odour standards into the air stream passed over the antennae of female $T$. obscurator mounted in an electroantennogram (EAG) setup. Odor standards were produced from dilution series of the respective compounds in paraffin oil (Uvasol quality, Merck/VWR). Small pieces of filter paper $\left(2 \mathrm{~cm}^{2}\right.$; Schleicher $\&$ Schuell, Dassel, Germany) were soaked with $100 \mu \mathrm{L}$ of the standard dilution. The filter paper was inserted into a 10-ml glass syringe (Poulten \& Graf GmbH, Wertheim, Germany). Within the air volume of the syringe, the odorant accumulated at a concentration proportional to the concentration of the substance in the solution and its vapor pressure according to Henry's law. A reproducible stimulus could be supplied by puffing $5 \mathrm{ml}$ of air over the antenna (Schütz et al., 1999). The resulting signals were amplified (100×).

The following standard substances were measured: Terpinen-4ol 97\% (Acros Organics), Octanal 99\% (Acros Organics), Nonanal 98\% (Merck Schuchardt), cis-3-Hexen- 1ol 98\% (Arcos Organics).

Field experiments

\section{Baited water traps}

For testing the attractiveness of selected volatiles to female $T$. obscurator under field conditions, yellow water traps were set out $10 \mathrm{~m}$ apart from the edges in oilseed rape and winter wheat fields, the latter being used by parasitoids overwintering. The chemicals tested were obtained from commercial sources (Undecane: cas 1120-21-4, Acros Organics 99\%; Terpinen-4-ol: CAS 562-74-3, Acros Organics 97\%). The undiluted liquids (300 $\mu \mathrm{l})$ were applied to pieces of cellulose sponge (10 mm thick) that were heat-sealed into polyethylene bags. Compounds were released individually by diffusion from bags. The rate of daily diffusion was $5.766 \mathrm{mg} /$ day Terpinen-4-ol and $19.42 \mathrm{mg}$ /day Undecane. The odour sources were replaced every three weeks. The response of field populations of adult T. obscurator to traps baited with volatiles was compared with the response to unbaited control traps. Captured insects were removed at intervals, identified by keys of Horstmann $(1971 ; 1981)$ and counted in the laboratory. 


\section{Statistical Analyses}

Significant differences between treatments in dual-choice bioassays were calculated by $\chi^{2}$-test $(\mathrm{p}<0.05)$. Data of peak area of GC analyses were log-transformed before testing for significant differences by Mann-Whitney-U-Test. Differences in frequency and proportion of volatiles detected in GC/MS were analysed by $\chi^{2}$-test. RM-ANOVA was applied to evaluate significant differences between the cumulative numbers of parasitoids in baited and unbaited yellow water traps.

\section{Results}

\section{Dual choice tests}

The first choice of naive females of $T$. obscurator was not significantly different between infested leaves and uninfested leaves. A total of $57.3 \%$ of naive females moved towards the infested leaves. They did not show a significant preference for the host-infested leaf compared to the uninfested leaf. Similarly, the residence time and the number of ovipositor probes by naïve females did not differ significantly (Fig. 1).

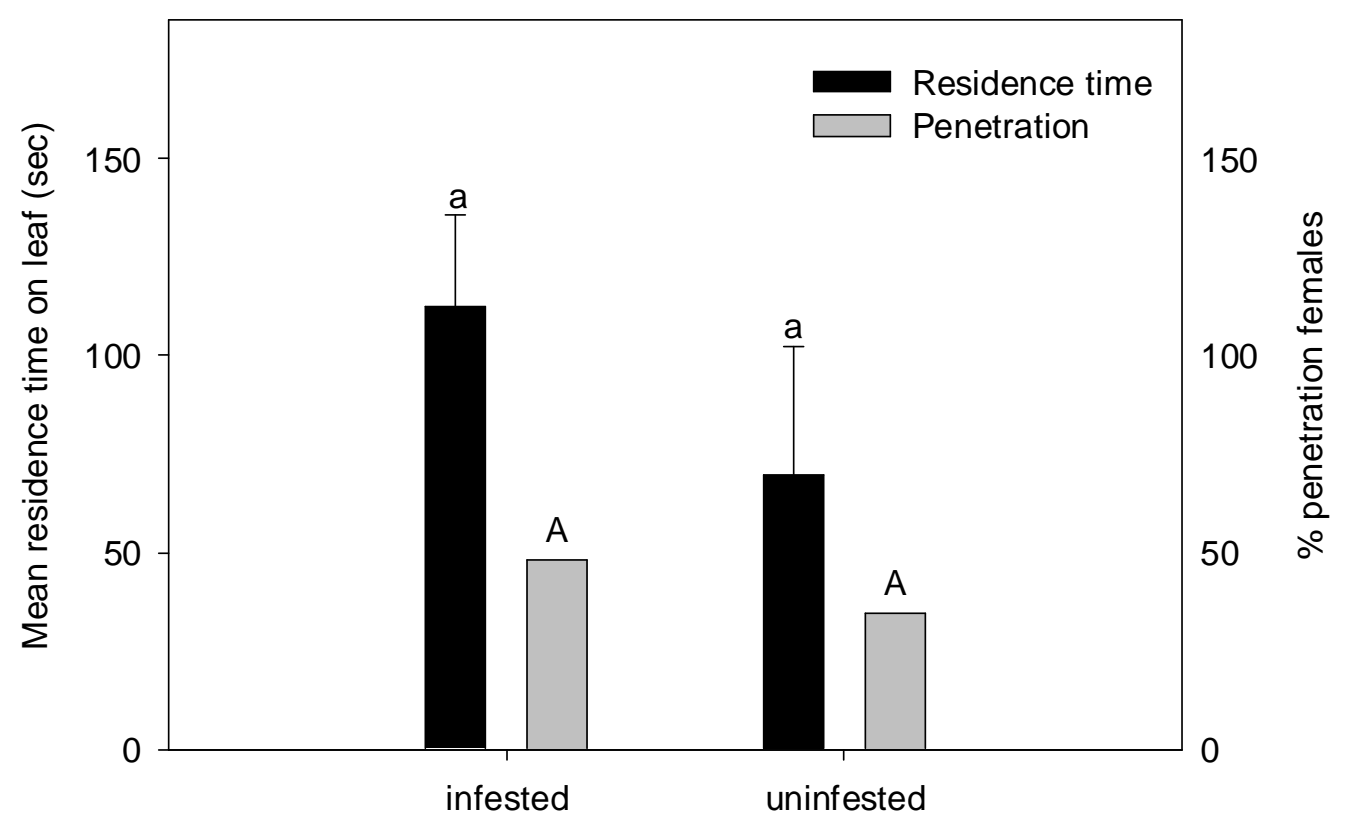

Fig 1: Mean residence time $(\mathrm{Xm}+\mathrm{SE})$ of naive female $T$. obscurator and $\%$ of penetrating females on oilseed rape leaves infested by larvae of $C$. pallidactylus and uninfested leaves. Observation period $5 \mathrm{~min}$. Columns with the same upper case/lower case letters are not significantly different $\left(\chi^{2}\right.$-Test, $\left.\mathrm{p}<0.05, \mathrm{n}=25\right)$. 


\section{Chapter II}

In contrast, $71 \%$ of the experienced females made their first choice to the herbivore-infested leaf. The oviposition experience prior to the bioassay significantly increased the residence time on the infested leaf compared to the uninfested leaf. Infested leaves elicited ovipositor probes by $55 \%$ of females while only $7.5 \%$ of females penetrated the the uninfested leaf (Fig 2).

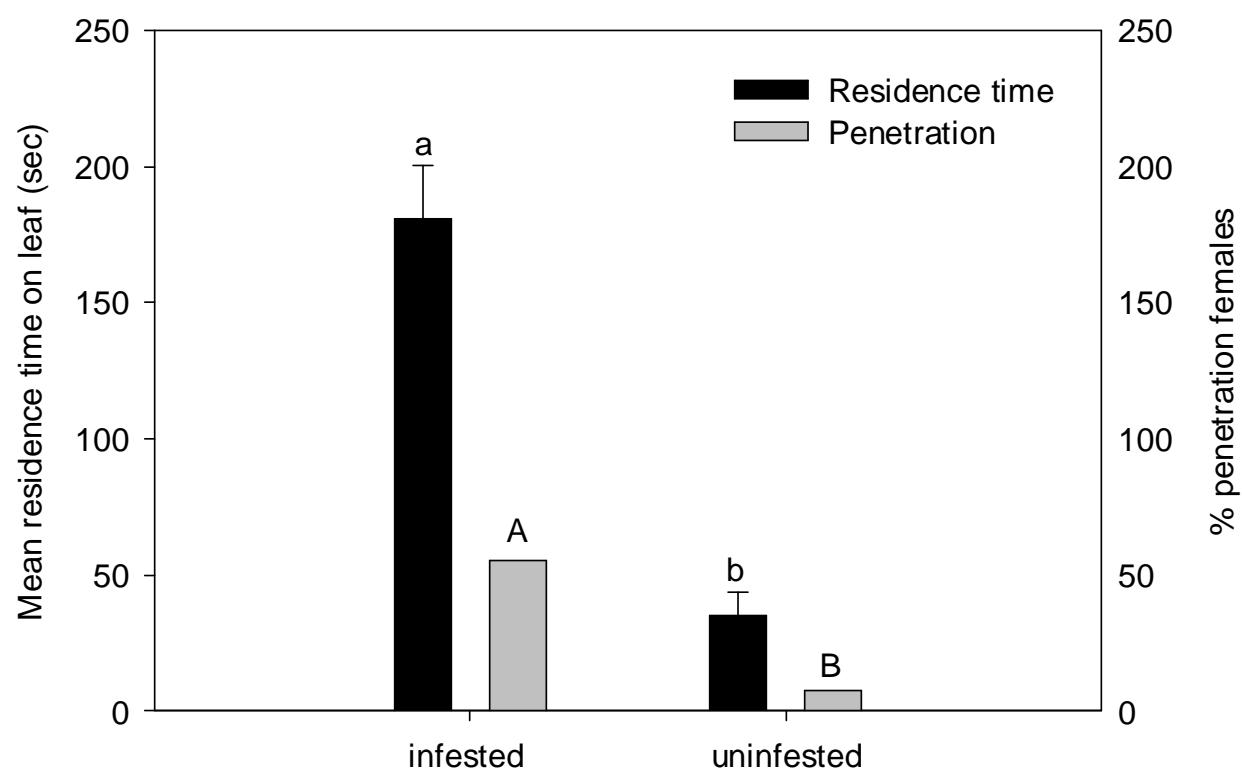

Fig 2: Mean residence time $(\mathrm{Xm}+\mathrm{SE})$ of experienced female T. obscurator and percentage of penetrating females on oilseed rape leaves infested by larvae of $C$. pallidactylus and uninfested leaves. Observation period $5 \mathrm{~min}$. Means with different upper case/lower case letters are significantly different $\left(\chi^{2}\right.$-Test, $\left.\mathrm{p}<0.05, \mathrm{n}=21\right)$.

\section{$Y$ - olfactometer tests}

In Y-olfactometer tests, experienced parasitoid females were significantly more attracted towards the odour of the infested leaf, whereas naive female parasitoids showed no clear preference for the infested or uninfested leaves (Fig 3).

Additional Y-olfactometer tests showed that a significantly higher percentage of experienced females of T. obscurator responded to infested leaves without larvae than to uninfested leaves. The odour from isolated host larvae alone did not attract female parasitoids. Uninfested leaves were significantly more attractive than clean air (Fig 4). 


\section{Chapter II}

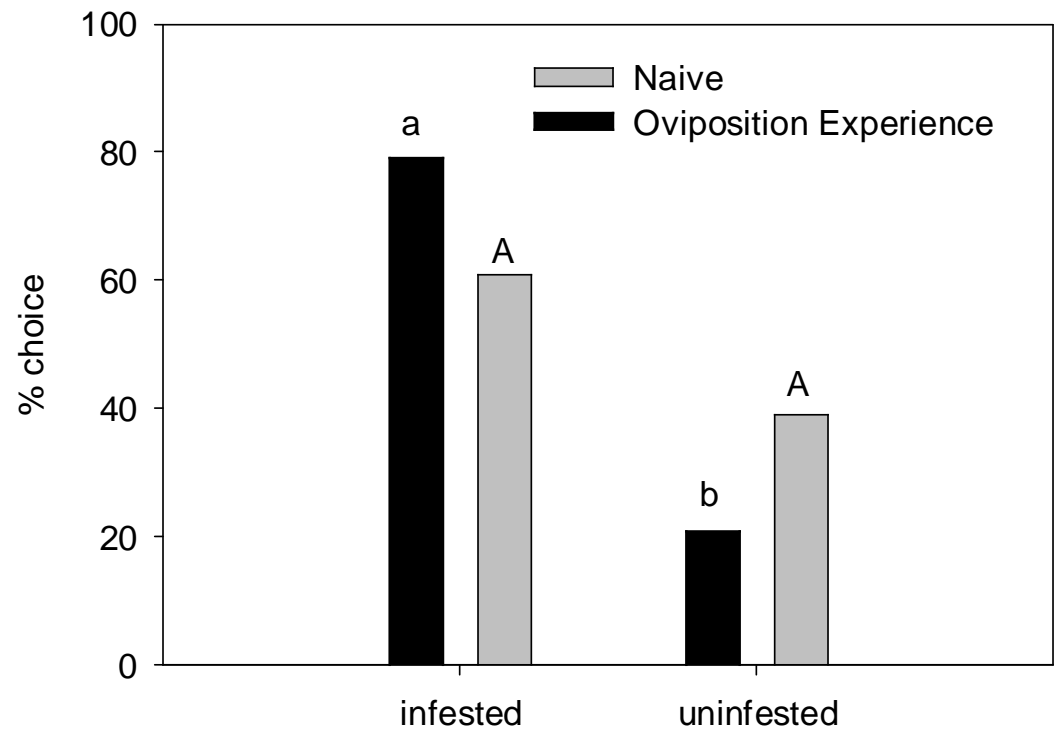

Fig 3: Percentage of naive and experienced females of T. obscurator attracted to volatiles emitted by oilseed rape leaves infested by $C$. pallidactylus larvae and uninfested leaves in Yolfactometer tests. Different upper case or lower case letters indicate significant differences $\left(\chi^{2}\right.$-Test, $\left.\mathrm{p}<0.05, \mathrm{n}=24\right)$.

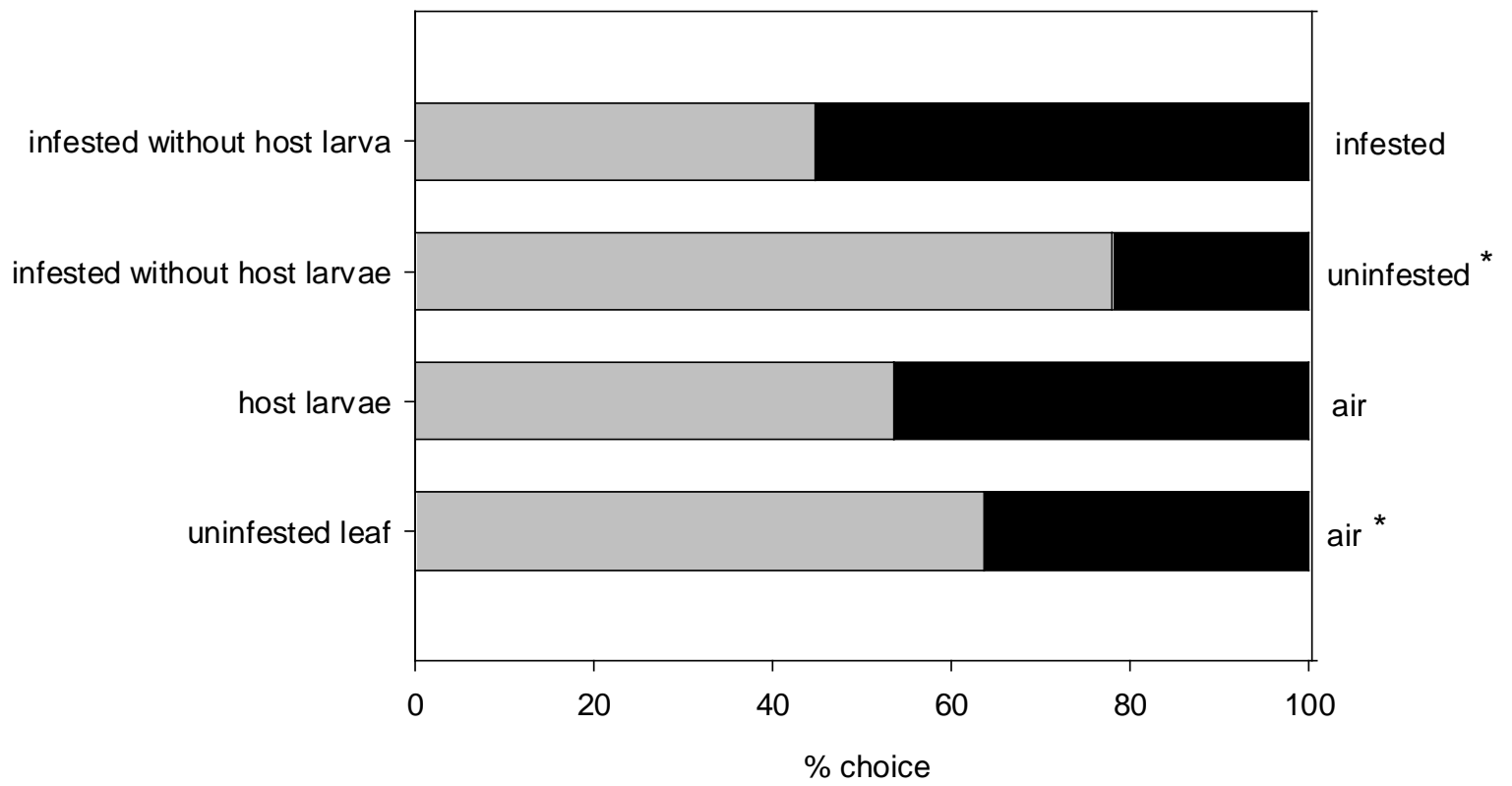

Fig 4: Percentage of experienced females of T. obscurator attracted to different odour sources in Y-olfactometer tests. $*$ indicates significant differences $\left(\chi^{2}\right.$-Test, $\left.\mathrm{p}<0.05, \mathrm{n}=24-31\right)$. 


\section{Volatiles emitted from infested and uninfested oilseed rape plants}

The volatile compounds 3-Hexen-ol, 2 Octanol, Unidentified II, Benzaldehyd, Octanal, Dodecane, $\alpha$-Farnesene and Acetophenone were only released from plants infested by C. pallidactylus larvae, but not from uninfested plants (Fig 5). In contrast, $\beta$-myrcene was only detected in infested plants. Infested as well as uninfested plants commonly elicited 1Hexenyl 2 -ethyl and Undecane, while Terpinen-4-ol was found more frequently in uninfested plants and 3-Hexen-1ol acetate and Naphtalene more frequently in infested plants. The records of individual volatiles differed between the replicated plants within each treatment.

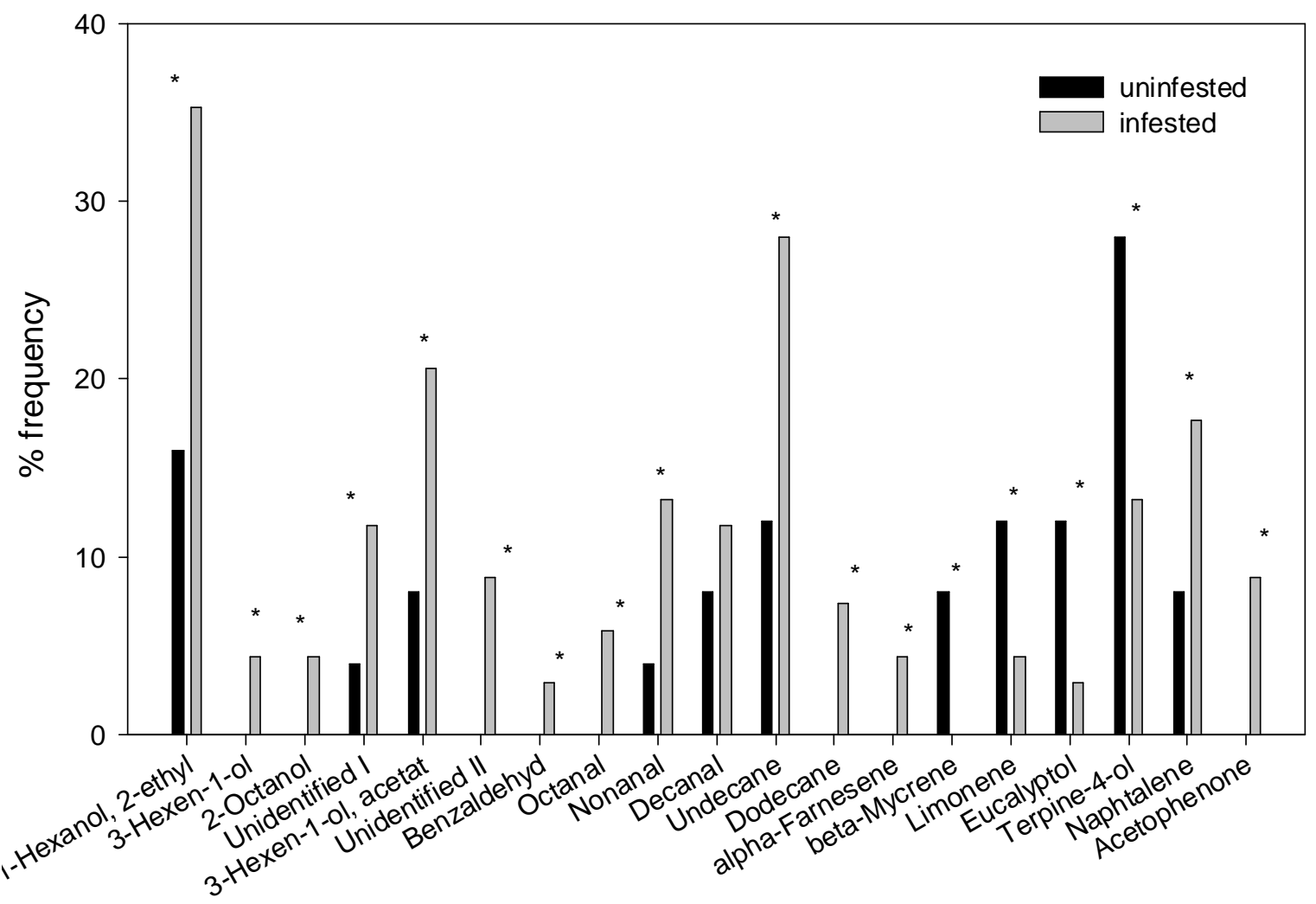

Fig 5: Proportion of plants infested by $C$. pallidactylus larvae and of uninfested plants (Brassica napus, cultivar Westar) that released plants volatiles Uninfested $\mathrm{n}=25$, infested $\mathrm{n}=$ $68, *$ indicates significant differences $\left(\chi^{2}-\right.$ Test, $\left.\mathrm{p}<0.05\right)$.

The infestation of plants by larvae of $C$. pallidactylus significantly increased the amount of volatiles released from plants (except Terpinen-4-ol). Plant infestation increased the total release of volatiles by $55.7 \%$. The infested plants produced several alcohols, aldehyde, terpenoids and acetophenone which were not found in uninfested plants (Fig 6). 


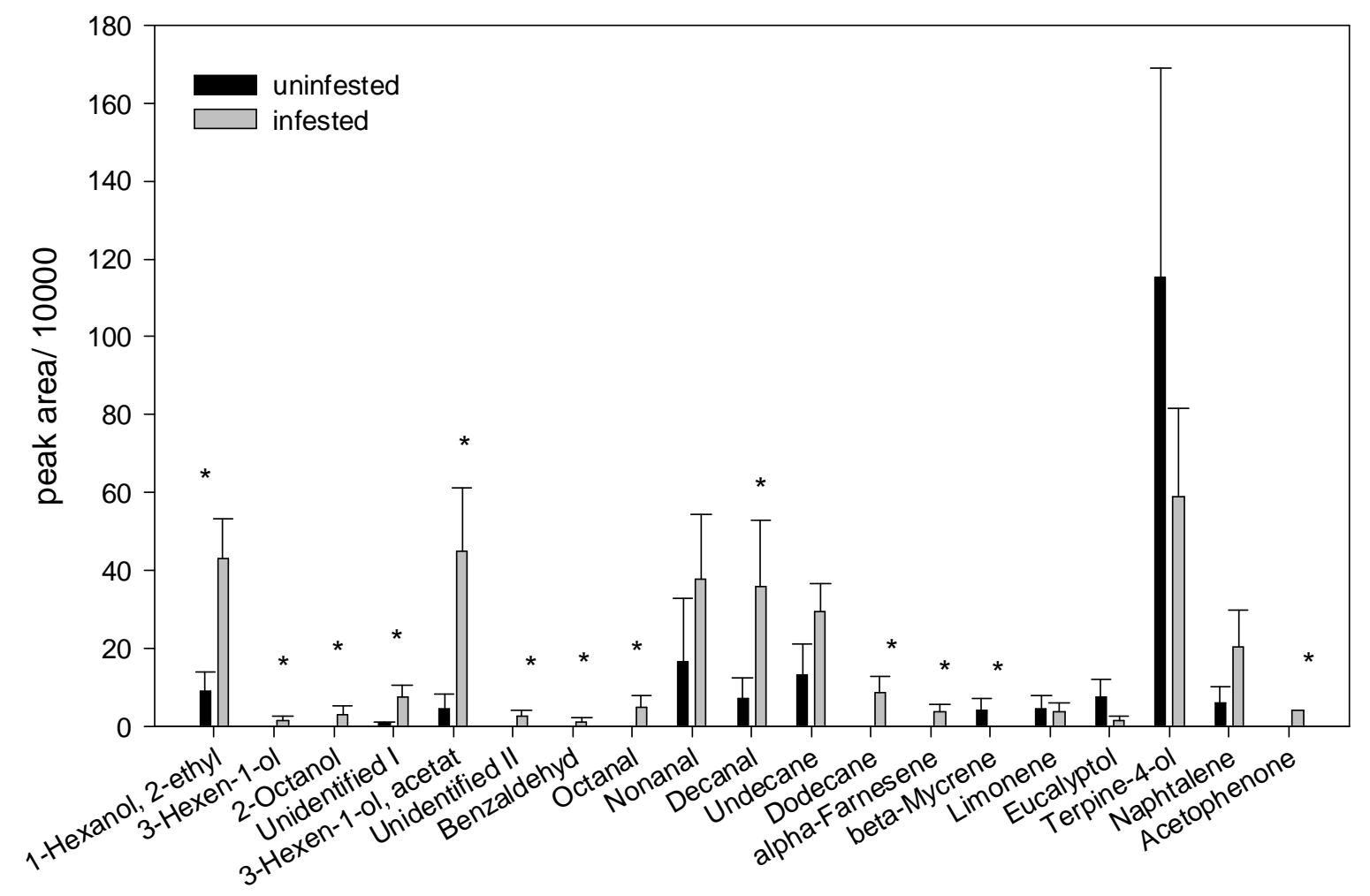

Fig 6: Amount of volatiles (mean peak area $+\mathrm{SE}$ ) released from plants infested by $C$. pallidactylus larvae and from uninfested plants (B. napus, cultivar Westar). Uninfested $\mathrm{n}=$ 25 , infested $n=68$. Internal standards: Eucalyptol: peak area of 7655387 is equivalent to $92,5 \mathrm{ng}$ Eucalyptol, Decanal: peak area of 932745 is equivalent to $82,8 \mathrm{ng}$ Decanal. * indicates significant differences (Mann-Whitney-U-test, $\mathrm{p}<0.05$ ). 


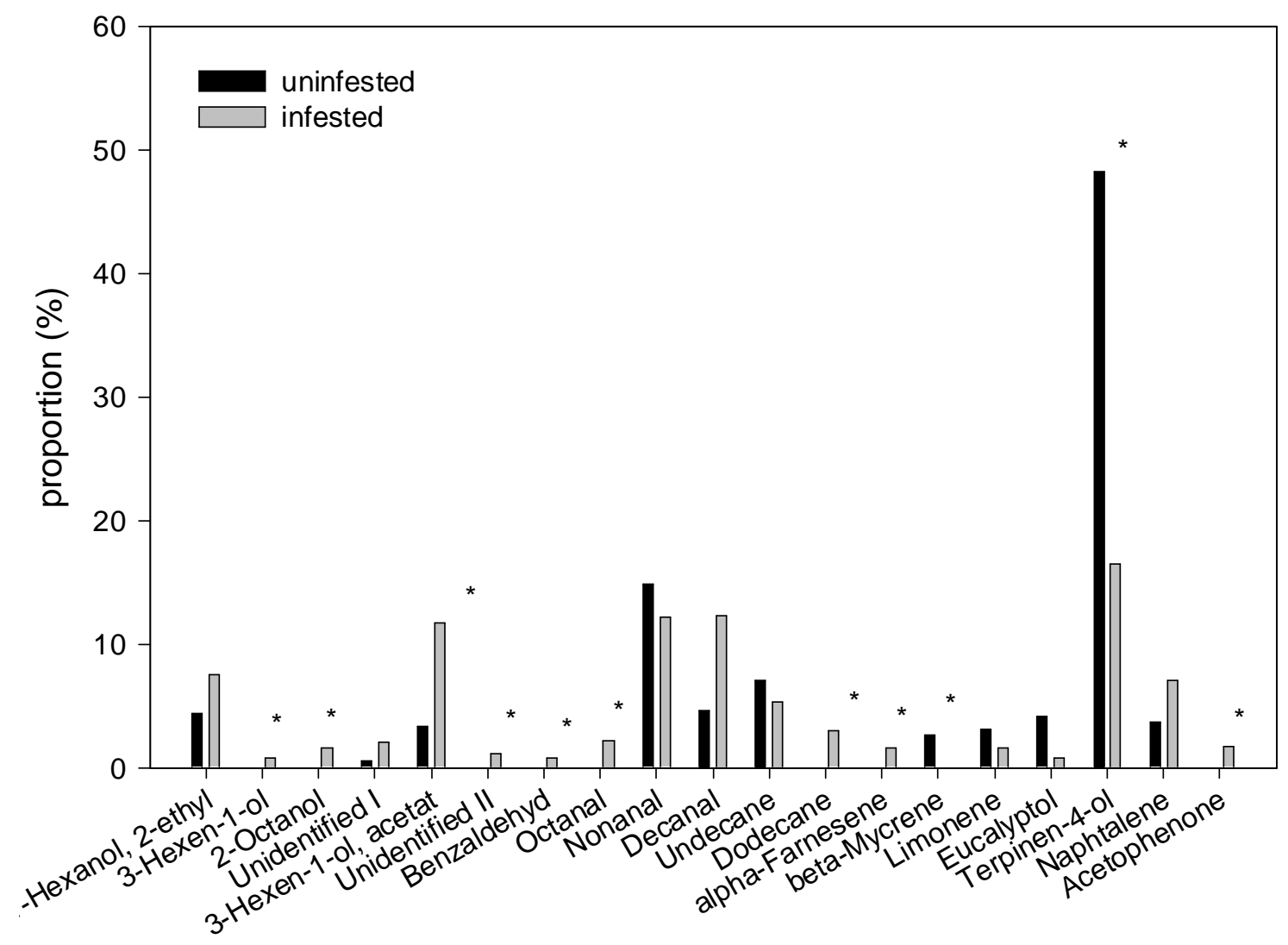

Fig 7: Relative amounts (\%) of individual compounds in the volatile blends of uninfested oilseed rape plants (B. napus, cultivar Westar) and plants infested by larvae of $C$. pallidactylus. $*$ indicates significant differences $\left(\chi^{2}-\right.$ Test, $\left.\mathrm{p}<0.05\right)$.

When the volatiles released from infested plants were tested in GC/MS-EAG analyses, 12 out of 19 volatile compounds elicited antennal responses by female $T$. obscurator in more than three of the 75 GC/MS-EAG experiments. Uninfested plants elicited responses to only six out of eleven compounds. Females of T. obscurator responded particularly to terpenoid, aldehyde and alcohol compounds (Table 3). The volatiles 1-Hexenol, 2-ethyl and Terpinen-4-ol elicited the strongest response of T. obscurator to uninfested plants, while Nonanal and $\alpha$-farnesene provoked the strongest response to infested plants (Table 3). 


\section{Chapter II}

Tab 3: EAG-responses of female T. obscurator to volatiles emitted from uninfested oilseed rape plants (B. napus, cultivar Westar) and plants infested by larvae of $C$. pallidactylus, Infested: $\mathrm{n}=75$, Uninfested $\mathrm{n}=27$.

\begin{tabular}{|c|c|c|}
\hline & $\begin{array}{l}\text { EAG-Response of } T \text {. } \\
\text { obscurator to volatiles of } \\
\text { uninfested plants }\end{array}$ & $\begin{array}{l}\text { EAG-Response of T. obscurator } \\
\text { on volatiles of infested plants }\end{array}$ \\
\hline 1-Hexanol, 2-ethyl & $* * * * *$ & $* *$ \\
\hline \multicolumn{3}{|l|}{ 3-Hexen-1-ol } \\
\hline 2-Octanol & & $*$ \\
\hline \multicolumn{3}{|l|}{ Unidentified I } \\
\hline \multicolumn{3}{|l|}{ 3-hexen-1-ol, acetate } \\
\hline Unidentified II & & $* *$ \\
\hline Benzaldehyd & & $*$ \\
\hline Octanal & & $*$ \\
\hline Nonanal & & $* * * *$ \\
\hline Decanal & $*$ & $*$ \\
\hline Undecane & & $* *$ \\
\hline \multicolumn{3}{|l|}{ Dodecane } \\
\hline$\alpha$-Farnesene & & $* * *$ \\
\hline$\beta$-Mycrene & $*$ & \\
\hline Limonene & $*$ & \\
\hline Eucalyptol & $*$ & $*$ \\
\hline Terpine-4-ol & $* * * * *$ & $*$ \\
\hline \multicolumn{3}{|l|}{ Napthalene } \\
\hline Acetophenone & & $*$ \\
\hline
\end{tabular}

The absolute sensitivity of the antennae of female $T$. obscurator towards four of the identified compounds was determined by using commercially available standards. The EAG dose responses obtained by antennal stimulation with reference standards in dilution series are depicted in Fig. 8. The highest EAG response was observed in response to Octanal, Terpinen4-ol and Nonanal, with amplitudes of $75 \mu \mathrm{V}$ to $110 \mu \mathrm{V}$ for the tested $10^{-2}$ dilution. At the $10^{-3}$ and $10^{-2}$ dilution level, the antenna responded to 3 -Hexen-1-ol with amplitudes of $30 \mu \mathrm{V}$. The EAG-response to all tested compounds increased strongly from the $10^{-4}$ dilution to the $10^{-2}$ dilution. 


\section{Chapter II}

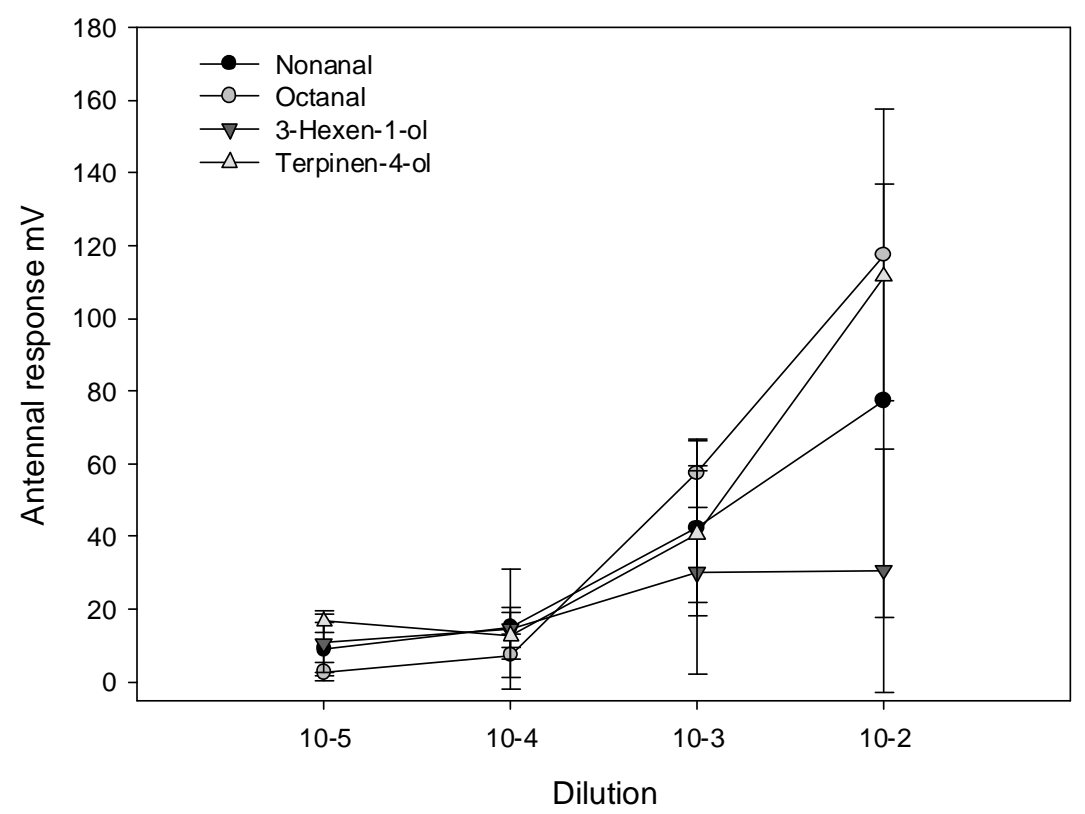

Fig 8: Electroantennogram dose- response curves of volatiles emitted from uninfested and infested plants, obtained from antennal stimulation of female T. obscurator. Puffs of $5 \mathrm{ml}$ of air were loaded with reference standards of plant odours. Each point represents the mean $+\mathrm{SE}$ antennal response.

Field experiment

\section{Baited yellow water traps}

At the overwintering site, in a winter wheat field, significantly higher numbers of female

T. obscurator were caught in traps baited with Undecane than in traps without Undecane (Fig 8). In the oilseed rape field the traps baited with Undecane were not preferred by female $T$. obscurator (Fig 9). 


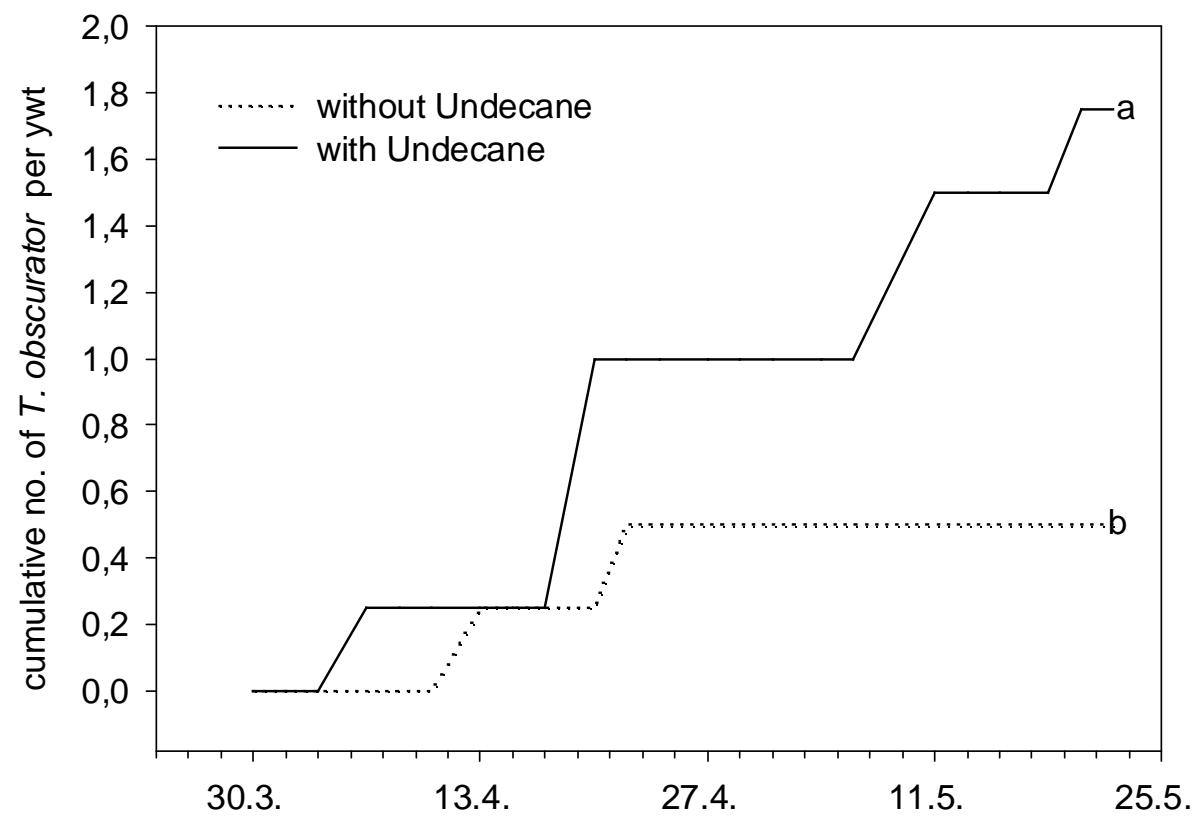

Fig 8: Cumulative number of female T. obscurator caught in yellow water traps (ywt) baited with Undecane and in unbaited traps at the overwintering field of parasitoids. RM-ANOVA; $p$ $\leq 0.05$.

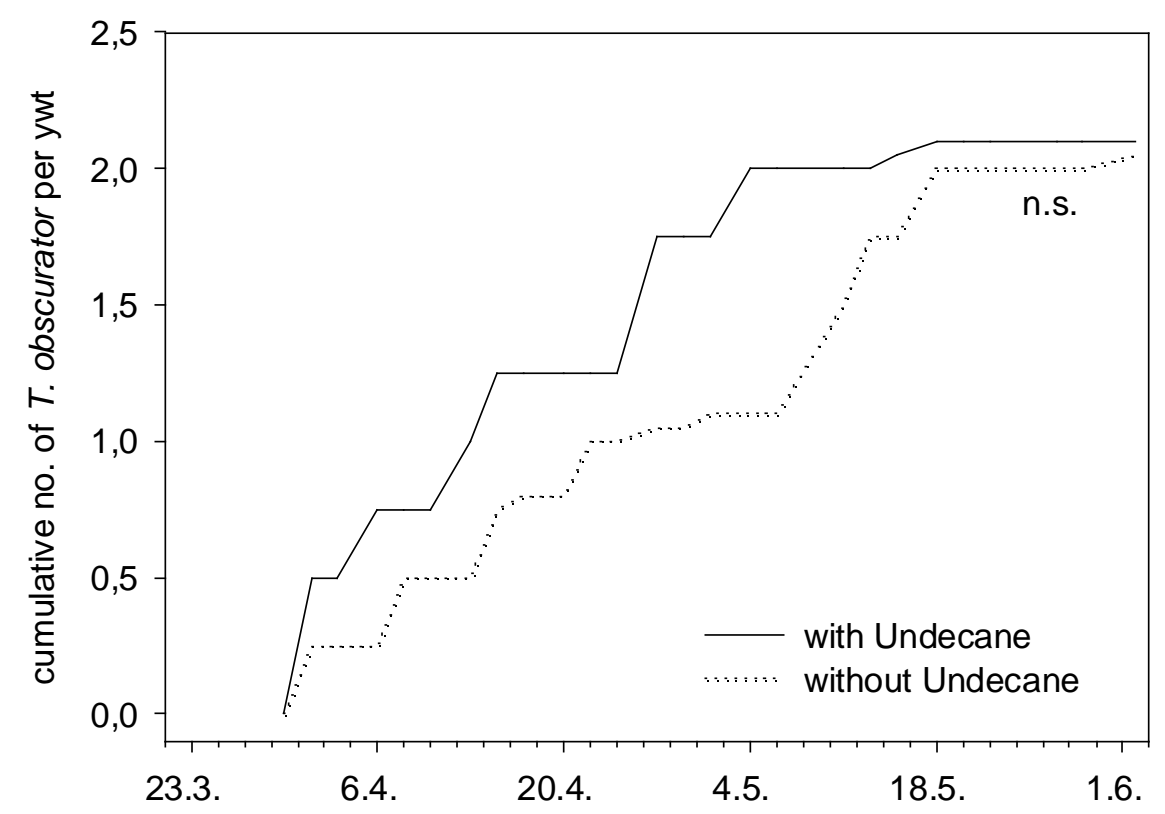

Fig 9: Cumulative number of female T. obscurator caught in yellow water traps (ywt) baited with Undecane and in unbaited traps in a crop of oilseed rape. RM-ANOVA; $p \leq 0.05$. 
Yellow water traps baited with Terpinen-4-ol did not attract significantly more females of

T. obscurator at the overwintering field than unbaited traps (Fig 10). In the oilseed rape field, however, significantly more female $T$. obscurator were caught in traps baited with Terpine-4ol than in traps without Terpinen-4-ol (Fig 11).

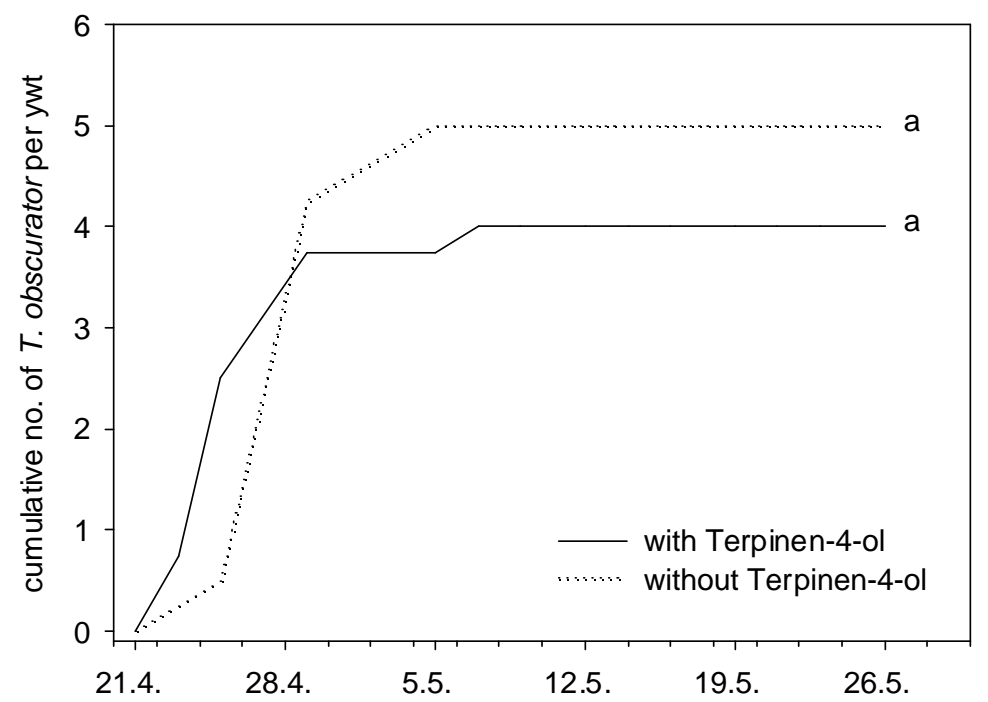

Fig 10: Cumulative number of female T. obscurator caught in yellow water traps (ywt) baited with Terpinen-4-ol and in unbaited traps at the overwintering field. RM-ANOVA; $p \leq 0.05$

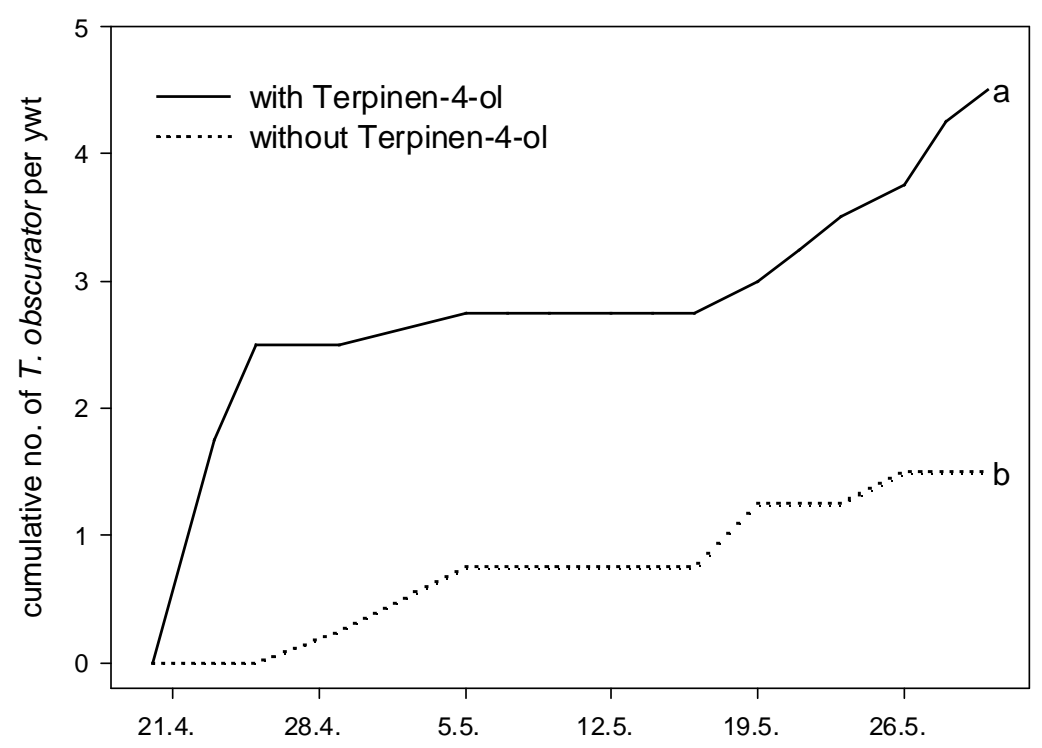

Fig 11: Cumulative number of female T. obscurator caught in yellow water traps (ywt), baited with Terpinen-4-ol and in unbaited traps in a crop of oilseed rape. RM-ANOVA; $p \leq 0.05$ 


\section{Chapter II}

\section{Discussion}

In laboratory bioassays, females of $T$. obscurator were able to discriminate between uninfested leaves and leaves infested by larvae of their host C. pallidactylus. Oviposition experience of females increased the probability of host finding significantly. Within five minutes of observation, $71 \%$ of experienced females made their first choice to infested leaves. Experienced females were clearly arrested on host-damaged leaves and significantly more females made oviposition probes into infested leaves than into uninfested leaves. There are various examples in the literature demonstrating that experienced females respond faster and exhibit more direct flights to a host-plant complex than naive females (Drost et al., 1986; McAuslane et al., 1991). These assoziations between stimuli and resources can be both innate (Wäckers, 1994) and learnt (Lewis \& Takasu, 1990; Vet \& Groenewold, 1990). Associative learning allows parasitoids to focus on the most reliable cues for host finding (Vet \& Groenewold, 1990; Jong \& Kaiser, 1991; Geervliet et al., 1997b). Furthermore, learning to respond to cues from one plant-host complex can facilitate host-finding when other hostinfested plants emit similar compounds or volatile blends (Geervliet et al., 1997b). Whether this increased response to infested leaves is due to an increased sensitivity or to assoziative learning remains to be elucidated.

Insect parasitoids respond to a variety of stimuli, including visual, vibrational, chemical, and tactile cues, when foraging for potential hosts (Allen et al., 1999; Meyhöfer \& Casas, 1999; Wäckers \& Lewis, 1999; Jönsson et al., 2005). Olfaction is often considered to provide the most important evidence for the presence of host larvae, particularly for endophagous hosts hidden within the leaves or stems (Vet et al, 1991a, Potting et al., 1995). Our Y-olfactometer bioassays demonstrated that olfactory stimuli originating from the host-plant complex are sufficient cues for discrimination of $T$. obscurator between infested and uninfested leaves. The parasitoids were attracted to the odour of infested oilseed rape leaves, even when the host larvae had been removed. Dissection of the host larvae from the petioles caused an artificial damage. In pre-experiments, mechanically damaged leaves did not attract female parasitoids compared to uninfested, undamaged leaves. Therefore we assume that females were attracted to volatiles of the host-plant complex rather than to the host larvae. The exact origin of the cues inducing host searching and oviposition of T. obscurator on herbivore-damaged leaves were not completely elucidated by our present experiments. It was not possible to separate the volatiles emitted from frass and faeces of host larvae from volatiles released by the infested leaf. Volatiles of the host larva itself did not attract parasitoid females. Similarly, in other studies herbivore-damaged plants were more attractive to parasitoids than the herbivore itself 


\section{Chapter II}

or its by-products (Turlings et al., 1991c; Geervliet et al., 1994). Potting et al. (1995) observed that infested maize stems remained attractive to the parasitoid Cotesia flavipes even when the stem-boring larvae of Chilo partellus were removed; the parasitoid did not make a distinction between infested stems with or without larvae. The frass of the host larvae attracted the parasitoid to the stem-borer infested stem: parasitoids were significantly attracted to frass when tested against larvae (Potting et al., 1995).

Host-derived stimuli and host products such as faeces are most reliable cues indicating presence, accessibility and suitability of hosts, but they are generally more difficult to detect (Vet \& Dicke, 1992). Jönsson \& Anderson (2008) found that the total amount of volatiles emitted by pollen beetle larvae was more than 400 times smaller than the average amount of volatiles collected from the inflorescences of an infested plant. Stimuli produced by host larvae might be used by parasitoids during a later phase in the host-location process, i.e., after landing on a damaged plant, where they have an arrestant effect (Turlings et al., 1991a; McCall et al., 1993; Mattiacci \& Dicke, 1995). The braconids Cotesia marginiventris, Cotesia glomerata and Cotesia rubeluca are highly attracted by odors emanating from herbivoredamaged plants, whereas odours of larval frass or host larvae were far less attractive to these parasitoids (Turlings et al., 1991b; Steinberg et al., 1992; Steinberg et al., 1993; Geervliet et al., 1994). Even if the odour emitted from the host or host products are reliable indicators for host presence, their long-range detectability is very low (Turlings et al., 1991a; Vet et al., 1991b).

In our olfactory studies the uninfested leaves were more attractive to female $T$. obscurator than clean air. Parasitoids are known to use volatiles derived from the oilseed rape plants for location of the host habitat. Females of C. rubecula were attracted to uninfested leaves indicating that host plant cues are involved in host habitat location (Kaiser \& Cardé, 1992). In long-range search for oilseed rape plants the parasitoids Phradis interstitialis and $T$. obscurator used odour-induced upwind anemotaxis (Williams et al., 2007). The plant odour is carried downwind from the host plant and disperse due to turbulent diffusion (Murlis et al., 2000). Following arrival at the host habitat, short-distance search is mainly based on contact chemical cues of lower volatility, i.e. host salivary gland or mandibular gland secretions, host frass, and cuticular secretions may be involved in locating the host larvae (Turlings et al., 1991c; Vet \& Dicke, 1992; Geervliet et al., 1994; Vinson, 1998; Meiners \& Hilker, 2000). In our dual choice experiment, the searching behaviour of female $T$. obscurator following host location, was based on chemosensory cues of low volatility detected by sensilla on the antennae and on tip of the ovipositor. After cleaning of antennae, head, thorax, legs, abdomen 


\section{Chapter II}

and wings, the searching behaviour of females consisted of walking along the leave, drumming with their antennae and tapping with their ovipositor into the petiol.

We found substantial differences between the volatile blend of infested and uninfested oilseed rape plants. However, there was a considerable variation between replicated plants within treatments, with some compounds detected in only few plants per treatment or in very small amounts. The high variation of volatiles between plants has also been observed by Agelopoulos \& Keller, (1994) and Mattiacci et al. (1994). The emission of herbivore-induced volatiles is strongly affected by abiotic factors such as air humidity, temperature, light, nutrients and soil substrate (Gouinguené \& Turlings, 2002) as well as by biotic factors such as plant cultivar, growth stage, and herbivore attack (Takabayashi et al.,1994). These factors are known to influence the quantitative and qualitative composition of volatile emissions (Jakobsen et al., 1994; Jakobson \& Olsen, 1994; Takabayashi et al., 1994; Gouinguené \& Turlings, 2002).

The main components of the volatile blend released from Brassica plants are terpenoids and green leaf volatiles (Mattiacci et al., 1994; Shiojiri et al., 2001). Further, characteristic compounds of Brassicaceae (Rask et al., 2000), the glucosinolates and their breakdown products isothiocyanates, have been reported to assist as synomones host location by parasitoids within plants of oilseed rape (Jönsson \& Anderson, 2008).

The terpenoids were released in analogous amounts from both herbivore-damaged and mechanically-damaged cabbage plants, as well as from undamaged plants (Mattiacci et al., 1994; Shiojiri et al., 2001). Terpenoids represent a major class among herbivore-induced synomones that are known to attract various carnivores (Takabayashi et al., 1994; Pichersky \& Gershenzon, 2002). In this study the flower terpenoid B-mycrene was solely detected in uninfested plants, while $\alpha$-farnesene was found only in infested plants. Mycrene was reported to be commonly released from uninfested cabbage plants, while $\alpha$-farnesene was emitted from P. xylostella damaged cabbage plants (Geervliet et al., 1997a; Vuorinen et al., 2004). Parasitoids use flower volatiles such as terpenoids and 2-ethyl-1-hexanol to locate nectar sources (Wäckers, 1994). Rape flower odour mainly consists of terpene compounds, with the sesquiterpene $\alpha$-farnesene being the dominant volatile emitted from oilseed rape particularly at flowering (Evans \& Allen-Williams, 1992).

Among the fatty acid derivates, aliphatic alcohols, aldehydes and esters are found. The sixcarbon compounds in this group, together with some of their derivates, are often referred to as "green leaf volatiles" (Hatanaka, 1993). They are found in many plant species (Hatanaka, 1993), and are typical plant volatiles which are induced by herbivory (Whitman \& Eller, 


\section{Chapter II}

1990; Arimura et al., 2005). More than $90 \%$ of volatiles released from rape leaves are green leaf volatiles (Evans \& Allen-Williams, 1992). They are synthesised by oxidative degradation of plant lipids and are continuously released by plants during aging or following injury (Hatanaka, 1993). An increased emission of green leaf volatiles was observed in Brussels sprouts and cabbage plants following larval feeding (Blaakmeer et al., 1994; Mattiacci et al., 1994; Geervliet et al., 1997a; Mattiacci et al., 2001). For example, (Z)-3- Hexen-1-ol comprised $31 \%$ of the total volatiles in the headspace of Brussels sprouts plants infested by Pieris brassicae, but only 4 - 9\% of volatiles from undamaged, artificially damaged, or caterpillar-regurgitate-treated leaves (Mattiacci et al., 1994). In this study, 3-Hexen-1-ol and 3-Hexen-1-ol acetat were found only in plants infested by C. pallidactylus, but not in uninfested plants.

Our method applied for collecting volatiles was not appropriate for detecting isothiocyanates, and it might be possible that these were released in sufficient amounts to affect parasitoid behaviour. Isothiocyanates are characteristic for most cruciferous plants (Rask et al., 2000). The parasitoids T. obscurator and T. fulvipes (Ulber \& Wedemeyer, 2006) and Platygaster subuliformis (Murchie et al., 1997) were strongly attracted to yellow water traps baited with 2-phenylethyl isothiocyanate in the field. The volatile 3-butenyl and 4-pentenyl isothiocyanate accounted for $<0.5 \%$ of the natural rape leaf volatiles (Evans \& AllenWilliams, 1992).

Most volatiles identified from oilseed rape in the current study are ubiquitous compounts released by a wide range of other plant species (Knudsen et al., 1993). Our GC/MS-EAG analyses showed that $T$. obscurator females responded to a range of 12 volatile compounds. Hymenopteran parasitoids are known to respond to a broad spectrum of plant volatiles (Baerecke, et al., 1989; Li et al., 1992; Smid et al., 2002). The braconids C. glomerata and $C$. rubecula are able to perceive a range of at least 20 odour components from the blend produced by Brussels sprouts plants following infestation by Pieris larvae (Smid et al., 2002). Quantitative and qualitative differences between the volatile blends of plants, rather than individual volatiles, could provide cues for host presence and might be used by parasitoids at host searching. Crucifers damaged by herbivores were found to release volatiles at higher rates than intact plants (Agelopoulos \& Keller, 1994; Blaakmeer et al., 1994; Geervliet et al., 1997a; Mattiacci et al., 2001). The quantitative differences between volatiles of Brussels sprouts plants infested by $P$. rapae and by artificially damaged plants allowed the preference of C. rubecula for infested leaves (Geervliet et al., 1994). Quantitative differences were also observed with many components in the current study. The increased amounts of volatiles and 


\section{Chapter II}

the composition of the induced volatiles in relation to non-induced compounds might have provided an important parameter supporting host location of T. obscurator.

The de novo production of several compounds might have been induced in response to cabbage stem weevil damage. In several studies the release of herbivore-induced plant volatiles has been shown to constitute an active response of the plant, apparent from the de novo production of volatile compounds that are not released by intact or mechanically damaged plants (Paré \& Tumlinson, 1997). In the current study T. obscurator responded to volatiles which were solely emitted by infested plants (exception 3-Hexen-1-ol, Dodecane). Particularly the aldehydes, benzaldehyd, octanal, nonanal and decanal elicited antennal responses on infested plants. Aldehydes were emitted also in response to wounding (Hu et al., 2008). In this study nonanal elicited the strongest response. This compound was also shown to be induced by whitefly-infested bean leaves and caterpillar-infested cabbages, respectively (Dicke, 1999; Birkett et al., 2003). Terpenoids can be synthesized de novo by plants in response to herbivore damage as well (Paré \& Tumlinson, 1999). Terpinen-4-ol was released in higher amounts by Brussels sprout plants infested with Plutella xylostella than in uninfested plants (Bukovinszky et al., 2005). In the EAG-experiments Terpinen-4-ol elicited strong response of $T$. obscurator to uninfested plants, wheras the EAG response to infested plants was less. In the field experiments on oilseed rape, yellow water traps baited with Terpinen-4-ol were more attractive to T. obscurator than unbaited traps. Terpinen-4-ol is released from the flowering parts of oilseed rape and other plants (Knudsen et al., 2006). Therefore it can be an important cue for location of flowers by T. obscurator. However, yellow water traps baited with Terpinen-4-ol were not attractive at the overwintering side. One explanation for this result may be that the background odours released from oilseed rape plants play an important role in activating this terpenoid compound into the right context (Pettersson, 2001), or the odour was masked by volatiles emitted from the surrounding rape plants.

The alkanes Undecane and Dodecane are well known constituents of the plant cuticle on stems and leaves. They have been recovered from herbivore faeces (Steidel et al., 2003; Bugalho et al., 2005), which might be a cue to the host for host searching parasitoids. This substance was also found in flowers and leaves of oilseed rape by Jakobsen et al. (1994). Females of T. obscurator responded clearly to Undecane in the EAG experiment of infested plants and to yellow water traps baited with Undecane at the overwintering fields.

The green leaf volatiles 3-Hexen-1-ol and 3-Hexen-1-ol acetat were only detected in infested plants, but did not elicit EAG-reponses of T. obscurator, indicating that they are not involved 


\section{Chapter II}

in host location. Because of the widespread occurence of green leaf volatiles, it was considered unlikely that the perception of these substances could be used to discriminate between host and nonhost plants (Light et al., 1988). Green leaf volatiles which are released after mechanical and herbivore damage were perceived by many hymenopteran parasitoids (Whitman \& Eller, 1990). However, their presence does not always elicit antennal response, but this may depend on the total composition of the volatile blends.

This study provides first informations on the impact of volatile cues emitted from the hostplant complex in host location of T. obscurator. The GC/MS-EAG analyses elucidated the identity of the volatiles released fro uninfested plants and plants infested by larvae of $C$. pallidactylus which are perceived by female T. obscurator. Further studies are needed to identify which compound or/and which mixture of volatiles are important in host location. This knowledge has important implications for integrated management of pests on oilseed rape, particularly those aiming to incorporate conservation biological control by parasitoids.

\section{Acknowledgement}

We would like to thank Prof Dr Stefan Schütz and Ulrike Eisenwiener for the performance of the EAG-GC. This study was funded by the Scholarship Program of the German Federal Environmental Foundation (DBU).

\section{References}

Agelopoulos, N. G. \& Keller, M. A. (1994). Plant-natural enemy association in tritrophic system, Cotesia rubecula-Pieris rapae- Brassicaceae (Cruciferae). III: Collection and identification of plant and frass volatiles. Journal of Chemical Ecology 20, 1955-1967.

ALFORD, D. V., NILSSON, C. \& UlBER, B. (2003). Insect pests of oilseed rape crops. Chapter 2 In: D.V. Alford (ed) Biocontrol of Oilseed Rape Pests. Blackwell, Oxford, UK, 9-41.

Allen, G. R., KAMIEN, D., BERRY, O., BYRNE, P. \& HuNT, J. (1999). Larvalposition, host cues, and planidial behavior in the sound-locating parasitoid fly Homotrixa alleni (Diptera: Tachinidae). Journal Of Insect Behavior 12, 67-79.

ArimurA, G., Kost, C. \& Boland, W. (2005). Herbivore-induced, indirect plant defense. Biochimica et Biophysica Acta 1734, 91-111.

BAERECKE, E. H., WILLIAMS, H. J. \& VinSON, S. B. (1989). Electroantennogram responses of Campoletis sonorensis (Hymenoptera: Ichneumonidae) to chemicals in cotton (Gossypium hirsutum L.). Journal of Chemical Ecology 15, 37-46.

Birkett, M. A., Chamberlain, K., Guerrieri, E., Pickett, J. A., Wadhams, L. J. \& YASUDA, T. (2003). Volatiles from whitefly-infested plants elicit a host-locating response in the parasitoid, Encarsia Formosa. Journal of Chemical Ecology 29, 1589-1600.

Blatkmeer, A., Geervliet, J. B. F., LoOn, J. J. A. v., Posthumus, M. A., Beek, T. A. v. \& GROOT, A. D. (1994). Comparative headspace analysis of cabbage plants damaged by 
two species of Pieris caterpillars: consequences for in-flight host location by Cotesia parasitoids. Entomologia Experimentalis et Applicata 73, 175-182.

Broschewitz, B., Steinbach, P. \& Goltermann, S. (1993). The effect of insect larval damage upon the attack of winter oilseed rape by Phoma lingam and Botrytis cinerea. Gesunde Pflanze 45, 106-110.

Bugalho, M. N., Milne, J. A., Mayes, R. W. \& Rego, F. C. (2005). Plant-wax alkanes as seasonal markers of red deer dietary components. Canadian Journal of Zoology 83, 465-473.

Bukovinszky, T., Gols, R., Posthumus, M. A., Vet, L. E. M. \& Lenteren, J. C. V. (2005). Variation in plant volatiles and attraction of the parasitoid Diadegma semiclausum (Hellén). Journal of Chemical Ecology 31, 461-480.

DICKE, M. (1999). Are herbivore-induced plant volatiles reliable indicators of herbivore identity to foraging carnivorous arthropods? Entomologia Experimentalis et Applicata 91, 131-142.

Drost, Y. C., LeWIS, W. J., ZANEN, P. O. \& KELLER, M. A. (1986). Beneficial arthropod behavior mediated by airborne semiochemicals I. Flight behavior and influence of preflight handling of Microplitis croceipes (Cresson). Journal of Chemical Ecology 12, 1247-1262.

Evans, K. A. \& ALLEN-WiLliams, L. J. (1992). Electroantennogram responses of the cabbage seed weevil, Ceutorhynchus assimilis, to oilseed rape, Brassica napus spp. oleifera, volatiles. Journal of Chemical Ecology 18, 1641-1659.

FÄrbert, P., Koch, U. T., FÄrbert, A., StATEN, R. T. \& CARdÉ, R. T. (1997). Pheromone concentration measured with electroantennogram in cotton fields treated for mating disruption of Pectinophora gossypiella (Lepidoptera: Gelechiidae). Environmental Entomology 26, 1105-1116.

GeERVLIET, J. B. F., VeT, L. E. M. \& DiCKE, M. (1994). Volatiles from damaged plants as a major cues in long-range host-searching by the specialist parasitoid Cotesia rubecula. Entomolgia Experimentalis et Applicata 73, 289-297.

Geervliet, J. B. F., Posthumus, M. A., Vet, L. E. M. \& Dicke, M. (1997a). Comparative analysis of headspace volatiles from different caterpillar-infested or uninfested food plants of Pieris species. Journal of Chemical Ecology 23, 2935-2953.

Geervliet, J. B. F., VReugdenhil, A. I., Dicke, M. \& VeT, L. E. M. (1997b). Learning to discriminate between infochemicals from different plant-host complexes by the parasitoid Cotesia glomerata and C. rubecula. Entomologia Experimentalis et Applicata 86, 241-252.

GouinguenÉ, S. P. \& TuRLINGS, T. C. J. (2002). The effects of abiotic factors on induced volatiles emission in corn plants. Plant Physiology 129, 1296-1307.

HatanaKA, A. (1993). The biogeneration of green odour by green leaves. Phytochemistry 34, 1201-1218.

HORSTMANN, K. (1971). Revision der europäischen Tersilochinen I (Hym.: Ichneumonidae). Veröffentlichung der Zool. Staatssammlung München 15, 47-138.

HORSTMANN, K. (1981). Revision der europäischen Tersilochinen II (Hymenoptera, Ichneumonidae). Spixiana Suppl. 4, 1-76.

Hu, Z., Shen, Y., LuO, Y., SHEN, F., GAO, H. \& GAO, R. (2008). Aldehyde volatiles emitted in succession from mechanically damaged leaves of poplar cuttings. Journal of Plant Biology 51, 269-275.

JakOBSEN, H. B., P.FriIs, NiElsen, J. K. \& OlSEN, C. E. (1994). Emission of volatiles from flowers and leaves of Brassica napus in situ. Phytochemistry 37, 695-699.

JAKOBSON, H. B. \& OLSEN, C. E. (1994). Influence of climatic factors on emission of flower volatiles in situ. Planta 192, 365-371. 
JONG, R. D. \& KAISER, L. (1991). Odor learning by Leptopilina boulardi, a specialist parasitoid (Hymenoptera: Eucoilidae). Journal Of Insect Behavior 4, 743-750.

JÖNSSON, M. \& ANDERSON, P. (2008). Emission of oilseed rape volatiles after pollen beetle infestation; behavioural and electrophysiological responses in the parasitoid Phradis morionellus. Chemoecology 17, 201-207.

JÖNSSON, M., LINDKVIST, A. \& ANDERSON, P. (2005). Behavioural responses in three ichneumonid pollen beetle parasitoids to volatiles emitted from different phenological stages of oilseed rape. Entomologia Experimentalis et Applicata 115, 363-369.

Kaiser, L., BARtheye, C., Kerguelen, V. \& Pham-Delegue, M.-H. (1995). Odour conditioning of ovipositor probing in a parasitic wasp. Ethology Ecology \& Evolution 7, 245-255.

KAISER, L. \& CARDE, R. T. (1992). In flight orientation to volatiles from the host-plant complex in Cotesia rubecula (Hym.: Braconidae): Increased sensitivity through olfactory experience. Physiological Entomology 17, 62-67.

KNUDSEN, J. T., ERIKSSON, R. \& GERSHENZON, J. (2006). Diversity and distribution of floral scent. The Botanical Review 71, 1-120.

KNUDSEn, J. T., TOLLSTEN, L. \& BerGSTRÖM, L. G. (1993). Floral scents-a checklist of volatile compounds isolated by head-space techniques. Phytochemistry 33, 253-280.

LEWIS, W. J. \& TAKASU, K. (1990). Use of learned odours by a parasitic wasp in accordance with host and food needs. Nature 348, 635-636.

LI, Y., DiCKENS, J. C. \& STEINER, W. W. M. (1992). Antennal olfactory responsiveness of Microplitis croceipes (Hymenoptera: Braconidae) to cotton plant volatiles. Journal of Chemical Ecology 18, 1761-1773.

LiGHT, D. M., JANG, E. B. \& DiCKENS, J. C. (1988). Electroantennogram responses of the mediteranean fruit fly, Ceratitis capitata, to a spectrum of plant volatiles. Journal of Chemical Ecology 14, 159-180.

MATTIACCI, L. \& DiCKE, M. (1995). The parasitoid Cotesia glomerata (Hymenoptera: Braconidae) discriminates between first and fifth larval instars of its host Pieris brassicae, on the basis of contact cues from frass, silk, and herbivore-damaged leaf tissue. Journal Of Insect Behavior 8, 485-498.

Mattiacci, L., Dicke, M. \& Posthumus, M. A. (1994). Induction of parasitoid attracting synomones in brussels sprouts plants by feeding of Pieris brassicae larvae: Role of mechanical damage and herbivore elicitor. Journal of Chemical Ecology 20, 22292247.

Mattiacci, L., Rocca, B. A., Scascighini, N., D’Alessandro, M., Hern, A. \& Dorn, S. (2001). Systemically induced plant volatiles emitted at the time of "danger". Journal of Chemical Ecology 27, 2233-2252.

MCAusLANE, H. J., Vinson, S. B. \& WiLliAMS, H. J. (1991). Influence of adult experience on host microhabitat location by the generalist parasitoid, Campoletis sonorensis (Hymenoptera: Ichneuminidae). Journal of Insect Behavior 4, 101-113.

MCCall, P. J., TuRlings, T. C. J., LeWIS, W. J. \& TuMLinson, J. H. (1993). Role of plant volatiles in host location by the specialist parasitoid Microplitis croceipes Cresson (Braconidae: Hymenoptera). Journal Of Insect Behavior 6, 625-639.

MEINERS, T. \& HILKER, M. (2000). Induction of plant synomones by oviposition of a phytophagous insect. Journal of Chemical Ecology 26, 221-232.

MEYHÖFER, R. \& CASAS, J. (1999). Vibratory stimuli in host location by parasitic wasps. Journal of Insect Physiology 45, 967-971.

Murchie, A. K., SMART, L. E. \& Williams, I. H. (1997). Responses of Dasineura brassicae and its parasitoids Platygaster subuliformis and Omphale clypealis to field traps baited with organic isothiocyanates. Journal of Chemical Ecology 23, 917-926. 
MuRLiS, J., WiLLIS, M. A. \& CARDÉ, R. T. (2000). Spatial and temporal structures of pheromone plumes in fields and forests. Physiological Entomology 25, 211-222.

PARÉ, P. W. \& TuMLINSON, J. H. (1997). Induced synthesis of plant volatiles. Nature 385, 3031.

PARE, P. W. \& Tumlinson, J. H. (1999). Plant volatiles as a defense against herbivores. Plant Physiology 121, 325-331.

PETTERSSON, E. M. (2001). Volatile attractants for three pteromalid parasitoids attacking concealed spruce bark beetles. Chemoecology 11, 89-95.

PICHERSKY, E. \& GERSHENZON, J. (2002). The formation and function of plant volatiles: perfumes for pollinator attraction and defense. Current Opinion in Plant Biology $\mathbf{5}$, 237-243.

Potting, R. P. J., Vet, L. E. M. \& Dicke, M. (1995). Host microhabitat location by stemborer parasitoid Cotesia flavipes: The role of herbivore volatiles and locally and systemically induced plant volatiles. Journal of Chemical Ecology 21, 525-539.

Rask, L., ANDrÉAsson, E., Ekbom, B., ERiKsson, S., PontopPidAn, B. \& MEIJER, J. (2000). Myrosinase: gene family evolution and herbivore defense in Brassicaceae. Plant Molecular Biology 42, 93-113.

SCHÜTZ, S., WeISSBECKER, B., KLEIN, A. \& HuMMEL, H. E. (1999). Detection of volatiles released by diseased potato tubers using a biosensor on the basis of intact insect antennae. Biosensors and Bioelectronics 14, 221-228.

SHIOJIRI, K., TAKABAYASHI, J., YANO, S. \& TAKAFUJI, A. (2001). Infochemically mediated tritrophic interaction webs on cabbage plants. Population Ecology 43, 23-29.

SMID, H. M., LOON, J. J. A. V., M.A.PosthumUS \& VET, L. E. M. (2002). GC-EAG-analysis of volatiles from Brussels sprouts plants damaged by two species of Pieris caterpillars: olfactory receptive range of a specialist and a generalist parasitoid wasp species. Chemoecology 12, 169-176.

STEIDEL, J. L. M., STEPPUHN, A. \& RUTHER, J. (2003). Specific foraging kairomones used by a generalist parasitoid. Journal of Chemical Ecology 29, 131-143.

StEINBERG, S., DiCKE, M. \& VET, L. E. M. (1993). Relative importance of infochemicals from first and second trophic level in long-range host location by the larval parasitoid Cotesia glomerata. Journal of Chemical Ecology 19, 47-59.

Steinberg, S., Dicke, M., Vet, L. E. M. \& WAnningen, R. (1992). Response of the braconid parasitoid Cotesia (=Apanteles) glomerata to volatile infochemicals: effects of bioassay set-up, parasitoid age and experience and barometric flux. Entomologia Experimentalis et Applicata 63, 163-175.

TAKabAYAShi, J., Dicke, M. \& Posthumus, M. A. (1994). Volatile herbivore-induced terpenoids in plant-mite interactions: Variation caused by biotic and abiotic factors. Journal of Chemical Ecology 20, 1329-1354.

TuRLings, T. C. J., TuMLINSON, J. H., ELLER, F. J. \& LEWIS, W. J. (1991a). Larval-damaged plants: source of volatile synomone that guide the parasitoid Cotesia marginiventris to the micro-habitat of its host. Entomologia Experimentalis et Applicata 58, 75-82.

Turlings, T. C. J., Tumlinson, J. H., EllER, F. J. \& LEWIS, W. J. (1991b). Larval-damaged plants: source of volatile synomones that guide the parasitoid Cotesia marginiventris $\mathrm{t}$ o the micro-habitat of its hosts. Entomolgia Experimentalis et Applicata 58, 75-82.

Turlings, T. C. J., Tumlinson, J. H., Heath, R. R., ProveauX, A. T. \& DoOlittle, R. E. (1991c). Isolation and identification of allelochemicals that attract the larval parasitoid, Cotesia marginiventris (Cresson), to the microhabitat of one of its hosts. Journal of Chemical Ecology 17, 2235-2251.

TuRLings, T. C. J., TumLinson, J. H. \& LEWIS, W. J. (1990). Exploitation of herbivoreinduced plant odors by host-seeking parasitic wasps. Science 250, 1251-1253. 
Ulber, B. (2003). Parasitoids of Ceutorhynchid stem weevils. In: D.V. Alford (ed) Biocontrol of Oilseed Rape Pests. Blackwell Publishing, Oxford, UK, 87-95.

UlBER, B. \& NitzSCHE, O. (2006). Phenology of parasitoids (Hym., Ichneumonidae, Tersilochinae) of oilseed rape pests in northern Germany in 1995-1997. IOBC/wprs Bulletin 29, 173-179.

UlBER, B. \& WEDEMEYER, R. (2006). Responses of Tersilochus microgaster and Tersilochus obscurator (Hymenoptera: Ichneumonidae) to volatile 2-phenylethyl-isothiocyanate. CD-Rom Proceedings of the International Symposium "Integrated Pest Management in Oilseed Rape Pests", Goettingen, Germany, 3-5 April 2006.

VET, L. E. M. \& DiCKE, M. (1992). Ecology of infochemical use by natural enemies in a tritrophic context. Annual Review Entomology 37, 141-172.

Vet, L. E. M. \& GROENEwOLD, A. W. (1990). Semiochemicals and learning in parasitoids. Journal of Chemical Ecology 16, 3119-3135.

VET, L. E. M., WÄCKERS, F. L. \& DiCKE, M. (1991a). How to hunt for hiding hosts: The reliability-detectability problem in foraging parasitoids. Netherlands Journal of Zoology 41, 202-213.

VET, L. E. M., WÄCKERS, F. L. \& DiCKE, M. (1991b). The reliability-detectability problem for foraging parasitoids: usability of 1st and 2nd trophic level stimuli. Insect Parasitoids, 6th European Workshop-Perugia 3-5 April 1991, Redia, Vol. LXXIV, n.2 $<$ Appendice $>$.

VINSON, S. B. (1998). The general host selection behaviour of parasitoid Hymenopteran and a comparison of initial strategies utilized by larvaphagous and oophagous species. Biological Control 11, 79-96.

Vuorinen, T., Nerg, A. M., Ibrahim, M. A., Reddy, G. V. P. \& Holopainen, J. K. (2004). Emission of Plutella xylostella- induced compounds from cabbage grown at elevated $\mathrm{CO}_{2}$ and orientation behavior of the natural enemies. Plant Physiology 135, 19841992.

WÄCKERS, F. L. (1994). The effect of food deprivation on the innate visual and olfactory preference in the parasitoid Cotesia rubecula. Journal of Insect Physiology 40, 641649.

WÄCKERS, F. L. \& LEWIS, W. J. (1999). A comparison of color-, shape- and pattern-learning by the hymenopteran parasitoid Microplitis croceipes. Journal of Comp. Physiology A 184, 387-393.

WeissbeckeR, B., Holighaus, G. \& SCHÜTZ, S. (2004). Gas chromatography with mass spectometric and electroantennographic detection: analysis of wood odorants by direct coupling of insect olfaction and mass spectrometry. Journal of Chromatography A 1056, 209-216.

Whitman, D. W. \& ElLER, F. J. (1990). Parasitic wasps orient to green leaf volatiles. Chemoecology 1, 69-75.

Williams, I. H., Frearson, D. J. T., BARARI, H. \& MCCARTNEY, A. (2007). First field evidence that parasitoids use upwind anemotaxis for host-habitat location. Entomologia Experimentalis et Applicata 123, 299-307. 


\title{
Effect of insecticide residuals on host finding cues of Tersilochus obscurator, the key parasitoid of cabbage stem weevil
}

\begin{abstract}
The cabbage stem weevil, Ceutorhynchus pallidactylus, is an economically important pest on crops of oilseed rape. Insecticides applied for control of pests might have negative effects on the key larval parasitoid, Tersilochus obscurator. In this study, the effect of the pyrethroid lambda-cyhalothrin and the neonicotinoid thiacloprid, both applied at full recommended field dose rates and reduced dose rates (50\%), on parasitoid behaviour was investigated. In dual choice experiments the first choice, residence time and oviposition activity of female T. obscurator were measured on untreated and insecticide treated leaves of oilseed rape. In olfactometer tests the response of T. obscurator to volatiles released from insecticide treated and untreated leaves were investigated. The volatile blends emitted from insecticide treated and untreated infested plants and the antennal response of $T$. obscurator to these volatiles were studied by using coupled GC/MS-EAG analyses.

Females of $T$. obscurator responded differently to residuals of the tested insecticides. They spent significantly less time foraging on leaves treated with fresh dried residuals of full and reduced dose rates of thiacloprid than on untreated leaves, but did not avoid residuals of lambda-cyhalothrin. The volatiles emitted from leaves with fresh dried residuals of thiacloprid were avoided by female parasitoids in olfactometer tests. As the insecticide compound per se caused no direct repellency to the parasitoids, an interaction between the plant and the insecticide thiacloprid might have influenced the qualitative and quantitative composition of the volatile blend released by the infested plants. Both insecticides reduced the number of females probing with their ovipositor in the insecticide treated leaves. Insecticides may have impaired host finding of $T$. obscurator by repellent effects, by interference with volatile emission from the plant or by masking of the attractive plant odours.
\end{abstract}

\section{Introduction}

The cabbage stem weevil, C. pallidactylus (Mrsh) (Col.: Curculionidae) is a major pests in winter oilseed rape, Brassica napus L. var. oleifera Metzg. in Central and Northern Europe (Alford et al., 2003; Dechert \& Ulber, 2004). Adult weevils colonize the crop in early spring. Females lay their eggs in small batches into leaf petioles. The larvae feed for 3-5 weeks, first in petioles and later in stems. Mature larvae migrate to soil for pupation (Alford et al., 2003; Dechert \& Ulber, 2004). The key larval endoparasitoid of cabbage stem weevil, Tersilochus obscurator Aubert (Hym.: Ichneumonidae), has been found in all European countries where 
the pest occurs (Ulber, 2003, Williams et al., 2005). Females lay their eggs singly into the host larvae while these are feeding within the pith of petioles. The koinobiont parasitoid remains in its first larval instar until the mature host larva has left the plant to pupate in soil; then it develops rapidly and kills the host prepupa. Adults overwinter in the soil of fields where oilseed rape has been grown the previous year and emerge in spring (Ulber, 2003).

Current pest control practices are based on broad spectrum chemical insecticides which also have neurotoxic side-effects to beneficial insects. Two or three insecticide treatments are commonly applied for control of major pests attacking oilseed rape, namely the rape stem weevil and cabbage stem weevil at stem elongation, the pollen beetle in bud stage and the cabbage seed weevil and brassica pod midge at flowering (Alford et al., 2003; MenzlerHokkanen et al., 2006; Bürger \& Gerowitt, 2009). The main period of activity of tersilochine parasitoids (except Tersilochus microgaster) in the crop occurs in the late bud stage up to the end of flowering of oilseed rape (Johnen et al., 2006; Ulber et al., 2006). Adult parasitoids might be affected by insecticides in different ways: they can be exposed directly to insecticide sprays (Jepson, 1989) or to the residuals on the plant foliage when foraging for hosts (Brown, 1989; Longley \& Jepson, 1996) or when feeding on contaminated water droplets and nectar (Langley \& Stark, 1996). Parasitoids may be affected by insecticides through direct mortality or sublethal effects on their physiology and behaviour. Insecticide residuals may cause repellency to parasitoids (Jiu \& Waage, 1990; Longley \& Jepson, 1996; Tran et al., 2004) or indirectly interfere with host location by masking plant volatiles and/or changing the production and emission of plant volatiles, which could prevent the parasitoid from recognising the host plant and the host (Thiery \& Visser, 1986; Nottingham et al., 1991). Plant odours are often considered to provide the most important cues for the presence of endophagous host larvae (Vet \& Dicke 1992; Potting et al. 1995; Dicke 1999; Jönsson \& Anderson, 2008).

This study has focused on the behavioural effects of the pyrethroid lambda-cyhalothrin and the neonicotinoid thiacloprid on female $T$. obscurator. The impact of chemical cues derived from sprayed and unsprayed oilseed rape leaves on first choice, residence time and oviposition behaviour of female wasps was investigated in dual-choice tests. The response of T. obscurator to volatiles released from insecticide-treated plants was studied in Yolfactometer assays and in gas-chromatography-electroantennodetection (GC/MS-EAG) analyses. 


\section{Material and Methods}

Laboratory experiments

\section{Test insects}

To obtain a large number of $T$. obscurator females of standardized age and similar physiological condition for the bioassays, larvae of $C$. pallidactylus were collected from the main stems of unsprayed oilseed rape fields. Pest larvae and parasitoids were reared to the adult stage in the laboratory as described by Neumann \& Ulber (pers. comm.).

\section{Plants infested by C. pallidactylus}

Oilseed rape plants (Brassica napus, cultivar Westar and Mozart) were grown under greenhouse conditions. To obtain plants with standardized levels of infestation by $C$. pallidactylus two oilseed rape plants (6-true-leaf stage) were exposed to three females and one male within an insect cage (BugDorm-2, Mega View Science and Education Services Co., Taichung, TW) measuring $60 \mathrm{~cm} \times 60 \mathrm{~cm} \times 60 \mathrm{~cm}$. Following an oviposition time of $24 \mathrm{~h}$, plants were removed and transferred to a climate chamber $\left(20^{\circ} \mathrm{C}, 16 \mathrm{~L}: 8 \mathrm{D}, 4.000 \mathrm{lux}\right)$.

Commercial formulations of two insecticides, thiacloprid (Biscaya, $240 \mathrm{~g}$ a.i./l) and lambdacyhalothrin (Karate Zeon, $100 \mathrm{~g}$ a.i./l), were diluted with distilled water and 0.3\% detergent (Tween 20). The concentration of the insecticides was calculated based on recommended field label rates. The insecticides were sprayed on the lower and upper side of infested oilseed rape leaves by using a hand sprayer. Control plants were sprayed with distilled water. When spray residuals had completely dried, the control and treated plants were used for the experiments. Plants carrying dried residuals of various age (1h, 3 days and 6 days) were used for the bioassays. Treated plants were stored in a climate chamber $\left(14^{\circ} \mathrm{C}, 18 \mathrm{~L}: 6 \mathrm{D}\right)$.

\section{Dual-choice test}

Observation experiments were designed to examine the response of $T$. obscurator females to insecticide treated and untreated leaves of oilseed rape plants which had been infested with larvae of $C$. pallidactylus as describes above. The first choice, residence time and ovipositor probes of female $T$. obscurator on treated and untreated oilseed rape leaves were recorded during 5 min observation time. An insecticide treated and an untreated leaf were exposed $10 \mathrm{~cm}$ apart in a perspex cage $(30 \mathrm{~cm} \times 20 \mathrm{~cm})$, with two walls covered by gauze for air exchange. The base of the petioles was sealed with wet cotton wool. The experiments were performed in a room without daylight. As the parasitoids are highly attracted to the light, the light source was set up below the experimental cage. Five to eight days old laboratory-reared females of $T$. obscurator were released individually in the centre of the experimental cage. 
Differences between the residence time on each leaf were analyzed by paired t-test $(\mathrm{p}<0.05)$ and differences between the numbers of probing females by $\chi^{2}$-test $(\mathrm{p}<0.05)$.

\section{$Y$ - Olfactometer test}

The response of female T. obscurator to volatiles emitted from insecticide-treated and untreated plants, both infested by larvae of $C$. pallidactylus, was investigated in a Yolfactometer bioassay. The Y-olfactometer allowed the insects to choose between two air streams carrying odours of different sources. The olfactometer consisted of a Y-shaped perspex tube, with arms of $120 \mathrm{~mm}$ length and $27 \mathrm{~mm}$ inner diameter connected at a $40^{\circ}$ angle to the central tube. As T. obscurator is strongly attracted by the light, the light source was positioned at the back of the two arms of the olfactometer, thereby stimulating insect movement to this direction. Air was pumped $\left(70 \mathrm{~cm}^{3} / \mathrm{sec}\right)$ into a gas-wash bottle filled with active charcoal and thereafter divided into two lines of Teflon tubing. The air flow was adjusted via two flow meters. The air was piped into bottles with distilled water. The tubes were connected to two bottles containing the odour sources. The position of the odour source was changed between sessions. Groups of five female $T$. obscurator were released into the central perspex tube of $15 \mathrm{~cm}$ length and allowed to move to one of odours in the two arms. Females that did not make a choice within 10 minutes were not included in the analyses. The first choice for one of the two odour sources was recorded when females moved into the respective arm of the olfactometer. To avoid any asymmetrical bias in the setup, the odour sources were changed after testing 10 parasitoids. For each combination, 30 naive females were tested. Significant differences between the choices of females were analysed by $\chi^{2}$-Test $(\mathrm{p}<0.05)$.

\section{Collection of plant volatiles}

Potted oilseed rape plants (cultivar Westar), eigher infested by larvae of C. pallidactylus as described above or uninfested, were used for collection of volatiles emitted from insecticide treated and untreated plants. A total of 68 infested untreated plants, 19 infested plants treated with lambda-cyhalothrin and 18 infested plants treated with thiacloprid were tested. Plants infested by $C$. pallidactylus larvae were enclosed within an ethylen-tetraflorethylen (ETFE) bag $(70 \mathrm{~cm}$ x $40 \mathrm{~cm} \times 40 \mathrm{~cm})$ in the greenhouse under daylight conditions, from 10 am to1 pm. The bags were mounted on a laboratory pedesta. The opening of the bag was closed around the stem base by mounting its opposite edges between aluminium splints and fixing 
with clips. Volatile trapping was started after $1 \mathrm{~h}$ to ensure air homogeneity within the bags. Volatiles were collected for 2 hours. An ETFE stopper containing two openings $(0.67 \mathrm{~mm}$ diameter) was inserted into the bags. Air containing volatiles was sucked off from the interior air volume of the bag through one of the openings by using a miniature vacuum pump (DC12/16 NK Fa. Fürgut, Germany). A volatile trapping device (Prec. Charcoal filter (1.5 $\mathrm{mg}$ ), Fa. Brechbuehler AG, Switzerland) was mounted between the bag and the pump at the inlet part of the pump. The outlet of the pump was connected with the bag by tubing to maintain a constant air circulation. The circulation of the pump was kept at a constant air flow by adjusting it to a power supply (PS-302 A, Fa. Conrad Electronic, Germany) at 9 volt. Plant volatiles were eluted from the absorbent characoal filter by using $75 \mu \mathrm{l}$ dichlormethan and methanol $(2: 1 ; \mathrm{v} / \mathrm{v})$.

\section{GC-MS/EAG analyses}

Samples were analyzed by coupled GC-MS/EAD, using a 6890N gas chromatograph (Agilent, Palo Alto, CA, USA) and a 5973N mass spectrometer (Agilent) (Weissbecker et al., 2004). The GC was equipped with a split/splitless (S/SL) injector and an HP-5MS column (Agilent; $30 \mathrm{~m}, 0.25 \mathrm{~mm}$ I.D, film thickness $0.25 \mu \mathrm{m}$ ). A GRAPHPACK 3D/2 flow splitter (Gerstel, Mülheim, Germany) was used to split the effluent from the column into two capillaries leading to the MS ( $1 \mathrm{~m}$ long, $0.1 \mathrm{~mm}$ ID) and to the EAD ( $1 \mathrm{~m}$ long, $0.15 \mathrm{~mm}$ ID). The restriction capillaries resulted in an equal split of the gas flow into the two setups. A modified "olfactory detector port" (ODP-2; Gerstel; (Weissbecker et al., 2004)) guided the capillary out of the GC oven within a flexible heating sleeve. Volatiles were eluted from the column into a flow of helium make-up gas, and then mixed with humidified air $\left(23^{\circ} \mathrm{C}, 80 \% \mathrm{RH}\right)$. The airflow (flow rate, $400 \mathrm{ml} / \mathrm{min}$ ) was directed through the flow tube $(15 \mathrm{~cm}$ long, $6 \mathrm{~mm} \mathrm{ID,}$ PTFE) to the insect antenna preparation that was housed in a PTFE detector cell. Excised antennae of $T$. obscurator were placed into an antenna holder milled from a perspex disc (Färbert et al., 1997). Within the holder, the ends of the antenna contacted an electrolyte solution that provided electrical contact to a pair of $\mathrm{Ag} / \mathrm{AgCl}$ electrodes. $\mathrm{EAD}$ potentials were amplified by a factor of 100 with a high-impedance amplifier (input impedance $100 \mathrm{M} \Omega$; Prof. Koch, Kaiserslautern, Germany) containing a built-in low-pass filter set to a cutoff frequency of $1 \mathrm{~Hz}$ to suppress the ubiquitous electrical supply frequency of $50 \mathrm{~Hz}$. An additional high pass filter set at a cutoff frequency of $0.01 \mathrm{~Hz}$ was used to suppress drift of the EAD signal. The amplified and filtered signal was digitized by using a 35900E A/D converter (Agilent) and recorded by the GC ChemStation software (Agilent). 


\section{Analytical Conditions}

One- $\mu \mathrm{l}$ aliquots of the samples were injected into the S/SL injector (temperature, $250^{\circ} \mathrm{C}$ ). The GC oven was programmed from $50^{\circ} \mathrm{C}$ for $1.5 \mathrm{~min}$, then $6^{\circ} \mathrm{C} / \mathrm{min}$ to $200^{\circ} \mathrm{C}$; hold for $5 \mathrm{~min}$. Helium was used as carrier gas $(1 \mathrm{ml} / \mathrm{min}, 24 \mathrm{~cm} / \mathrm{sec})$. The GC-MS interface was held at $280^{\circ} \mathrm{C}$. The heating sleeve of the ODP was set to $230^{\circ} \mathrm{C}$. The MS used electron impact ionization (EI) at $70 \mathrm{eV}$, in scan mode (35-300 mass units, 2.78 scans/sec). For preliminary peak identification, the NIST mass spectral library (National Institute of Standards and Technology, Gaithersburg, MD USA) was used. Subsequently, the retention time of compounds were compared with those of synthetic standards and the Retention Time Internal Database.

\section{Results}

Response offemale T. obscurator to insecticide residues in dual-choice tests

The residence time of female $T$. obscurator on untreated leaves and leaves treated with the full recommended field dose rate of lambda-cyhalothrin was not significantly different. The age of the insecticide residuals had no significant effect on the time spent on the leaf (Fig 1).

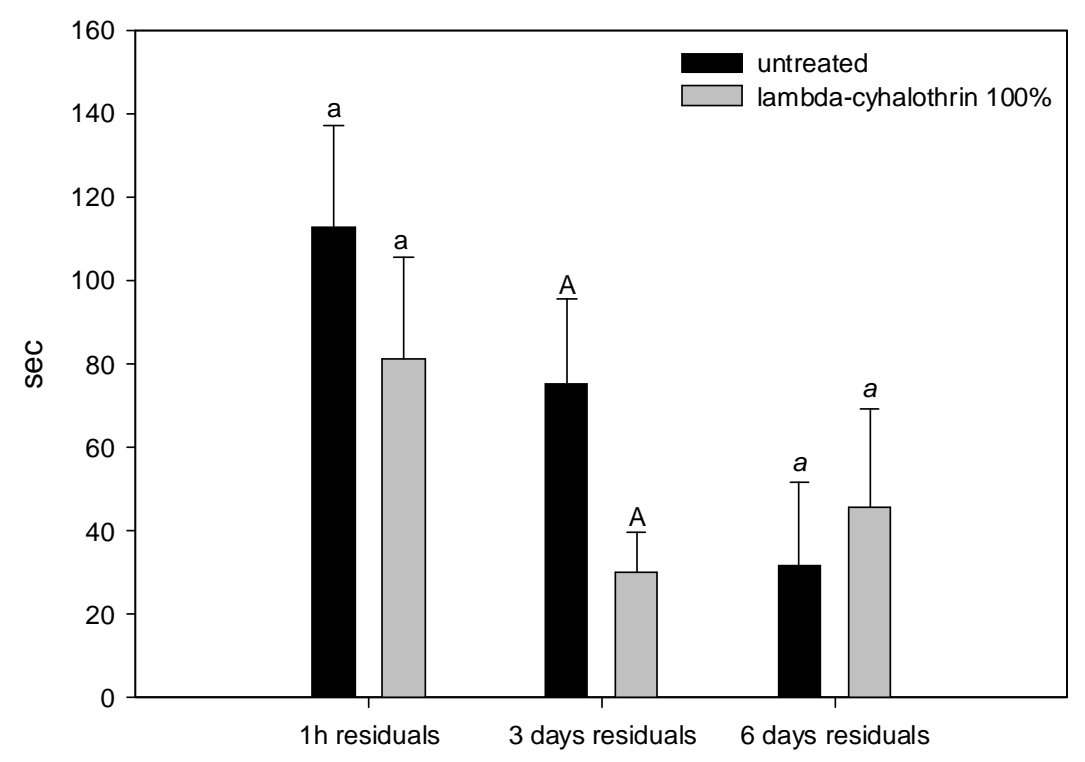

Fig 1: Residence time (sec + SE) of female T. obscurator on leaves infested by larvae of $C$. pallidactylus, treated with full dose rate of lambda-cyhalothrin and untreated leaves. Leaves with different residual age and untreated leaves were compared in dual choice test. Paired ttest, $\mathrm{p}>0.05, \mathrm{n}=32$. 
Significantly more parasitoids conducted ovipositor probes into untreated leaves than into leaves with 3 days old residuals of $100 \%$ lambda-cyhalothrin. Fresh dried residuals and six days old residuals had no significant effect on the percentage of females penetrating the infested leaves (Fig 2).

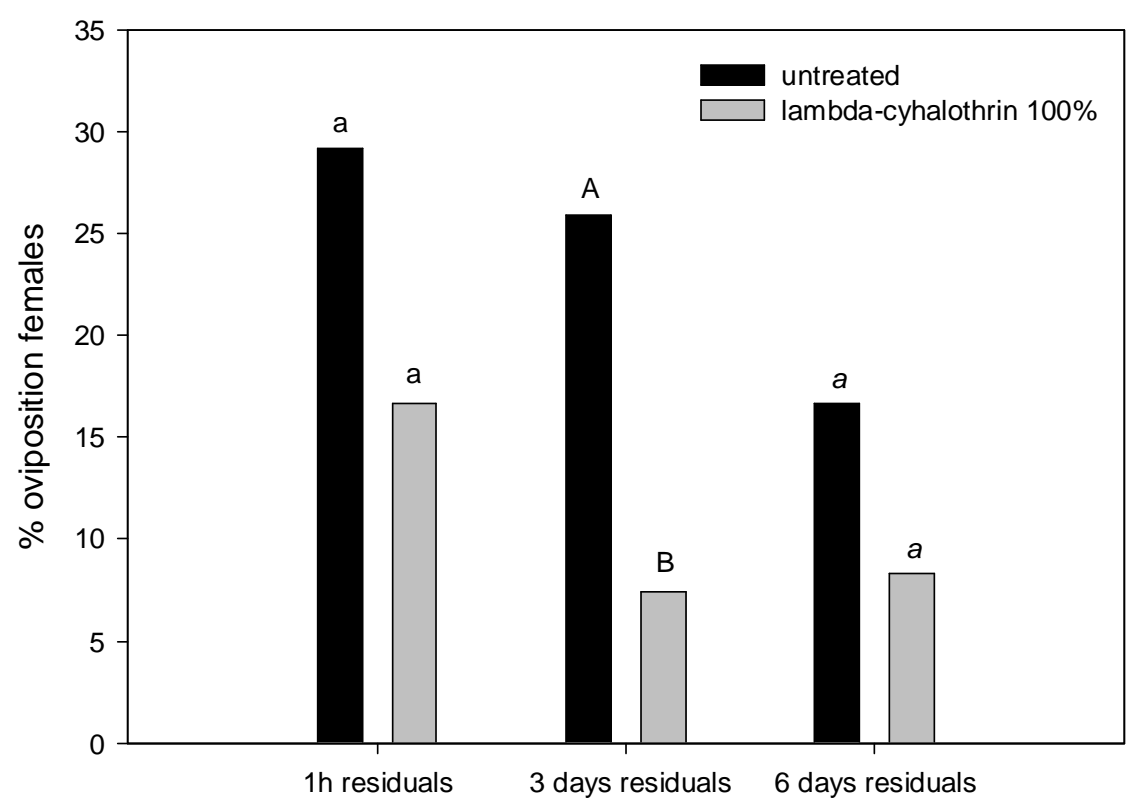

Fig 2: Percentage of female T. obscurator probing with their ovipositor into leaves infested by larvae of $C$. pallidactylus. Parasitoids had a choice between untreated leaves and leaves with residuals of various age of the full dose rate of lambda-cyhalothrin, $\chi^{2}$-Test, $\mathrm{p}<0,0013, \mathrm{n}=$ 32 .

The age of residuals had no significant effect on residence time of female $T$. obscurator on untreated leaves and leaves treated with $50 \%$ reduced dose rate of lambda-cyhalothrin (Fig 3). 


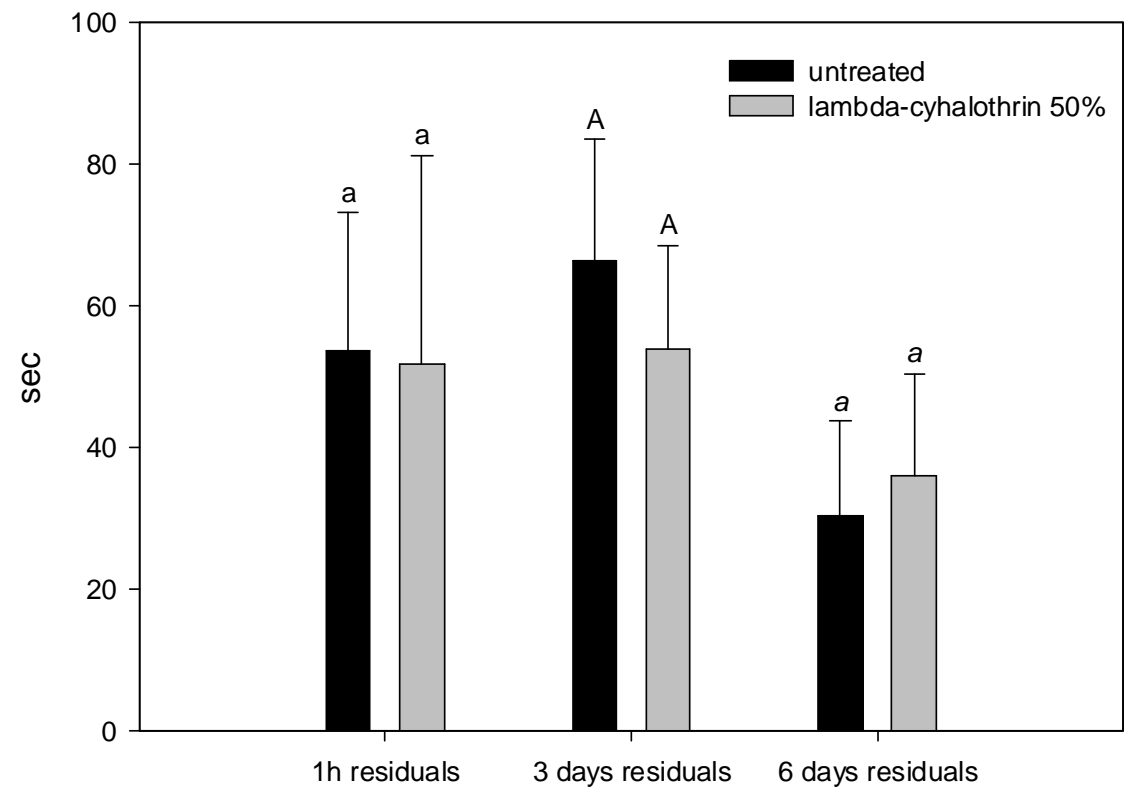

Fig 3: Residence time (sec $+\mathrm{SE}$ ) of female T. obscurator on leaves infested by larvae of $C$. pallidactylus following treatment with reduced dose rate (50\%) of lambda-cyhalothrin.

Leaves with different residual age and untreated leaves were compared in dual-choice tests. Paired t-test, $\mathrm{p}>0.05, \mathrm{n}=30$.

There was no significant difference between the percentage of females penetrating into untreated leaves and leaves with residuals of various age of $50 \%$ reduced field dose rate of lambda-cyhalothrin (Fig 4).

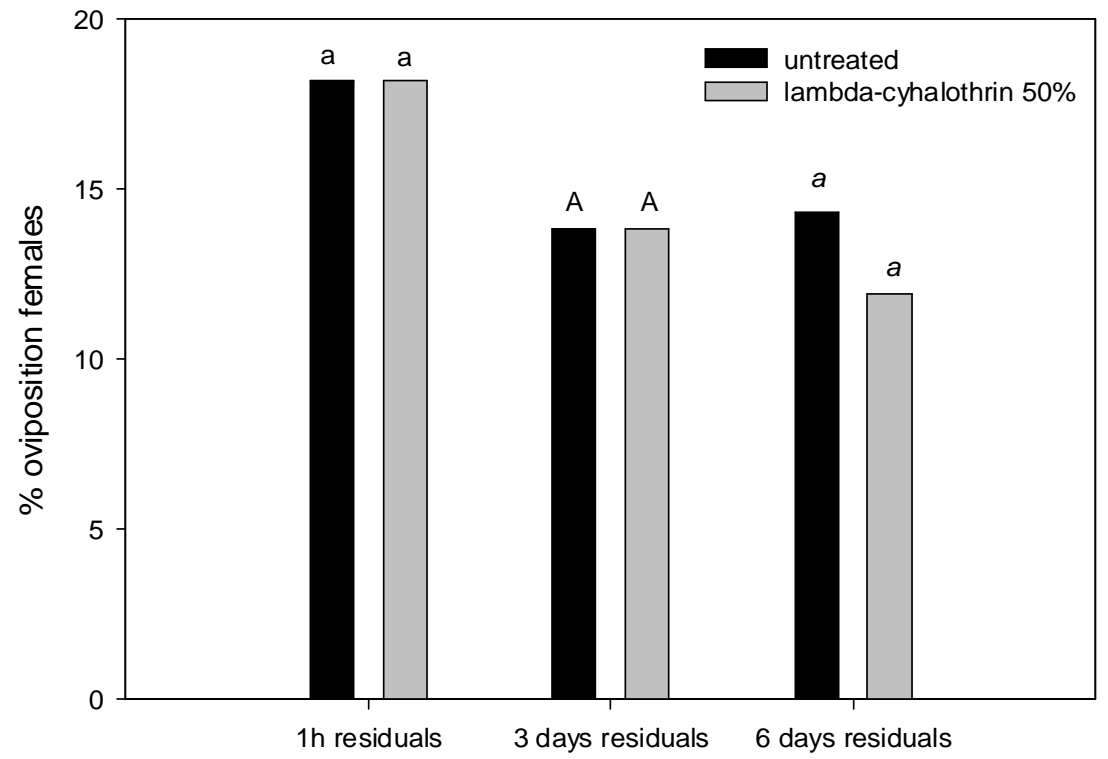

Fig 4: Percentage of female T. obscurator probing with their ovipositor into leaves infested by larvae of $C$. pallidactylus. Parasitoids had a choice between untreated leaves and leaves with residuals of various age of reduced rates $(50 \%)$ of lambda-cyhalothrin, $\chi^{2}$-Test, $\mathrm{p}<0,0013, \mathrm{n}$ $=30$. 
Females of $T$. obscurator spent significantly more time on untreated leaves than on leaves with fresh dried residues of the $100 \%$ dose rate of thiacloprid. Three and six days old residues of thiacloprid had no significant influence on the residence time on treated and untreated leaves (Fig 5).

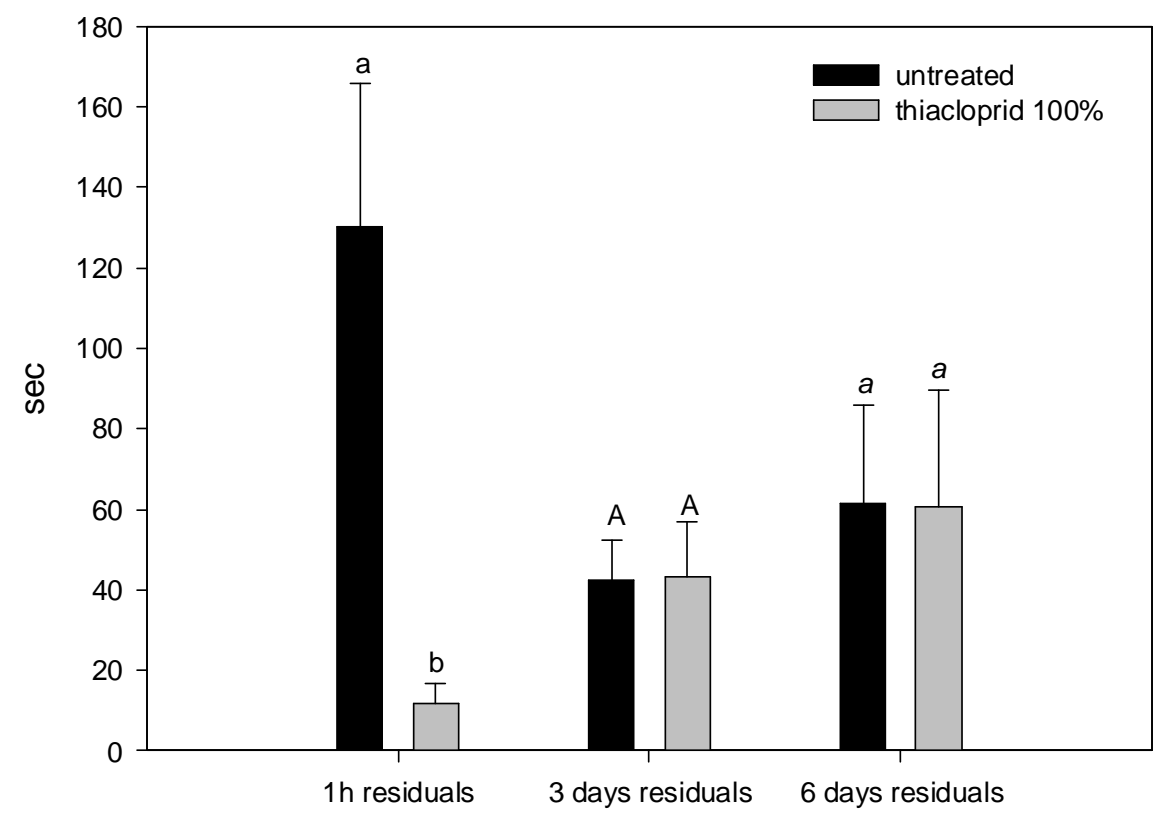

Fig 5: Residence time ( $\mathrm{sec}+\mathrm{SE}$ ) of female T. obscurator on leaves infested by larvae of $C$. pallidactylus, following treatment with the full dose rates of thiacloprid. Leaves with different residual age and untreated leaves were compared in dual-choice tests. Paired t-test, $\mathrm{p}=$ $0,0036, \mathrm{n}=34$

Significantly more ovipositor probes were conducted by females into untreated leaves than into leaves carrying fresh dried residues of $100 \%$ thiacloprid. Three and six days old residues of thiacloprid had no significant influence on ovipositor probings (Fig 6).

Fresh dried residues of $50 \%$ thiacloprid reduced the residence time of parasitoids significantly (Fig 7). Three and six days old residues had no effect on residence time on treated or untreated leaves. 


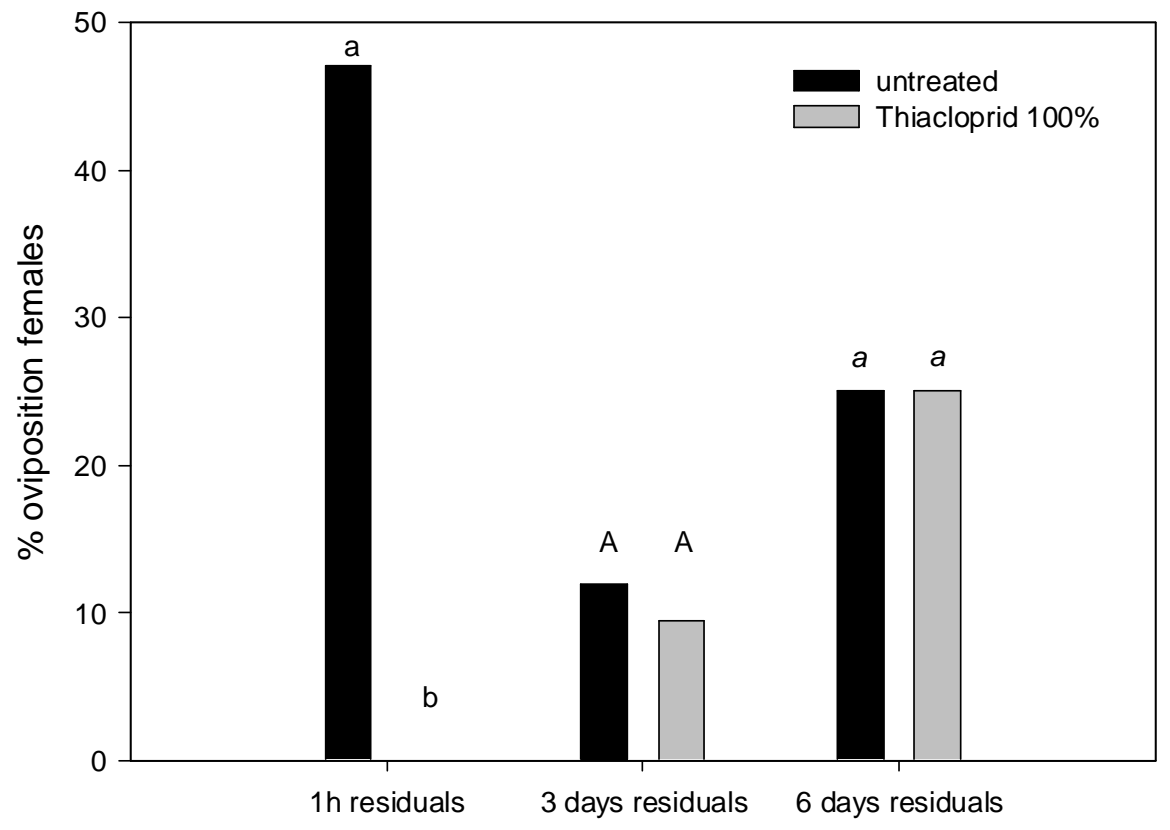

Fig 6: Percentage of female T. obscurator probing with their ovipositor into leaves infested by larvae of $C$. pallidactylus. Parasitoids had a choice between untreated leaves and leaves with residuals of various age of full dose rates of thiacloprid, $\chi^{2}$-Test, $p<0,001, n=34$.

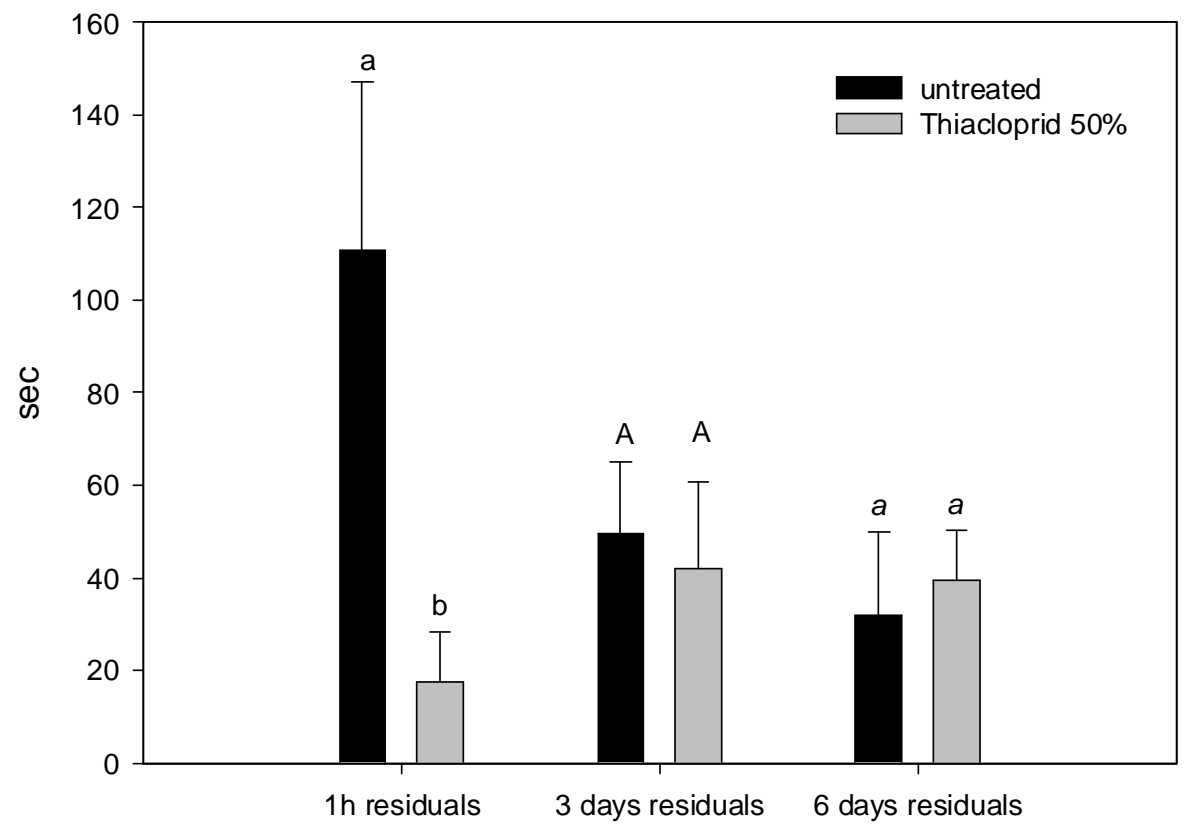

Fig 7: Residence time (sec $+\mathrm{SE}$ ) of female T. obscurator on leaves infested by larvae of $C$. pallidactylus, following treatment with reduced dose rate (50\%) of thiacloprid. Leaves with different residual age and untreated leaves were compared in dual-choice tests. Paired t-test, $\mathrm{p}$ $<0.05, \mathrm{n}=28$ 
Fresh dried residues of $50 \%$ thiacloprid significantly reduced the percentage of females penetrating in treated leaves, while three and six days old residues had no significant effect (Fig 8).

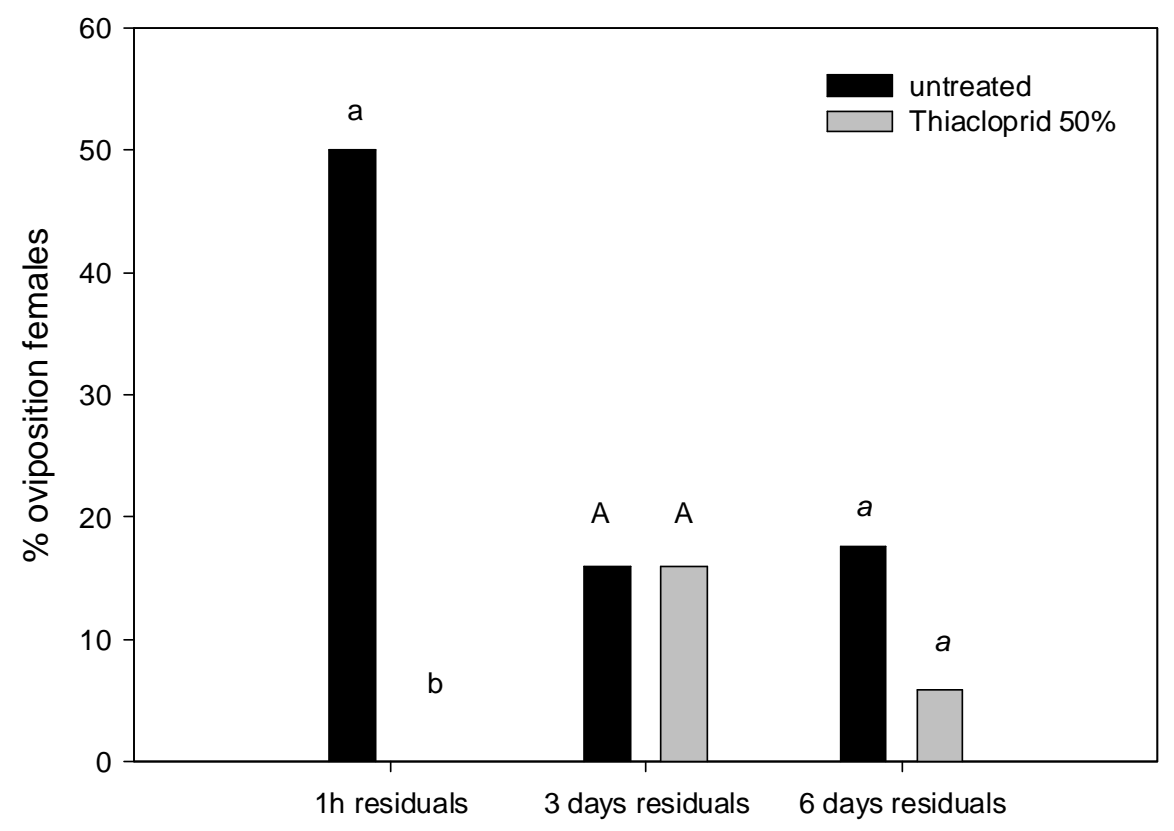

Fig 8: Percentage of female T. obscurator probing with their ovipositor into leaves infested by larvae of $C$. pallidactylus. Parasitoids had a choice between untreated leaves and leaves with residuals of various age of reduced rates $(50 \%)$ of thiacloprid, $\chi^{2}$-Test, $p<0,05, n=28$.

Response of female T. obscurator to the volatile blend emitted from insecticide treated and untreated plants

In the Y-olfactometer tests, the response of female $T$. obscurator did not differ between the odour of untreated leaves and leaves carrying residuals of various age of the full recommended field dose rate of lambda-cyhalothrin (Fig 9). When exposed on filter paper, lambda-cyhalothrin had no effect on the choice of T. obscurator.

Females of $T$. obscurator significantly prefered the odour emitted from infested leaves without insecticide residuals to infested leaves with fresh dried residuals of $100 \%$ thiacloprid (Fig 10). Three and six days old residuals of thiacloprid had no effect on T. obscurator. Thiacloprid exposed on filter paper had no effect on choice of the parasitoids. 


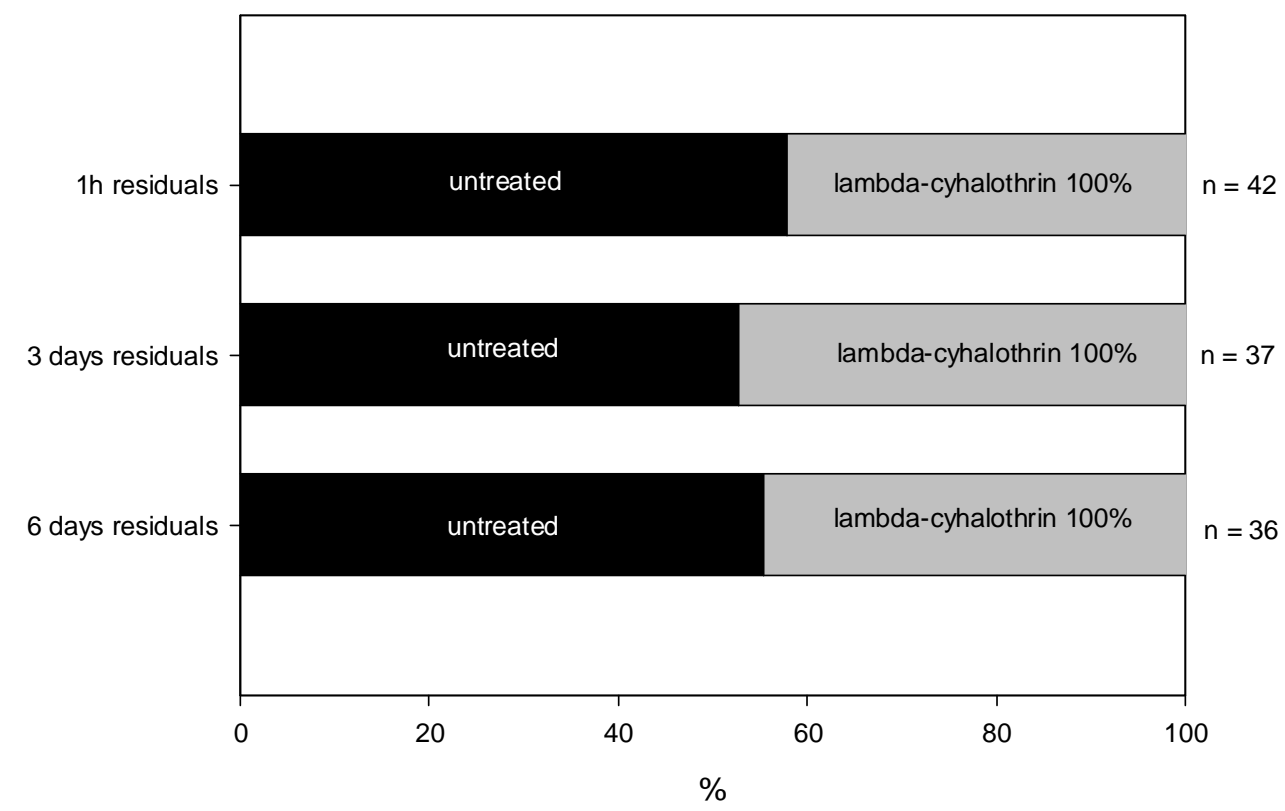

Fig 9: Response of female T. obscurator to the odour of untreated leaves and leaves carrying residues of $100 \%$ of lambda-cyhalothrin in Y-olfactometer tests. All leaves were infested by C. pallidactylus larvae, $\chi^{2}$-test, $\mathrm{p}<0,05$.

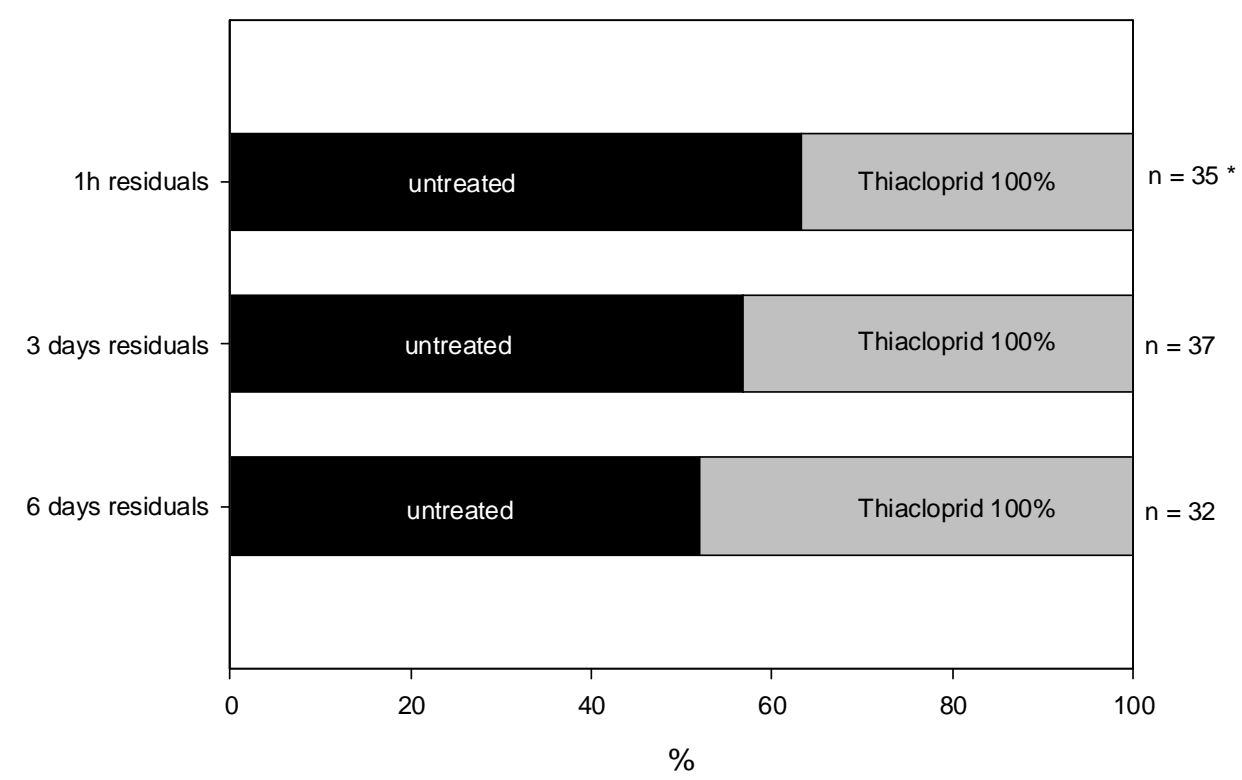

Fig 10: Response of female T. obscurator to the odour of untreated leaves and leaves carrying residues of $100 \%$ of thiacloprid in Y-olfactometer tests. All leaves were infested by $C$. pallidactylus larvae, $\chi^{2}$-test, $\mathrm{p}=0,008291$. 
Volatile compounds emitted from infested insecticide-treated and untreated plants

The volatile blends collected from plants treated with lambda-cyhalothrin or thiacloprid did not contain Terpinen-4-ol and Unidentified I (Fig 11). Plants treated with lambda-cyhalothrin did not emit 2-Octanol and Octanal, and plants treated with thiacloprid did not release Napthalene. The most common volatiles released from untreated plants were 1-Hexanol, 2ethyl, Undecane and 3-Hexanol acetat. Plants treated with thiacloprid commonly emitted 1Hexanol, 2-ethyl, Unidentified I, 3-Hexen-1-ol acetate, and plants treated with lambdacyhalothrin 1-Hexanol, 2-ethyl, 3-Hexen-1-ol acetate and Decanal. Generally, the proportion of infested insecticide-treated and untreated,oilseed rape plants that emitted the individual volatiles varied between replicates within each treatment.

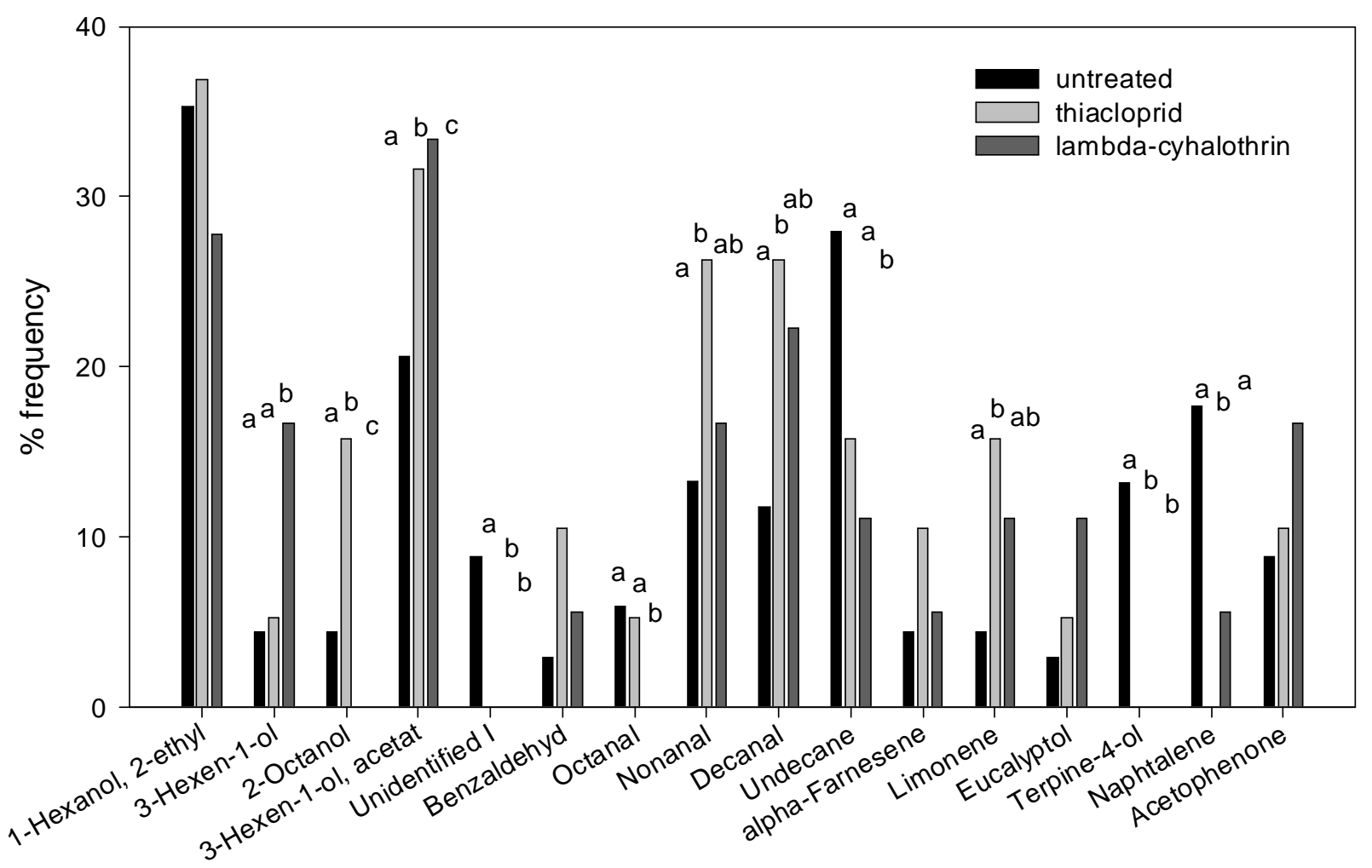

Fig 11: Relative frequency (\%) of individual compounds in the volatile blends emitted from B. napus plants infested by $C$. pallidactylus, following treatment with thiacloprid, lambdacyhalothrin or untreated, in GC/MS analyses.

Insecticide treatments induced significant qualitative and quantitative differences between the volatile blends emitted from insecticide-treated and untreated plants (Fig 12). Plants treated with either insecticide did not emit Terpinen-4-ol and Unidentified I. Plants treated with 
thiacloprid did not release Napthalene and plants treated with lambda-cyhalothrin did not release 2-Octanol and Octanal. Infested plants treated with thiacloprid emitted higher amounts of 2-Octanol, 3-Hexen-1-ol, acetate, Benzaldehyd, Nonanal and $\alpha$-farnesene. Treatments with lambda-cyhalothrin resulted in higher amounts of 3-Hexen-1-ol (Fig 12), compared to untreated plants. Reduced amounts of 1-Hexanol, 2-ethyl, Undecane and Napthalene were observed from plants treated with lambda-cyhalothrin compared to untreated plants. Thiacloprid reduced the amount of Octanal (Fig 12).

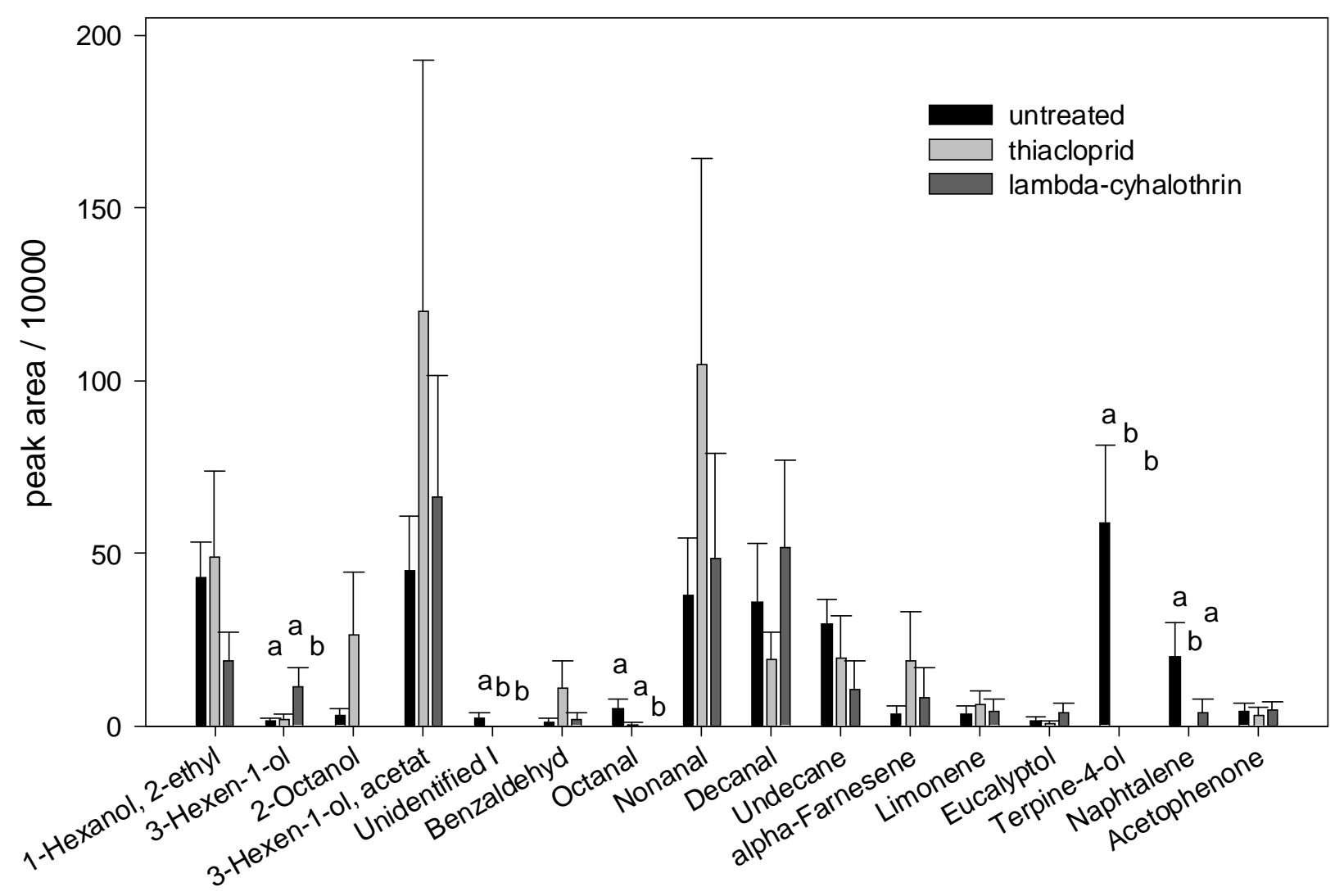

Fig 12: Quantitative analyses of oilseed rape plants infested with larvae of C. pallidactylus in GC/MS. Plants were treated with lambda-cyhalothrin or thiacloprid and untreated plants were compared. Xm + SE, Eucalyptol: peak area 7655387 is equivalent to $92.5 \mathrm{ng}$ Eucalyptol, Decanal: peak area of 932745 is equivalent to $82.8 \mathrm{ng}$ Decanal; Mann-Whitney-U-Test $\mathrm{p}<$ 0.05 . 
The relative amounts of individual volatiles that were emitted from infested, untreated oilseed rape plants and plants treated with either insecticide differed significantly (Fig 13). The total amount of emitted volatiles increased by about $13.1 \%$ after treatment with thiacloprid and decreased by about 3.3\% after application of lambda-cyhalothrin, compared to the volatile blend of untreated plants.

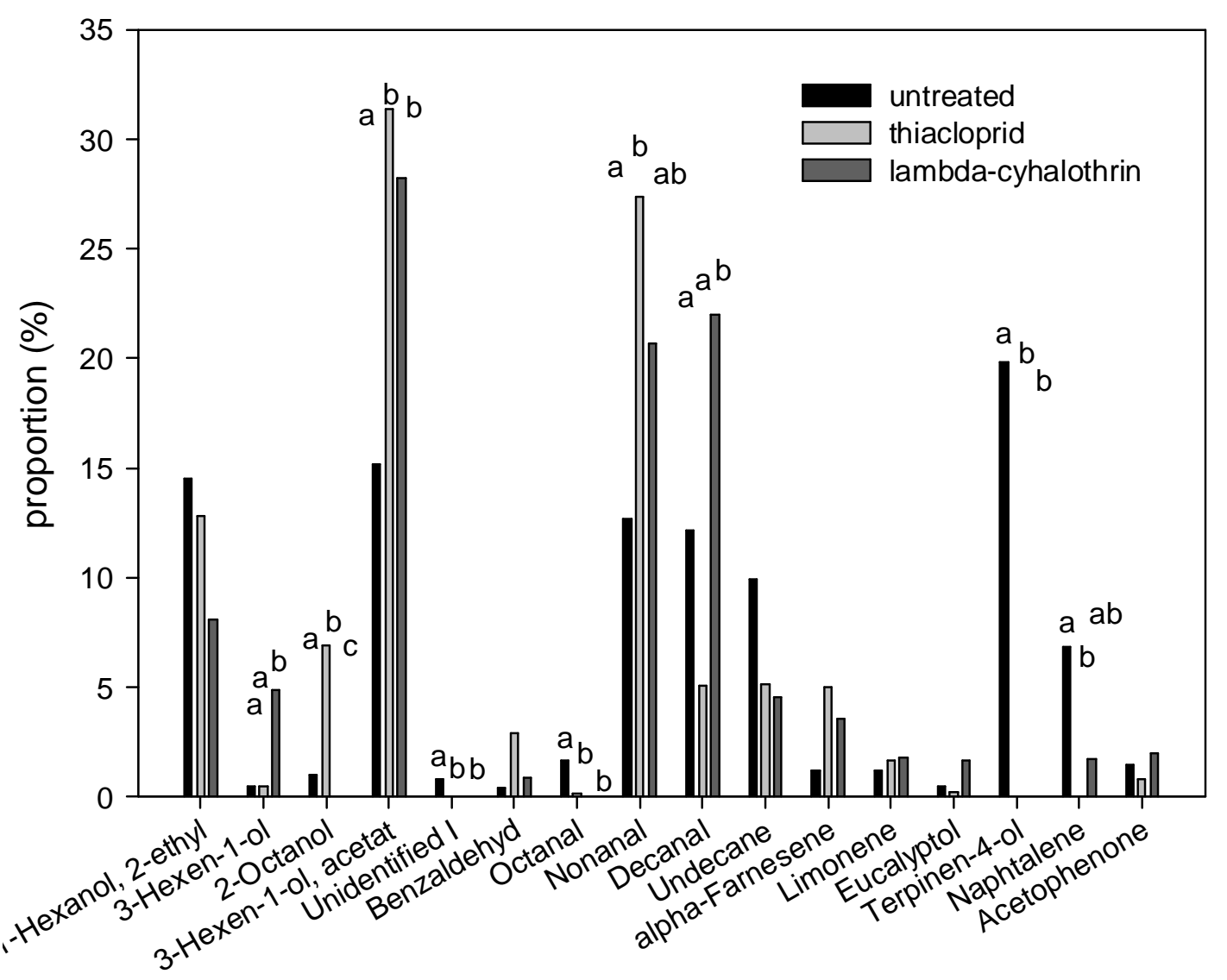

Fig 13: Relative proportion (\%) of plant volatiles (Brassica napus, cultivar Westar) emitted by plants infested with larvae of $C$. pallidactylus in GC/MS. Plants were treated with lambdacyhalothrin or thiacloprid and untreated plants were compared.

The GC-EAG analyses demonstrated that female $T$. obscurator responded to a higher number of volatiles from samples collected from untreated oilseed rape plants than from samples collected from plants treated with thiacloprid or lambda-cyhalothrin (Tab 3). Females responded to twelve and five of 18 compounds detected in untreated oilseed rape plants and insecticides treated plants, respectively. 
Tab 3: EAG-response and response intensity of female T. obscurator to volatiles of oilseed rape plants (OSR) (cultivar Westar) infested by larvae of $T$. obscurator, untreated or treated with full dose rated of Biscaya (thiacloprid) or Karate Zeon (lambda-cyhalothrin)

\begin{tabular}{|l|c|l|l|}
\hline & $\begin{array}{l}\text { EAG-response of T. } \\
\text { obscurator to } \\
\text { volatiles of infested, } \\
\text { untreated OSR }\end{array}$ & $\begin{array}{l}\text { EAG-response of T. } \\
\text { obscurator on volatile } \\
\text { of infested with } \\
\text { thiacloprid treated } \\
\text { OSR }\end{array}$ & $\begin{array}{l}\text { EAG-response of } T . \\
\text { obscurator on volatile } \\
\text { of infested with } \\
\text { lambda-cyhalothrin } \\
\text { treated OSR }\end{array}$ \\
\hline 1-Hexanol, 2 ethyl & $*$ & & \\
\hline 3-Hexen-1-ol & $*$ & & \\
\hline 2-Octanol & $*$ & & \\
\hline 3-Hexen-1-ol, acetat & $* *$ & & \\
\hline Unidentified I & $*$ & & \\
\hline Benzaldehyd & $*$ & & \\
\hline Octanal & $* *$ & & \\
\hline Nonanal & $*$ & & \\
\hline Decanal & $* *$ & & \\
\hline Undecane & $*$ & & \\
\hline$\alpha$-Farnesene & $*$ & & \\
\hline Limonene & $*$ & & \\
\hline Eucalyptol & $*$ & & \\
\hline Terpinen-4-ol & $*$ & & \\
\hline Naphtalene & $*$ & & \\
\hline Acetophenone & $*$ & & \\
\hline
\end{tabular}

- $=0-100 \mathrm{mV}, * *=100-200 \mathrm{mV}, * * *=200-300 \mathrm{mV}, * * * *=300-400 \mathrm{mV}$, $* * * * *=400-500 \mathrm{mV}$

\section{Discussion}

In addition to lethal effects on natural enemies, insecticides also might affect host location via repellent activity or indirectly through masking of attractive plant volatiles and/or changing the production and emission of these volatiles. The comparison of the effects of volatile and contact chemical cues derived from treated and untreated leaves in dual-choice test showed significant differences between the distributions of parasitoids on plants treated with lambdacyhalothrin or thiacloprid and untreated plants. Females of $T$. obscurator did not discriminate significantly between plants treated with lambda-cyhalothrin and untreated plants, but 
significantly avoided leaves with fresh dried residuals of reduced and full dose rates of thiacloprid. Three and six days old residuals of thiacloprid did not cause avoidance by female T. obscurator, which may be due to the quick absorption of the systemic insecticide from the plant surface into the tissue (Williams \& Price, 2004; Tomizawa \& Casida, 2005). Thiacloprid has been reported to have no persistent effect on the egg parasitoid Trichogramma cacoeciae and the larval parasitoid Encarsia formosa (Schuld \& Schmuck, 2000; Richter, 2006;).

Various studies have demonstrated significant differences in the behaviour and distribution of parasitoids between plants treated with different insecticides, indicating that the insecticides were not equally avoided (Akol et al., 2003). Borgemeister et al. (1993) did not detect avoidance of pirimicarb by the aphid parasitoid Aphidius rhopalosiphi, but he noted repellent effects of the pyrethroid fenvalerate and the organophosphate demeton-s-methyl on foraging of $A$. rhopalosiphi on aphid-free cereal plants. The aphid parasitoid A. ervi showed disrupted olfactory orientation towards host-infested plants with residuals of lambda-cyhalothrin, but not with residuals of deltamethrin (Desneux et al., 2006). Exposure of A. rhopalosiphi to deltamethrin residuals resulted in shorter visit times, grooming more actively and resting less frequently than on insecticide-free plants (Longley \& Jepson, 1996). Females of Diaretiella rapae spent significantly less time foraging on plants sprayed with pirimicarb than on untreated plants, regardless of the presence of aphid hosts (Umoru et al., 1996). Search time allocation is an important component for parasitism efficiency. The modification of this behaviour can interfere with the reproductive capacity of parasitoids (Komeza et al., 2001). The shorter time spent foraging on the plant would reduce the probability of successful oviposition encounters with hosts after an insecticide application. In this study, the percentage of females conducting ovipositor probes in leaves treated with the full dose rate of lambdacyhalothrin and with full and reduced dose rates of thiacloprid decreased significantly compared to untreated leaves, which may reduce the level of parasitism. In field experiments, parasitism of $C$. pallidactlus and M. aeneus larvae was reduced following application of taufluvalinate and lambda-cyhalothrin (Klukowski et al. 2006). Reduced ovipositor insertions on neonicotinoid (imidacloprid) treated leaves was also observed with the parasitoid Neochrysocharis formosa (Tran et al., 2004).

The avoidance behaviour observed in the bioassays may resulted from two possible mechanisms: (1) masking of attractive host plant odours by insecticides and/or interference with the production and emission of plant volatiles, which could prevent the parasitoid from recognising the host plant and the host (Thiery \& Visser 1986; Nottingham et al. 1991). (2) 
The insecticide odour could have a direct repellent effect on parasitoids (Jiu \& Waage, 1990, Longley \& Jepson 1996; Tran et al. 2004). When applied on filter paper, the odour of both insecticides was not avoided by the parasitoids. This suggests that an indirect effect of the insecticide via production and emission or masking of plant volatiles is more likely to affect the attraction to infested plants. The results of our olfactometer experiments are compatible with the results of the dual choice tests. Female T. obscurator avoided the odour of infested leaves treated with thiacloprid, while the odour of leaves treated with lambda-cyhalothrin did not cause avoidance. Similar repellent effects on foraging females of $D$. rapae have also been found with the pyrethroid permethrin and the organophosphorus malathion (Jiu \& Waage, 1990). Different responses of parasitoids to volatiles emitted by sprayed plants may be due to the mode of action of the insecticides or to a lack of tolerance. The parasitoid A. ervi did not show behavioural responses to lambda-cyhalothrin, chlorpyrifos and pirimicarb, but when exposed to triazamate showed a reduction of the time spent in the odour flow, which may due to a lack of tolerance to triazamate (Desneux et al., 2004). Avoidance of treated plants through repellency or altered behaviour may reduce the toxicological risks for the insect in the field (Longley \& Jepson, 1996). Preliminary studies on the side-effects of insecticides on hymenopteran parasitoids in the field showed lower toxicity of insecticides to the parasitoid species T. obscurator and T. fulvipes attacking stem weevil larvae. This was related to the vertical distribution of the parasitoids within the crop which provided a behavioural refuge from insecticidal sprays and residuals (Neumann \& Ulber, pers. comm.). In addition, the parasitoids responded to insecticide application by changing their dispersal behaviour. Emigration flights of $T$. obscurator and T. fulvipes from the insecticide treated field were more frequent than immigration flights, whereas in the untreated field immigration flights prevailed over the whole observation period (Neumann \& Ulber, pers. comm.). The toxicity of insecticides tested in field experiments was low, but the level of parasitism was reduced in insecticide-treated plants compared to untreated plants (Neumann \& Ulber, pers. comm.). The current study demonstrated a reduction of ovipositor probing by female T. obscurator on insecticide-treated leaves, which might be due to repellency and/or interruption of host location by the tested insecticides.

For host location, parasitoids use herbivore-induced plant volatiles because cues derived directly from the host are difficult to detect (Turlings et al., 1991; Geervliet et al., 1994; Vinson, 1998). The herbivore-induced changes of the volatile blend may be quantitative, i.e. individual volatiles that are also present in uninfested plants are emitted from infested plants in larger total amounts, their relative proportion changes, or both (Agelopoulos \& Keller, 
1994; Blaakmeer et al., 1994; Geervliet et al., 1997; Mattiacci et al., 2001; Mumm et al., 2003). The quantitative differences between volatiles released from Brussels sprouts plants following infestation by $P$. rapae caterpillars and artificially damaged may have caused the preference of $C$. rubecula for infested leaves (Geervliet et al., 1994). Females of Cotesia plutellae prefered infested cabbage plants which had been treated with syringa extract of Melia azedarach tree to untreated infested plants, which may be due to larger quantities of volatile compounds emitted by cabbage plants treated with syringa extract (Charleston et al., 2006). In the current study, among the 16 compounds identified, five compounds were emitted in larger amounts from thiacloprid-treated plants and two compounds from lambdacyhalothrin-treated plants; however, these differences were not statistically significant. Moreover, the amount of some compounds was reduced in insecticide-treated plants compared to untreated plants. The relative proportion, i.e. the amount of individual compounds within the total volatile blend, has potential to elicit specific behavioural responses of parasitoids (Roseland et al., 1992). Vet et al. (1998) demonstrated that qualitative differences between odour sources are more important than quantitative.

Herbivory can induce de novo production of volatiles in plants, resulting in qualitative changes of the composition of the emitted volatile blend (Turlings et al., 1990; Dicke et al., 1990a; Dicke et al., 1990b; Paré \& Tumlinson, 1997). Quantitative and qualitative differences of the volatile blend might serve as indicators for host presence and might be used by parasitoids for host location (Roseland et al., 1992; Geervliet et al., 1994; Vet et al. 1998). In this study, the chemical analyses of the headspace composition of insecticide-treated and untreated plants showed qualitative and quantitative differences, which may have influenced host location.

Insecticide-treated plants did not emit Terpinen-4-ol and Unidentified I; both elicited EAGresponses to the untreated plants. Further, plants treated with lambda-cyhalothrin did not emit 2- Octanol and Octanal which were also perceived by parasitoid antennae in the EAG. In field experiments, yellow water traps baited with Terpinen-4-ol were more attractive to female $T$. obscurator than unbaited traps (Neumann \& Ulber, pers. comm.). Terpinen-4-ol is commonly released from the flowering parts of oilseed rape and other plants (Knudsen et al., 2006). Therefore it can be an important cue for location of flowers by T. obscurator. Further, among herbivore-induced synomones the terpenoids represent a major class that are known to attract various carnivores (Takabayashi et al., 1994; Pichersky \& Gershenzon, 2002).

In the past, no references were available indicating an influence of insecticides on the production and emission of plant volatiles. However, insecticide effects on plant physiology, 
e.g. greening effects by pyrethroids as well as effects on the hormonal regulation and assimilation of carbon and nitrogen by the fungicide strobilurin, have been demonstrated (Venancio et al., 2003).

The current study demonstrated that, in addition to toxic effects of insecticides on natural enemies, repellency and interference with host location by parasitoids can reduce the parasitism efficiency. Therefore, in the pesticide registration process more emphasis should be given, in addition to toxicological analyses of pesticides on natural enemies, to the evaluation of repellent and other behavioural effects on parasitoids.

\section{Acknowledgement}

We would like to thank Prof Dr Stefan Schütz and Ulrike Eisenwiener for their support and the performance of the EAG-GC. This study was funded by the Scholarship Program of the German Federal Environmental Foundation (DBU).

\section{References:}

Agelopoulos, N. G. \& Keller, M. A. (1994). Plant-natural enemy association in tritrophic system, Cotesia rubecula-Pieris rapae- Brassicaceae (Cruciferae). III: Collection and identification of plant and frass volatiles. Journal of Chemical Ecology 20, 1955-1967.

Akol, A. M., Nuagi, P. G. N., Sithanantham, S. \& J.M.MueKe. (2003). Effects of two neem insecticides formulations on the attractiveness, acceptability and suitability of diamondback moth larvae to the parasitoid Diadegma mollipla (Holmgren) (Hym., Ichneumonidae). Journal of Applied Entomology 127, 325-331.

Alford, D. V., NILSSON, C. \& UlBER, B. (2003). Insect pests of oilseed rape crops. Chapter 2 In: D.V. Alford (ed) Biocontrol of Oilseed Rape Pests. Blackwell, Oxford, UK, 9-41.

Blatkmeer, A., Geervliet, J. B. F., Loon, J. J. A. V., Posthumus, M. A., BeeK, T. A. V. \& GROOT, A. D. (1994). Comparative headspace analysis of cabbage plants damaged by two species of Pieris caterpillars: consequences for in-flight host location by Cotesia parasitoids. Entomologia Experimentalis et Applicata 73, 175-182.

Borgemeister, C., PoEHLing, H.-M., DinTER, A. \& Höller, C. (1993). Effects of insecticides on life history parameters of the aphid parasitoid Aphidius rhopalosiphi (Hym.: Aphidiidae). Entomophaga 38, 245-255.

BROwn, K. C. (1989). The design of experiments to assess the effects of pesticides on beneficial arthropods in orchards: Replication verus plot size. In: Jepson P.C. (Ed.), Pesticide and Non-target Invertebrates. Intercept, Wimborne., 71-93.

BÜRGER, J. \& GEROWITT, B. (2009). Anwendungsmuster von Pflanzenschutzmitteln in Winterweizen und Winterraps. Gesunde Pflanze 61, 11-17.

Charleston, D. S., Gols, R., Hordijk, K. A., KFIR, R., Vet, L. E. M. \& Dicke, M. (2006). Impact of botanical pesticides derived from Melia azedarach and Azadirachta indica plants on the emission of volatiles that attract parasitoids of the diamondback moth to cabbage plants. Journal of Chemical Ecology 32, 325-349. 
DECHERT, G. \& UlBER, B. (2004). Interactions between the stem-mining weevils Ceutorhynchus napi Gyll. and Ceutorhynchus pallidactylus (Marsh.) (Coleoptera: Curculionidae) in oilseed rape. Agricultural and Forest Entomology 6, 193-198.

DESNEuX, N., DENOYELle, R. \& KAISER, L. (2006). A multi-step bioassay to assess the effect of the deltamethrin on the parasitis wasp Aphidius ervi. Chemosphere 65, 1697-1706.

DESNEUX, N., RAFALIMANANA, H. \& KAISER, L. (2004). Dose-response relationship in lethal and behavioural effects of different insecticides on the parasitic wasp Aphidius ervi. Chemosphere 54, 619-627.

DICKE, M., BEEK, T.A.V., POSTHUMUS, M.A., DOM, N.B., BOKHOVEN, H.V. \& GROTT, A.D. (1990a). Isolation and identification of volatile kairomones that affects acarine predator-prey interactions. Journal of Chemical Ecology 16, 381-396.

DICKE, M., SABELIS, M.W., TAKABAYASHI, J., BRUIN, J. \& POSTHUMUS, M.A. (1990b). Plant strategies of manipulating predator-prey interactions through allelochemicals: prospects for application in pest control. Journal of Chemical Ecology 16, 3091-3118.

DICKE, M. (1999). Are herbivore-induced plant volatiles reliable indicators of herbivore identity to foraging carnivorous arthropods? Entomologia Experimentalis et Applicata 91, 131-142.

FÄrbert, P., Koch, U. T., FÄrbert, A., Staten, R. T. \& CARdÉ, R. T. (1997). Pheromone concentration measured with electroantennogram in cotton fields treated for mating disruption of Pectinophora gossypiella (Lepidoptera: Gelechiidae). Environmental Entomology 26, 1105-1116.

Geervliet, J. B. F., Posthumus, M. A., Vet, L. E. M. \& Dicke, M. (1997). Comparative analysis of headspace volatiles from different caterpillar-infested or uninfested food plants of Pieris species. Journal of Chemical Ecology 23, 2935-2953.

GEERVLIET, J. B. F., VET, L. E. M. \& DiCKE, M. (1994). Volatiles from damaged plants as a major cues in long-range host-searching by the specialist parasitoid Cotesia rubecula. Entomolgia Experimentalis et Applicata 73, 289-297.

JEPSON, P. C. (1989). The temporal and spatial dynamics of pesticide side-effects on nontarget invertebrates. In: Jepson P.C. (Ed.), Pesticide and Non-target Invertebrates. Intercept, Wimborne., 95-127.

JIU, G. D. \& WAAGE, J. K. (1990). The effect of insecticides on the distribution of foracing parasitoids, Diaeretiella rapae (Hym.: Braconidae) on plants. Entomophaga 35, 4956.

Johnen, A., Williams, I. H., Ferguson, A. W., Büchs, W., KlukowsKi, Z., LuiK, A., NILSSON, C. \& ULBER, B. (2006). MASTER: construction of phenological models of key parasitoids in Europe and prospects for spray windows compatible with their conservation in winter oilseed rape. CD-Rom Proceedings of the International Symposium "Integrated Pest Management in Oilseed Rape Pests", Goettingen, Germany, 3-5 April 2006.

JÖNSSON, M. \& ANDERSON, P. (2008). Emission of oilseed rape volatiles after pollen beetle infestation; behavioural and electrophysiological responses in the parasitoid Phradis morionellus. Chemoecology 17, 201-207.

KLUKOWSKI, Z., TWARDOWSKI, J. \& IRZYKOWSKI, M. (2006). The impact of insecticide application and timing on parasitoid activity and levels of parasitism. CD-Rom Proceedings of the International Symposium "Integrated Pest Management in Oilseed Rape Pests", Goettingen, Germany, 3-5 April 2006.

KNUDSEN, J.T., ERIKSSON, R. \& GERSHENZON, J. (2006). Diversity and distribution of floral scent. The Botanical Review 71, 1-120.

Komeza, N., Foullet, P., Bouletreau, M. \& DelpueCh, J. M. (2001). Modification, by the Insecticide Chlorpyrifos, of the Behavioral Response to Kairomones of a 
Parasitoid Wasp, Leptopilina boulardi. Archiv Environmental Contamination and Toxicology 41, 436-442.

LANGLEY, M. \& STARK, J. D. (1996). Analytical Techniques for quantifying direct, residual and oral exposure of an insect parasitoid to an Organophosphate Insecticide. Bulletin of Environmental Contamination Toxicology 57, 683-690.

LONGLEY, M. \& JEPSON, P. C. (1996). The influence of insecticide residues on primary parasitoids and hyperparasitoid foraging behaviour in the laboratory. Entomolgia Experimentalis et Applicata 81, 259-269.

Mattiacci, L., Rocca, B. A., Scascighini, N., D’Alessandro, M., Hern, A. \& Dorn, S. (2001). Systemically induced plant volatiles emitted at the time of "danger". Journal of Chemical Ecology 27, 2233-2252.

MenZler-HokKanen, I., HoKkANen, H. M. T., BÜCHS, W., KluKOWsKi, Z., LuIK, A., NiLSSON, C., UlBER, B. \& WILLIAMS, I. H. (2006). Insect problems in European oilseed rape cultivation, and how to deal with them: the OSR framers`perspective. IOBC/wprs Bulletin 29, 91-94.

Mumm, R., Schrank, K., Wegener, R., SchulZ, S. \& Hilker, M. (2003). Chemical analysis of volatiles emitted by Pinus sylvestris after induction by insect oviposition. Journal of Chemical Ecology 29, 1235-1251.

Nottingham, S. F., Hardie, J., Dawson, G. W., Hick, A. J., Pickett, J. A., Wadhams, L. J. \& WoODCOCK, C. M. (1991). Behavioral and electrophysiological responses of aphids to host and nonhost plant volatiles. Journal of Chemical Ecology 17, 12311242.

PARÉ, P. W. \& TuMLInsON, J. H. (1997). Induced synthesis of plant volatiles. Nature 385, 3031.

PICHERSKY, E. \& GERSHENZON, J. (2002). The formation and function of plant volatiles: perfumes for pollinator attraction and defense. Current Opinion in Plant Biology $\mathbf{5}$, 237-243.

POTTING, R.P.J., VET, L.E.M. \& DICKE, M. (1995). Host microhabitat location by stem-borer parasitoid Cotesia flavipes: The role of herbivore volatiles and locally and systemically induced plant volatiles. Journal of Chemical Ecology 21, 525-539.

RICHTER, E. (2006). A method to prove long term effects of neonicotinoids on whitefly parasitoids. IOBC/wprs Bulletin 29, 61-65.

Roseland, C. R., BATES, M. B., CARlson, R. B. \& OSETO, C. Y. (1992). Discrimination of sunflower volatiles by the red sunflower seed weevil. Entomologia Experimentalis et Applicata 62, 99-106.

SCHULD, M. \& SCHMUCK, R. (2000). Effects of Thiacloprid, a New Chloronicotinyl Insecticide, On the Egg Parasitoid Trichogramma cacoeciae. Ecotoxicology 9, 197205.

TAKABAYASHI, J., DICKE, M. \& POSTHUMUS, M.A. (1994). Volatile herbivore-induced terpenoids in plant-mite interactions: Variation caused by biotic and abiotic factors. Journal of Chemical Ecology 20, 1329-1354.

THIERY, D. \& VISSER, J. H. (1986). Masking of plant odour in the olfactory orientation of the Colorado potato beetle. Entomologia Experimentalis et Applicata 41, 165-172.

TOMIZAWA, M. \& CASIDA, J. E. (2005). Neonicotinoid Insecticide Toxicology: Mechanism of Selective Action. Annual Review Pharmacology Toxicology 45, 247-268.

TRAN, D. H., TAKAGI, M. \& TAKASU, K. (2004). Effects of selective insecticides on host searching and oviposition behavior of Neochrysocharis formosa (Westwood) (Hymenoptera: Eulophidae), a larval parasitoid of the American serpentine leafminer. Applied Entomology Zoology 39, 435-441.

TURLINGS, T.C.J., TUMLINSON, J.H. \& LEWIS, W.J. (1990). Exploitation of herbivoreinduced plant odors by host-seeking parasitic wasps. Science 250, 1251-1253. 
Turlings, T. C. J., Tumlinson, J. H., Heath, R. R., Proveaux, A. T. \& Doolittle, R. E. (1991). Isolation and identification of allelochemicals that attract the larval parasitoid, Cotesia marginiventris (Cresson), to the microhabitat of one of its hosts. Journal of Chemical Ecology 17, 2235-2251.

UlBer, B. (2003). Parasitoids of Ceutorhynchid stem weevils. In: D. V. Alford (ed) Biocontrol of Oilseed Rape Pests. Blackwell Publishing, Oxford, UK, 87-95.

Ulber, B., NitzSCHE, O. \& WedEMEYER, R. (2006). Phenology of tersilochine parasitoids in Germany and prospects for spray windows compatible with their conservation. $C D$ Rom Proceedings of the International Symposium "Integrated Pest Management in Oilseed Rape Pests", Goettingen, Germany, 3-5 April 2006.

UMORU, P. A., POWELL, W. \& CLARK, S. J. (1996). Effect of pirimicarb on the foraging behaviour of Diaeretiella rapae (Hymenoptera: Braconidae) on host-free and infested oilseed rape plants. Bulletin of Entomological Research 86, 193-201.

Venancio, W. S., Rodrigues, M., Begliomini, E. \& SouZA, N. D. (2003). Physiological effects of strobilurin fungicides on plants. UEPG Ci. Exatas Terra, Ci. Agr. Eng., Ponta Grossa 9, 59-68.

VET, L.E.M. \& DICKE, M. (1992). Ecology of infochemical use by natural enemies in a tritrophic context. Annual Review Entomology 37, 141-172.

Vet, L. E. M., Jong, A. G. D., FrAnChI, E. \& PAPAJ, D. R. (1998). The effect of complete versus incomplete information on odour discrimination in a parasitic wasp. Animal Behaviour 55, 1271-1279.

VinSON, S. B. (1998). The general host selection behaviour of parasitoid Hymenopteran and a comparison of initial strategies utilized by larvaphagous and oophagous species. Biological Control 11, 79-96.

WeissbeCKER, B., Holighaus, G. \& SCHÜTZ, S. (2004). Gas chromatography with mass spectometric and electroantennographic detection: analysis of wood odorants by direct coupling of insect olfaction and mass spectrometry. Journal of Chromatography A 1056, 209-216.

WILLIAMS, I.H., BÜCHS, W., HOKKANEN, H. MENZLER-HOKKANEN, I. JOHNEN, A.; KLUKOWSKI, Z.; LUIK, A.; NILSSON, C. \& ULBER, B. (2005). MASTER-Integrating biological control within IPM for winter oilseed rape across Europe. Proceedings of the BCPC International Congress, Crop Science \& Technology, Glasgow, 31 October- 2 November 2005, 1, 301-308.

WiLLIAMS, L. \& PRICE, L. D. (2004). A space-efficient contact toxicity bioassay for minute Hymenopteran, used to test the effects of novel and conventional insecticides on the egg parasitoids Anaphes iole and Trichogramma pretiosum. BioControl 49, 163-185. 


\title{
Effect of insecticides on parasitism of stem mining pests and migration of tersilochine parasitoids on winter oilseed rape (Brassica napus L.)
}

\begin{abstract}
Rape stem weevil, Ceutorhynchus napi and cabbage stem weevil, C. pallidactylus are major pests of winter oilseed rape (Brassica napus L.) in Europe. Control practices are mainly based on broad spectrum insecticides that are often applied routinely and without regard to pest control thresholds. Their extensive usage might have a strong negative impact on natural enemies. The stem-mining larvae of $C$. napi and $C$. pallidactylus are parasitized by the specialist larval endoparasitoids, Tersilochus fulvipes and T. obscurator, respectively.

In 2007 and 2008, we evaluated two insecticides, the systemic neonicotinoid thiacloprid and the contact pyrethroid lambda-cyhalothrin for their effects on parasitism and migration behaviour of $T$. fulvipes and T. obscurator. In randomized field plot experiments, the insecticides were applied either at full recommended field dose rates or at $50 \%$ reduced rates, both before and after the main immigration period of tersilochine parasitoids into the crop of oilseed rape. Migration flight directions of tersilochine parasitoids to and from crops of oilseed rape were determined by using double-sided malaise-traps, placed at the edges of insecticide treated and untreated crops.
\end{abstract}

The level of parasitism of $C$. napi and C. pallidactylus by T. fulvipes and T. obscurator, respectively, ranged between $7.7-16.3 \%$ and $0-28.1 \%$, respectively. Parasitism was not significantly affected by any of the tested insecticide treatments. Measures to protect parasitoids, such as the application of systemic insecticide, reduction of field dose rate and early spraying before immigration of tersilochine parasitoids did not increase parasitism, compared to spraying full doses at main period of parasitoids activity. Parasitoids responded to insecticide application by increased emigration from the treated field and rapid reinvasion as compared to untreated fields. Further, due to their vertical distribution at the bottom of the crop, they may be protected from insecticide sprays.

This knowledge may help to conserve parasitoids and may improve the integration of chemical and biological control in IPM strategies for controlling pests on oilseed rape. 


\section{Chapter IV}

\section{Introduction}

The rape stem weevil, C. napi Gyll. and the cabbage stem weevil, C. pallidactylus (Mrsh) (Col.: Curculionidae) are major pests of winter oilseed rape, Brassica napus L. var. oleifera Metzg. in Central and Northern Europe (Alford et al., 2003). Females lay their eggs into stems and into petioles and midribs of leaves, respectively (Alford et al., 2003; Dechert \& Ulber, 2004). The larvae of both species mine within the pith of host plants. Mature larvae migrate to soil for pupation. The stem-mining larvae of $C$. napi and $C$. pallidactylus are commonly attacked by the specialist, univoltine, koinobiont parasitoids Tersilochus obscurator Aub. and T. fulvipes Grav. (Hym.: Ichneumonidae), respectively (Ulber, 2003). Female parasitoids lay their eggs through the tissue of stems and petioles singly into the host larvae. When the full-grown host larva has left the plant to pupate in soil, the parasitoid larva develops rapidly and kills the host prepupae. The adult parasitoid diapauses in its pupal cocoon until it emerges in the following spring to migrate to the new oilseed rape crops (Ulber, 2003). In the literature, levels of parasitism of $C$. napi and $C$. pallidactylus have been reported to range between $0 \%-98 \%$ and 6\% - 54\%, respectively (Jourdheuil, 1960; Sedivy, 1983; Ulber, 2003).

Current control practices of pests on oilseed rape are mainly based on broad spectrum synthetic insecticides, which are often applied routinely and prophylactically without regard to pest control thresholds, thereby reducing the economic profitability of the crop (Williams 2004). Three to four insecticide treatments are applied commonly to the crop in autumn, spring and summer (Menzler-Hokkanen et al., 2006). Frequent pyrethroid applications have recently caused widespread resistance of pollen beetles in many European countries (Hansen, 2003; Wegorek \& Zamojska, 2006, Müller et al., 2008). Further, insecticides may harm natural enemies of pests. The main period of activity of tersilochine parasitoids (except Tersilochus microgaster) occurs in the late bud stage up to the end of flowering of oilseed rape (Johnen et al., 2006; Ulber et al., 2006). Therefore, insecticides applied during this period might have negative impact on natural control of pest populations by their parasitoids. Adult parasitoids can be exposed to insecticide spray droplets (Croft \& Brown, 1975; Jepson, 1989) or to insecticide residuals when foraging on the plant surface (Longley \& Jepson, 1996a) or through contact and feeding on contaminated water droplets and nectar (Longley \& Jepson, 1996b). The effect of insecticides on parasitoid populations may be affected by the mode of action, dosage, persistency and temporal and spatial application (Alford et al., 1992; Jepson, 1989; Poehling, 1989). 
Harmful effects of insecticides on natural enemies, including parasitoids, might be avoided by applying more selective insecticides (Iwata et al., 1985; Brunner et al., 2001). In particular, systemic insecticides, e.g. neonicotinoids and their metabolites, are quickly absorbed by the plant tissue and therefore claimed to be fairly safe for beneficial insects foraging on the plant surface (Stapel et al, 2000).

Further, application of insecticides at reduced dose rates and before the main activity period of natural enemies might help to conserve parasitoids on the crop (Poehling, 1989; Longley et al., 1997; Booth et al., 2007).

Previous studies on the effect of insecticides on parasitoids of pests on oilseed rape have shown that the number of adult parasitoids may be reduced by application of the pyrethroids tau-fluvalinate and lambda-cyhalothrin (Klukowski, 2006), by organochlorine insecticides (Winfield, 1963) and by the organophosphate fenitrothion (Hokkanen, et al., 1988), compared to untreated plots. Parasitism of Ceutorhynchus assimilis by Trichomalus perfectus was affected by triazophos, while alpha-cypermethrin was less harmful (Alford et al., 1992; Murchie et al., 1997).

The aim of this study was to evaluate in field experiments the effect of two insecticides, the systemic neonicotinoid thiacloprid and the contact pyrethroid lambda-cyhalothrin on parasitism and migration behaviour of T. fulvipes and T. obscurator. The insecticides were applied either at the full recommended field dose rate or at $50 \%$ reduced rate, both before and after main immigration of tersilochine parasitoids into the crop.

\section{Material and Methods}

\section{Design of field experiments}

Field plot experiments were conducted in the year 2007 and 2008 in crops of oilseed rape close to Goettingen (Germany). In each year, the treatments were arranged in a randomized block design with four replicated plots $(15 \mathrm{~m} * 16 \mathrm{~m})$ of each treatment. The pyrethoid lambdacyhalothrin (Karate Zeon, 100g a.i./l) and the neonicotinoid thiacloprid (Biscaya, 240g a.i./l) were applied at $100 \%$ and $50 \%$ of the recommended field dose rate, respectively, with 240 1/ha of water. The first application was carried out before the main immigration of parasitoids at early flowering (BBCH 61/62) and the second application at peak activity, during mid to end of flowering (BBCH 65/69). Four plots were kept untreated as control. In total, nine different treatments were compared in each experiment. 


\section{Chapter IV}

\section{Level of parasitism}

The effect of insecticide application on the level of larval parasitism of C. napi and C. pallidactylus was determined from samples of 20-25 plants collected at random from each plot in May, before mature host larvae started to migrate to soil for pupation. In the laboratory, stems and lateral recames were cut longitudinal to collect the larvae. The mean number of larvae sampled for dissection ranged between 49 and 408 larvae/treatment (mean 114 larvae/ treatment). They were stored in $70 \%$ Ethanol and later dissected in a drop of water under a stereo microscope. Larvae were cut off using a fine needle, and the body contents were teased apart to detect parasitoid eggs or larvae.

\section{Phenology of adult parasitoids}

The phenology of parasitoids was monitored by using yellow water traps (33 x 26 × $6 \mathrm{~cm}$ ) that were filled with 1.5 litres of water and a few drops of detergent. Four traps were exposed 10 meter from each field edge and were emptied three times per week from March till June.

The vertical distribution of parasitoids within the crop canopy of an untreated oilseed rape field was determined by using eight yellow water traps. For trapping parasitoid species foraging on the level of buds and flowers, trap height was raised to the top of the canopy as the crop grew. For parasitoids foraging on stems and leaves four traps were placed at ground level. Traps were emptied weekly during the main period of parasitoid activity from 17 April to 19 May 2009. All insects caught were stored in $70 \%$ Ethanol and later identified by using keys of Horstmann $(1971 ; 1981)$.

\section{Directional migration of adult parasitoids}

The flight direction of parasitoids to and away from an insecticide-treated and untreated field was assessed following the second insecticide treatment. Four double-sided malaise traps were established around an insecticide-treated and an untreated field of oilseed rape, one at each side close to the field border. Traps were made up of fine black nylon net with sloping roof, a central vertical partition, and open sides. They were arranged with their longitudinal axes parallel to the circumference of the field. The lateral openings were on average $160 \mathrm{~cm}$ long sloping from 75 to $85 \mathrm{~cm}$ high. A central longitudinal partition divided the trap into two halves, each surmounted at its highest point by a collecting bottle. The parasitoids flew through the opening into one half of the trap and moved up the central netting, where they were trapped in one of the two collecting bottles. The distal half of each trap sampled the insects flying towards the oilseed rape field, whereas the proximal half sampled parasitoids 
flying away from the field. Parasitoids were captured by malaise traps during their main activity period and when insecticides were applied between 27 April and 19 May 2008. They were collected daily between 08:00 and 10:00 a.m. from each trap. Parasitoid samples were conserved in $70 \%$ Ethanol and later identified and counted. Identification followed keys of Horstmann $(1971,1981)$.

\section{Statistical analysis}

All data were proofed for normal distribution by Kolmogorow-Smirnov test. When a normal distribution existed the data were subjected to ANOVA; differences between means $(\mathrm{p} \leq 0.05)$ were evaluated by Tukey-HSD test. For estimating differences between the vertical distribution of parasitoids, the paired t-test was applied. RM-ANOVA was used to evaluate significant differences between the cumulative numbers of parasitoids in double-sided malaise traps. Statistical analyses were performed by Statistica (Version 8).

\section{Results}

\section{Phenology of adult stem weevils and their parasitoids}

In 2007, the immigration of $C$. napi and $C$. pallidactylus started between 4 to 6 March. Peak activity of adults was recorded on 14 March, with 346,5 and 178 weevils/trap, respectively. First adults of T. obscurator and T. fulvipes were captured on 6 March and 12 March, respectively, with peak activity occuring on 10 April (Fig 1).

In 2008, first adults of C. napi and C. pallidactylus were caught on 31 March and 29 April, respectively. Peak activity of C. napi (38 weevils/trap) and C. pallidactylus ( 9 weevils/trap) was found on 21 April and 29 April, respectively. First adults and peak activity of $T$. obscurator and T. fulvipes were observed in yellow water traps on 23 April (Fig 2). 


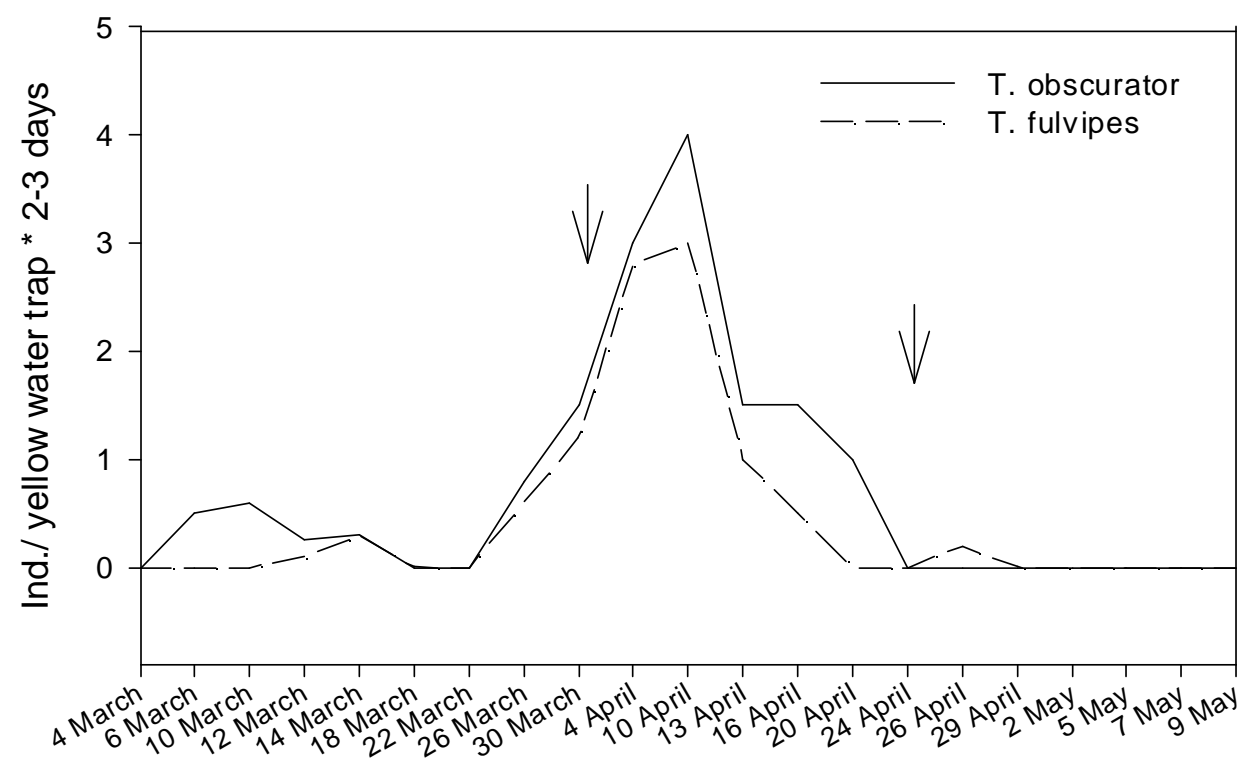

Fig 1: Mean number of adult T. fulvipes and T. obscurator caught in yellow water traps on a crop of oilseed rape in 2007, $\downarrow=$ date of insecticide application.

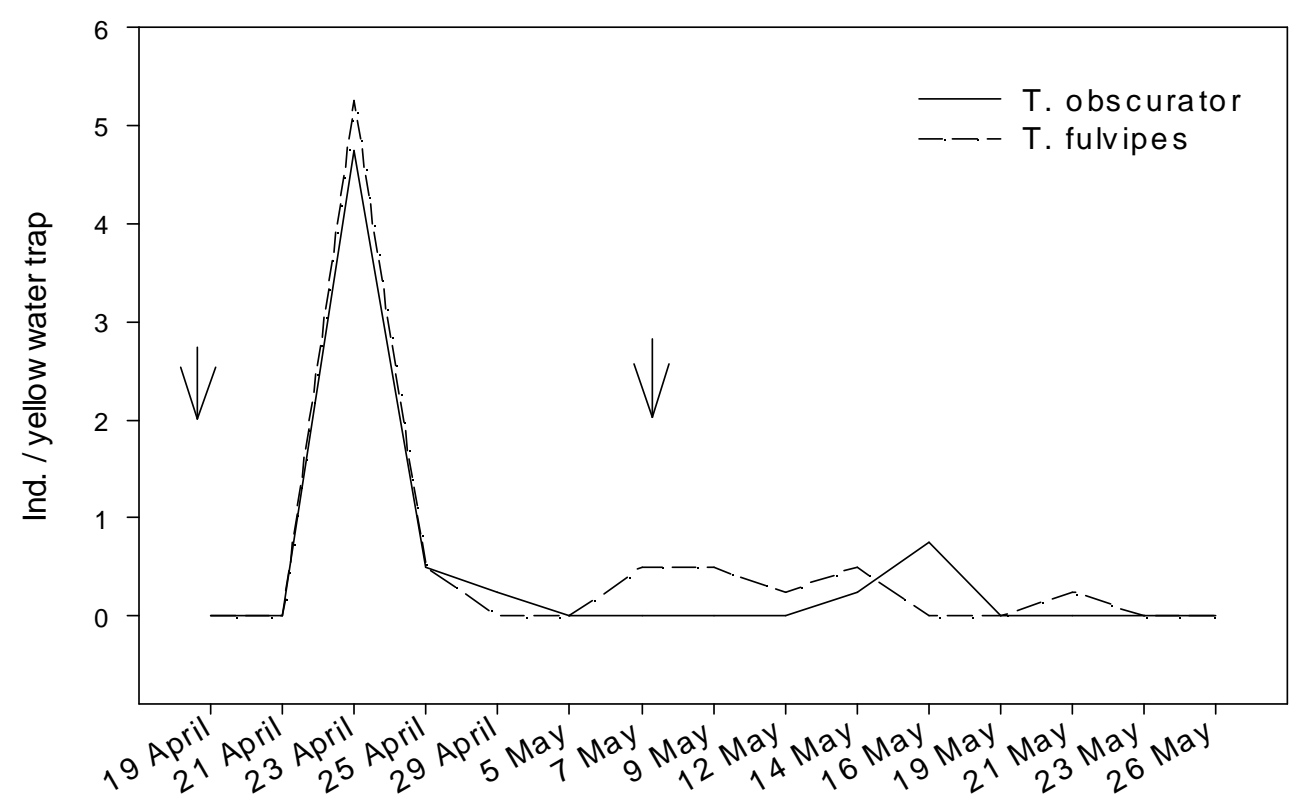

Fig 2: Mean number of adult T. fulvipes and T. obscurator caught in yellow water traps on a crop of oilseed rape in 2008, $\downarrow=$ date of insecticide application. 


\section{Chapter IV}

Larval abundance and parasitism of $\mathrm{C}$. napi by $\mathrm{T}$. fulvipes

In 2007 and 2008, the insecticide treatments had no significant effect on the abundance of

C. napi larvae (Fig 3 and 4). Mean number of host larvae per plant amounted to $4.6 \pm 0.7$ and $0.84 \pm 0.35$, respectively. The level of parasitism was not significantly affected by any of the tested insecticide treatments. The insecticide compound, the dose rate and the time of application had no significant effect on the level of parasitism (Fig 3 and 4). The overall percentage of larval parasitism of $C$. napi in 2007 and 2008 was $11.3 \pm 1.85 \%$ and $12.5 \pm 4.9$ $\%$, respectively.

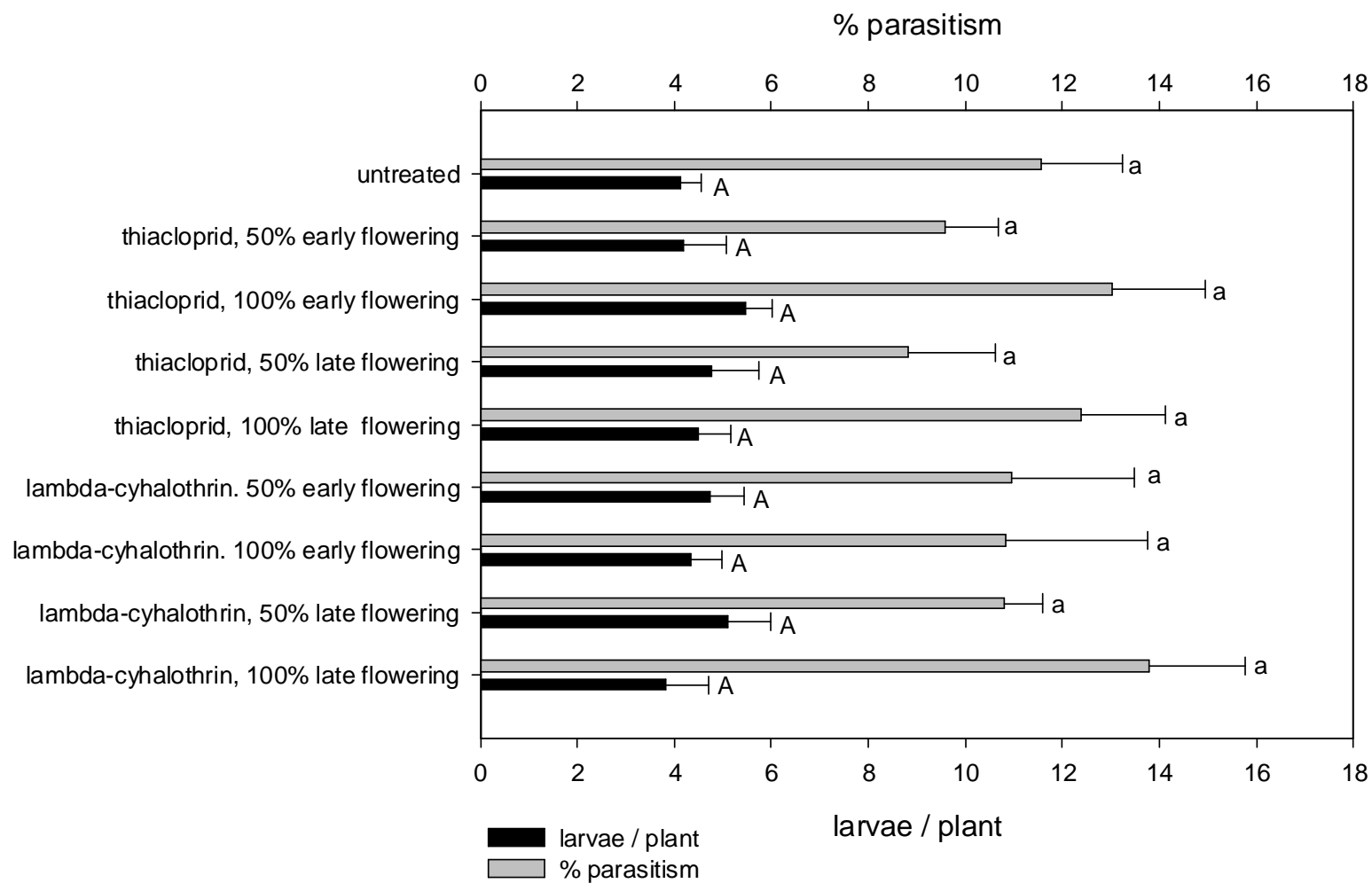

Fig 3: Mean larval abundance (+ SE) of $C$. napi and mean level of parasitism (+ SE) in oilseed rape plots following different insecticide treatments in 2007. Thiacloprid or lambdacyhalothrin was applied at full dose rate $(100 \%)$ or reduced dose rate $(50 \%)$ in early flowering or late flowering. Means followed by the same upper/lower case letters are not significantly different. Larvae/ plant: ANOVA; Tukey HSD; $\mathrm{n}=36 ; \mathrm{F}=0.47 ; \mathrm{p}>0.05$. Percent parasitism: ANOVA; Tukey HSD; $\mathrm{n}=36, \mathrm{~F}=0.6 ; \mathrm{p}>0.05$. 


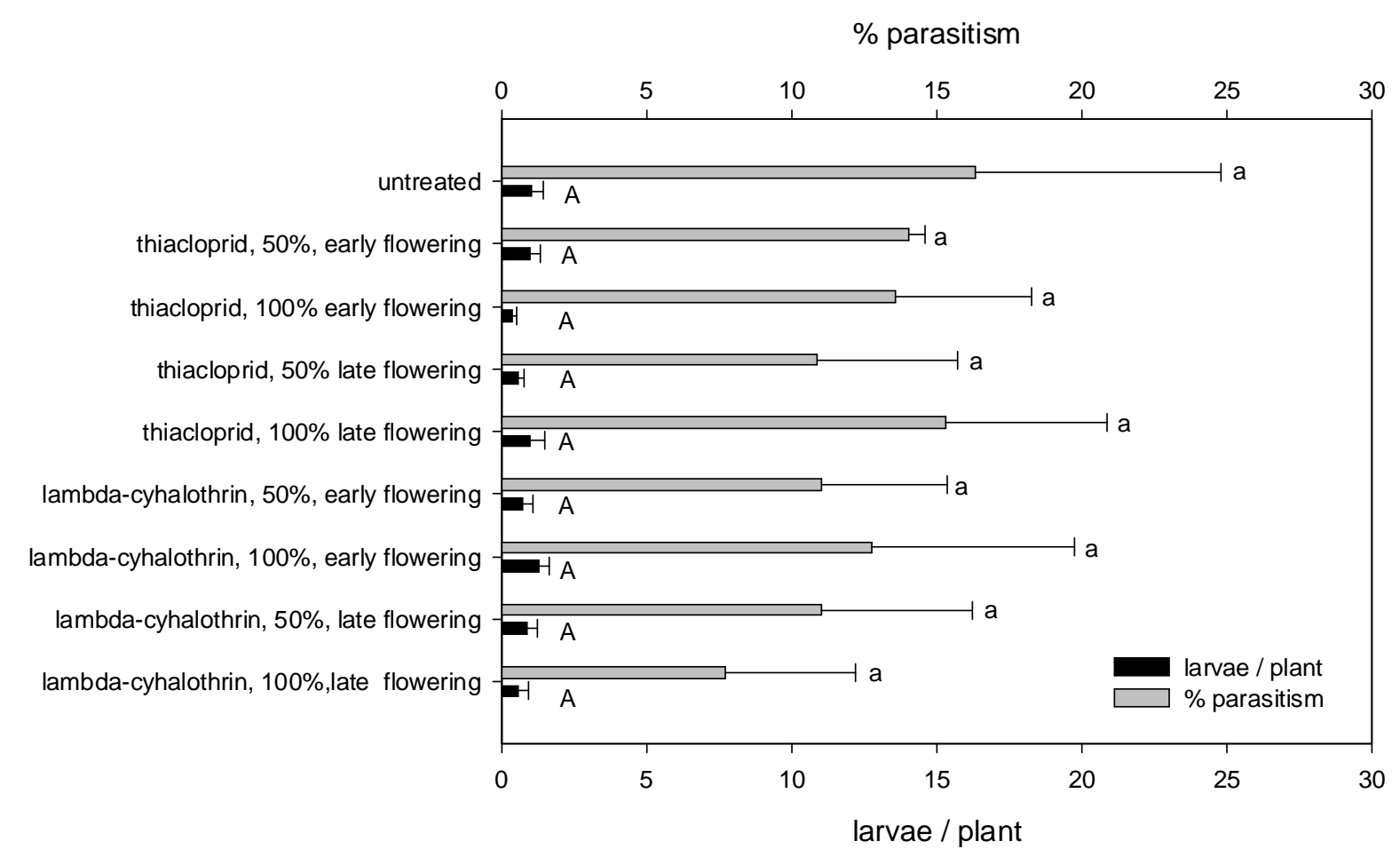

Fig 4: Mean larval abundance (+ SE) of $C$. napi and mean level of parasitism (+ SE) in oilseed rape plots following different insecticide treatments in 2008. Thiacloprid or lambdacyhalothrin was applied at full dose rate $(100 \%)$ or reduced dose rate $(50 \%)$ in early flowering or late flowering. Means followed by the same upper/lower case letters are not significantly different. Larvae/ plant: ANOVA; Tukey HSD; $\mathrm{n}=36 ; \mathrm{F}=0.63 ; \mathrm{p}>0.05$. Percent parasitism: ANOVA; Tukey HSD; $\mathrm{n}=36, \mathrm{~F}=0.25 ; \mathrm{p}>0.05$.

Larval abundance and parasitism of C. pallidactylus by T. obscurator

In 2007 , the mean number of $C$. pallidactylus larvae/plant was significantly lower in plots treated at early flowering with $100 \%$ of the recommended dose rate of thiacloprid $(1.6 \pm 0.55)$ than in plots treated at flowering with $50 \%$ of the recommended dose rate of thiacloprid $(6.8 \pm$ 1.05). The mean number of larvae per plant was $4.8 \pm 1.25$ (Fig 5). The level of parasitism of C. pallidactylus by $T$. obscurator was not significantly different between insecticide treated and untreated plots, between plots treated with thiacloprid or lambda-cyhalothrin and between the tested application rates (100\% vs. $50 \%$ of recommended dose rate) or application dates (bud stage vs. flowering) (Fig 5). In 2007, mean level of parasitism was 20.7\% \pm 3.6. In 2008, the level of infestation by $C$. pallidactylus larvae was too low for obtaining reliable results on effects of insecticide application on parasitism. 


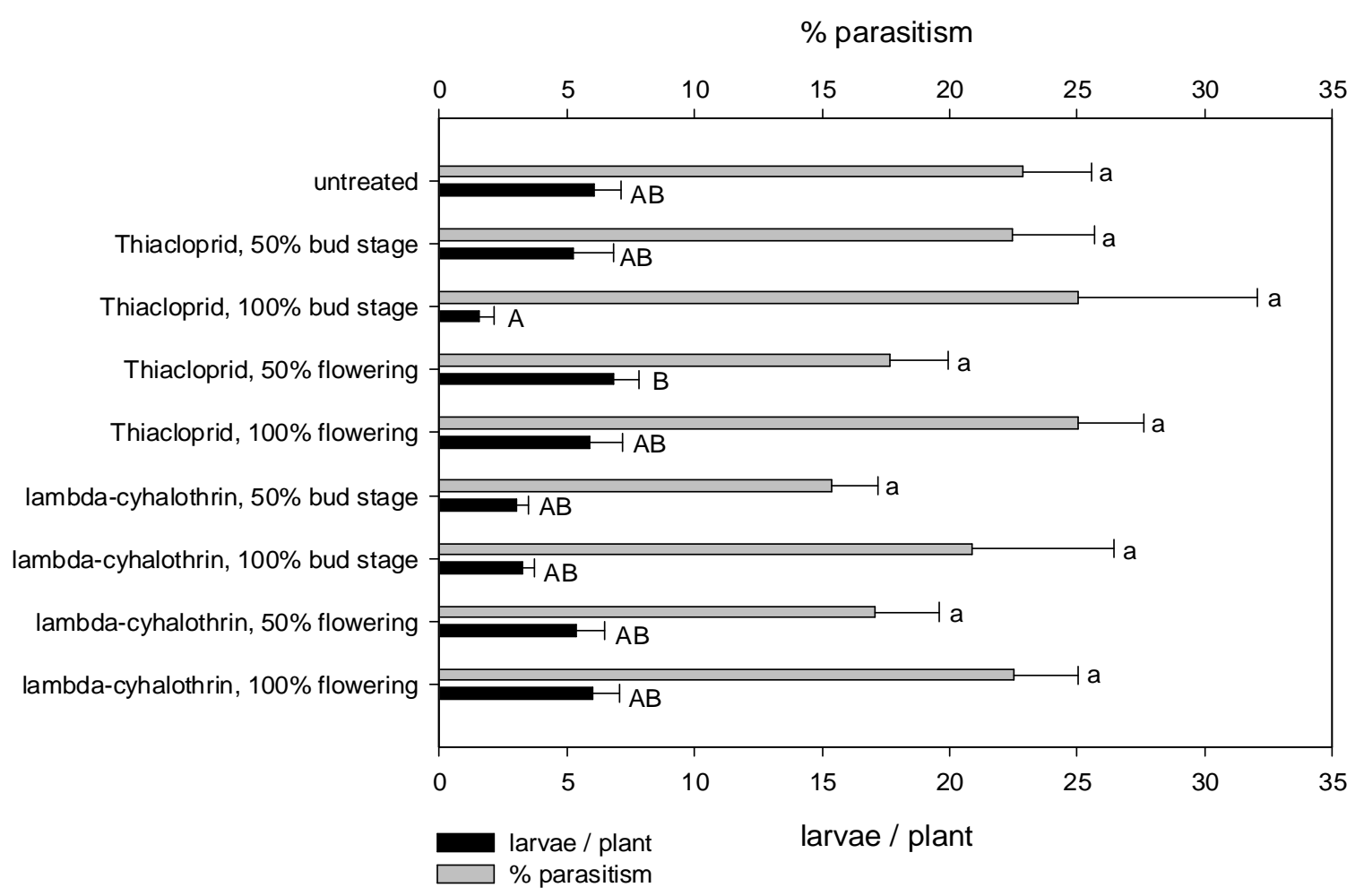

Fig 5: Mean larval abundance (+ SE) of $C$. pallidactylus and mean level of parasitism (+ SE) in oilseed rape plots following different insecticide treatments in 2007. Thiacloprid or lambda-cyhalothrin was applied at full dose rate $(100 \%)$ or reduced dose rate $(50 \%)$ in early flowering or late flowering. Means followed by the same upper/lower case letters are not significantly different. Larvae/ plant: ANOVA; Tukey HSD; $\mathrm{n}=36 ; \mathrm{F}=3.0 ; \mathrm{p}>0.05$. Percent parasitism: ANOVA; Tukey HSD; $\mathrm{n}=36, \mathrm{~F}=0.8 ; \mathrm{p}>0.05$.

\section{Vertical distribution of adult parasitoids within the crop canopy}

Adult females of $T$. fulvipes and T. obscurator were more abundant in yellow water traps placed at soil level than in traps placed on top of the crop canopy (Fig 6). There was no significant difference between numbers of male T. fulvipes caught at different heights of the crop canopy. 


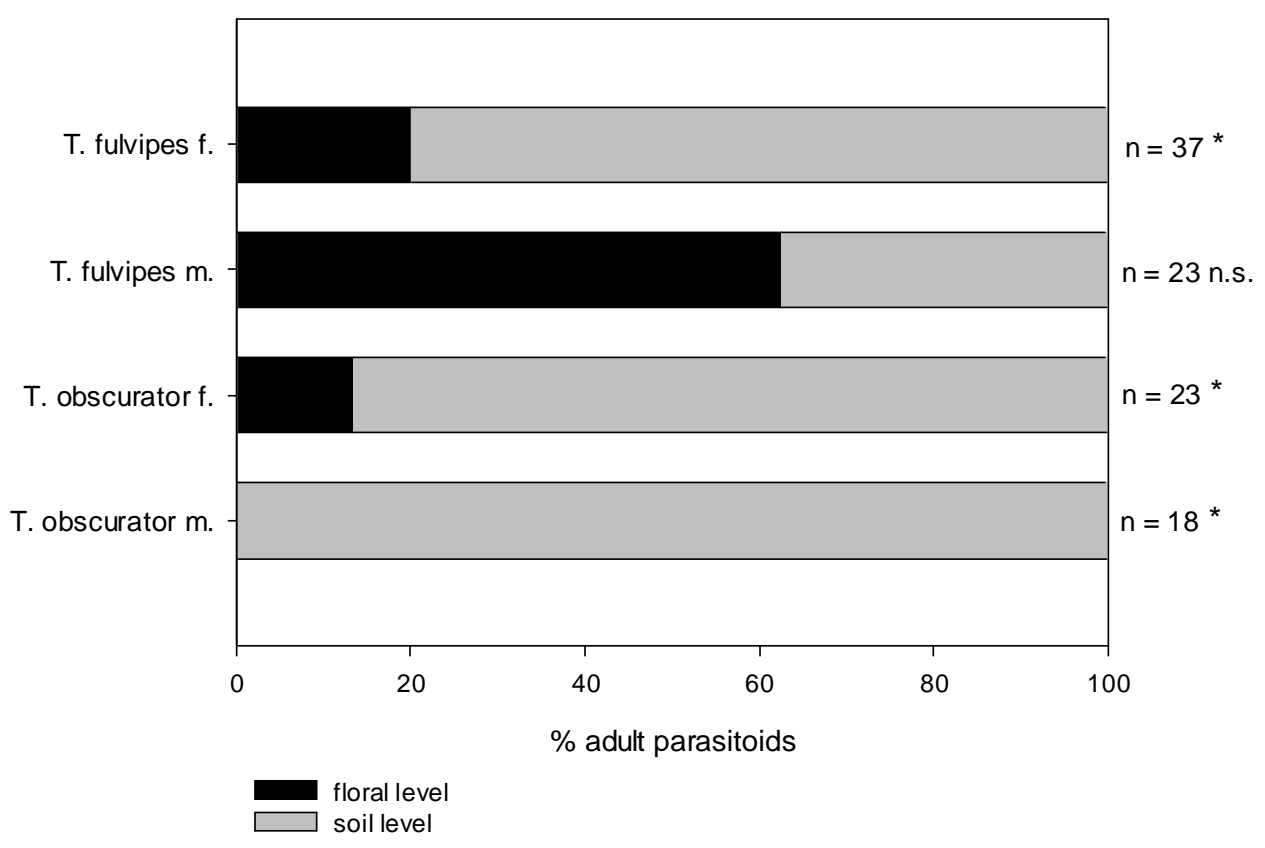

Fig 6: Mean proportion of female and male T. fulvipes and T. obscurator caught in yellow water traps at the top of the crop canopy and at ground level of oilseed rape; trapping period 17 April -19 May 2009. * = significant difference (paired t-test, $\mathrm{p} \leq 0.05) .(\mathrm{m}=$ male, $\mathrm{f}=$ female)

Migration flights offemale T. obscurator and T. fulvipes towards and away from insecticide treated and untreated crops of oilseed rape

The cumulative numbers of female $T$. obscurator as assessed by using bi-directional malaise traps, differed significantly between emigration and immigration flights. In the untreated field the number of parasitoids flying towards the crop was greater than the number of parasitoids flying away from the field (Fig 7). In contrast, in the insecticide-treated field the emigration prevailed over the immigration during seven days following treatment (Fig 8). 


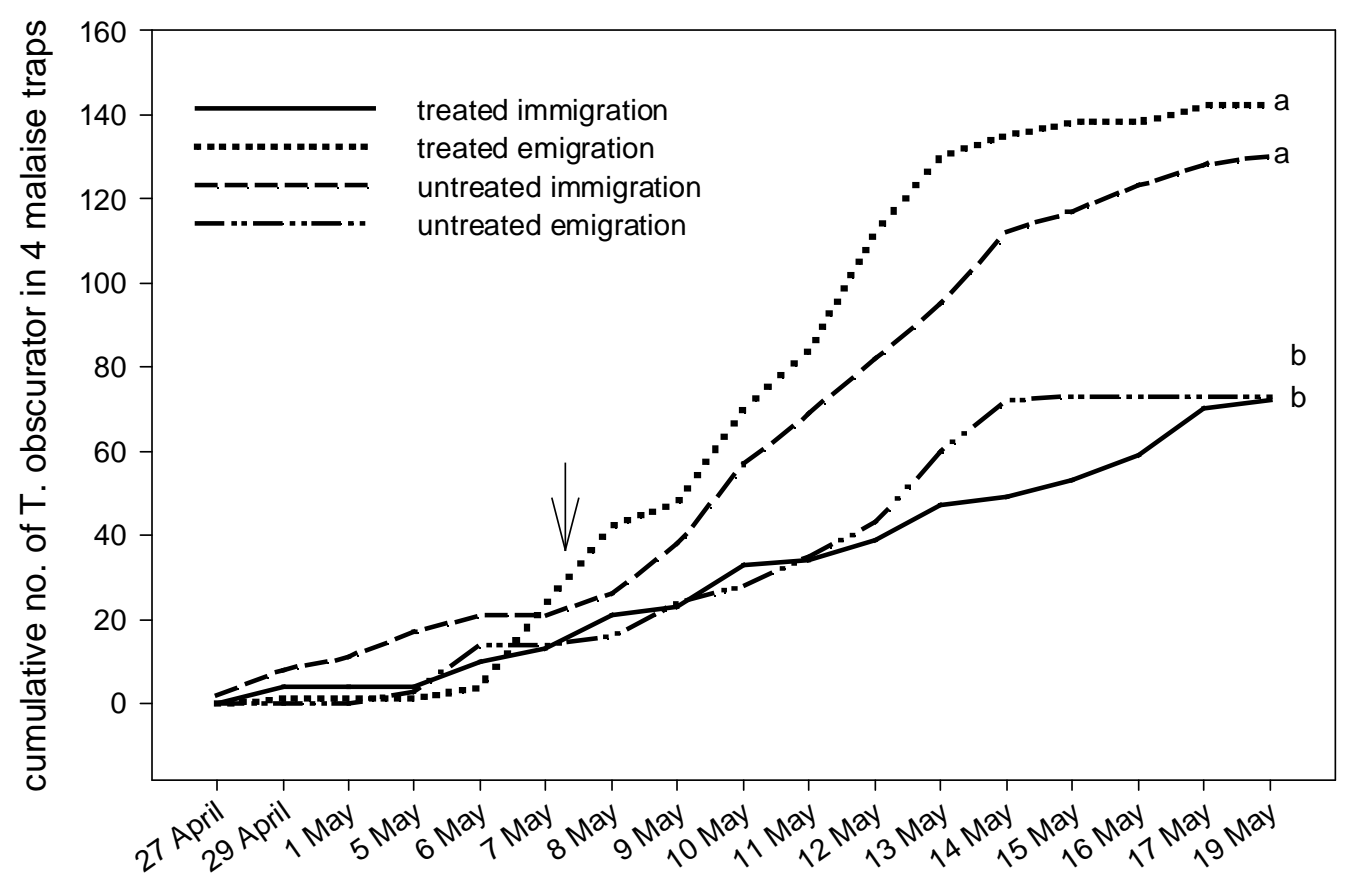

Fig 7: Cumulative number of female T. obscurator caught in directional malaise traps placed around the border of untreated and treated oilseed rape fields in 2008. Different letters indicate significant differences, RM-ANOVA; $\mathrm{p} \leq 0.05, \downarrow=$ date of insecticide application

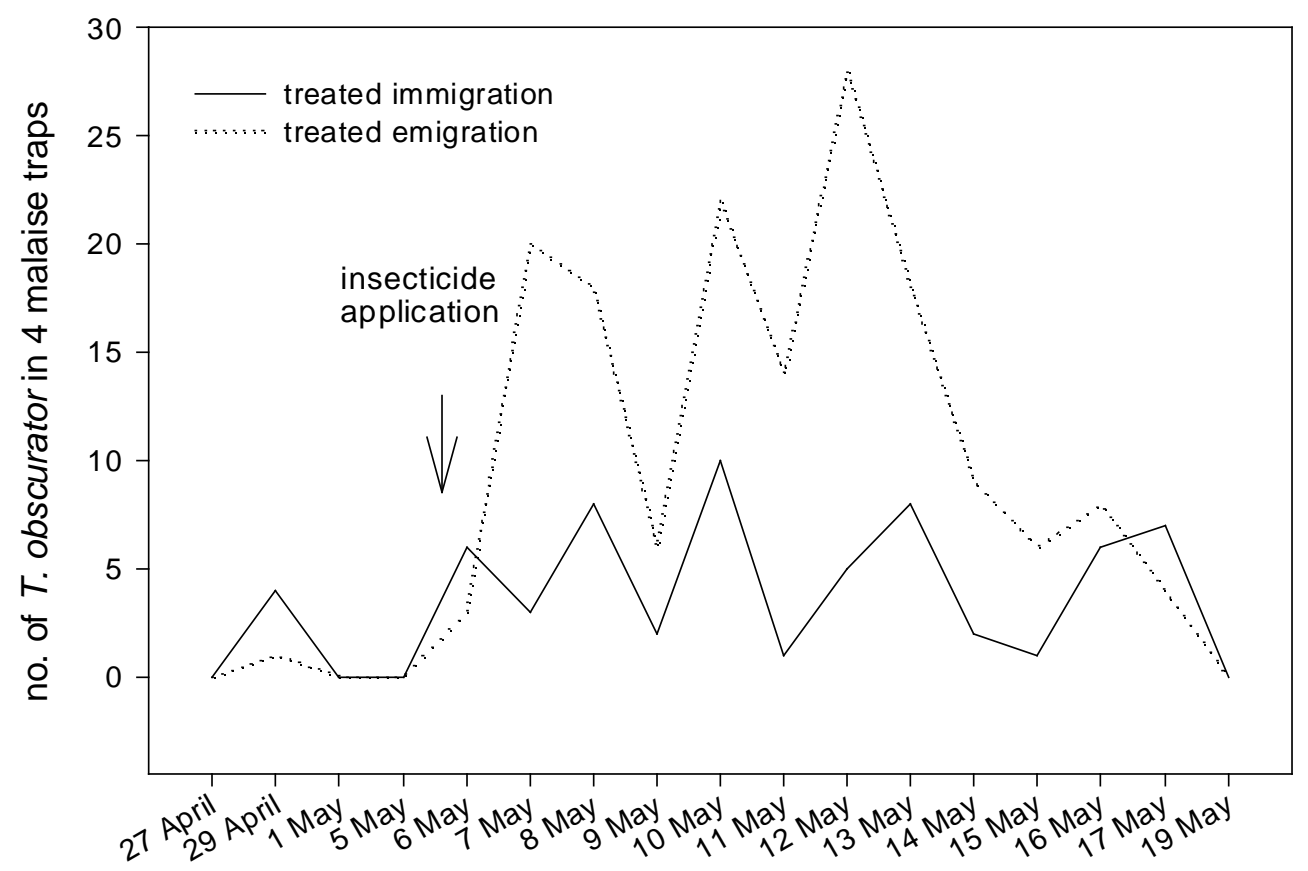

Fig 8: Daily numbers of female $T$. obscurator caught in directional malaise traps, placed around the border of an untreated and treated oilseed rape field in 2008. $\downarrow=$ date of insecticide application. 
Similarly, emigration flights of T. fulvipes differed between untreated and insecticide-treated crops of oilseed rape. Significantly more adult $T$. fulvipes emigrated from the insecticidetreated field than from the untreated field. The immigration flights were not significantly different between insecticide treated and untreated fields (Fig 9).

Captures of $T$. fulvipes increased after insecticide application; emigration flights prevailed over immigration flights in the treated field. Seven days after treatment, the number of captured parasitoids decreased (Fig 10).

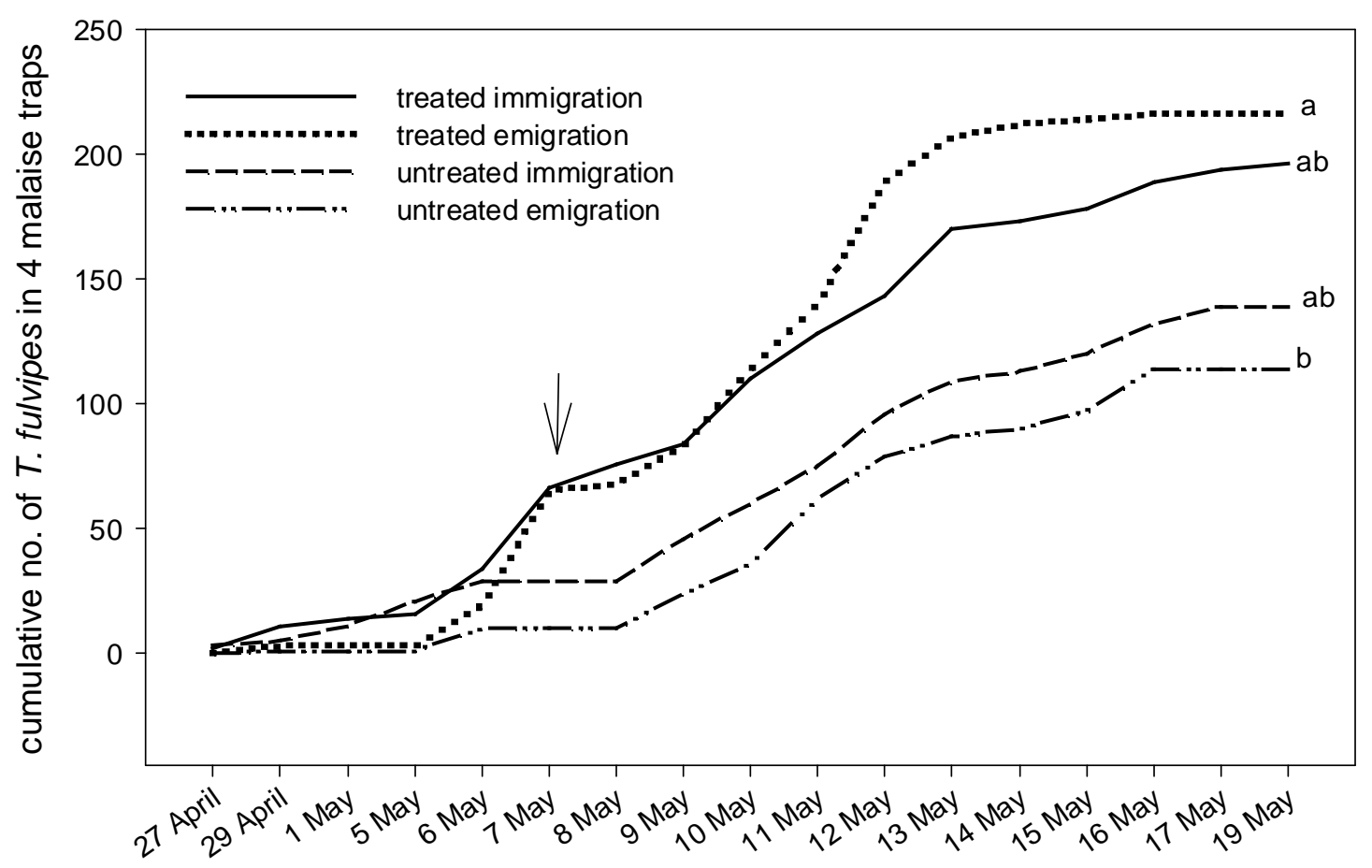

Fig 9: Cumulative number of female T. fulvipes caught in directional malaise traps placed around the border of an untreated and treated oilseed rape fields in 2008. Different letters indicate significant differences, RM-ANOVA; $\mathrm{p} \leq 0.05, \downarrow=$ date of insecticide application. 


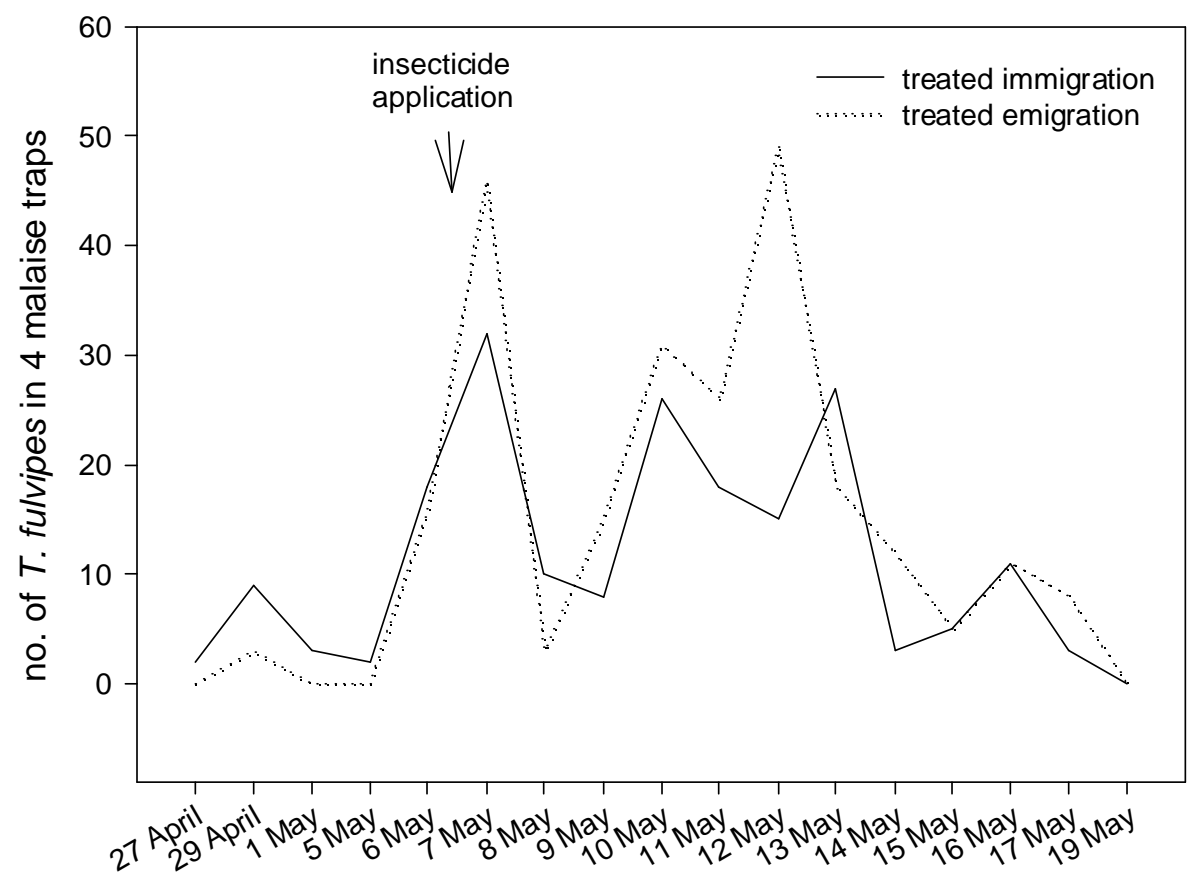

Fig 10: Daily numbers of female T. fulvipes caught in directional- malaise traps placed around the border of an untreated and treated oilseed rape fields in 2008. $\downarrow=$ date of insecticide application.

\section{Discussion}

The period of main activity of tersilochine parasitoids (except T. microgaster) in crops of winter oilseed rape commonly persists from the late bud stage until the end of flowering, with peak activity at full flowering (Johnen et al., 2006; Ulber et al., 2006). Consequently, insecticide applications during flowering might have detrimental effects on parasitoid populations. In contrast to this expectation, in this study the level of parasitism of stem weevil larvae was not significantly affected by insecticide application neigher by early application nor by spraying at the end of flowering. In earlier studies, application of pyrethroid sprays at flowering of oilseed rape as well had no negative effect on levels of parasitism of C. napi and C. assimilis (Winfield, 1963; Klukowski, 2006)

The choice of selective insecticides is an important step to conserve populations of beneficial species in IPM systems. Many pyrethroids are known to have a broad-spectrum activity on a large variety of herbivores and natural enemies (Casida et al., 1983). In contrast, systemic insecticides and their metabolites are claimed to be fairly safe for beneficials, because they are quickly absorbed from the plant surface into the tissue, thereby minimizing detrimental effects on beneficial insects (Stapel et al., 2000, Tomizawa \& Casida, 2005). It has been 


\section{Chapter IV}

reported in the literature that thiacloprid has no persistent effect on the egg parasitoid Trichogramma cacoeciae and Encarsia formosa (Schuld \& Schmuck, 2000; Richter, 2006).

Reduction of parasitism of cabbage stem weevil larvae after application of lambdacyhalothrin ranged between $6.5 \%$ and $10.4 \%$ (Klukowski et al., 2006). However, in our study the level of parasitism was not increased in plants treated with thiacloprid as compared to lambda-cyhalothrin.

Another approach for increasing the selectivity of pesticides is the application of reduced dose rates (Poehling, 1989; Longley et al., 1997; Booth et al., 2007). Although reduced dose rates may provide only partial control of the primary pests, they can contribute substantially to conservation of natural enemies (Ripper, 1956). It has been proved in various studies that reduced rates of insecticides can provide sufficient control of pests (Ripper, 1956; Poehling, 1989; Acheampong \& Stark, 2004; Booth et al., 2007). In our study, reduced dose rates of lambda-cyhalothrin and thiacloprid did not increase the parasitism by $T$. obscurator and $T$. fulvipes as compared to full dose rates. In plants treated with the full dose of thiacloprid and lambda-cyhalothrin, the level of parasitism was even slightly higher than at 50\% reduced dose rates. This may have resulted from stimulatory effects of low-level residuals of insecticides on surviving parasitoids which might have induced hyperactivity of the tested species, thereby increasing the level of parasitism. A short-term benefit of hyperactivity on host finding and oviposition has been suggested by Rafalimanana et al. (2002) when exposing the parasitoid Leptopilina heterotoma to sublethal doses of chlorpyrifos. The parasitoid Aphidius rhopalosiphi groomed more actively and rested less frequently on deltamethrin residues than on insecticide-free plants (Longley \& Jepson, 1996b). On plants treated with permethrin the parasitoid Diaeretiella rapae spend a greater proportion of their time walking, which may be due to the locomotory stimulation by the insecticide (Jiu \& Waage, 1990). Hyperactivity of insects has also been observed by other authors following application of insecticides (Wiles \& Jepson, 1994; Bayley \& Baatrup, 1996; Umoru et al., 1996; Singh et al., 2001; Prasifka et al., 2008). This effect may be due to amplification of stimulus perception by continued firing of synapses (Rafalimanana et al., 2002).

In addition to insecticide effects, the level of parasitism can also be affected by responses of parasitoids to host density. In literature reviews examining the impact of host density on parasitism rates, $48-66 \%$ of studies provided evidence for density dependence, and in about half of these there was direct rather than inverse density dependence (Lessells, 1985; Stiling, 1987; Walde \& Murdoch, 1988). In our study, the timing of insecticide treatment was related to the period just before and during the main activity of adult parasitoids. In order to 


\section{Chapter IV}

guarantee a sufficiently high infestation of host larvae for analyses of parasitim, treatments were applied 3-4 weeks following the main oviposition period of the Ceutorhynchid stem weevils. As the number of endophagous stem weevil larvae per plant was only little reduced by any of the insecticide applications, parasitism was not influenced by density-dependence. The exposure of nontarget insects to residuals of contact insecticides is influenced by the persistence and distribution of the chemical compound within the crop canopy and by the foraging behaviour and vertical distribution of the insect species. In our study, significantly higher numbers of $T$. fulvipes and T. obscurator were caught in yellow water traps placed at ground level than at the flower level. A higher abundance of parasitoids attacking the stem weevils on leaves and stems of oilseed rape was also observed by Nitzsche (1998). This vertical distribution of adult parasitoids within the crop may have provided a behavioural refuge from the insecticide sprays and residues. Studies using fluorescence spray tracers showed that the pesticide deposition in crops of oilseed rape declined from the top of the canopy to the ground level (Goltermann, 1995). The deposition of insecticides in dense crops was only $18 \%$ close to the soil level, whereas $44.5 \%$ of the dose applied was deposited down to soil level in thin oilseed rape crops (Goltermann, 1995). This effect is influenced by application rates and spray volumes, environmental conditions, growth stage and crop density (Cilgi \& Jepson, 1992). Reduced side effects of insecticides on natural enemy populations have also been observed when these were applied in the late-whorl stage of maize as compared to the mid-whorl stage. Plants in the late-whorl stage reduced the spray penetration, thereby providing a better physical refuge within the crop (Armenta et al., 2003).

Adult parasitoids responded to insecticide application by changing their dispersal behaviour. Emigration flights of $T$. fulvipes and T. obscurator from the insecticide treated field were more frequent than immigration flights, whereas in the untreated field immigration flights prevailed during the total observation period. Adults of T. fulvipes and T. obscurator recolonized the treated field about one week post treatment. Significantly higher numbers of emigration flights from treated plots following insecticide application indicated repellent effects on adult parasitoids. This was confirmed by the dual-choice tests in the laboratory: fresh residues of thiacloprid on oilseed rape leaves were repellent to T. obscurator (Neumann \& Ulber, pers. comm.). However, no repellency was found on two days old residues of thiacloprid. In contrast, residues of lambda-cyhalothrin did not significantly change the residence time of $T$. obscurator on treated oilseed rape leaves (Neumann \& Ulber, pers. comm.). 


\section{Chapter IV}

A similar pattern of reinvasion of oilseed rape plots following the decline of insecticide activity was also found with Trichomalus perfectus when exposed to triazophos residues (Murchie et al., 1997). Similarly, residues of fenvalerate, pirimicarb and deltamethrin on winter wheat caused a temporally limited decrease of the activity of aphid parasitoids (Borgemeister, 1992; Longley et al., 1997). Application of carbamate, pyrethroid and organosphosphate insecticides resulted in a reduced abundance of insect natural enemies for a period of 8 to 15 days (Armenta et al., 2003). Following application of tau-fluvalinate and lambda-cyhalothrin, the abundance of $T$. obscurator and $T$. fulvipes was reduced even two weeks after the treatment as compared to untreated winter oilseed rape plots (Klukowski et al., 2006). The longer avoidance of parasitoids following treatment compared to our study may be due to the larger plots size ( 30 x 30 meter).

Rapid re-invasion of insecticide treated plots by parasitoids can be due to small experimental plots (Brown, 1989; Jepson, 1989; Cilgi \& Jepson, 1992). This is particularly the case in parasitoids showing a high dispersal ability (Smart et al., 1989). Because of the rapid reinvasion following insecticide treatment, small plots are only suitable for short-term scale monitoring studies (Jepson, 1989). This so called "horizontal recruitment" may be influenced by landscape characteristics, (Thies \& Tscharntke, 1999; Zaller et al., 2009), pesticide drift into adjacent non-target areas, (Langhof, 2005), plant stage (Winfield, 1963) and availability and distribution of the prey (Waage, 1989). To reduce the impact of recolonisation of parasitoids in studies on long-term effects of insecticides, large scale plots are needed.

The level of parasitism of stem mining weevils was not significantly reduced by insecticide treatments, therefore insecticide application and protection of parasitoids is possible. Measures aimed to protect parasitoids, such as application of systemic insecticides, reduction of dose rates and early spraying before immigration of parasitoids into the oilseed rape crop, did not increase parasitism.

\section{References}

ALFORD, D. V., MURCHIE, A. \& WILLIAMS, I. H. (1992). Observation on the impact of standard insecticide treatments on Trichomalus perfectus, a parasitoid of seed weevil on winter oilseed rape in the UK. IOBC/wprs Bulletin 18, 122-126.

Alford, D. V., NILSSON, C. \& UlbER, B. (2003). Insect pests of oilseed rape crops. Chapter 2 In: D.V. Alford (ed) Biocontrol of Oilseed Rape Pests. Blackwell, Oxford, UK, 9-41.

Armenta, R., Martínez, A. M., Chapman, J. W., Magallanes, R., Goulson, D., Caballero, P., Cave, R. D., Cisneros, J., Valle, J., Castillejos, V., Penagos, D. I., GARCía, L. F. \& WiLLIAMS, T. (2003). Impact of a Nucleopolyhedrovirus Bioinsecticide and Selected Synthetic Insecticides on the Abundance of Insect Natural 
Enemies on Maize in Southern Mexico. Journal of Economic Entomology 96, 649661.

BAYLEY, M. \& BAATRUP, E. (1996). Pesticide uptake and locomotor behaviour in the woodlouse: an experimental study employing video tracking and ${ }^{14} \mathrm{C}$-labelling. Ecotoxicology 5, 35-45.

Booth, L. H., Wratten, S. D. \& P.KehrLi. (2007). Effects of reduced rates of two insecticides on enzyme activity and mortality of an aphid and its lacewing predator. Journal of Economic Entomology 100, 11-19.

BORGEMEISTER, C. (1992). Primär-und Hyperparasitoiden von Getreideblattläusen: Interaktionen und Beeinflussung durch Insektizide. Agrarökologie 3.

BROwn, K. C. (1989). The design of experiments to assess the effects of pesticides on beneficial arthropods in orchards: Replication verus plot size. In: Jepson P.C. (Ed.), Pesticide and Non-target Invertebrates. Intercept, Wimborne., 71-93.

BRunNer, J. F., Dunley, J. E., DoERR, M. D. \& BEERS, E. H. (2001). Effect of Pesticides on Colpoclypeus florus (Hymenoptera: Eulophidae) and Trichogramma platneri (Hymenoptera: Trichogrammatidae), Parasitoids of Leafrollers in Washington. Journal of Economic Entomology 94, 1075-1084.

CASida, J. E., GAMmON, D. W., GLiCKMAN, A. H. \& LAWRENCE, L. J. (1983). Mechanism of Selective Action of Pyrethroid Insecticides. Annual Review Pharmacology Toxicology 23, 413-438.

CiLgi, T. \& JEPSON, P. C. (1992). The use of tracers to estimate the exposure of beneficial insects to direct pesticide spraying in cereals. Annals of Applied Biology 121, 239-247.

CRofT, B. A. \& A.W.Brown. (1975). Responses of arthropod natural enemies to insecticides. Annual Reviews Entomology 20, 285-335.

DECHERT, G. \& ULBER, B. (2004). Interactions between the stem-mining weevils Ceutorhynchus napi Gyll. and Ceutorhynchus pallidactylus (Marsh.) (Coleoptera: Curculionidae) in oilseed rape. Agricultural and Forest Entomology 6, 193-198.

GOLTERMANN, S. (1995). Nützlingsschonender Insektizideinsatz im Winterraps? Raps 13, 153-154.

HANSEN, L. M. (2003). Insecticide-resistant pollen beetles (Meligethes aeneus F) found in Danish oilseed rape (Brassica napus L) fields. Pest Management Science 59, 10571059.

Hokkanen, H., Husberg, G.-B. \& SÖDERBlOM, M. (1988). Natural enemy conservation for the integrated control of the rape blossom beetle Meligethes aeneus F. Annales Agriculturae Fenniae 27, 281-294.

HORSTMANN, K. (1971). Revision der europäischen Tersilochinen I (Hym.: Ichneumonidae). Veröffentlichung der Zool. Staatssammlung München 15, 47-138.

HoRSTMANN, K. (1981). Revision der europäischen Tersilochinen II (Hymenoptera, Ichneumonidae). Spixiana Suppl. 4, 1-76.

Iwata, Y., MacConnell, J. G., Flor, J. E., Putter, I. \& Dinoff, T. M. (1985). Residues of Avermectin $\mathrm{B}_{1}$ a on and in Citrus Fruits and Foliage. Journal of Agricultural Food Chemistry 33, 467-471.

JEPSON, P. C. (1989). The temporal and spatial dynamics of pesticide side-effects on nontarget invertebrates. In: Jepson P.C. (Ed.), Pesticide and Non-target Invertebrates. Intercept, Wimborne., 95-127.

JIU, G. D. \& WAAGE, J. K. (1990). The effect of insecticides on the distribution of foracing parasitoids, Diaeretiella rapae (Hym.: Braconidae) on plants. Entomophaga 35, 4956.

Johnen, A., Williams, I. H., Ferguson, A. W., Büchs, W., Klukowski, Z., Luik, A., NILSSON, C. \& UlBER, B. (2006). MASTER: construction of phenological models of key parasitoids in Europe and prospects for spray windows compatible with their 
conservation in winter oilseed rape. CD-Rom Proceedings of the International Symposium "Integrated Pest Management in Oilseed Rape Pests", Goettingen, Germany, 3-5 April 2006.

JOURDHEUIL, P. (1960). Influence de quelque facteurs écologique sue les fluctuations de population d'une biocé nose parasitaire. Ann. Epiph. 11, 445-658.

KLUKOWSKI, Z. (2006). The impact of insecticide application and timing on parasitoid activity and levels of parasitism. CD-Rom Proceedings of the International Symposium "Integrated Pest Management in Oilseed Rape Pests", Goettingen, Germany, 3-5 April 2006.

KLUKOWSKI, Z., TwARDOWSKI, J. \& IRZYKOWICZ, M. (2006). Subsequent effect of taufluvalinate (Maverik) and lambda-cyhalothrin (Karate) pyrethroids on the activity of carabid beetles (Coleoptera: Carabidae) in winter oilseed rape. IOBC/wprs Bulletin 29, 125-130.

LANGHOF, M. (2005). Insecticide drift from agricultural spraying into field margin habitats and its effect on non-target arthropods: residual toxicity, impact on populations, and recolonisation processes. Dissertation University Hannover, Germany.

LESSELLS, C. M. (1985). Parasitoid foraging: Should parasitism be density dependent? Journal of Animal Ecology 54, 27-41.

LONGLEY, M. \& JEPSON, P. C. (1996a). Effects of honeydew and insecticide residues on the distribution of foraging aphid parasitoids under glasshouse and field conditions. Entomologia Experimentalis et Applicata 81, 189-198.

LONGLEY, M. \& JEPSON, P. C. (1996b). The influence of insecticide residues on primary parasitoids and hyperparasitoid foraging behaviour in the laboratory. Entomologia Experimentalis et Applicata 81, 259-269.

LONGLEY, M., JEPSON, P. C., IZQUIERDO, J. \& SOTHERTON, N. (1997). Temporal and spatial changes in aphid and parasitoid populations following applications of deltamethrin in winter wheat. Entomologia Experimentalis et Applicata 83, 41-52.

MenZler-HokKanen, I., HoKKANen, H. M. T., BÜChS, W., KluKowski, Z., LuIK, A., NiLSSON, C., UlBER, B. \& WILLIAMS, I. H. (2006). Insect problems in European oilseed rape cultivation, and how to deal with them: the OSR framers`perspective. IOBC/wprs Bulletin 29, 91-94.

MUELLER;A., HEIMBACH,U. \& THIEME,T. (2008). Pyrethroid sensitivity monitoring in Germany of oilseed rape pest insects other than pollen beetle. EPPO Bulletin 38, 8590.

MuRCHIE, A. K., WILliAMS, I. H. \& ALFORD, D. V. (1997). Effects of commercial insecticide treatments to winter oilseed rape on parasitism of Ceutorhynchus assimilis Paykull (Coleoptera: Curculionidae) by Trichomalus perfectus (Walker) (Hymenoptera: Pteromalidae). Crop Protection 16, 199-202.

NitzSCHE, O. (1998). Auftreten und Effizienz von Parasitoiden als natürliche Gegenspieler von Schadinsekten im Winterraps unter besonderer Berücksichtigung unterschiedlicher Bodenbearbeitungsmaßnahmen nach Winterraps. PhD thesis, Georg-August-University of Goettingen, Germany.

POEHLING, H. M. (1989). Selective application strategies for insecticides in agricultural crops. In: Jepson P.C. (Ed.), Pesticide and Non-target Invertebrates. Intercept, Wimborne., 151-175.

PrasifKA, J. R., LOPEZ, M. D., Hellmich, R. H. \& PrasifKA, P. L. (2008). Effects of insecticide exposure on movement and population size estimates of predatory ground beetles (Coleoptera: Carabidae). Pest Management Science 64, 30-36.

RAFAlimanana, H., KAiSER, L. \& DelPUECH, J.-M. (2002). Stimulating effects of the insecticide chlorpyrifos on host searching and infestation efficacy of a parasitoid wasp. Pest Management Science 58, 321-328. 
RICHTER, E. (2006). A method to prove long term effects of neonicotinoids on whitefly parasitoids. IOBC/wprs Bulletin 29, 61-65.

RIPPER, W. E. (1956). Effect of pesticides on balance of arthropod populations. Annual Reviews Entomology 1, 403-438.

SCHULD, M. \& SCHMUCK, R. (2000). Effects of Thiacloprid, a New Chloronicotinyl Insecticide, On the Egg Parasitoid Trichogramma cacoeciae. Ecotoxicology 9, 197205.

SEDIVY, J. (1983). Tersilochinae as parasitoids of insect pests of winter rape (Hymenoptera: Ichneumonidae). Cont. Am. Ent. Inst. 20, 266-276.

SinGH, S. R., WALTERS, K. F. A. \& PORT, G. R. (2001). Behaviour of the adult seven spot ladybird, Coccinella septempunctata (Coleoptera: Coccinellidae), in response to dimethoate residue on bean plants in laboratory. Bulletin of Entomological Research 91, 221-226.

Smart, L. E., Stevenson, J. H. \& W Alters, J. H. H. (1989). Development of the trial methology to assess short-term effects of pesticides on beneficial arthropods in arable crops. Crop Protection 8, 169-180.

StAPEL, J. O., CORTESERO, A. M. \& LEWIS, W. J. (2000). Disruptive Sublethal Effects of Insecticides on Biological Control: Altered Foraging Ability and Life Span of a Parasitoid after Feeding on Extrafloral Nectar of Cotton Treated with Systemic Insecticides. Biological Control 17, 243-249.

STILING, P. D. (1987). The frequency of density dependence in insect host-parasitoid systems. Ecology 68, 844-856.

THIES, C. \& TSCHARNTKE, T. (1999). Landscape structure and biological control in agroecosystems. Science 285, 893-895.

TOMIZAWA, M. \& CASIDA, J. E. (2005). Neonicotinoid Insecticide Toxicology: Mechanism of Selective Action. Annual Review Pharmacology Toxicology 45, 247-268.

UlBer, B. (2003). Parasitoids of Ceutorhynchid stem weevils. In: D.V. Alford (ed) Biocontrol of Oilseed Rape Pests. Blackwell Publishing, Oxford, UK, 87-95.

Ulber, B., NitzSCHE, O. \& WEDEMEYER, R. (2006). Phenology of tersilochine parasitoids in Germany and prospects for spray windows compatible with their conservation. $C D$ Rom Proceedings of the International Symposium "Integrated Pest Management in Oilseed Rape Pests", Goettingen, Germany, 3-5 April 2006.

UMORU, P. A., POWELL, W. \& ClARK, S. J. (1996). Effect of pirimicarb on the foraging behaviour of Diaeretiella rapae (Hymenoptera: Braconidae) on host-free and infested oilseed rape plants. Bulletin of Entomological Research 86, 193-201.

WAAGE, J. (1989). The population ecology of pest-pesticide-natural enemy interactions. In: Jepson P.C. (Ed.), Pesticide and Non-target Invertebrates. Intercept, Wimborne., 8193.

WALDE, S. J. \& MuRDOCH, W. W. (1988). Spatial density dependence in parasitoids. Annual Review Entomology 33, 441-466.

WEGOREK, P. \& ZAMOJSKA, J. (2006). Resistance of pollen beetle (Meligethes aeneus F.) to pyrethroids, chloronicotinyls and organophosphorous insecticides in Poland. IOBC/wprs Bulletin 29, 135-140.

WILES, J. A. \& JEPSON, P. C. (1994). Sub-lethal effects of deltamethrin residues on the within-crop behaviour and distribution of Coccinella septempunctata. Entomologia Experimentalis et Applicata 72, 33-45.

WILLIAMS I.H. (2004). Integrating parasitoids into management of pollen beetle on oilseed rape. Agronomy Research 4, 465-470.

WINFIELD, A. L. (1963). A study on the effects of insecticides on parasites of larvae of blossom beetles (Meligehtes aeneus F., Coleoptera: Nitidulidae). Entomologia Experimentalis et Applicata 6, 309-318. 
Zaller, J. G., Moser, D., Drapela, T., SchmÖGer, C. \& Frank, T. (2009). Parasitism of stem weevils and pollen beetles in winter oilseed rape is differentially affected by crop management and landscape characteristics. BioControl 54, 505-514. 


\section{Impact of insecticide treatments on mortality, parasitism and host location of parasitoids attacking pollen beetle larvae}

\section{Abstract}

The pollen beetle, Meligethes aeneus $\mathrm{F}$., is one of the most important pests on oilseed rape in Europe. To prevent damage to the crop several insecticide treatments are applied each year. The extensive use of pyrethroid insecticides has resulted in resistance of pollen beetles to this chemical group. In addition, extensive use of insecticides can cause harmful, undesirable side effects on natural enemies. Eggs and larvae of pollen beetles are commonly parasitized by the specialist endoparasitoids Phradis interstitialis and Tersilochus heterocerus in Europe.

In field experiments, the effect of the contact pyrethroids lambda-cyhalothrin and taufluvalinate and the systemic neonicotinoid thiacloprid on the level of parasitism of pollen beetle larvae was investigated in 2006 to 2008. Insecticides were applied before and after the main immigration of parasitoids into the oilseed rape field, at both the recommended field dose rate and at $50 \%$ reduced dose rate. In laboratory assays, the effects of insecticide residues on mortality and host location of $P$. interstitialis and $T$. heterocerus were studied.

In field experiments, the application of thiacloprid and tau-fluvalinate significantly reduced the level of parasitism compared to untreated plots, while treatments with lambda-cyhalothrin had no significant effect on parasitism. Insecticide dosage and time of application did not significantly affect the parasitism. Parasitism of artificially exposed pollen beetle larvae was only reduced for 3 to 5 days post treatments and then increased again.

In laboratory dose-response tests, lambda-cyhalothrin was more toxic to $P$. interstitialis and $T$. heterocerus than tau-fluvalinate and thiacloprid. In two-choice tests, female P. interstitialis spent significantly less time foraging on buds treated with thiacloprid and tau-fluvalinate than on untreated buds, indicating a repellent effect of these insecticides. On buds treated with lambda-cyhalothrin, the residence time was not reduced compared to untreated buds. Although lambda-cyhalothrin proved to be more toxic, no effect on levels of parasitism of pollen beetle larvae was observed in the field. For conservation of parasitoids, the choice of selective insecticides can be more appropriate than the application of reduced dose rates or using temporal spray windows. This study demonstrated that in addition to toxicity of insecticides, behavioural effects of insecticides need to be considered. Repellency of insecticides has potential to reduce parasitism as well. Strategies improving survival of natural enemies, which might reduce the need for chemical control of pollen beetles are discussed. 


\section{Introduction}

The pollen beetle, Meligethes aeneus F. (Col., Nitidulidae) is one of the most damaging pests of oilseed rape in Europe. Adult pollen beetles migrate to the crop when the temperature rises above $12-15^{\circ} \mathrm{C}$ in spring (Nilsson 2003). Females oviposite into buds that are at least 2-3 mm large. The adults and the two larval instars feed on pollen in buds and flowers. Mature larvae drop to the soil for pupation; new-generation beetles emerge 40 - 50 days later (Nilsson, 1988). There is only one generation per year. New-generation beetles overwinter in woodland litter (Nilsson \& Andreasson, 1987). The oilseed rape crop is most susceptibel to pollen beetles during the early bud stage and becomes less sensitive as the flowers develop (Alford et al., 2003). Commonly one to four insecticide sprays are necessary in order to avoid excessive crop losses (Menzler-Hokkanen et al., 2006). The extensive use of pyrethroids has led to widespread resistance to these insecticides in many European countries, including Germany (Heimbach et al., 2006), Denmark (Hansen, 2003), France (Ballanger et al., 2007) and Poland (Wegorek \& Zamojska, 2006). Consequently, strategies of reduced insecticide usage, as manifested in IPM programs (Kogan, 1998), become more important. Integration of natural enemies is one important step. In Central Europe, the larval endoparasitoids Phradis interstitialis (Hym., Ichneumonidae) and Tersilochus heterocerus (Hym., Ichneumonidae) are the most important natural enemies of pollen beetle (Williams 2006). The level of parasitism by these parasitoids ranges from $10 \%$ to $50 \%$, occasionally exceeding $80 \%$ (Nitzsche, 1998; Büchi, 2002; Nilsson, 2003).

Adult parasitoids migrate to the oilseed rape crop in spring, mainly during flowering. They seek their hosts in the buds and flowers of oilseed rape to oviposit into the eggs or larvae. Female $P$. interstitialis parasitizes primarily pollen beetle eggs within green buds (Osborn, 1960; Winfield, 1963; Nilsson, 2003; Jönsson et al., 2005), while female T. heterocerus preferentially search for second instar larvae (Nilsson, 2003).

The first parasitoids occured on the crop of oilseed rape when the cumulative temperaturesum exceeded 300 day-degrees (Jourdheuil, 1960; Hokkanen et al., 1988); this is commonly coinciding with insecticide applications against pollen beetle. Avoidance of insecticide use during the period of main activity in the crop might have potential for safe integration of insecticide use with conservation of parasitoids.

An important component for maintaining populations of beneficial species in IPM is the use of selective pesticides and selective application of insecticides. Selectivity may be achieved by using reduced dose rates (Booth et al., 2007). In studies conducted in cereals reduced rates of insecticides were found to be sufficiently effective against aphids, while conserving natural 
enemies (Poehling, 1989; Wiles \& Jepson, 1995; Booth et al., 2007). Application of insecticide compounds that are selective to pest species can help to conserve parasitoids in the crop. The broad-spectrum pyrethroids cyfluthrin and lambda-cyhalothrin are highly toxic to honey-bees, while the selective pyrethroid tau-fluvalinate can be used to control parasitic mites inside honey bee colonies (Johnson et al., 2006). Further, systemic insecticides and their metabolites are claimed to be fairly safe for beneficial insects, because they are quickly absorbed from the plant surface into the tissue, thereby minimizing the effect as contact insecticides to natural enemies foraging on the plant surface (Stapel et al., 2000; Tomizawa \& Casida, 2005).

Adult parasitoids can be exposed to insecticide spray droplets (Croft \& Brown, 1975; Jepson, 1989), to dried residues when foraging on plant surface (Longley \& Jepson, 1996a; Longley \& Jepson, 1996b) and through feeding on contaminated water droplets and nectar (Longley \& Jepson, 1996a). Various effects of insecticides on parasitoids of pollen beetle have been found in earlier studies. The abundance of $P$. morionellus and $T$. heterocerus was reduced after application of organochlorines (Winfield, 1963). The pyrethroids deltamethrin and alphacypermethrin were less harmful to P. morionellus than the organophosphate fenitrothion (Hokkanen et al., 1988). Following application of tau-fluvalinate the number of Phradis spp. was reduced for three days, while lambda-cyhalothrin caused a reduction of $P$. interstitialis until the end of its activity period (Klukowski et al. 2006). Application of various insecticides (azinphos-azinphosmethyl, methoxychlor, permethrin) during the bud stage did not have any impact on parasitism of pollen beetle larvae compaired to untreated plots. (Nilsson \& Andreasson, 1987).

In addition to increased mortality, sublethal effects of insecticides on the development rate, reproduction, longevity as well as behaviour of parasitoids have been reported by Desneux et al. (2007). Parasitoids use herbivore-induced plant volatiles for host finding (Vinson, 1998). Insecticides can interrupt host searching by masking attractive plant odours and/or interference with the receptors that perceive the odour (Haynes, 1988).

The aim of this study was to analyse the effect of two pyrethroids (tau-fluvalinate, lambdacyhalothrin) and a neonicotinoid (thiacloprid) on parasitism of pollen beetle larvae by $P$. interstitialis and T. heterocerus in field experiments. The insecticides were applied either at the full recommended field dose rate or at $50 \%$ reduced rate, both before and after main immigration of parasitoids into the oilseed rape crop. The laboratory experiments focused on the effect of insecticides on mortality and host searching behaviour of these parasitoids. 


\section{Material and Methods}

\section{Field experiments}

Field experiments were conducted on crops of oilseed rape close to Goettingen (Germany) in 2006, 2007 and 2008. The field trials were arranged in a randomized block design with four replicated plots per treatment (2006: $24 \mathrm{~m} * 26 \mathrm{~m}, 2007 / 2008: 15 \mathrm{~m} * 16 \mathrm{~m}$ ). In addition to the pyrethroid lambda-cyhalothrin (Karate Zeon, $100 \mathrm{~g}$ a.i./l), the pyrethroid tau-fluvalinate (Mavrik, $240 \mathrm{~g}$ a.i./l) and the neonicotinoid thiacloprid (Biscaya, 240g a.i./l) were tested in 2006 and 2007/2008, respectively. The insecticides were applied at 100\% and 50\% of the recommended field dose rate with 240 1/ha of water. The first application was carried out before the main immigration of parasitoids at early flowering ( $\mathrm{BBCH} 61 / 62)$ and the second application at peak activity, at mid to end of flowering (BBCH 65/69). Four plots were kept untreated as control. In total, nine different treatments were compared in each experiment

\section{Level of parasitism}

In 2006 and 2007, larvae of M. aeneus were collected in May from buds and flowers (Williams et al., 2003) of 20-25 plants per plot. In 2008, samples were collected by beating the larvae from the main raceme into a tray (Williams et al., 2003). The number of larvae sampled varied between 30 and 465 larvae/treatment, the mean number of dissected larvae was 251. Larvae were stored in $70 \%$ Ethanol and later dissected in a drop of water under a stereo microscope The larvae were cut off using a fine needle, and the body contents were teased apart to detect parasitoids eggs or larvae.

\section{Semifield experiment}

In 2006 and 2007, oilseed rape plants were artificially infested by eggs and larvae of pollen beetle and exposed to parasitisation in the field plots. Two adult pollen beetle females and males were caged for 3 days on the main raceme of potted oilseed rape plants for oviposition in the greenhouse. Hatching larvae were reared up to the $2^{\text {nd }}$ instar. Following the late insecticide application three infested plants were positioned randomly in each plot for 2 and 3 days. In 2006 and 2007 plants were removed after 3, 6 and 9 days and after 4, 7 and 10 days, respectively, following insecticide application and new plants were exposed in each plot for parasitisation. Pollen beetle larvae were collected from each plant and stored in $70 \%$ Ethanol for dissection as described above. 


\section{Chapter V}

\section{Yellow water traps}

The phenology of parasitoids was monitored by using yellow water traps $(33 \times 26 \times 6 \mathrm{~cm})$ that were filled with 1.5 litres of water and a few drops of detergent. Four traps were exposed 10 meter from field edges and were emptied three times per week from March till June.

The vertical distribution of parasitoids within the crop canopy was determined on an untreated oilseed rape field by using eight yellow water traps. For trapping parasitoid species foraging on the level of buds and flowers trap height was raised to the top of the canopy as the crop grew; for parasitoids foraging on stems and leaves four traps were placed at ground level. Traps were emptied weekly during the main period of parasitoid activity from 17 April to 19 May 2009. All insects caught were stored in $70 \%$ Ethanol and later identified by using keys of Horstmann $(1971 ; 1981)$.

\section{Traps at soil level}

The adult parasitoids and pests that were killed directly by insecticide application were collected by white trays $(13 \times 18 \mathrm{~cm})$ placed below the canopy at ground level. Twenty trays were exposed randomly in all treated and untreated plots. Twenty-four hours after spraying, the dead parasitoids and pests were counted.

\section{Two-choice test}

Females of $P$. interstitialis used for the two-choice test were caught by sweep netting from an untreated crop of oilseed rape in April/May. They were stored for at least $24 \mathrm{~h}$ in the laboratory until they were used for the experiments. Provisional species-level identifications of live parasitoids were made based on the ovipositor morphology. At the end of the experiment the identification was confirmed by using precise taxonomic characters (Horstmann, 1971, 1981). Field-collected buds infested with eggs and larvae of pollen beetle were treated with full doses of lambda-cyhalothrin, tau-fluvalinate and thiacloprid, respectively, by using a hand sprayer. Treated buds of various residual age (1hour, 3 days, 6 days) and untreated buds were offered $10 \mathrm{~cm}$ apart in a petri dish of $15 \mathrm{~cm}$ diameter to female $P$. interstitialis for parasitisation. Single females were observed for $5 \mathrm{~min}$ and the residence time on the buds was measured. Each treatment was repeated 20 - 30 times.

\section{Toxicity test}

Adult parasitoids collected by sweep-netting from an untreated oilseed rape field were tested for lethal effects of lambda-cyhalothrin, tau-fluvalinate and thiacloprid. The parasitoids were 
stored for $24 \mathrm{~h}$ in a climate chamber at $14{ }^{\circ} \mathrm{C}$ and a photoperiod $12 \mathrm{~L}: 12 \mathrm{D}$. They were provided with oilseed rape flowers and water before using in the glass-vial bioassay. The active ingredients of lambda-cyhalothrin, thiacloprid and tau-fluvalinat were diluted in acetone. Pure acetone was used as control. The dilution $(200 \mu \mathrm{l})$ was pipetted into a glas vial (height $6.5 \mathrm{~cm}$, radius $1.2 \mathrm{~cm}$ ) and rotated. Following evaporation of the aceton the inner surface of the vial was covered homogeneously by insecticide residuals. To establish the dose-mortality relationship, the parasitoids were exposed to seven up to ten different concentrations of the insecticides. Ten parasitoids (60\% P. interstitialis, $40 \%$ T. heterocerus) were released into each vial. Mortality tests were performed at $14{ }^{\circ} \mathrm{C}$ under $12 \mathrm{~L}: 12 \mathrm{D}$. Four replicates were carried out for each concentration of the insecticides. Mortality of adult parasitoids was determined after $5 \mathrm{~h}$.

\section{Statistical analysis}

All data were tested for normal distribution using the non-parametric Kolmogorov-SmirnovTest. ANOVA was performed for normal distributed data; differences between means were evaluated by Tukey-HSD test and LSD-test $(\mathrm{p} \leq 0.05)$. Non-normal distributed data were tested for significant differences $(\mathrm{p} \leq 0.05)$ between insecticide treatments using the MannWhitney-U test. Paired t-tests were used for estimating differences between the vertical distribution of parasitoids. The $\chi^{2}$ - test was used for data of the laboratory experiments. Statistical analysis was done by STATISTICA Version 8. The data obtained from the glassvial bioassays were used for calculation of dose-response-relationships and analyzed by applying the probit model (PoloPlus, LeOra Software).

\section{Results}

\section{Phenology of adult parasitoids}

In 2006, first females of $P$. interstitialis were captured on crops of oilseed rape on 3 May, followed by male $P$. interstitialis and female $T$. heterocerus on 5 May. Male $T$. heterocerus colonized the crop on 10 May. Early insecticide application was conducted nine days before parasitoids colonized the field on 24 April. Late insecticide treatments were applied at peak activity of female $P$. interstitialis on 7 May (Fig 1). Peak activity of female $P$. interstitialis and male P. interstitialis was recorded on 5 May and 8 May, respectively. Peak activity of female $T$. heterocerus and male $T$. heterocerus was found on 8 May and 10 May, respectively (Fig 1). 


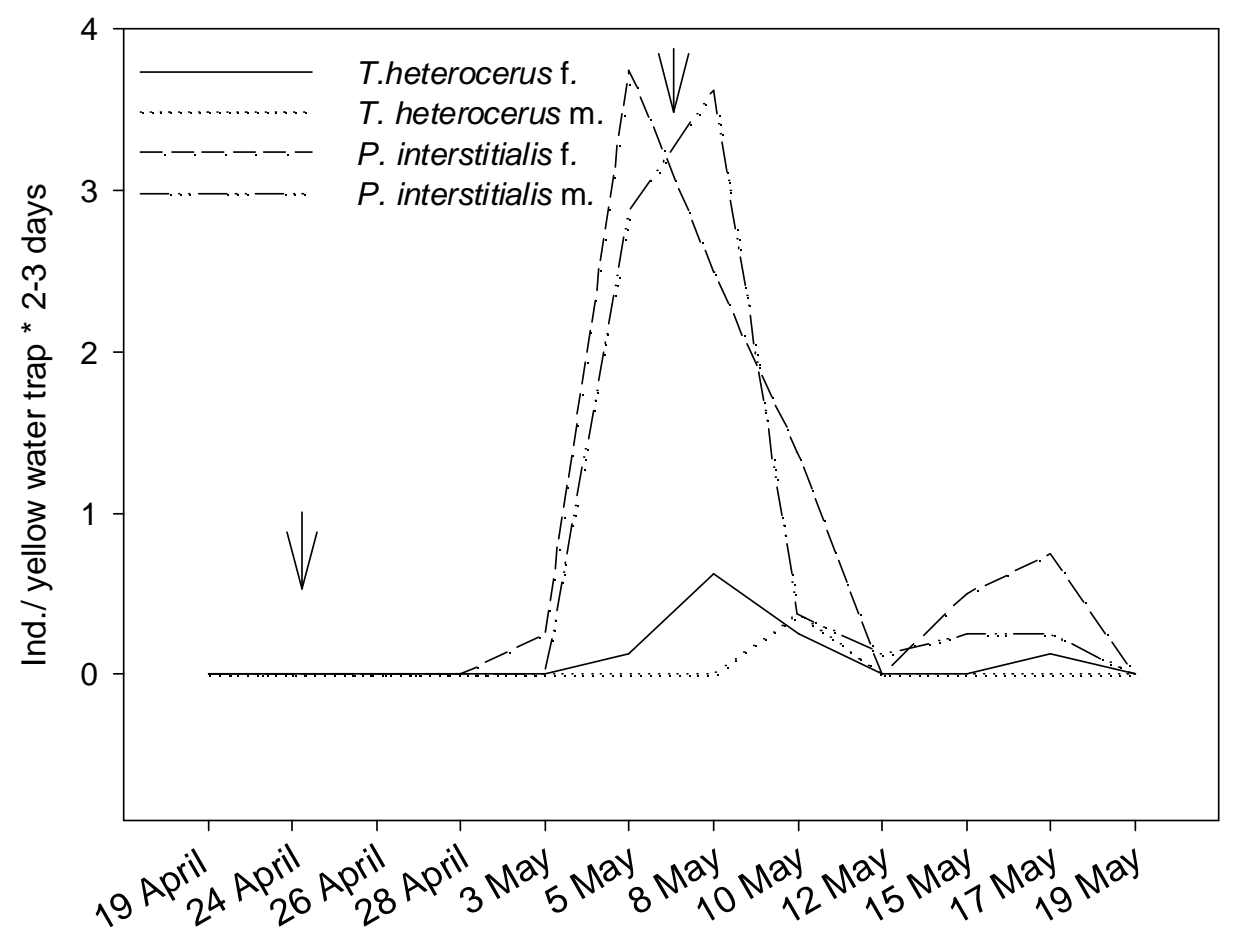

Fig 1: Mean number of adult P. interstitialis and T. heterocerus caught in yellow water traps in the oilseed rape field trial near Goettingen in 2006. $\downarrow=$ date of insecticide application

In 2007, male $P$. interstitialis colonized the oilseed rape crop on 10 April, followed by female P. interstitialis on 16 April and male and female T. heterocerus on 20 and 24 April, respectively. The early application of insecticides was on 13 April, before peak activity while the late treatments were applied following the main immigration on 2 May (Fig 2). Peak activity of male $P$. interstitialis was observed on 10 April, while female $P$. interstitialis was most abundant on 24 and 26 April. Males and females of T.heterocerus were most abundant on 29 April (Fig 2).

In 2008, parasitoids started to colonize the oilseed rape field on 29 April. Insecticides were applied on 23 April and 7 May, respectively (Fig 3). Peak activity of male T. heterocerus was observed on 5 May, while the number of female T. heterocerus peaked on 7 May. The highest number of female and male $P$. interstitialis was caught on 21 April and 29 April, respectively (Fig 3). 


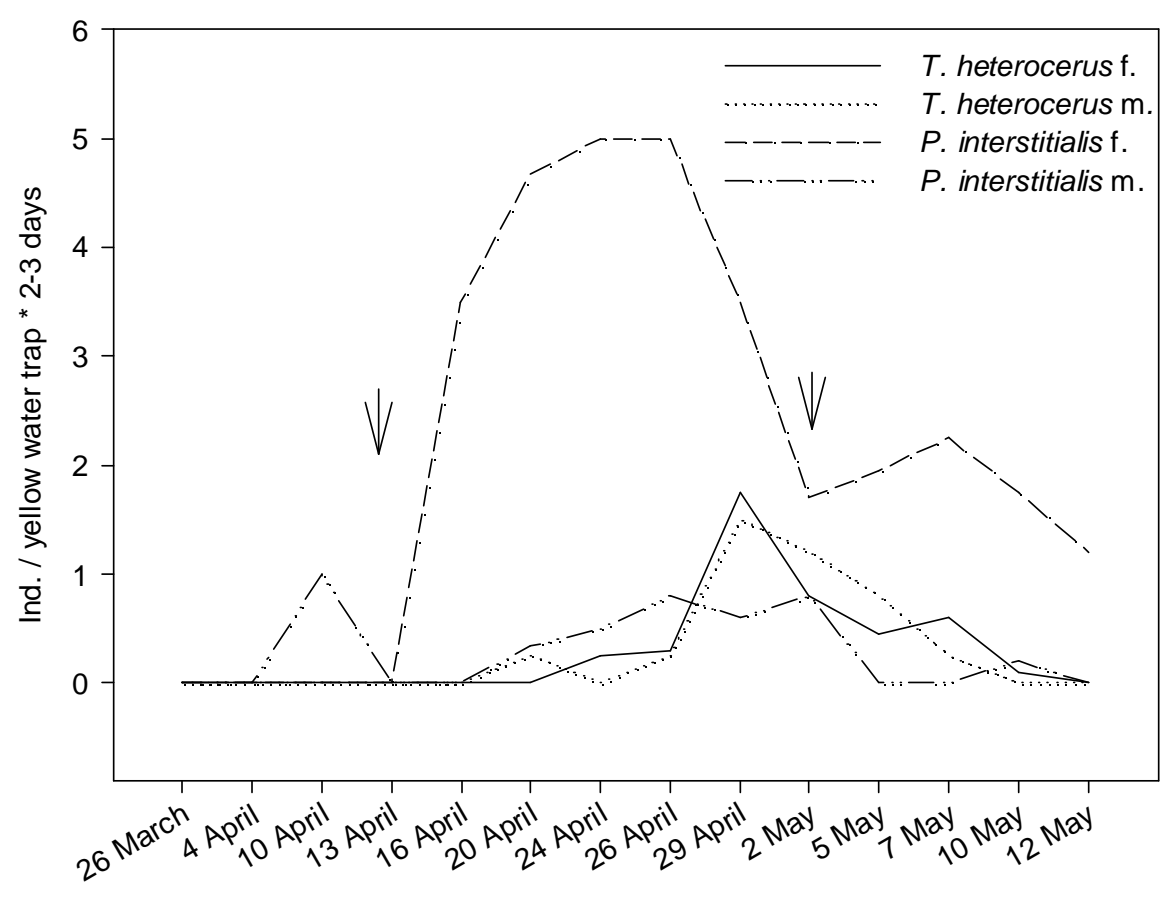

Fig 2: Mean number of adult $P$. interstitialis and $T$. heterocerus caught in yellow water traps in the oilseed rape field trial near Goettingen in 2007. $\downarrow=$ date of insecticide application

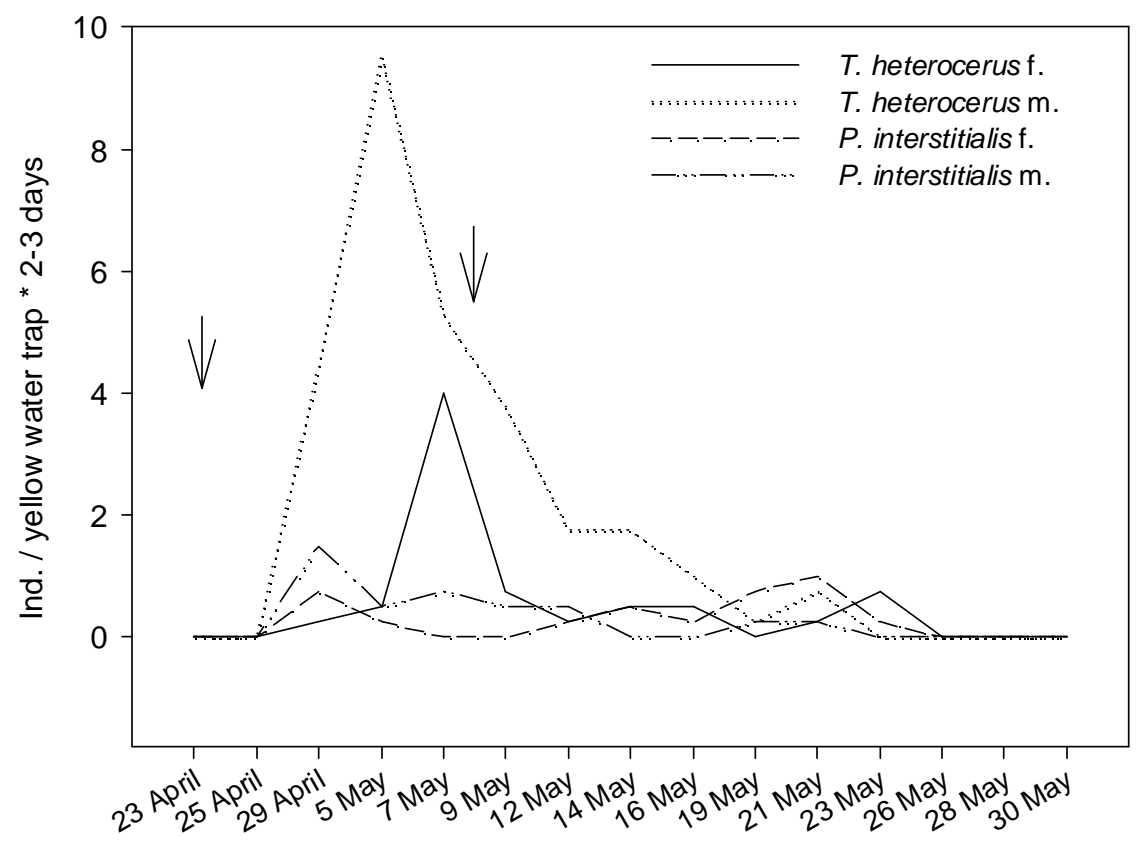

Fig 3: Mean number of adult $P$. interstitialis and T. heterocerus caught in yellow water traps in the oilseed rape field trial near Goettingen in 2008. $\downarrow=$ date of insecticide application 
Abundance and level of parasitism of pollen beetle larvae

In 2006, the insecticide treatments during flowering reduced the mean number of pollen beetle larvae from $4.4 \pm 0.7$ larvae/plant in untreated plots to $1.5 \pm 0.2$ larvae/plant in treated plots. Number of larvae was significantly reduced in plots treated with $50 \%$ tau-fluvalinate during flowering as compared to plots treated with $100 \%$ and $50 \%$ of tau-fluvalinate in bud stage and to untreated plots (Fig 4). In plots treated with $100 \%$ of lambda-cyhalothrin in bud stage significantly more larvae/plant were found compared to plots treated with $50 \%$ taufluvalinate during flowering.

Parasitism of larvae ranged between $8.1 \%$ and $26.5 \%$. The highest level of parasitism was recorded in the untreated plots, while the lowest level of parasitism was found in plots treated with $50 \%$ tau-fluvalinate during flowering. This treatment reduced the level of parasitism by $18.5 \%$ compared to untreated plots. The level of parasitism was reduced in plots treated with lambda-cyhalothrin by $10 \%$ and in plots treated with tau-fluvalinate by $11.8 \%$ compared to untreated plants, but this difference was not significant. Applications in the bud stage and during flowering reduced the level of parasitism by $9.4 \%$ and $12.4 \%$, respectively, compared to untreated plots. Full dose rates decreased parasitism by $9.3 \%$ and $50 \%$ reduced field dose rate by $12.6 \%$, compared to untreated plots. Application of $50 \%$ tau-fluvalinate at flowering reduced the level of parasitism significantly by $10.7 \%$ in contrast to plants treated with both dosages of lambda-cyhalothrin at bud stage. The level of parasitism was positively correlated with the number of larvae/ plant $\left(\mathrm{y}=12.55+1.38, \mathrm{r}^{2}=0.14, \mathrm{~F}=5.4, \mathrm{p}=0.0258, \mathrm{n}=36\right)$. 


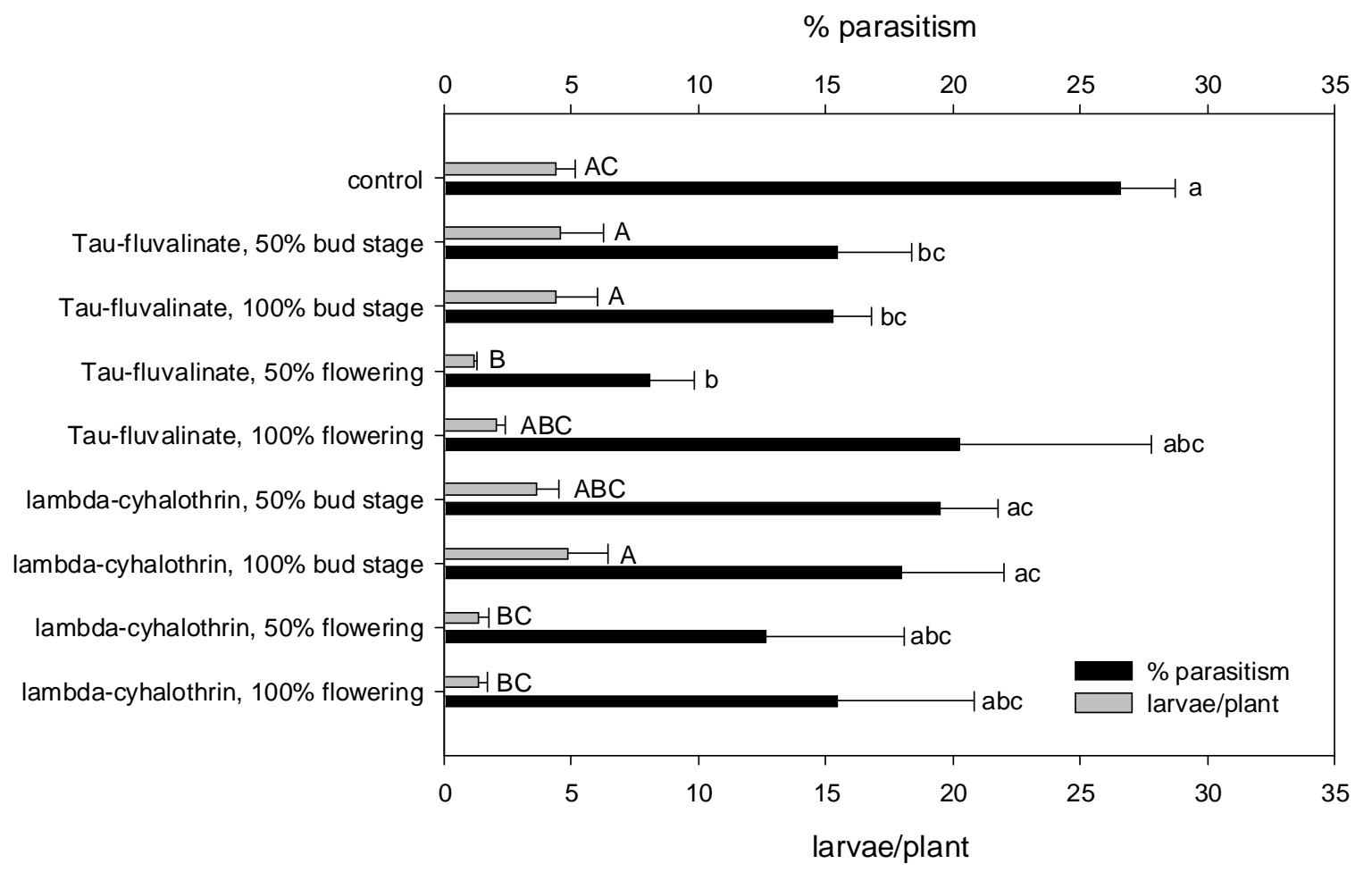

Fig 4: Mean level of infestation (+ SE) by M. aeneus and mean level of parasitism (+ SE) on plants following different insecticide treatments in 2006. Tau-fluvalinate or lambdacyhalothrin, full field dose rate $(100 \%)$ or reduced field dose rate $(50 \%)$, application in bud stage or during flowering. Means followed by the same upper/lower case letters are not significantly different. Larvae/ plant: ANOVA; LSD-test; $\mathrm{n}=36 ; \mathrm{F}=2.2 ; \mathrm{p} \leq 0.05$. Parasitism: ANOVA; LSD-test; $\mathrm{n}=36, \mathrm{~F}=1.5 ; \mathrm{p} \leq 0.05$.

In 2007, the number of pollen beetle larvae per plant was significantly reduced in plots treated with thiacloprid (mean $0.6 \pm 3.5$ larvae/plant) (except 50\% thiacloprid in bud stage) and in plots treated with 50\% lambda-cyhalothrin during flowering (1.1 \pm 0.3 larvae/plant) compared to untreated plots $(3.9 \pm 0.7$ larvae/plant $)$.

The level of larval parasitism did not differ significantly between all insecticide treatments and untreated plots. Average level of parasitism was $29.8 \% \pm 3.1$ (Fig 5). There was no correlation between the number of larvae/plant and the level of parasitism. 


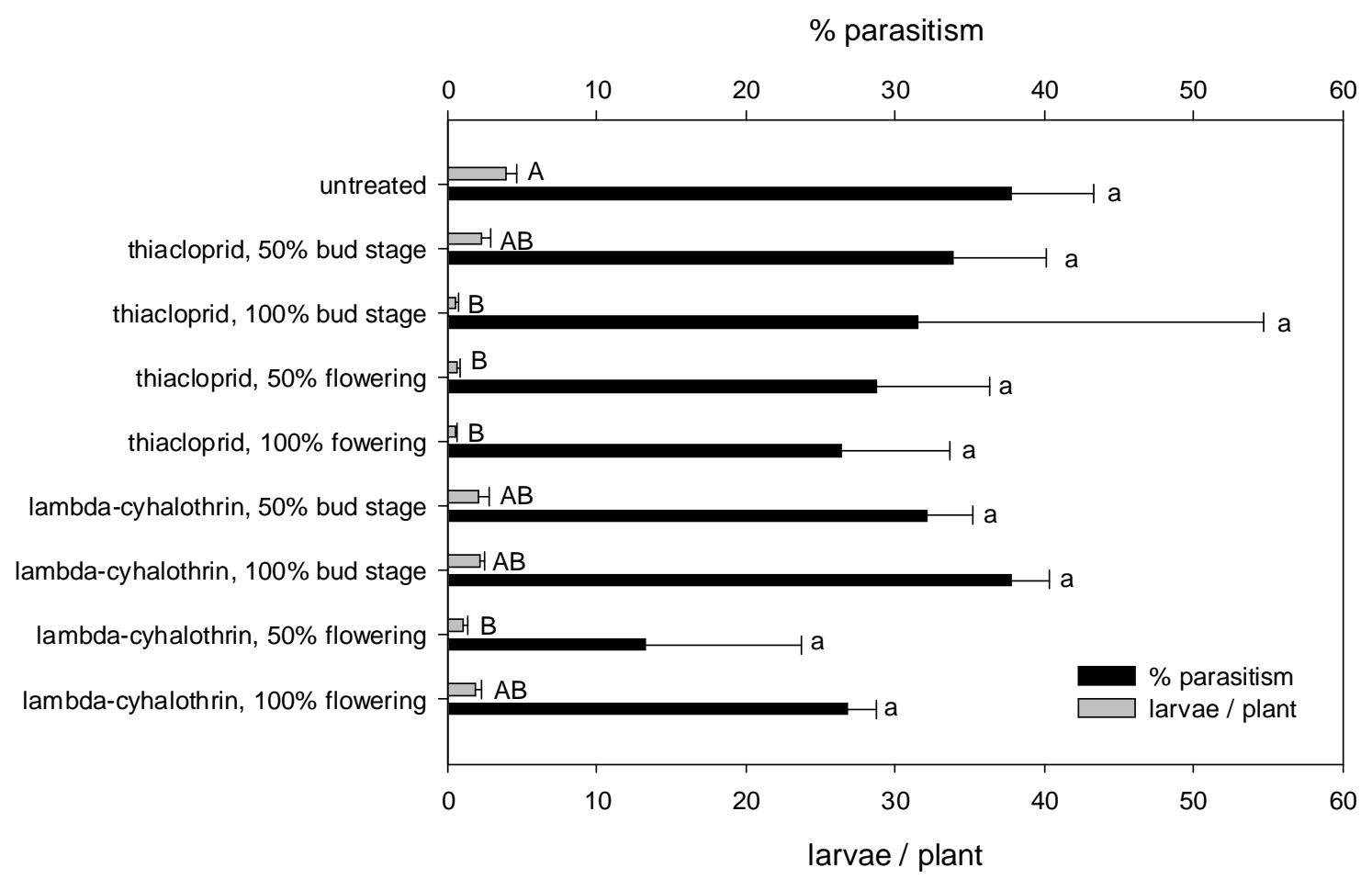

Fig 5: Mean level of infestation (+ SE) by M. aeneus and mean level of parasitism (+ SE) on plants following different insecticide treatments in 2007. Thiacloprid or lambda-cyhalothrin, full field dose rate $(100 \%)$ or reduced field dose rate $(50 \%)$, application in bud stage or during flowering. Means followed by the same upper/lower case letters are not significantly different. Larvae/ plant: ANOVA; Tukey-HSD; $\mathrm{n}=36 ; \mathrm{F}=6.0 ; \mathrm{p} \leq 0.05$. Parasitism: ANOVA; Tukey-HSD; $\mathrm{n}=36, \mathrm{~F}=0.8 ; \mathrm{p} \leq 0.05$.

In 2008, the abundance of pollen beetle larvae per plant showed no significant difference between insecticide-treated and untreated plots. The level of parasitism ranged between 25.9 $\%$ and $55.2 \%$. Parasitism was significantly reduced in plots treated with thiacloprid (except $50 \%$ thiacloprid in bud stage) compared to untreated plots. In comparison to plots treated with $50 \%$ lambda-cyhalothrin in bud stage and to untreated plots, a significantly lower level of parasitism was found in plots treated with the full field dose rate of thiacloprid during flowering (Fig 6). 


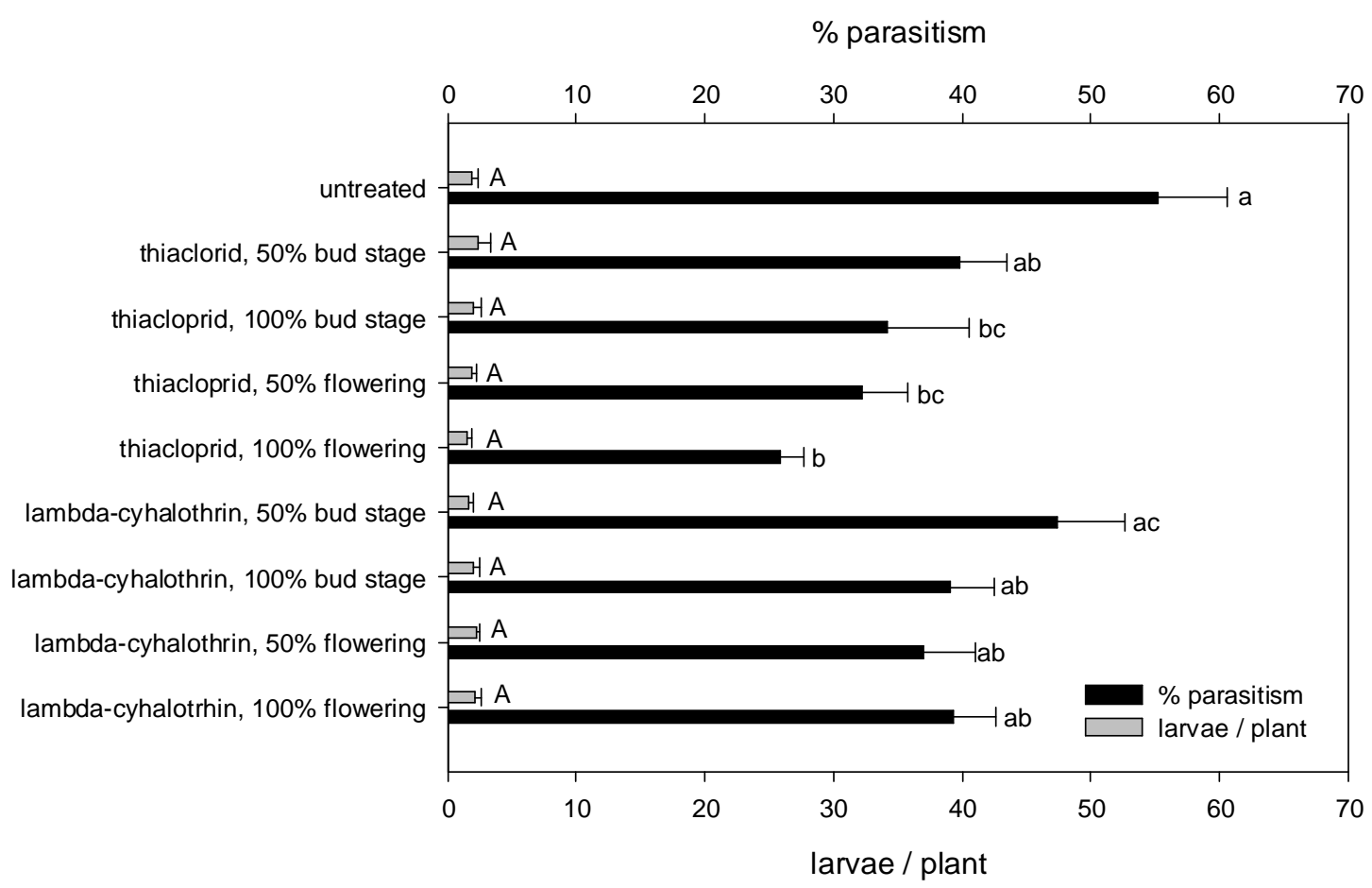

Fig 6: Mean level of infestation (+ SE) by M. aeneus and mean level of parasitism (+ SE) on plants following different insecticide treatments in 2008. Thiacloprid or lambda-cyhalothrin, full field dose rate $(100 \%)$ or reduced field dose rate $(50 \%)$, application in bud stage or during flowering. Means followed by the same upper/lower case letters are not significantly different. Larvae/ plant: ANOVA; Tukey-HSD; $\mathrm{n}=36 ; \mathrm{F}=0.2 ; \mathrm{p} \leq 0.05$. Parasitism: ANOVA; Tukey-HSD; $\mathrm{n}=36, \mathrm{~F}=4.0 ; \mathrm{p} \leq 0.05$.

\section{Level of parasitism of artificially infested plants}

Parasitism of pollen beetle larvae following exposure on potted oilseed rape plants in the treated and untreated plots was on a low level between 1 to 3 days after insecticide application, particularly in plots treated with lambda-cyhalothrin. Parasitism increased significantly during the days 3 to 6 after application and decreased again significantly 6 to 9 days after spraying, due to unfavorable weather conditions. During 3 to 6 days after spraying the highest level of parasitism was found in untreated plots (Fig 7). 


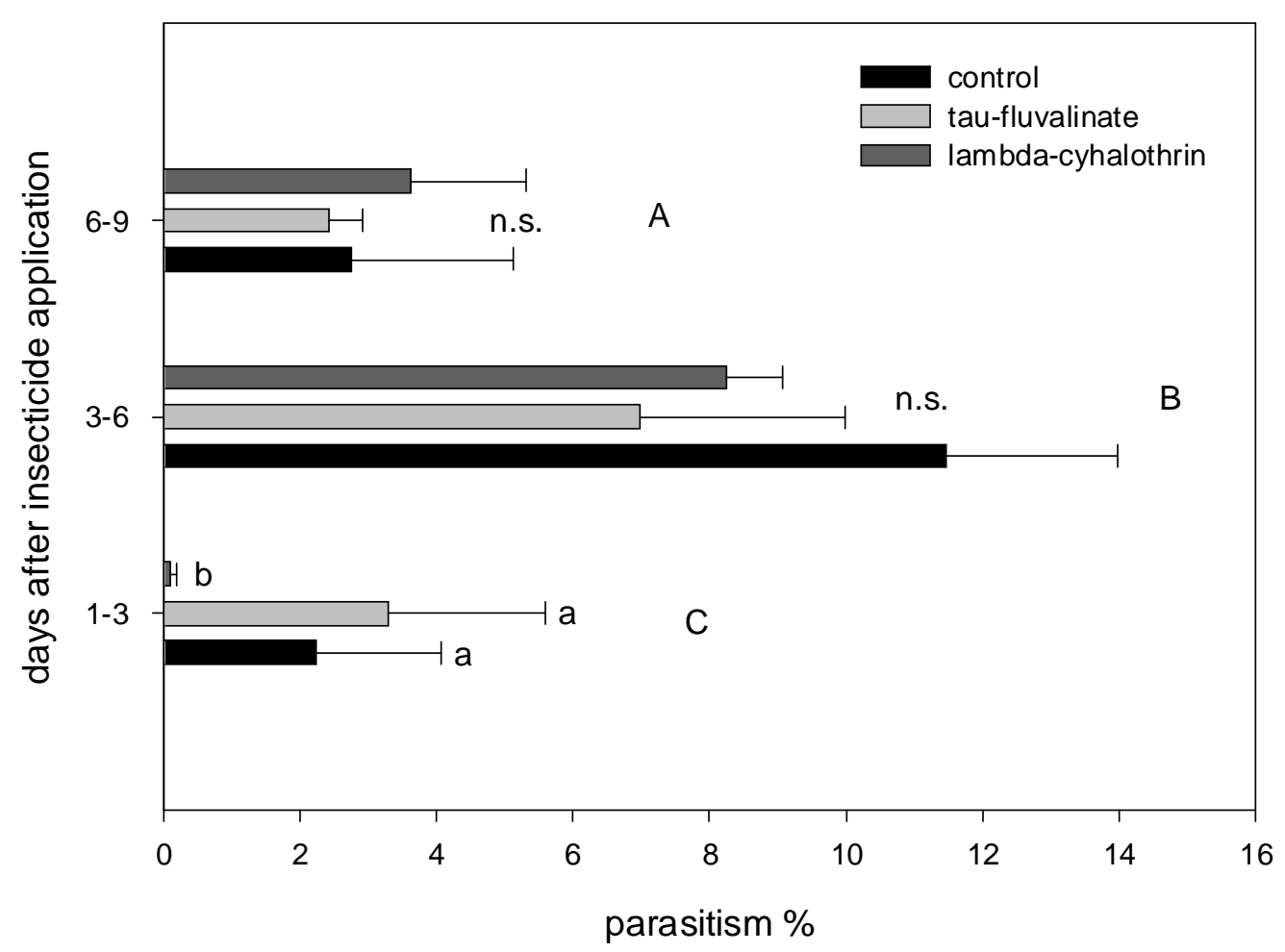

Fig 7: Mean level of parasitism (+ SE) of Meligethes larvae which were exposed on potted plants on day 1, 3 and 6 after insecticide application during flowering in 2006. Upper case letters $=$ significant difference between exposure dates, lower case letter $=$ significant difference between untreated and treated plots. Insecticide treatments: Mann-Whitney U-test; $\mathrm{n}=36 ; \mathrm{p} \geq 0.05$; Exposure dates: Nonparametric test, Kolmogorov-Smirnov-test; $\mathrm{n}=108 ; \mathrm{p} \leq$ 0.05 .

In 2007, the mean level of parasitism during the days 1 to 4 after insecticide application was significantly lower (mean $0.7 \pm 0.2$ ) than during the days 5 to 6 after spraying (mean $9.9 \pm$ 2.6). During the days 5 to 6 , parasitism of larvae was higher on treated plants than on untreated plants, but this was not significantly different (Fig 8).

The mean number of host larvae ranged between 3.3 and 7.4 larvae per plant in 2006 and between 3.5 and 8.1 larvae per plant in 2007. 


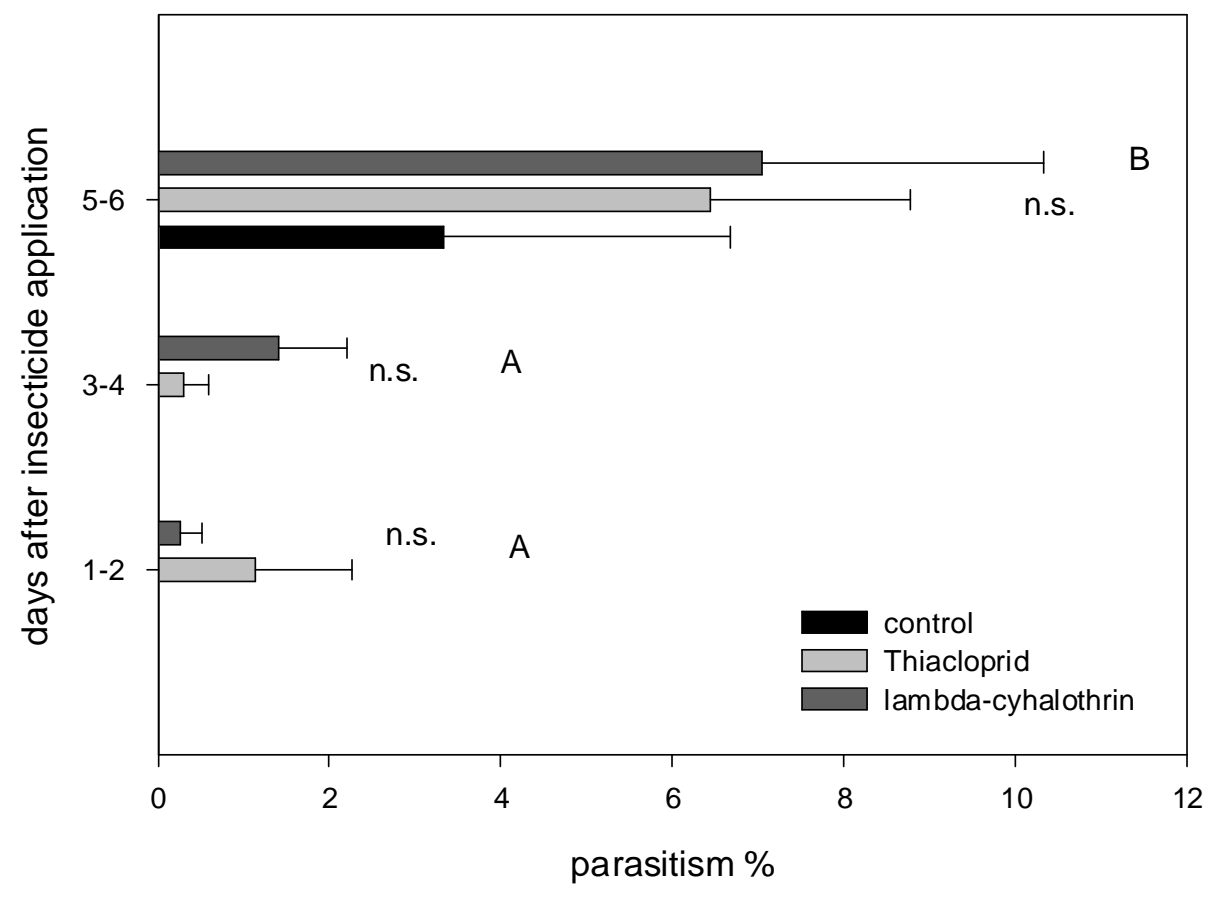

Fig 8: Mean level of parasitism (+ SE) of Meligethes larvae which were exposed on potted plants on day 1, 3 and 6 after insecticide application during flowering in 2007.Upper case letters $=$ significant difference between exposure dates, n.s. $=$ no difference between untreated and treated plots. Insecticide treatments: Mann-Whitney U-test; $n=36 ; p \geq 0.05$; Exposure dates: Nonparametric test, Kolmogorov-Smirnov-test; $\mathrm{n}=108 ; \mathrm{p} \leq 0.05$.

The vertical distribution of adult parasitoids in the crop canopy of oilseed rape showed that significantly more females and males of $T$. heterocerus and male $P$. interstitialis were abundant on the top of the canopy than at soil level. Female P. interstitialis showed no clear preference (Fig 9). 


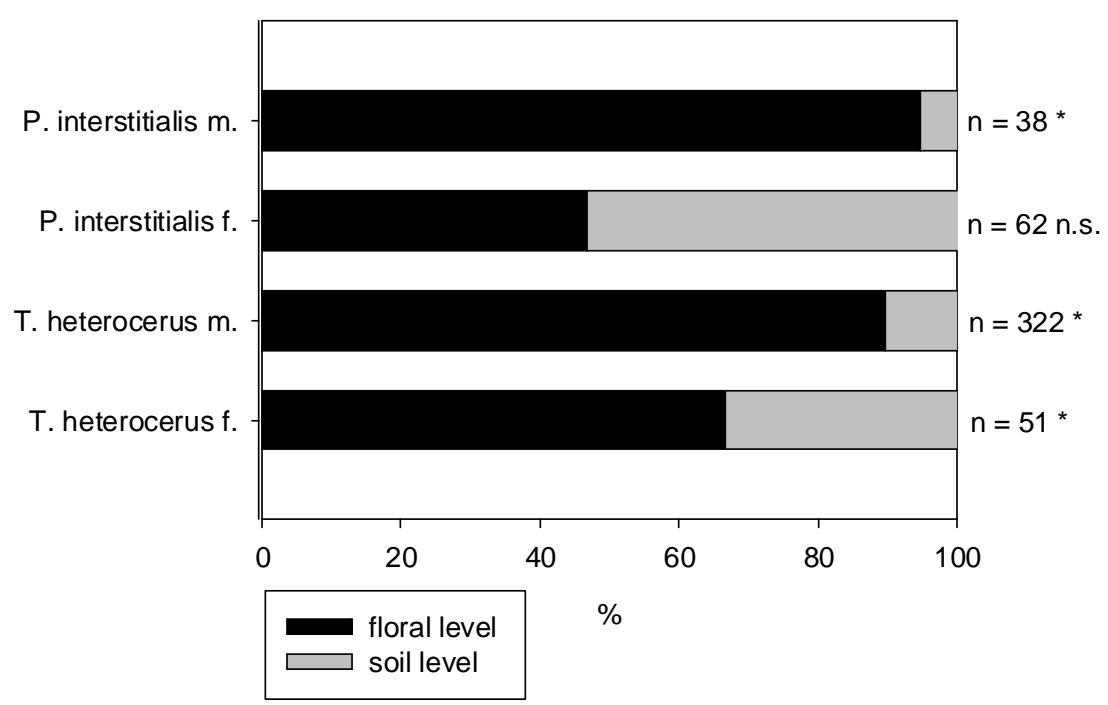

Fig 9: Mean number of female and male parasitoids caught in yellow water traps at the top of crop canopy and at ground level in an oilseed rape crop; trapping period 17 April - 19 May 2009. paired t-test, $\mathrm{p} \leq 0.05$. $(\mathrm{m}=$ male, $\mathrm{f}=$ female $)$

\section{Abundance of dead parasitoids in traps after insecticide application}

Twenty-four hours after insecticide application, only two males of T. heterocerus and one female of $P$. interstitialis were caught in total in the traps exposed at the ground of plots treated with thiacloprid at late flowering. No parasitoids were caught in untreated plots and plots treated with lambda-cyhalothrin.

\section{Two-choice test}

Buds carrying fresh dried residues of thiacloprid (100\%) were significantly avoided by female $P$. interstitialis. Three and six days old residues of thiacloprid also reduced the residence time of females on treated buds compared to untreated buds, but this difference was not significant (Fig 10).

Buds treated with $100 \%$ lambda-cyhalothrin or $100 \%$ tau-fluvalinate had significant effect on the residence time of $P$. interstitialis on treated buds compared to untreated buds. Female $P$. interstitialis tended to spend more time on buds treated with lambda-cyhalothrin, but they spent less time on buds sprayed with tau-fluvalinate as compared to unsprayed buds (Fig 11 and 12). 


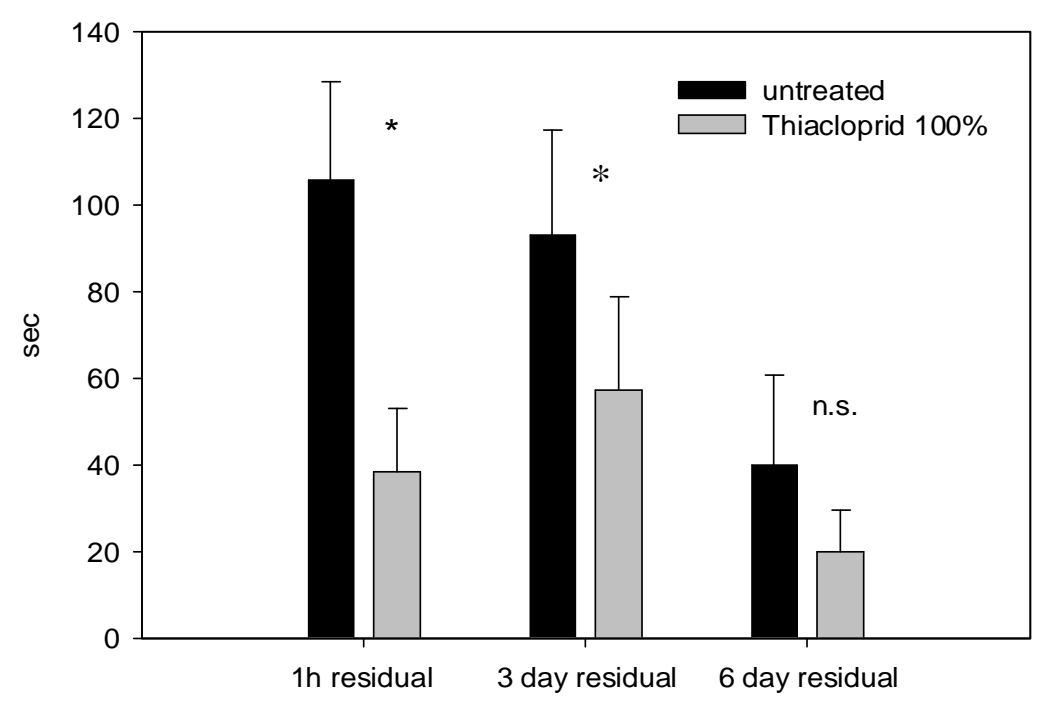

Fig 10: Mean time (sec + SE) spent by adult females of Phradis interstitialis on untreated buds and buds treated with thiacloprid of different residual age during the observation time of 5 min. $\chi_{2}-$ test, $\mathrm{p} \leq 0.05 ; \mathrm{n}=21-30$.

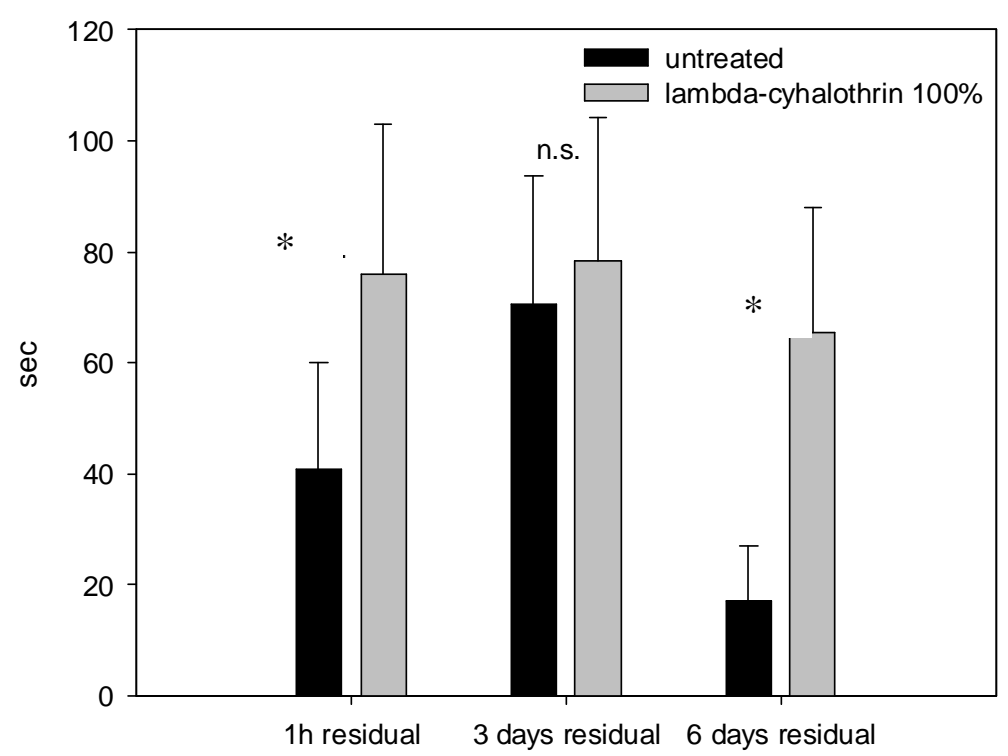

Fig 11: Mean time (sec + SE) spent by adult females of Phradis interstitialis on untreated buds and buds treated with lambda-cyhalothrin of different residual age during the observation time of 5 min. $\chi_{2}-$ test, $\mathrm{p} \leq 0.05 ; \mathrm{n}=20-25$. 


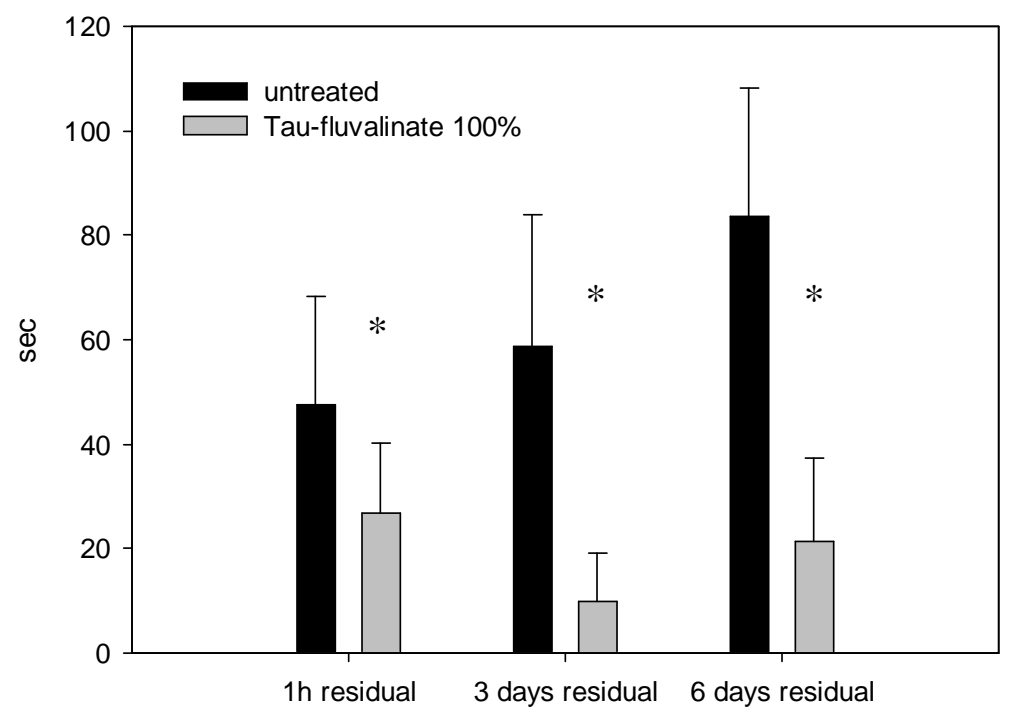

Fig 12: Mean time (sec + SE) spent by adult females of Phradis interstitialis on untreated buds and buds treated with tau-fluvalinate of different residual age during the observation time of 5 min. $\chi_{2}$ - test, $\mathrm{p} \leq 0.05 ; \mathrm{n}=20$.

\section{Toxicity of insecticides to $\mathrm{P}$. interstitialis and $\mathrm{T}$. heterocerus}

In the glass-vial bioassay the $\mathrm{LD}_{50}$ of lambda-cyhalothrin was at $12 \%\left(0.0093 \mu \mathrm{g} / \mathrm{cm}^{2}\right)$ of the recommended field dose rate. The dose-mortality equation was $\mathrm{Y}=14.34+2.52 \mathrm{x} .\left(\mathrm{df}=1, \mathrm{r}^{2}\right.$ $=0.35, \mathrm{p}<0.05)$. The toxicity of tau-fluvalinate showed an $\mathrm{LD}_{50}$ of $59.52 \%\left(=0.119 \mu \mathrm{g} / \mathrm{cm}^{2}\right)$ of the recommended field dose rate. The dose-mortality equation was $\mathrm{Y}=-0.52+0.37 \mathrm{x}(\mathrm{df}=$ $\left.1, \mathrm{r}^{2}=0.31, \mathrm{p}<0.05\right)$. The $\mathrm{LD}_{50}$ of thiacloprid could not be determined $5 \mathrm{~h}$ after exposure to the insecticide residuals, because only $13.4 \%$ of the parasitoids died after $5 \mathrm{~h}$ on residuals of various concentrations. Mortality in control treatments ranged between 0 and $13 \%$.

\section{Discussion}

The parasitoid P. interstitialis was reported to colonize the oilseed rape crop from mid April onwards and T. heterocerus from the end of April to the beginning of May (Nilsson, 2003; Ulber et al., 2006; Williams, 2006), which corresponds to our observations in the field experiments. Three to four insecticide treatments are applied commonly to the crop in autumn, spring and summer (Menzler-Hokkanen et al., 2006). Consequently, insecticide applications during flowering may have detrimental effects on parasitoid populations. 
Adult parasitoids can be exposed to insecticide spray droplets (Croft \& Brown, 1975; Jepson, 1989) or when foraging on the plant surface for hosts (Longley \& Jepson, 1996a; Longley \& Jepson, 1996b) and through feeding on contaminated water droplets and nectar (Longley \& Jepson, 1996a). Our assessment of the vertical distribution of adult parasitoids within the crop showed that parasitoids of pollen beetle larvae are mainly active at the top of the canopy, which has also been observed by Ulber and Nitzsche (2006). Therefore, insecticide application may have detrimental effects on these parasitoids.

However, levels of parasitism of pollen beetle larvae did not differ significantly between the early and late application of the tested insecticides. The interval between the early insecticide application and the immigration of adult parasitoids into the crop might have been too short, and parasitoids might have been affected by insecticde residuals on the early treated plants. Depending on weather and UV-photolysis, the half life time of pyrethroids can vary from some days to weeks (Börner, 1997).

Besides the temporal targeting of insecticide application, another approach for increasing selectivity of pesticides is to reduce the dose rates (Poehling, 1989; Longley et al., 1997; Booth et al., 2007). Many studies on the effect of reduced field dose rates on pests and their natural enemies have been focused on aphids. Various studies have shown that reduced rates of insecticides can provide sufficient control of aphids, while protecting populations of natural enemies (Ripper, 1956; Poehling, 1989; 1995; Longley et al., 1997; Acheampong \& Stark, 2004; Booth et al., 2007). In this study no significant difference occured between the levels of parasitism at 50\% reduced rates and full dose rates on. The difference between the levels of parasitism at full and reduce dose rates amounted only to $4-5 \%$.

The choice of selective insecticides is an important step to conserve populations of beneficial species in IPM. Many pyrethroids are known to have a broad-spectrum activity on a large variety of herbivores and natural enemies (Casida et al., 1983; Tillmann \& Mulrooney, 2000). Due to the different chemical structure of the active compound, tau-fluvalinate may be less harmful to natural enemies than lambda-cyhalothrin (Johnson et al., 2006). Tau-fluvalinate is being used for control of parasitic mites inside honey bee colonies, while the pyrethroids cyfluthrin and lambda-cyhalothrin are highly toxic to honey bees (Johnson et al., 2006). In contrast, systemic insecticides and their metabolites are claimed to be fairly safe for beneficials, because they are quickly absorbed from the plant surface into the tissue, thereby minimizing detrimental effects on natural enemies (Stapel et al., 2000; Tomizawa \& Casida, 2005). In literature, it has been reported that thiacloprid showed no persistent effect on the egg parasitoid Trichogramma cacoeciae and the larval parasitoid Encarsia formosa (Schuld 
\& Schmuck, 2000; Richter, 2006). In contrast to our expectation, in this study the treatments with tau-fluvalinate and thiacloprid significantly reduced the parasitism of pollen beetle larvae, while treatments with lambda-cyhalothrin had no significant effect, compared to untreated plots.

Parasitoids may be affected by insecticides through lethal toxic affects or through sublethal effects on physiology and behaviour. In our laboratory dose-response tests, lambdacyhalothrin was more toxic to $P$. interstitialis and T. heterocerus than tau-fluvalinate and thiacloprid. The mortality in the control vials ranged between $0 \%$ and $13 \%$, which has been agreed to be acceptable for control treatments (Mead-Briggs et al., 2006) when evaluating effects of plant protection products on Aphidius rhopalosiphi. Even very low doses $(0.125 \%-$ $1.5 \%$ ) of the tested insecticides had a strong influence on the locomotory activity of $70 \%$ $80 \%$ of wasps. Parasitoids walked slowly and uncoordinated, with weak movements of the antennae up to paralysis. However, this glass-vial test was performed under worst-case conditions. The test method maximised the availabilty and persistence of the insecticide (Barrett et al., 1994), and parasitoids were forced to stay in permanent contact with the insecticide treated glass surface. The results of the glass-vial test can not be applied directly for estimations of the insecticide toxicity under field conditions. The toxicity of the pyrethroids lambda-cyhalothrin and tau-fluvalinate to Phradis spp. was lower on treated leaves than on treated filter paper (Jackowski et al., 2009). Tau-fluvalinate was less toxic than lambda-cyhalothrin; survival of Phradis spp. exposed to residuals of tau-fluvalinate and lambda-cyhalothrin on treated leaf discs was $17.3 \%$ and $14.7 \%$ higher than on filter paper 6.5 hours after exposure, respectively (Jackowski et al., 2009).

In our study, females of $P$. interstitialis significantly avoided treated buds covered with fresh dried and 3 days old residuals of thiacloprid and with fresh, 3 days and 6 days old residues of tau-fluvalinate, compared to untreated buds. Females spent significantly more time on fresh dried residues and six days old residues of lambda-cyhalothrin than on untreated buds. The preference of parasitoids for plants covered by insecticide residuals as compared to untreated plants has been rarely reported in the literature, e.g. the organophosphate malathion increased the residence time on treated sorghum plants to Aphelinus asychis (Rao et al., 1999).

In contrast, there are numerous reports on repellent effects of insecticides on natural enemies: females of Diaretiella rapae spent significant less time foraging on plants sprayed with pirimicarb, permethrin and malathion than on untreated plants, regardless of the presence of their aphid hosts (Jiu \& Waage, 1990, Umoru et al. 1996). The aphid parasitoid Aphidius ervi showed disrupted olfactory orientation towards host-infested plants treated with lambda- 
cyhalothrin, but not to residuals of deltamethrin (Desneux et al., 2006). Search time allocation is an important component for parasitism efficiency. The modification of this behaviour can interfere with the reproductive capacity of parasitoids (Komeza et al., 2001). The reduced time spent foraging on the plant would reduce the probability of successful oviposition encounters with hosts after an insecticide application.

Parasitoids use olfactory cues in host habitat location, while contact chemical cues of low volatility are used in location of the host larvae (Vet \& Dicke, 1992; Vinson, 1998). Insecticides may obstruct host location through (1) masking of attractive host plant odours and/or interference with the production and emission of plant volatiles, which could prevent the parasitoid from recognising the host plant and the host (Thiery \& Visser 1986; Nottingham et al. 1991). (2) The insecticide odour could have a direct repellent effect on the insects (Jiu \& Waage, 1990, Tran et al. 2004). Quantitative and qualitative differences in volatile blends of plants infested by cabbage stem weevil larvae, which were treated with lambda-cyhalothrin or thiacloprid, have been observed by Neumann \& Ulber (pers. comm.). It is well know that parasitoids attacking pollen beetle larvae respond to volatiles emitted by infested plants (Jönsson et al., 2005).

Repellency of insecticides may induce a change of the dispersal behaviour of the parasitoids. Our previous studies have shown that emigration flights of Tersilochus fulvipes and $T$. obscurator from insecticide treated fields were more frequent than immigration flights, wheras in the untreated field immigration flights prevailed. The parasitoids recolonized the treated field about one week post treatment (Neumann \& Ulber, pers. comm.). This fits to our results concerning parasitism of pollen beetle larvae on plants exposed directly after the insecticide application. Level of parasitism was low during the first 4 to 5 days after treatment and than increased again. However, in 2006, the level of parasitism decreased again six days post treatment. This may be due to unfavourable weather conditions: in 2006, six days after spraying the temperature decreased from $15.9^{\circ} \mathrm{C}$ to $13.5^{\circ} \mathrm{C}$ and the solar radiation from 273 $\mathrm{kWh} / \mathrm{m}^{2}$ to $213 \mathrm{kWh} / \mathrm{m}^{2}$, which might have reduced the foraging activity of the parasitoids. The influence of abiotic factors like temperature, humidity and solar radiation on flight activity of hymenopteran parasitoids was investigated in various studies (Abraham, 1975; Weisser et al., 1997; Fournier \& Boivin, 2000; Langer et al., 2004).

The level of parasitism may also be affected by host density. A positive correlation between the number of larvae per plant and the level of parasitism was only observed in 2006. Nilsson \& Andreasson (1987) found no correlation between host density and parasitization rate of pollen beetles larvae. Reviews examining the impact of host density on parasitism rates have 
found that in $48-66 \%$ of studies there is evidence of density dependence, and in about half of these that there is direct rather than inverse density dependence (Lessells, 1985; Stiling, 1987; Walde \& Murdoch, 1988).

Within IPM strategies, application of insecticides may be required if pest numbers exceed the threshold levels. In our study, the reduction of dose rates and temporal targeting of insecticide spraying before the main activity of parasitoids attacking pollen beetle did not result in the expected increase of parasitism. For conservation biocontrol of pests on oilseed rape, the choice of selective active ingredients was more effective than early application dates and reduced dose rates. In addition, to toxic effects of insecticides on natural enemies, repellency and interference with host location by parasitoids can reduce the parasitism efficiency.

\section{References}

ABRAHAM, R. (1975). Über die Wirkung der Temperatur auf die Flugaktivität parasitischer Hymenopteren. Zeitschrift Angewandten Entomologie 79, 113-123.

ACHEAMPONG, S. \& STARK, J. (2004). Can reduced rates of pymetrozine and natural enemies control the cabbage aphid, Brevicoryne brassicae (Homoptera: Aphididae), on broccoli? International Journal of Pest Management 50, 275-279.

Alford, D. V., NiLSSON, C. \& UlBER, B. (2003). Insect pests of oilseed rape crops. Chapter 2 In: D.V. Alford (ed) Biocontrol of Oilseed Rape Pests. Blackwell, Oxford, UK, 9-41.

BALLANGER, Y., DÉTOURNÉ, D., DELORME, R. \& PINOCHET, X. (2007). France, difficulties to manage insect pests of winter oilseed rape (Brassica napus var. oleifera):resistance to insecticides. 12 International Rapeseed Congress, China 2007, Vol. 4, 276-279.

BARrett, K., Grandy, N., HARrison, E. G., HASSAN, S. \& OOMEN, P. (1994). Guidance document on regulatory testing procedures for pesticides with non-target arthropods. ESCORT Workgroup, Wageningen, The Netherlands 1994. Society of Environmental Toxicology and Chemistry-Europe (SETAC)

BOERNER, H. (1997). Pflanzenkrankheiten und Pflanzenschutz, Verlag Eugen Ulmer, Stuttgart, 7. Auflage.

Booth, L. H., Wratten, S. D. \& P.KehrLi. (2007). Effects of reduced rates of two insecticides on enzyme activity and mortality of an aphid and its lacewing predator. Journal of Economic Entomology 100, 11-19.

BÜCHI, R. (2002). Mortality of pollen beetle (Meligethes spp.) larvae due to predators and parasitoids in rape fields and the effect of conservation strips. Agricultural, Ecosystems and Environment 90, 255-263.

Casida, J. E., Gammon, D. W., Glickman, A. H. \& LAWrence, L. J. (1983). Mechanism of Selective Action of Pyrethroid Insecticides. Annual Review Pharmacology Toxicology 23, 413-438.

Croft, B. A. \& A.W.Brown. (1975). Responses of arthropod natural enemies to insecticides. Annual Reviews Entomology 20, 285-335.

DesneuX, N., DeCourtye, A. \& DelPUECH, J.-M. (2007). The sublethal effects of pesticides on beneficial arthropods. Annual Reviews Entomology 52, 81-106.

DesneuX, N., DENOYELle, R. \& KAISER, L. (2006). A multi-step bioassay to assess the effect of the deltamethrin on the parasitic wasp Aphidius ervi. Chemosphere 65, 1697-1706. 
FOURNIER, F. \& BOIVIN, G. (2000). Comparative dispersal of Trichogramma evanescence and Trichogramma pretiosum (Hymenoptera: Trichogrammatidae) in relation to environmental conditions. Environmental Entomology 29, 55-63.

HANSEN, L. M. (2003). Insecticide-resistant pollen beetles (Meligethes aeneus F) found in Danish oilseed rape (Brassica napus L) fields. Pest Management Science 59, 10571059.

HAYNES, K. F. (1988). Sublethal effects of neurotoxic insecticides on insect behavior. Annual Reviews Entomology 33, 149-168.

Heimbach, U., MülleR, A. \& THIEME, T. (2006). First steps to analyse pyrethroid resistance of different oilseed rape pests in Germany: An extended abstract. IOBC/wprs Bulletin 29, 131-134.

HokKanen, H., Husberg, G.-B. \& SÖDERBLOM, M. (1988). Natural enemy conservation for the integrated control of the rape blossom beetle Meligethes aeneus F. Annales Agriculturae Fenniae 27, 281-294.

HORSTMANN, K. (1971). Revision der europäischen Tersilochinen I (Hym.: Ichneumonidae). Veröffentlichung der Zool. Staatssammlung München 15, 47-138.

HoRSTMANN, K. (1981). Revision der europäischen Tersilochinen II (Hymenoptera, Ichneumonidae). Spixiana Suppl. 4, 1-76.

JACKOWSKI, J., KLUKOWSKI, Z. \& IRZYKOWICZ, M. (2009). The effect of tau-fluvalinate and lambda-cyhalothrin on two parasitic species of Phradis spp. (Hymenoptera, Ichneumonidae, Tersilochinae). Pestycydy/Pesticides 2008 3-4, 79-92.

JEPSON, P. C. (1989). The temporal and spatial dynamics of pesticide side-effects on nontarget invertebrates. In: Jepson P.C. (Ed.), Pesticide and Non-target Invertebrates. Intercept, Wimborne., 95-127.

JIU, G. D. \& WAAGE, J. K. (1990). The effect of insecticides on the distribution of foracing parasitoids, Diaeretiella rapae (Hym.: Braconidae) on plants. Entomophaga 35, 4956.

JOURDHEUIL, P. (1960). Influence de quelque facteurs écologique sur les fluctuations de population d'une biocé nose parasitaire. Ann. Epiph. 11, 445-658.

Johnson, R. M., Wen, Z., SChUler, M. A. \& Berenbaum, M. R. (2006). Mediation of Pyrethroid Insecticide Toxicity to Honey Bees (Hymenoptera: Apidae) by Cytochrome P450 Monooxygenases. Journal of Economic Entomology 99, 1046-1050.

JÖNSSON, M., LINDKVIST, A. \& ANDERSON, P. (2005). Behavioural responses in three ichneumonid pollen beetle parasitoids to volatiles emitted from different phenological stages of oilseed rape. Entomologia Experimentalis et Applicata 115, 363-369.

KLUKOWSKI, Z., TwARDOWSKI, J. \& IRZYKOWICZ, M. (2006). Subsequent effect of taufluvalinate (Maverik) and lambda-cyhalothrin (Karate) pyrethroids on the activity of carabid beetles (Coleoptera: Carabidae) in winter oilseed rape. IOBC/wprs Bulletin 29, 125-130.

KOGAN, M. (1998). Integrated pest management: Historical perspectives and contemporary developments. Annual Review Entomology 43, 243-270.

Komeza, N., Foulllet, P., Bouletreau, M. \& DelpueCh, J. M. (2001). Modification, by the Insecticide Chlorpyrifos, of the Behavioral Response to Kairomones of a Parasitoid Wasp, Leptopilina boulardi. Archiv Environmental Contamination and Toxicology 41, 436-442.

LANGER, A., BoIVIN, G. \& HANCE, T. (2004). Oviposition, flight and walking capacitiy at low tempertures of four aphid parasitoid species (Hymenopteran: Aphidiinae). European Journal of Entomology 101, 473-479.

LESSELLS, C. M. (1985). Parasitoid foraging: Should parasitism be density dependent? Journal of Animal Ecology 54, 27-41. 
LONGLEY, M. \& JEPSON, P. C. (1996a). Effects of honeydew and insecticide residues on the distribution of foraging aphid parasitoids under glasshouse and field conditions. Entomolgia Experimentalis et Applicata 81, 189-198.

LONGLEY, M. \& JEPSON, P. C. (1996b). The influence of insecticide residues on primary parasitoids and hyperparasitoid foraging behaviour in the laboratory. Entomologia Experimentalis et Applicata 81, 259-269.

LONGLEY, M., JEPSON, P. C., IZQUIERDO, J. \& SOTHERTON, N. (1997). Temporal and spatial changes in aphid and parasitoid populations following applications of deltamethrin in winter wheat. Entomologia Experimentalis et Applicata 83, 41-52.

Mead-Briggs, M. A., Grimm, C., Moll, M., Schuld, M., Ufer, A. \& WalKer, H. (2006). An extended laboratory test for evaluating the effect of plant protection products on the parasitic wasp, Aphidius rhopalosiphi (De Stefani-Perez) (Hymenoptera, Braconidae). In: M.P. Candolfi, S. Blümel, R. Forster et al. (2000):Guidlines to evaluate side-effects of plant protection products to non-target arthropods. IOBC, BART and EPPO Joint Initiative

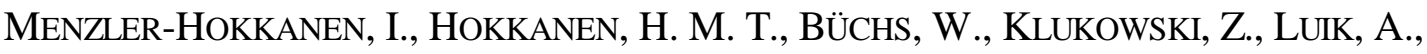
NiLSSON, C., UlBER, B. \& WILLIAMS, I. H. (2006). Insect problems in European oilseed rape cultivation, and how to deal with them: the OSR framers`perspective. IOBC/wprs Bulletin 29, 91-94.

NILSSON, C. (1988). The pollen beetle (Meligethes aeneus F.) in winter and spring rape at Alnarp 1976-1978. III. Mortality factors. Växtskyddsnotiser 52, 145-150.

NILSSON, C. (2003). Parasitoids of pollen beetles. In: D.V. Alford (ed) Biocontrol of Oilseed Rape Pests. Blackwell Publishing, Oxford, UK, 73-85.

NILSSON, C. \& ANDREASSON, B. (1987). Parasitoids and predators attacking pollen beetles (Meligethes aeneus $\mathrm{F}$.) in spring and winter rape in southern Sweden. IOBC/wprs Bulletin 4, 64-73.

NitzSCHE, O. (1998). Auftreten und Effizienz von Parasitoiden als natürliche Gegenspieler von Schadinsekten im Winterraps unter besonderer Berücksichtigung unterschiedlicher Bodenbearbeitungsmaßnahmen nach Winterraps. PhD thesis, Georg-August-University of Goettingen, Germany.

Nottingham, S. F., Hardie, J., Dawson, G. W., Hick, A. J., Pickett, J. A., Wadhams, L. J. \& WoODCOCK, C. M. (1991). Behavioral and electrophysiological responses of aphids to host and nonhost plant volatiles. Journal of Chemical Ecology 17, 12311242.

OSBORN, P. (1960). Observation of the natural enemies of Meligethes aeneus (F.) and $M$. viridescence (F.) (Coleoptera: Nitidulidae). Parasitology 50, 91-110.

PoEHLING, H. M. (1989). Selective application strategies for insecticides in agricultural crops. In: Jepson P.C. (Ed.), Pesticide and Non-target Invertebrates. Intercept, Wimborne., 151-175.

RaO, A., Vinson, S. B., GilstraP, F. E. \& Michels, G. J. (1999). Response of an aphid parasitoid, Aphelinus asychis to its host, plant, host-plant complex, and to malathion. Entomologia Experimentalis et Applicata 91, 449-456.

RICHTER, E. (2006). A method to prove long term effects of neonicotinoids on whitefly parasitoids. IOBC/wprs Bulletin 29, 61-65.

RIPPER, W. E. (1956). Effect of pesticides on balance of arthropod populations. Annual Reviews Entomology 1, 403-438.

SCHULD, M. \& SCHMUCK, R. (2000). Effects of Thiacloprid, a New Chloronicotinyl Insecticide, On the Egg Parasitoid Trichogramma cacoeciae. Ecotoxicology 9, 197205.

StAPEl, J. O., Cortesero, A. M. \& Lewis, W. J. (2000). Disruptive Sublethal Effects of Insecticides on Biological Control: Altered Foraging Ability and Life Span of a 
Parasitoid after Feeding on Extrafloral Nectar of Cotton Treated with Systemic Insecticides. Biological Control 17, 243-249.

STILING, P. D. (1987). The frequency of density dependence in insect host-parasitoid systems. Ecology 68, 844-856.

THIERY, D. \& VISSER, J. H. (1986). Masking of plant odour in the olfactory orientation of the Colorado potato beetle. Entomologia Experimentalis et Applicata 41, 165-172.

Tillmann, P. G. \& MulroOnEY, J. E. (2000). Effect of Selected Insecticides on the Natural Enemies Coleomegilla maculata and Hippodamia convergens (Coleoptera: Coccinellidae), Geocoris punctipes (Hemiptera: Lygaeidae), and Bracon mellitor, Cardiochiles nigriceps, and Cotesia marginiventris (Hymenoptera: Braconidae) in Cotton. Journal of Economic Entomology 93, 1638-1643.

TOMIZAWA, M. \& CASIDA, J. E. (2005). Neonicotinoid Insecticide Toxicology: Mechanism of Selective Action. Annual Review Pharmacology Toxicology 45, 247-268.

Tran, D. H., TAKAGI, M. \& TAKASU, K. (2004). Effects of selective insecticides on host searching and oviposition behavior of Neochrysocharis formosa (Westwood) (Hymenoptera: Eulophidae), a larval parasitoid of the American serpentine leafminer. Applied Entomology Zoology 39, 435-441.

UMORU, P. A., POWELl, W. \& ClARK, S. J. (1996). Effect of pirimicarb on the foraging behaviour of Diaeretiella rapae (Hymenoptera: Braconidae) on host-free and infested oilseed rape plants. Bulletin of Entomological Research 86, 193-201.

UlBER, B. \& NiTZSCHE, O. (2006). Phenology of parasitoids (Hym., Ichneumonidae, Tersilochinae) of oilseed rape pests in northern Germany in 1995-1997. IOBC/wprs Bulletin 29, 173-179.

Ulber, B., NitzSCHE, O. \& WEDEMEYER, R. (2006). Phenology of tersilochine parasitoids in Germany and prospects for spray windows compatible with their conservation. $C D$ Rom Proceedings of the International Symposium "Integrated Pest Management in Oilseed Rape Pests", Goettingen, Germany, 3-5 April 2006.

VET, L.E.M. \& DICKE, M. (1992). Ecology of infochemical use by natural enemies in a tritrophic context. Annual Review Entomology 37, 141-172.

VINSON, S. B. \& WILLIAMS, H. J. (1991). Host selection behavior of Campoletis sonorensis: A Model System. Biological Control 1, 107-117.

WALDE, S. J. \& MuRDOCH, W. W. (1988). Spatial density dependence in parasitoids. Annual Review Entomology 33, 441-466.

WEGOREK, P. \& ZAMOJSKA, J. (2006). Resistance of pollen beetle (Meligethes aeneus F.) to pyrethroids, chloronicotinyls and organophosphorous insecticides in Poland. IOBC/wprs Bulletin 29, 135-140.

WEISSER, W. W., VÖLKL, W. \& HASSELL, M. P. (1997). The importance of adverse weather conditions for behaviour and population ecology of an aphid parasitoid. Journal of Animal Ecology 66, 386-400.

WILES, J. A. \& JEPSON, P. C. (1995). Dosage reduction to improve the selectivity of deltamethrin between aphids and coccinellids in cereals. Entomologia Experimentalis et Applicata 76, 83-96.

WILLIAMS, I.H., BÜCHS, R. \& ULBER, B. (2003). Sampling, trapping and rearing oilseed rape pests and their parasitoids. In: D.V. Alford (Ed.) Biocontrol of Oilseed Rape Pests. Blackwell Publishing, Oxford, UK.

WILLIAMS, I.H. (2006). Integrating parasitoids into management of pollen beetle on oilseed rape. Agronomy Research 4, 465-470.

WINFIELD, A. L. (1963). A study on the effects of insecticides on parasites of larvae of blossom beetles (Meligethes aeneus F., Coleoptera: Nitidulidae). Entomologia Experimentalis et Applicata 6, 309-318. 


\section{General discussion}

Insecticides applied for control of pest insects on field crops may have undesirable sideeffects to natural enemies. Many commonly used pesticides have been found to be even more toxic to natural enemies than to the herbivorous pests (Jepson, 1989). These adverse effects can lead to resurgence of pest populations, i.e. a secondary pest outbreaks (Croft \& Brown, 1975) and subsequently an increase in the need for insecticide treatments. Therefore, better knowledge of the impact of pesticides on key natural enemies of target pests is important for the success of IPM strategies. Conservation of natural enemies might be achieved by optimization of insecticide use as far as product selection, timing of application and reduction of field dose rates are concerned. This knowledge would help to provide recommendations to farmers and consultants for minimizing negative effects on parasitoids and other biocontrol agents. Parasitoids use chemical cues for locating their hosts in crops of oilseed rape (Jönsson \& Anderson, 2008). However, very little was known whether these chemical cues are modified by insecticide application which might cause indirect effects on host location by parasitoids. The following discussion initially is focused on the behavioural and electrophysiological response of parasitoids to volatile emission by uninfested oilseed rape plants and by plants infested by stem boring larvae of $C$. pallidactylus. Subsequently, lethal and sublethal effects of insecticides on parasitoids in laboratory and field experiments are discussed. Finally, strategies for conservation of parasitoid populations are considered.

\section{Host searching}

Plants have evolved strategies to defend themselves directly and/or indirectly against herbivory. Direct defense mechanisms may prevent herbivores from feeding and oviposition via physical barriers, such as thorns, trichomes, waxes, or secondary chemical compounds, e.g. the production of glucosinolates in the plant family Brassicaceae (Bartlet et al., 1999). Indirect defence mechanisms work by producing and releasing of volatile compounds that are attractive to natural enemies (Paré \& Tumlinson, 1997; Dicke, 1999; Paré \& Tumlinson, 1999; Mattiacci et al., 2001). The herbivore induced changes of the volatile blend can be both quantitative and qualitative. Volatiles that are present in uninfested plants may be emitted from infested plants in larger amounts (Agelopoulus \& Keller, 1994; Blaakmeer et al. 1994; Gerrvliet et al., 1997; Mattiacci et al. 2001; Mumm et al, 2003; Bukovinsky et al. 2005). Qualitative changes in the composition of the emitted blend commonly result from de novo production of plant compounds following herbivory (Paré \& Tumlinson, 1997). 


\section{Chapter VI}

Parasitoids are known to use plant volatiles in foraging for hosts and food sources. The process of searching for host plants and hosts for oviposition or feeding has been described as 1) host habitat location 2) microhabitat location and acceptance 3) host location and acceptance (Vinson, 1998).

Olfactory and visual stimuli are commonly used in habitat location, while contact chemical cues of lower volatility, such as host salivary gland or mandibular gland secretions, host frass, and cuticular secretions may be involved in locating the host larvae (Vet \& Dicke, 1992; Vinson, 1998, Meiners \& Hilker, 2000). In long-range search parasitoids of pests on oilseed rape, Phradis interstitialis and T. obscurator, use odour induced upwind anemotaxis (Williams et al., 2007). The plant odour is carried downwind from the host plant and dispersed due to turbulent diffusion (Murlis et al. 2000). The colour yellow is a strong visual cue for the parasitoids. In the field, all parasitoid species are attracted to yellow water traps (Williams et al., 2003). In laboratory olfactometer bioassays, parasitoids attacking pollen beetle larvae were more attracted to flower yellow than to bud green (Jönsson et al., 2005).

Stimuli arising from the herbivore are most reliable in indicating host presence, suitability and accessibility. However, they are not easily perceptible over long distances, as herbivores have developed strategies to avoid their detection (Vet et al., 1991a). Various studies documented that herbivore-damaged plants were more attractive to parasitoids than the herbivore itself or its by-products (Turlings et al. 1991a, Geervliet et al. 1994; Potting et al., 1995). Host plants provide more discernible cues because of their large biomass, however, host-plant volatiles are far less reliable cues for host location, particularly of endophagous host larvae in the plant (Potting et al., 1995; Vinson, 1998). Parasitoids may overcome this problem by responding to special types of plant volatiles induced after herbivory, known as herbivore-induced synomones, which can differ in quality and quantity from those emitted by intact plants (Dicke \& Sabelis, 1988; Vet \& Dicke, 1992; Dicke, 1994). In some plant species, these volatiles have a unique odour blend whose chemical profile is different from uninfested or even mechanically damaged plants (Turlings et al., 1991b; Geervliet et al., 1994; Potting et al., 1995). Several chemical compounds of the volatile blend have been identified as playing a significant role in parasitoid recruitment by herbivore-injured plants (Du et al. 1998, NgiSong et al. 2000). The main components of the volatile blend released from Brassica plants are the terpenoids and the green leaf volatiles (Mattiacci et al., 1994; Shiojiri et al., 2001). They are a major class among herbivore-induced synomones that may attract natural enemies (Takabayashi et al., 1994; Pichersky \& Gershenzon, 2002). Emissions of green leaf volatiles increase in the headspace of damaged cabbage plants compared to undamaged plants, and 
assist host searching of parasitoids (Mattiacci et al., 1994; Smid et al. 2002). The volatile breakdown products of glucosinolates, the isothiocyanates, are released when plant tissue is damaged, e.g. by herbivory (Rask et al., 2000, Hopkins et al., 2009). Field experiments have shown that the parasitoids T. obscurator, T. fulvipes and Platygaster subuliformis are strongly attracted to yellow water traps baited with 2-phenylethyl-isothiocyanate (Murchie et al., 1997a; Ulber \& Wedemeyer, 2006).

Plant volatiles are known to comprise a large diversity in terms of chemical composition and complexity of blends, their changeability in time, and their dependence on rearing conditions (Jakobsen et al., 1994; Jakobson \& Olsen, 1994; Takabayashi et al., 1994; Gouinguené \& Turlings, 2002). Natural enemies may cope with this complexity through experience, and many volatile blends have been shown to be characteristic for a particular plant-herbivore complex (Turlings et al. 1990 ; Vet \& Groenewold, 1990; Vet et al., 1991a). Experience with host location and oviposition may result in enhanced response in host location ( McAuslane et al., 1991; Kester \& Barbosa, 1992;). There are various examples in the literature, demonstrating that experienced females respond faster and exhibit more direct flights to a host-plant complex than naive females (Drost et al., 1986; McAuslane et al., 1991). These associations between stimuli and resources can be both innate (Wäckers, 1994) and learnt (Lewis \& Takasu, 1990; Vet \& Groenewold, 1990) or of sensitisation to plant and host cues (Kaiser et al., 1995). Associative learning allows parasitoids to focus on the most reliable cues (Vet \& Groenewold, 1990; Jong \& Kaiser, 1991). Furthermore, learning to respond to specific cues from one plant-host complex can facilitate host-finding when other host-infested plants emit similar compounds or volatile blends (Geervliet et al., 1997).

Our study has shown that females of $T$. obscuator are able to discriminate between plants infested by $C$. pallidactylus and uninfested plants. In olfactometer tests, uninfested leaves were more attractive to the parasitoids than clean air, indicating that the plant volatiles of uninfested plants may be involved in host habitat location. Experience with host-plant cues significantly increased the probability of the detection of infested leaves by female $T$. obscurator, while naive wasps showed no clear preference for infested leaves compared to uninfested. The Y-olfactometer bioassay demonstrated that olfactory stimuli originating from the host-plant complex are sufficient cues to differentiate between infested and uninfested leaves. The parasitoids were attracted to the odour of infested oilseed rape leaves, even when the host larvae had been removed, while volatiles of the host larva itself did not attract the wasps. The GC-EAG experiments showed that the volatile blend of infested oilseed rape plants differed in its quantitative and qualitative composition from uninfested plants; the 


\section{Chapter VI}

antennae of the specialist parasitoid $T$. obscurator were able to perceive volatiles released specifically from infested plants. Twelve of the 19 compounds released by infested oilseed rape plants elicited antennal responses. Six of them were only emitted by infested plants, while only six of the 11 compounds emitted from uninfested plants elicited antennal response by female T. obscurator. Qualitative and quantitative differences between volatile blends of plants could be important cues for host presence and might be used by parasitoids at host searching (Gerrvliet et al. 1994, Paré \& Tumlinson, 1999).

The GC/MS-EAG analyses demonstrated that female T. obscurator responded to a wide range of volatile compounds, such as terpenoids, aldehydes and alcohols. The ability to detect a broad spectrum of plant volatiles is common in hymenopteran parasitoids (Baehrecke et al., 1989; Li et al., 1992; Smid et al., 2002). It might be favourable for parasitoids to generalize very similar odours instead of investing too much time to differentiate between several odours (Meiners et al., 2003). Parasitoids may solve this problem by associative learning, as described above. Their ability to learn should allow parasitoids to distinguish among plant volatiles originated from different types of plant damage, which enable them to focus on volatile cues of their potential host.

The short-range host searching behaviour of female $T$. obscurator and P. interstitialis, investigated in dual choice experiment following host location, showed the response to chemosensory cues of low volatility detected by sensilla on the antennae and on the tip of the ovipositor: after cleaning of the antennae, head and thorax, legs, abdomen and wings, searching behaviour by the females consisted of walking along the leaf or buds, respectively, drumming with their antennae and tapping with their ovipositor into the petiol or buds, respectively.

\section{Lethal and sublethal effects of insecticides on parasitoids}

In addition to lethal effects for insects, insecticide residues can alter their behaviour through neurotoxic activity. In this study, the toxicity of pesticides on natural enemies was analysed in the laboratory under standardised conditions. The experiments were performed under worstcase conditions: the test method maximises the availability and persistence of the compound, and the parasitoids were forced to stay continuously in contact with the insecticide treated glas surface (Barrett et al., 1994). Although these glass-vial tests did not provide exact information on insecticide efficacy in the field, they permit a ranking of the relative toxicity and selectivity of the tested insecticides. The test method applied in the laboratories may affect the results: the mortality of Phradis spp. on residuals of lambda-cyhalothrin and tau- 


\section{Chapter VI}

fluvalinate differed considerably when sprayed on oilseed leaf discs or on filter paper. Taufluvalinate was less toxic than lambda-cyhalothrin. Survival of Phradis spp. exposed on residuals on leaf discs treated with tau-fluvalinate and lambda-cyhalothrin was $17.3 \%$ and $14.7 \%$ higher than on filter paper, respectively (Jackowski et al., 2009). Due to the different chemical structure of the active compound, tau-fluvalinate may be less harmful to natural enemies than lambda-cyhalothrin. The additional aromatic ring allows more rapid detoxification and results in a lower toxicity to insects (Johnson et al., 2006). Tau-fluvalinate is used for control of parasitic mites inside honey bee colonies, while the pyrethroid cyfluthrin and lambda-cyhalothrin are highly toxic to honey bees (Johnson et al., 2006). However, the initial contact toxicity of the pyrethroids deltamethrin and alphacypermethrin and the organophosphate fenitrothion to the parasitoid P. morionellus was less than the toxicity of the organophosphate fenitrothion (Hokkanen et al. 1988).

Sublethal effects of insecticides are defined as physiological or behavioural effects on individuals, which have survived exposure to the pesticide (Desneux et al., 2007). Sublethal effects of insecticides may impact fecunditiy, longevity, sex ratio and behaviour through neurotoxic activity (Delpuech \& Meyer, 2003). Host location by parasitoids may be interrupted by insecticides via masking the attractive plant odour and/or interrupt plant volatile production and emission. In addition, insecticides may have direct repellent effects on natural enemies (Thiery \& Visser, 1986; Croft, 1990; Nottingham et al., 1991; Haynes, 1988). Interference with host location by insecticide residuals has been reported repeatedly: exposing Aphidius rhopalosiphi to residuals of deltamethrin resulted in shorter visit time, grooming more actively and resting less frequently than parasitoids on insecticide-free plants (Longley \& Jepson, 1996). Females of Diaretiella rapae spent significant less time foraging on plants sprayed with pirimicarb than on untreated plants, regardless of the presence of aphid hosts (Umoru et al. 1996). The reduced time spent foraging on the plant may reduce the probability of successful oviposition encounters with hosts after an insecticide application. Various studies demonstrated significant differences in the behaviour and distribution of parasitoids between plants treated with different insecticides, indicating that the insecticides were not equally avoided: Borgemeister et al. (1993) did not detect avoidance of pirimicarb by the aphid parasitoid Aphidius rhopalosiphi, but he noted repellent effects of the pyrethroid fenvalerate and the organophosphate demeton-s-methyl foraging on aphid-free cereal plants. The aphid parasitoid Aphidius ervi showed disrupted olfactory orientation towards hostinfested plants treated with lambda-cyhalothrin, but not to residuals of deltamethrin (Desneux 


\section{Chapter VI}

et al., 2004). The modification of searching behaviour by insecticides could interfere with the reproduction capacity of parasitoids (Komeza et al. 2001).

In literature, only very little information is available which focuses on the influence of insecticide application on the plant volatile blend. Females of Cotesia plutella preferred infested cabbage plants treated with syringa extract from Melia azedarach to untreated infested plants. This was assigned to larger quantities of volatile compounds emitted by cabbage plants treated with syringa extract (Charleston et al., 2006). Physiological effects of pesticides on plants have been demonstrated by the greening effect, as well as influences on hormonal regulation and assimilation of carbon and nitrogen by the fungicide strobilurin (Venancio et al., 2003).

In our study host location was impaired on insecticide treated leaves. On plants treated with thiacloprid or tau-fluvalinate, the residence time and the number of females conducting ovipositor probes into treated plants were reduced. Residuals of lambda-cyhalothrin were not avoided, but significant less females penetrated in treated plants. The Y-olfactometer experiment demonstrated that volatiles emitted by sprayed plants induced repellency, while volatiles emitted from the insecticide itself were not avoided, indicating an interaction between the plant and the insecticide. In GC/MS analyses, the volatile blends emitted by untreated and insecticide treated plants differed significantly in their quantitative and qualitative composition. Volatiles derived from the insecticide itself could not be determined. Some volatiles which elicited antennal responses in untreated plants were not emitted from insecticide treated plants. Terpinen-4-ol and Unidentified I were not released after application of either insecticide, 2-Octanol and Octanal were not emitted following treatment with lambda-cyhalothrin. Females of $T$. obscurator responded less to volatiles emitted from insecticide treated plants than from untreated plants.

\section{Impact of insecticides on parasitism on oilseed rape fields}

Three to four insecticide treatments are applied commonly to oilseed rape crops in autumn, spring and summer (Menzler-Hokkanen et al., 2006). Among these, insecticide treatments against pollen beetles (Meligethes aeneus), cabbage seedpod weevil (Ceutorhynchus obstrictus syn. C. assimilis) and brassica pod midge (Dasineura brassicae) fall within the main period of activity of tersilochine parasitoids found on winter oilseed rape (Alford et al., 2003; Menzler-Hokkanen et al., 2006; Bürger \& Gerowitt, 2009). Adult parasitoids may be exposed to insecticide sprays (Jepson, 1989) or to residuals when foraging on plant foliage (Longley \& Jepson, 1996) or when feeding on contaminated water droplets and nectar 


\section{Chapter VI}

(Langley \& Stark, 1996). The exposure of nontarget insects to residuals of contact insecticides is influenced by the persistence and distribution of the chemical compound within the crop canopy. Studies using fluorescence spray tracers showed that pesticide deposition in crops of oilseed rape declined from the top of the canopy to the ground level (Goltermann, 1995). The deposition of insecticides in dense crops was only $18 \%$ of the applied dose close to the soil level, whereas $44.5 \%$ were deposited down to soil level in thin oilseed rape crops (Goltermann, 1995). This effect is influenced by application rate, spray volume, environmental conditions, growth stage and crop density (Cigli \& Jepson, 1992). Parasitoids of stem weevils which are mainly abundant at lower levels of the crop canopy might therefore be protected from insecticide sprays. Nitzsche (1998) observed a higher abundance of $T$. obscurator at the bottom and of T. heterocerus at the top of the crop canopy, which corresponds with the microhabitat of their host larvae.

The results of the toxicity tests obtained from laboratory experiments can not be transferred to field situations. The seed weevil parasitoid Trichomalus perfectus changed its dispersal behaviour following treatment of alphacypermethrin and colonized the treated plots, resulting in a non-significant reduction in parasitism of C. assimilis larvae (Murchie et al. 1997b). A rapid re-invasion of treated plots may be due to small experimental plots (Brown, 1989; Cigli \& Jepson, 1992; Jepson, 1989), particularly with insects showing high dispersal ability (Smart et al. 1989). This "horizontal recruitment" can be influenced by landscape characteristics (Thies \& Tscharntke, 1999; Zaller et al., 2009), pesticide drift into adjacent non-target areas (Langhof, 2005), plant stage (Winfield, 1963) and availability and distribution of prey (Waage, 1989).

The effect of lambda-cyhalothrin and tau-fluvalinate on the abundance of adult parasitoids on oilseed rape crops and the influence on the level of parasitism have been studied in field trials in Poland (Kukowski 2006). The application of the insecticides caused a significant reduction of the number of T. fulvipes and T. obscurator. Even two weeks after the treatment with taufluvalinate and lambda-cyhalothrin the total number of adult T. obscurator and T. fulvipes was reduced by about $39 \%$ and $58 \%$, respectively, compared to untreated plots (Klukowski, 2006). When applied following main immigration the number of adult Phradis spp. was reduced in plots treated with tau-fluvalinate for 3 days and in plots treated with lambdacyhalothrin until the end of their activity period (Klukowski, 2006). Parasitism of M. aeneus larvae was significantly reduced in plots treated with lambda-cyhalothrin or tau-fluvalinate, while parasitism of $C$. assimilis larvae was not affected. The level of parasitism of $C$. pallidactylus larvae significantly decreased in one year in plots treated with lambda- 


\section{Chapter VI}

cyhalothrin or tau-fluvalinate compared to untreated plots. The author supposed that the constantly higher level of parasitism in untreated plots might be due to a density dependent host-parasitoid relationship (Klukowski, 2006). Reduced parasitism of cabbage seed weevil larvae has been observed following application of triazophos at the end of flowering. In contrast to untreated plots, the level of parasitism was reduced from $64.7 \%$ to $11.1 \%$ (1993) and from $51.3 \%$ to $28.6 \%$ (1994), respectively, while application of alphacypermethrin before the main immigration of these parasitoids did not reduce parasitism (Murchie et al., 1997).

In this study the level of parasitism of pollen beetle larvae was significantly reduced in plots treated with thiacloprid and tau-fluvalinate compared to untreated plots, while no significant effect was found in plots treated with lambda-cyhalothrin. These results fit to the observations of our laboratory experiments: residuals and volatile blends of thiacloprid and tau-fluvalinate treated plants were avoided, while treatment with lambda-cyhalothrin did not cause repellency. The parasitism of stem mining pests was not affected by the tested insecticides, which might be due to their vertical distribution and activity at the bottom of the crop canopy. Further, the parasitoid species changed their dispersal behaviour: emigration flights of $T$. obscurator and T. fulvipes from the insecticide treated field were more frequent than immigration flights, whereas in the untreated field immigration flights prevailed over the total observation period. The dispersal behaviour of P. interstitialis and T. heterocerus could not be analysed in the field, because only very few individuals were captured in malaise traps. These species are known to forage on top of the crop canopy which might inhibit their ingress into malaise traps (Nitzsche, 1998). Parasitoids recolonized the treated field about one week post treatment. This is in agreement with our results concerning the parasitism of pollen beetle larvae in plants exposed after insecticide application. The level of parasitism was low during the first 4 to 5 days after treatment and than increased again.

\section{Strategies for conservation of parasitoids}

Conservation of parasitoids from insecticide effects might be achieved by applying selective insecticide compounds, reduced dose rates and temporal targeting of insecticide sprays.

Apart from the choice of selective insecticides, another approach for increasing the selectivity of pesticides is to reduce the dose rates (Poehling, 1989; Longley et al., 1997; Booth et al., 2007). Most studies on the effects of reduced field dose rates on pests and their natural enemies have been focused on aphids. Various studies have shown that reduced rates of insecticides can provid sufficient control of aphids, while protecting populations of natural enemies (Ripper, 1956; Poehling, 1989; Niehoff \& Poehling, 1995; Longley et al., 1997; 


\section{Chapter VI}

Acheampong \& Stark, 2004; Booth et al., 2007). When applied at 50\% dose rate, taufluvalinate and lambda-cyhalothrin allowed an initially higher survival of $8.8 \%$ of Phradis spp.. However, at 1 and 6.5 hours following exposure to lambda-cyhalothrin or taufluvalinate, respectively, 100\% mortality occured (Jackowski et al., 2009).

The higher risk of development resistance to the insecticides may be an argument against applying reduced dose rates. This is based on the opinion that high dose rates kill sensitive individuals and therefore minimize built up of resistent genotypes. Resistance may develop due to changes in the enzyme systems, resulting in more rapid detoxification or sequestration of the insecticide, or due to mutations at the target site, thereby preventing the insecticidetarget site interaction (Zlotkin, 1999). Reduced risk of resistance formation and of cross resistance should be achieved by reducing the number of applications, spraying of recommended field dose rates and mixtures of compounts with different target sites.

In this study, contrary to our expectation, reduced field dose rates did not increase parasitism as compared to full dose rates. In the laboratory experiments, female $T$. obscurator responded similarly to plants treated with thiacloprid at full and $50 \%$ reduced dose rates, whereas the number of penetrating females was lower on leaves treated with full doses of lambdacyhalothrin than on leaves treated with $50 \%$ dose rates. Generally, the differences between levels of parasitism in different treatments were small, which may be due to small plot sizes and the fast re-colonization by the highly dispersal parasitoids.

Temporal targeting of insecticide application with regard to pest incidence and parasitoid phenology on oilseed rape might protect the wasps from harmful effects. To avoid killing of parasitoids, insecticides should be applied outside the period of their main activity. To determine such spray windows, the use of phenological models could minimize effects on parasitoids. Various studies have shown that the phenologies of tersilochine parasitoids have a species-specific sequence (Ulber \& Nitzsche, 2006). Females of T. microgaster immigrate in the early bud stage in March, while T. obscurator, T. fulvipes and T. heterocerus colonize the crop from mid April onwards (Sedivy, 1983; Nilsson, 2003; Barari et al., 2005). Murchie et al. (1997b) determined a dissociation between immigration flights of cabbage seed weevil and its key parasitoid $T$. perfectus into oilseed rape crops. The pests arrive before the parasitoid, which provides an opportunity for temporal targeting of insecticides before main migration of the parasitoids. However, parasitoids are active over a long period during spring and summer which might coincide with pest control. 
In the current study no significant differences occured between plots treated at early flowering or late flowering. Insecticide application in the early bud stage could not be tested, because this would have resulted in very low numbers of stem weevil larvae and pollen beetle larvae, thereby preventing studies on effects of insecticides on parasitism.

\section{References}

ACHEAMPONG; S. \& STARK, J. (2004). Can reduced rates of pymetrozine and natural enemies control the cabbage aphid, Brevicoryne brassicae (Homoptera: Aphididae), on broccoli? International Journal of Pest Management 50, 275-279.

Agelopoulos, N. G. \& KeLleR, M. A. (1994). Plant-natural enemy association in tritrophic system, Cotesia rubecula-Pieris rapae- Brassicaceae (Cruciferae). III: Collection and identification of plant and frass volatiles. Journal of Chemical Ecology 20, 1955-1967.

Alford, D. V., NiLSSON, C. \& UlBER, B. (2003). Insect pests of oilseed rape crops. Chapter

2 In: D.V. Alford (ed) Biocontrol of Oilseed Rape Pests. Blackwell, Oxford, UK, 9-41.

BAEHRECKE, E. H., WiLliAMS, H. J. \& VinsON, S. B. (1989). Electroantennogram responses of Campoletis sonorensis (Hymenoptera: Ichneuminidae) to chemicals in cotton (Gossypium hirsutum L.). Journal of Chemical Ecology 15, 37-46.

BARARI, H., COOK, S. M. \& WILLIAMS, I. H. (2005). Effect of turnip rape (Brassica rapa) trap crop on stem-mining pests and their parasitoids in winter oilseed rape (Brassica napus). Biological Control 50, 69-86.

BARTLET, E., KIDDLE, G., WILliAMS, I. \& WALlsgrove, R. (1999). Wound-induced increase in the glucosinolate content of oilseed rape and their effect on subsequent herbivory by a crucifer specialist. Entomologia Experimentalis et Applicata 91, 163-167.

BARRETT, K., GRANDY, N., HARRISON, E. G., HASSAN, S. \& OOMEN, P. (1994). Guidance document on regulatory testing procedures for pesticides with non-target arthropods. ESCORT Workgroup, Wageningen, The Netherlands 1994. Society of Environmental Toxicology and Chemistry-Europe (SETAC)

BlaAkmeer, A., Geervliet, J. B. F., LoOn, J. J. A. V., Posthumus, M. A., BeeK, T. A. V. \& GROOT, A. D. (1994). Comparative headspace analysis of cabbage plants damaged by two species of Pieris caterpillars: consequences for in-flight host location by Cotesia parasitoids. Entomologia Experimentalis et Applicata 73, 175-182.

Booth, L. H., WratTEN, S. D. \& P.KeHRLI. (2007). Effects of reduced rates of two insecticides on enzyme activity and mortality of an aphid and its lacewing predator. Journal of Economic Entomology 100, 11-19.

Borgemeister, C., PoEHLing, H.-M., DinTER, A. \& Höller, C. (1993). Effects of insecticides on life history parameters of the aphid parasitoid Aphidius rhopalosiphi (Hym.: Aphidiidae). Entomophaga 38, 245-255.

BRown, K. C. (1989). The design of experiments to assess the effects of pesticides on beneficial arthropods in orchards: Replication verus plot size. In: Jepson P.C. (Ed.), Pesticide and Non-target Invertebrates. Intercept, Wimborne., 71-93.

BÜRGER, J. \& GEROWITT, B. (2009). Anwendungsmuster von Pflanzenschutzmitteln in Winterweizen und Winterraps. Gesunde Pflanze 61, 11-17.

Bukovinszky, T., Gols, R., Posthumus, M. A., Vet, L. E. M. \& Lenteren, J. C. v. (2005). Variation in plant volatiles and attraction of the parasitoid Diadegma semiclausum (Hellén). Journal of Chemical Ecology 31, 461-480.

Charleston, D. S., Gols, R., Hordijk, K. A., KFir, R., Vet, L. E. M. \& Dicke, M. (2006). Impact of botanical pesticides derived from Melia azedarach and Azadirachta indica 
plants on the emission of volatiles that attract parasitoids of the diamondback moth to cabbage plants. Journal of Chemical Ecology 32, 325-349.

Cilgi, T. \& JEPSON, P. C. (1992). The use of tracers to estimate the exposure of beneficial insects to direct pesticide spraying in cereals. Annals of Applied Biology 121, 239-247.

Croft, B. A. (1990). Arthropod biological control agents and pesticides. Wiley, New York.

CRoft, B. A. \& A.W.Brown. (1975). Responses of arthropod natural enemies to insecticides. Annual Reviews Entomology 20, 285-335.

DELPUECH, J. M. \& MEYET, J. (2003). Reduction in the sex ratio of the progeny of a parasitoid wasp (Trichogramma brassicae) surviving the insecticide chlorpyrifos. Archiv Environmental Contamination and Toxicology 45, 203-208.

DesneuX, N., DecourTye, A. \& DelPUECH, J.-M. (2007). The sublethal effects of pesticides on beneficial arthropods. Annual Reviews Entomology 52, 81-106.

DesneuX, N., RAfalimananA, H. \& KAISER, L. (2004). Dose-response relationship in lethal and behavioural effects of different insecticides on the parasitic wasp Aphidius ervi. Chemosphere 54, 619-627.

DICKE, M. (1994). Local and systemic production of volatile herbivore induced terpenoids: their role in plant-carnivore mutualism. Journal of Plant Physiology 143, 465-472.

DICKE, M. (1999). Are herbivore-induced plant volatiles reliable indicators of herbivore identity to foraging carnivorous arthropods? Entomolgia Experimentalis et Applicata 91, 131-142.

DICKE; M: \& SABELIS; M.W. (1988). How plants obtain predatory mites as bodyguards. Netherlands Journal of Zoology 38, 148-165.

Drost, Y. C., LewIS, W. J., ZANen, P. O. \& KelleR, M. A. (1986). Beneficial arthropod behavior mediated by airborne semiochemicals I. Flight behavior and influence of preflight handling of Microplitis croceipes (Cresson). Journal of Chemical Ecology 12, 1247-1262.

DU, Y.J., POPPY, G.M., POWELL, W., PICKETT, J.A., WADHAMS, L.J. \& WOODCOCK, C.M. (1998). Identification of semiochemicals released during aphid feeding that attract parasitoid Aphidius ervi. Journal of chemical Ecology 24, 1355- 1368.

GeErvliet, J. B. F., Posthumus, M. A., Vet, L. E. M. \& Dicke, M. (1997). Comparative analysis of headspace volatiles from different caterpillar-infested or uninfested food plants of Pieris species. Journal of Chemical Ecology 23, 2935-2953.

GeERVLIET, J. B. F., Vet, L. E. M. \& DiCKE, M. (1994). Volatiles from damaged plants as a major cues in long-range host-searching by the specialist parasitoid Cotesia rubecula. Entomolgia Experimentalis et Applicata 73, 289-297.

GOLTERMANN, S. (1995). Nützlingsschonender Insektizideinsatz im Winterraps? Raps 13, 153-154.

GouinguenÉ, S. P. \& TuRLingS, T. C. J. (2002). The effects of abiotic factors on induced volatiles emission in corn plants. Plant Physiology 129, 1296-1307.

HAYNES, K. F. (1988). Sublethal effects of neurotoxic insecticides on insect behavior. Annual Reviews Entomology 33, 149-168.

HOPKINS, R. J., DAM, N. M. V. \& LOON, J. J. A. V. (2009). Role of Glucosinolates in insectplant relationships and multitrophic interactions. Annual Review Entomology 54, 5783.

Hokkanen, H., HusberG, G.-B. \& SöDERBlom, M. (1988). Natural enemy conservation for the integrated control of the rape blossom beetle Meligethes aeneus F. Annales Agriculturae Fenniae 27, 281-294.

Hu, Z., SHEN, Y., LuO, Y., SHEN, F., GAO, H. \& GAO, R. (2008). Aldehyde volatiles emitted in succession from mechanically damaged leaves of poplar cuttings. Journal of Plant Biology 51, 269-275. 
JACKOWSKI, J., KLUKOWSKI, Z. \& IRZYKOWICZ, M. (2009). The effect of tau-fluvalinate and lambda-cyhalothrin on two parasitic species of Phradis spp. (Hymenoptera, Ichneumonidae, Tersilochinae). Pestycydy/Pesticides 2008 3-4, 79-92.

JaKobsen, H. B., P.FrIIS, NIELSEN, J. K. \& OlSEN, C. E. (1994). Emission of volatiles from flowers and leaves of Brassica napus in situ. Phytochemistry 37, 695-699.

JAKOBSON, H. B. \& OLSEN, C. E. (1994). Influence of climatic factors on emission of flower volatiles in situ. Planta 192, 365-371.

JEPSON, P. C. (1989). The temporal and spatial dynamics of pesticide side-effects on nontarget invertebrates. In: Jepson P.C. (Ed.), Pesticide and Non-target Invertebrates. Intercept, Wimborne., 95-127.

Johnson, R. M., Wen, Z., Schuler, M. A. \& Berenbaum, M. R. (2006). Mediation of Pyrethroid Insecticide Toxicity to Honey Bees (Hymenoptera: Apidae) by Cytochrome P450 Monooxygenases. Journal of Economic Entomology 99, 10461050.

JONG, R. D. \& KAISER, L. (1991). Odor learning by Leptopilina boulardi, a specialist parasitoid (Hymenoptera: Eucoilidae). Journal Of Insect Behavior 4, 743-750

JÖNSSON, M., LINDKVIST, A. \& ANDERSON, P. (2005). Behavioural responses in three ichneumonid pollen beetle parasitoids to volatiles emitted from different phenological stages of oilseed rape. Entomolgia Experimentalis et Applicata 115, 363-369.

JÖNSSON, M. \& ANDERSON, P. (2008). Emission of oilseed rape volatiles after pollen beetle infestation; behavioural and electrophysiological responses in the parasitoid Phradis morionellus. Chemoecology 17, 201-207.

Kester, K. M. \& BARBOSA, P. (1992). Effects of postemergence experience on searching and landing responses of the insect parasitoid, Cotesia congregata (Say) (Hymenoptera: Braconidae), to plants. Journal Of Insect Behavior 5, 301-320.

Kaiser, L., BARTHEye, C., Kerguelen, V. \& PhAM-Delegue, M.-H. (1995). Odour conditioning of ovipositor probing in a parasitic wasp. Ethology Ecology \& Evolution 7, 245-255.

KLUKOWSKI, Z., TwARDOWSKI, J. \& IRZYKOWICZ, M. (2006). Subsequent effect of taufluvalinate (Maverik) and lambda-cyhalothrin (Karate) pyrethroids on the activity of carabid beetles (Coleoptera: Carabidae) in winter oilseed rape. IOBC/wprs Bulletin 29, 125-130.

Komeza, N., Fouillet, P., Bouletreau, M. \& Delpuech, J. M. (2001). Modification, by the Insecticide Chlorpyrifos, of the Behavioral Response to Kairomones of a Parasitoid Wasp, Leptopilina boulardi. Archiv Environmental Contamination and Toxicology 41, 436-442.

LANGHOF, M. (2005). Insecticde drift from agricultural spraying into field margin habitats and its effect on non-target arthropods: residual toxicity, impact on populations, and recolonisation processes. Dissertation University Hannover, Germany.

LANGLEY, M. \& STARK, J. D. (1996). Analytical Techniques for quantifying direct, residual and oral exposure of an insect parasitoid to an Organophosphate Insecticide. Bulletin of Environmental Contamination Toxicology 57, 683-690.

LEWIS, W. J. \& TAKASU, K. (1990). Use of learned odours by a parasitic wasp in accordance with host and food needs. Nature 348, 635-636.

LI, Y., DiCKENS, J. C. \& STEINER, W. W. M. (1992). Antennal olfactory responsiveness of Microplitis croceipes (Hymenoptera: Braconidae) to cotton plant volatiles. Journal of Chemical Ecology 18, 1761-1773.

LONGLEY, M. \& JEPSON, P. C. (1996). The influence of insecticide residues on primary parasitoids and hyperparasitoid foraging behaviour in the laboratory. Entomolgia Experimentalis et Applicata 81, 259-269. 
LONGLEy, M., JEPSON, P. C., IZQUIERDO, J. \& SOTHERTON, N. (1997). Temporal and spatial changes in aphid and parasitoid populations following applications of deltamethrin in winter wheat. Entomolgia Experimentalis et Applicata 83, 41-52.

MattiacCi, L., Dicke, M. \& Posthumus, M. A. (1994). Induction of parasitoid attracting synomones in brussels sprouts plants by feeding of Pieris brassicae larvae: Role of mechanical damage and herbivore elicitor. Journal of Chemical Ecology 20, 22292247.

Mattiacci, L., Rocca, B. A., Scascighini, N., D’Alessandro, M., Hern, A. \& Dorn, S. (2001). Systemically induced plant volatiles emitted at the time of "danger". Journal of Chemical Ecology 27, 2233-2252.

MCAuslane, H. J., VinSON, S. B. \& WiLliams, H. J. (1991). Influence of adult experience on host microhabitat location by the generalist parasitoid, Campoletis sonorensis (Hymenoptera: Ichneuminidae). Journal of Insect Behavior 4, 101-113.

MEINERS, T. \& HILKER, M. (2000). Induction of plant synomones by oviposition of a phytophagous insect. Journal of Chemical Ecology 26, 221-232.

MEINERS, T., W ÄCKERS, F. \& LEWIS, W. J. (2003). Associative learning of complex odours in parasitoid host location. Chemical Senses 28, 231-236.

MenZler-HokKanen, I., HoKkanen, H. M. T., BüChS, W., KluKOwski, Z., LuIK, A., NiLSSON, C., UlBER, B. \& WILLIAMS, I. H. (2006). Insect problems in European oilseed rape cultivation, and how to deal with them: the OSR framers perspective. IOBC/wprs Bulletin 29, 91-94.

Mumm, R., Schrank, K., Wegener, R., Schulz, S. \& Hilker, M. (2003). Chemical analysis of volatiles emitted by Pinus sylvestris after induction by insect oviposition. Journal of Chemical Ecology 29, 1235-1251.

MurChIE, A. K., SMART, L. E. \& Williams, I. H. (1997a). Responses of Dasineura brassicae and its parasitoids Platygaster subuliformis and Omphale clypealis to field traps baited with organic isothiocyanates. Journal of Chemical Ecology 23, 917-926.

MurChIE, A. K., WiLliams, I. H. \& ALFORD, D. V. (1997b). Effects of commercial insecticide treatments to winter oilseed rape on parasitism of Ceutorhynchus assimilis Paykull (Coleoptera: Curculionidae) by Trichomalus perfectus (Walker) (Hymenoptera: Pteromalidae). Crop Protection 16, 199-202.

MURLIS, J., WILLIS, M.A. \& CARDÈ, R.T. (2000). Spatial and temporal structures of pheromones plumes in fields and forests. Physiologicyl Entomology 25, 211-222.

NiEHOFF, B. \& PoEHLING, H. M. (1995). Population dynamics of aphids and syrphid larvae in winter wheat treated with different rates of pirimicarb. Agricultural, Ecosystems and Environment 52, 51-55.

NGI-SONG, A.J., NJAGI, P.G.N, TORTO, B. \& OVERHOLT, W.A. (2000). Identification of behaviourally active components from maize volatiles for the stemborer parasitoid Cotesia flavipes Cameron (Hymenoptera: Braconidae). Insect Science and its Application 20, 181-189.

NILSSON, C. (2003). Parasitoids of pollen beetles. In: D.V. Alford (ed) Biocontrol of Oilseed Rape Pests. Blackwell Publishing, Oxford, UK, 73-85.

NitzSCHE, O. (1998). Auftreten und Effizienz von Parasitoiden als natürliche Gegenspieler von Schadinsekten im Winterraps unter besonderer Berücksichtigung unterschiedlicher Bodenbearbeitungsmaßnahmen nach Winterraps. PhD thesis, Georg-August-University of Goettingen, Germany.

Nottingham, S. F., Hardie, J., Dawson, G. W., Hick, A. J., Pickett, J. A., Wadhams, L. J. \& WoODCOCK, C. M. (1991). Behavioral and electrophysiological responses of aphids to host and nonhost plant volatiles. Journal of Chemical Ecology 17, 12311242. 
PARÉ, P. W. \& TuMLinson, J. H. (1997). Induced synthesis of plant volatiles. Nature 385, 3031.

PARÉ, P. W. \& TuMLinson, J. H. (1999). Plant volatiles as a defense against herbivores. Plant Physiology 121, 325-331.

PICHERSKY, E. \& GERSHENZON, J. (2002). The formation and function of plant volatiles: perfumes for pollinator attraction and defense. Current Opinion in Plant Biology 5, 237-243.

POEHLING, H. M. (1989). Selective application strategies for insecticides in agricultural crops. In: Jepson P.C. (Ed.), Pesticide and Non-target Invertebrates. Intercept, Wimborne., 151-175.

Potting, R. P. J., Vet, L. E. M. \& Dicke, M. (1995). Host microhabitat location by stemborer parasitoid Cotesia flavipes: The role of herbivore volatiles and locally and systemically induced plant volatiles. Journal of Chemical Ecology 21, 525-539.

RAsk, L., ANDrÉASSON, E., EKBOM, B., ERIKSSON, S., PONTOPPIDAN, B. \& MEIJER, J. (2000). Myrosinase: gene family evolution and herbivore defense in Brassicaceae. Plant Molecular Biology 42, 93-113.

RIPPER, W. E. (1956). Effect of pesticides on balance of arthropod populations. Annual Reviews Entomology 1, 403-438.

SEDIVY, J. (1983). Tersilochinae as parasitoids of insect pests of winter rape (Hymenoptera: Ichneumonidae). Cont. Am. Ent. Inst. 20, 266-276.

ShioJiRI, K., TAKABAYASHI, J., YANO, S. \& TAKAFUJI, A. (2001). Infochemically mediated tritrophic interaction webs on cabbage plants. Population Ecology 43, 23-29.

SMART, L. E., SteVEnSON, J. H. \& WALTERS, J. H. H. (1989). Development of the trial methology to assess short-term effects of pesticides on beneficial arthropods in arable crops. Crop Protection 8, 169-180.

SMID, H. M., LoON, J. J. A. V., M.A.Posthumus \& VET, L. E. M. (2002). GC-EAG-analysis of volatiles from Brussels sprouts plants damaged by two species of Pieris caterpillars: olfactory receptive range of a specialist and a generalist parasitoid wasp species. Chemoecology 12, 169-176.

Takabayashi, J., Dicke, M. \& Posthumus, M. A. (1994). Volatile herbivore-induced terpenoids in plant-mite interactions: Variation caused by biotic and abiotic factors. Journal of Chemical Ecology 20, 1329-1354.

THIERY, D. \& VISSER, J. H. (1986). Masking of plant odour in the olfactory orientation of the Colorado potato beetle. Entomologia Experimentalis et Applicata 41, 165-172.

THIES, C. \& TSCHARNTKE, T. (1999). Landscape structure and biological control in agroecosystems. Science 285, 893-895.

TuRLings, T. C. J., TuMLINSON, J. H. \& LEWIS, W. J. (1990). Exploitation of herbivoreinduced plant odors by host-seeking parasitic wasps. Science 250, 1251-1253.

TuRLings, T. C. J., TuMLINSON, J. H., Eller, F. J. \& LEWIS, W. J. (1991a). Larval-damaged plants: source of volatile synomone that guide the parasitoid Cotesia marginiventris to the micro-habitat of its host. Entomologia Experimentalis et Applicata 58, 75-82.

Turlings, T. C. J., Tumlinson, J. H., Heath, R. R., Proveaux, A. T. \& Doolittle, R. E. (1991b). Isolation and identification of allelochemicals that attract the larval parasitoid, Cotesia marginiventris (Cresson), to the microhabitat of one of its hosts. Journal of Chemical Ecology 17, 2235-2251.

UMORU, P. A., POWELL, W. \& ClARK, S. J. (1996). Effect of pirimicarb on the foraging behaviour of Diaeretiella rapae (Hymenoptera: Braconidae) on host-free and infested oilseed rape plants. Bulletin of Entomological Research 86, 193-201.

UlBER, B. \& NiTZSCHE, O. (2006). Phenology of parasitoids (Hym., Ichneumonidae, Tersilochinae) of oilseed rape pests in northern Germany in 1995-1997. IOBC/wprs Bulletin 29, 173-179. 
ULBER, B. \& WEDEMEYER, R. (2006). Responses of Tersilochus microgaster and Tersilochus obscurator (Hymenoptera: Ichneumonidae) to volatile 2-phenylethyl-isothiocyanate. CD-Rom Proceedings of the International Symposium "Integrated Pest Management in Oilseed Rape Pests", Goettingen, Germany, 3-5 April 2006.

VET, L. E. M. \& DICKE, M. (1992). Ecology of infochemical use by natural enemies in a tritrophic context. Annual Review Entomology 37, 141-172.

Vet, L. E. M., WÄCKERS, F. L. \& DiCKE, M. (1991a). How to hunt for hiding hosts: The reliability-detectability problem in foraging parasitoids. Netherlands Journal of Zoology 41, 202-213.

Vet, L. E. M. \& GROENEWOLD, A. W. (1990). Semiochemicals and learning in parasitoids. Journal of Chemical Ecology 16, 3119-3135.

Venancio, W. S., Rodrigues, M., Begliomini, E. \& Souza, N. D. (2003). Physiological effects of strobilurin fungicides on plants. UEPG Ci. Exatas Terra, Ci. Agr. Eng., Ponta Grossa 9, 59-68.

VINSON, S. B. (1998). The general host selection behaviour of parasitoid Hymenopteran and a comparison of initial strategies utilized by larvaphagous and oophagous species. Biological Control 11, 79-96.

WAAGE, J. (1989). The population ecology of pest-pesticide-natural enemy interactions. In: Jepson P.C. (Ed.), Pesticide and Non-target Invertebrates. Intercept, Wimborne., 8193.

WÄCKERS, F. L. (1994). The effect of food deprivation on the innate visual and olfactory preference in the parasitoid Cotesia rubecula. Journal of Insect Physiology 40, 641649.

WILLIAMS, I.H., BUECHI, R. \& ULBER, B. (2003). Sampling, trapping and rearing oilseed rape pests and their parasitoids. In: D.V. Alford (Ed.) Biocontrol of Oilseed Rape Pests. Blackwell Publishing, Oxford, UK.

Williams, I. H., FreARSON, D. J. T., BARARI, H. \& MCCARTNEY, A. (2007). First field evidence that parasitoids use upwind anemotaxis for host-habitat location. Entomologia Experimentalis et Applicata 123, 299-307.

WINFIELD, A. L. (1963). A study on the effects of insecticides on parasites of larvae of blossom beetles (Meligehtes aeneus F., Coleoptera: Nitidulidae). Entomolgia Experimentalis et Applicata 6, 309-318.

Zaller, J. G., Moser, D., Drapela, T., SCHMÖGER, C. \& FranK, T. (2009). Parasitism of stem weevils and pollen beetles in winter oilseed rape is differentially affected by crop management and landscape characteristics. BioControl 54, 505-514.

ZlotKIN, E. (1999). The insect voltage-gated sodium channel as target of insecticides. Annual Review Entomology 44, 429-455. 


\section{Summary}

Lethal and sublethal effects of insecticides on mortality, migration and host searching behaviour of tersilochine parasitoids on winter oilseed rape

Oilseed rape (Brassica napus L.) is attacked by a wide range of economically important insect pests. Current control practices are mainly based on broad spectrum insecticides that are often applied routinely and without regard to pest control thresholds. The extensive usage of insecticides might have strong negative impact on natural enemies. Almost all pest species on oilseed rape are parasitized by specialist larval endoparasitoids which are mainly active in the late bud stage up to the end of flowering. Insecticides applied during this period for control of pollen beetle, cabbage seed weevil and brassica pod midge could negatively affect these beneficial parasitoids.

The effects of two contact pyrethroids (tau-fluvalinate, lambda-cyhalothrin) and a systemic neonicotinoid (thiacloprid) on parasitism of larvae of Meligethes aeneus, Ceutorhynchus napi and C. pallidactylus were investigated in field experiments in the years 2006 to 2008 . The insecticides were applied at full recommended field dose rates and reduced rates (50\%), either at the beginning or the end of flowering. Additionally, potted plants infested with pollen beetle larvae were exposed in the plots at various intervals post treatment. Further, the vertical distribution and migration of adult parasitoids in the canopy of treated and untreated plots of oilseed rape were observed. In laboratory experiments, the toxicity of the insecticides to parasitoids attacking pollen beetle larvae, Phradis interstitialis and Tersilochus heterocerus, was determined in glass-vial tests. The role of volatiles emitted from uninfested plants and from plants infested by larvae of $C$. pallidactylus, as well as the volatile blend emitted from insecticide-treated infested plants, were analysed in behavioural and electrophysiological (EAG-GC/MS) bioassays, using female Tersilochus obscurator as test insects.

In the GC-EAG experiments the volatile blend emitted from infested oilseed rape was different from the volatiles of uninfested plants; the parasitoids were able to discriminate between volatiles emitted from infested and uninfested plants. Dual-choice tests demonstrated that previous experience with host-plants significantly increased the probability of host detection by female T. obscurator. In Y-olfactometer assays, the wasps were differently attracted to volatiles of undamaged oilseed rape plants compared to clean air and infested plants, even when the host larvae were removed. The isolated host larvae were not attractive. 
Foraging females of $T$. obscurator avoided infested plants with fresh dried residuals of thiacloprid; three and six days old residuals had no repellent effect. Residuals of lambdacyhalothrin had no effect on the residence time on sprayed leaves as compared to untreated leaves. However, oviposition of females in infested treated leaves was reduced by both insecticides compared to infested untreated leaves. Similar effects were found with $P$. interstitialis, the parasitoid attacking pollen beetle larvae. Females spent less time foraging on buds treated with thiacloprid and tau-fluvalinate as compared to untreated buds. On buds treated with lambda-cyhalothrin the residence time was not reduced.

In the Y-olfactometer bioassay T. obscurator avoided the volatile blend emitted from leaves treated with thiacloprid. The insecticide odour itself had not effect on the choice of parasitoids. Volatiles emitted from leaves treated with lambda-cyhalothrin had no repellent effect on T. obscurator. The composition of the volatile blends emitted from plants treated with thiacloprid or lambda-cyhalothrin differed from the volatile blend of untreated oilseed rape plants. Several volatiles of untreated plants which elicited antennal responses were not detected in insecticide treated plants. The toxicity of the tested insecticides to P. interstitialis and $T$. heterocerus declined in the sequence lambda-cyhalothrin, tau-fluvalinate and thiacloprid.

In the field experiments, the application of thiacloprid and tau-fluvalinate significantly reduced the level of parasitism of pollen beetle larvae compared to untreated plots. Treatment with lambda-cyhalothrin had no significant effect. Measures targeted to reduce side effects of insecticides on parasitoids, such as reduced-rate insecticide application and spraying before main immigration of parasitoids into the crop, did not significantly alter the level of parasitism as compared to full-rate application or late spraying during full-flowering. The parasitism of artificially exposed $M$. aeneus larvae up to 4 to 5 days post treatment was on a low level and than increased again. The level of parasitism of stem-mining larvae was not significantly different between insecticide-treated and untreated plants. Parasitoids of pollen beetle larvae were mainly active at the top of the crop canopy, while parasitoids of stem weevil larvae mainly foraged close to the ground level, where they might have been protected from the insecticide sprays. Adult parasitoids responded to insecticide application by changing their dispersal behaviour. They emigrated from the treated field and recolonized it one week post treatment. 
In conclusion, this study demonstrated that the volatile blends emitted from uninfested and infested oilseed rape plants, as well as insecticide-treated and untreated plants, differed qualitatively and quantitatively. Parasitoids were able to perceive the differences between blends. Previous experience of females increased the ability to discriminate between volatile blends. The tested insecticides induced repellency which influenced the parasitism and migration behaviour of parasitoids. Within crops of oilseed rape, parasitoids may be protected from insecticides due to behavioural refuges. The choice of a selective active ingredient was more effective for conservation of natural biocontrol by parasitoids than the application of half-dose rates or the early timing of insecticide application. 


\section{Acknowledgement}

I would like to thank Prof Dr Stefan Vidal, who did the reviewing of this thesis, and allowed me to work in his Entomological Section. Many thanks to Prof Dr Stefan Schütz for the coreviewing and giving me the opportunity to perform the GC/MS-EAG experiments in his institut. I am especially grateful to Dr Bernd Ulber for supporting me in my experiments and his consistent collaboration. Many thanks to Mrs Eisenwiener for the performance of the GC/MS-EAG experiments and her patience with the highly disperse parasitoids.

I am also grateful to: Doro Mennerich, Marie-Luise Krüger, Michael Eickermann, Hubertus Reintke, Rainer Wedemeyer, Angelika Metje, Eugen Hodyl, Frank Gremmes, Heike Pannwitt, Elena Wennemuth and Florian Rekate for helping me in the field, in the greenhouse in the laboratory and for the nice collaboration. Finally I expressed my deepest thanks to my family and Christian.

This study was funded by the Scholarship Program of the German Federal Environmental Foundation (DBU). 


\section{Curriculum vitae}

$9^{\text {th }}$ February, 1980

1999

$1999-2005$

$2006-2009$ born in Freckenhorst, Germany

Matriculation Augustin Wibbelt Gymnasium, Warendorf

Study of Agricultural Science at Georg-August-

University, Göttingen, Germany and Universidad de

Politécnica, Valencia, Spain

PhD-study at Georg-August-University, Göttingen 